\title{
A ADMINISTRACÃO PÚBLICA MUNICIPAL E O ABASTECIMENTO DE HORTIGRANJEIROS: 0 CASO DOS . VAREJÕES MUNICIPAIS DE' PIRACICABA, ESTADO DE SÃO PAULO.
}

\section{FRANCISCO CONSTANTINO CROCOMO \\ Economista}

ORIENTADOR: PROF. DR. GERALDO S. A. DE GAMARGO BARROS

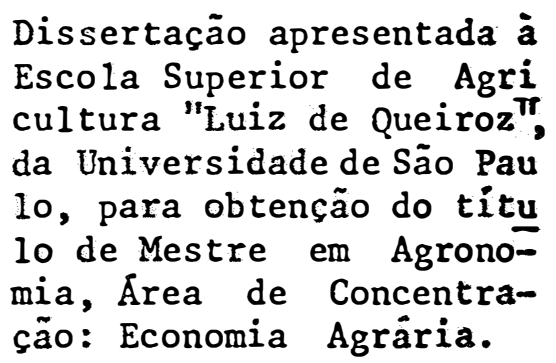

P I R A C I C A B A

ESTADO DE SÃO PAULO - BRASIL

JANEIRO - 1992 
Eicha catalográfica preparada pela Seção de Livros da Divisão de Biblioteca e Documentação - PCAP/uSP

Crocomo, Francisco Constantino

C938f A administração pública municipal e o abastecimento de hortigranjeiros: o caso dos varejoes municipais de Piraci caba, Estado de São Paulo. Piracicaba, 1992.

159p. ilus.

Diss. (Mestre) - ESALQ

Bibliografia.

1. Administração pública municipal - Piracicaba, SP 2. Comercialização agr icola frutigranjeiro - Abastecimento - Piragicaba, sP 4. VarejãoPiracicaba, SP I. Escola Superior de Agricultura Luiz de Queiroz, Piracicaba 
Aos meus pais Francisco \& Immaculada e a meus irmãos dedico este trabalho, pelo incentivo constante.

ofereco este trabalho:

Para minha esposa Faridi e meu filho Marcio, que tornaram as horas de trabal ho agradáveis. Pelo apoio, mesmo sendo privados de minha presenca em muitas oportunidades. 


\section{AGRADECI MENTOS}

Ao professor Dr. Geraldo S. A. de Camargo Barros meus agradecimentos pela segura e eficiente orientacão.

A todos os funcionários da SEMA - Secretaria Municipal de Agricultura e Abastecimento de Piracicaba-SP. em especial atencão a Ramiro San Juan Mene, Francisco Ernesto Guastalli, João Batista Lopes, o Secretário Mario Tomazello e Simone I. Monetta assessora do abastecimento.

Ao convênio SEMAVESALQ - Departamento de Economia e Sociologia Rural, a todos estagiários e em especial ao engenheiro agrônomo Vinicius Aparecido Goncal ves.

Aos funcionários do Departamento de Economia e dos Varejöes da C.EAGESP.

Aos runcionários do Setor de precos no varejo do IEA - Instituto de Economia Agricola da Secretaria de Agricultura do Estado de São Paulo.

Ao Departamento de Economia da UNIMEP Universidade Metodista de Piracicaba, pelo apoio recebido durante a realização deste trabalho.

Ao Liduardo R. Fischer pelo excelente trabal ho de digitacão. 


\section{SUMARIO}

LISTA DE TABELAS $\ldots \ldots \ldots \ldots \ldots \ldots \ldots \ldots \ldots \ldots \ldots \ldots \ldots \ldots \ldots \ldots$

LISTA DE FIGURAS $\ldots \ldots \ldots \ldots \ldots \ldots \ldots \ldots \ldots \ldots \ldots \ldots \ldots \ldots \ldots \ldots \ldots$

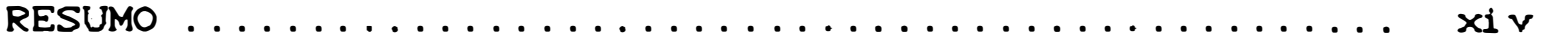

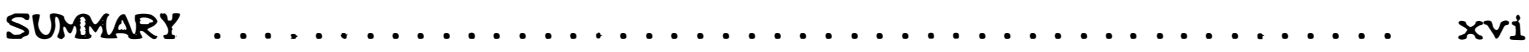

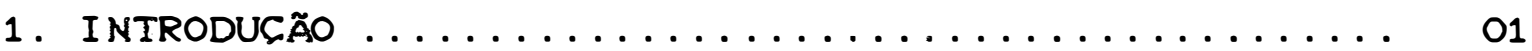

1.1. Caracterizacão do Problema .............. 01

1.2. objetivos ....................... oz

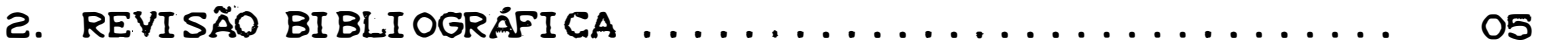

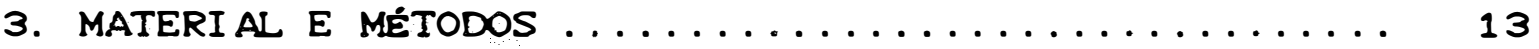

3.1. Material e Fonte de Dados ................ 13

3.1.1. Caracterizacão das estruturas das unidades de comercializacão ............. 13

3.1.2. Produtos selecionados e comparacão de seus precos .................. 13

3.1.3. Período, Periodícidade, Tratamento e fontes dos precos ................ 14

3. 2. Margens de Comercializacão .............. 16

3. 3. Relacão de Precos entre Atacado e Varejo e entre Unidades Varejistas ................ 18

3. 3.1. Comparacão a serem feitas ........... 18

3. 3.2. Procedimento estatistico ........... 18 
4. A AGÃo PúBlica NO ABASTECI MENTO DE hORTI GRANJEIROS .

4.1. Aspectos da Evol ucão do Sistema do Abastecimento Alimentar no Brasil ............. 21

4.2. Planos e Programas Nacionais ............... 24

4. 3. Acão do Setor Público no Estado de São Paulo .. 26

4. 4. Acão das Prefeituras ................... 29

5. O MUNICIPIO DE PI RACICABA E O SISTEMA DE ABASTECI MENTO DE HORTIGRANJEIROS ................

5.1. Principais Características Sócio-Econômicas do Municipio de Piracicaba - SP ............ 36

5.1.1. Área e producão agricola ........... 36

5.1.2. Aspectos sócio-econômicos ........... 38

5.1.3. Renda da popul aç̃o .............. 39

5.2. Breve Histórico da Comercializacão de Hortigranjeiros em Piracicaba - SP ............ 40

5. 3. Caracterizacão das Unidades de Comercializacão de Hortigranjeiros sob a Acão Pública Municipal

5. 3. 1. Mercado Municipal ................

48

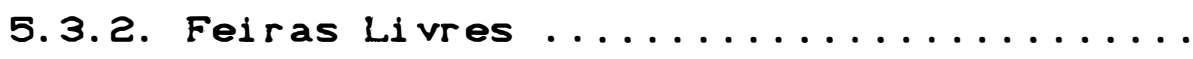

51

5. 3. 3. CEASA - Piraci caba-SP Companhia de Entre postos e Armazéns Gerais de São Paulo -

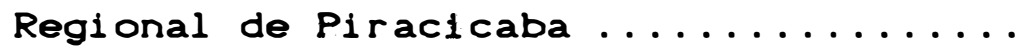

6. ADMINISTRAC̆̃O MUNICIPAL DE PIRACI CABA E O SISTEMA DE

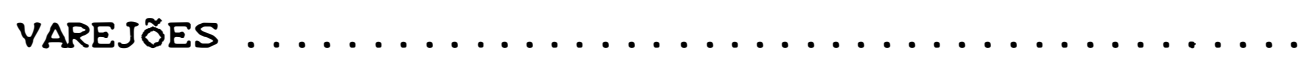

6. 1. Varejão Sorocabana a Experiência Pilôto .......

6.2. Infra-estrutura e Operacionalizacão do Sistema Municipal de Varejôes de Piracicaba-SP .......

6.2.1. Cronologia das implantacôes dos Varejôes e Varejinhos em Piracicaba-SP ......... 
6.2.2. Aspectos da estrutura e operacionalizacão do sistema municipal dos Varejões.. 72

7. ANÁlise dA POLÍ TICA DE PREÇOS DOS VAREJõES DE PIRA-

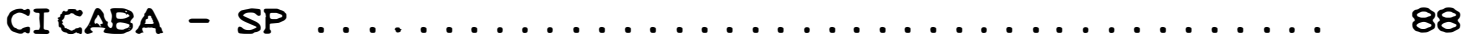

7.1. Transmissão de Precos ................ 88

7.1.1. Efeito das variacões de precos do atacado de São Paulo sobre o atacado de Piracicaba .................... 89

7.1.1.1. Análise da transmissão de precos por produto ........... 89

7.1.2. Efeito das variacões de precos do atacado sobre unidades varejistas ........ 95 7.1.2.1. Para Piracicaba-SP ........ 95 7.1.2.2. Para São Paulo-SP ......... 102

7.2. Margens de Comercializacão .............. 109

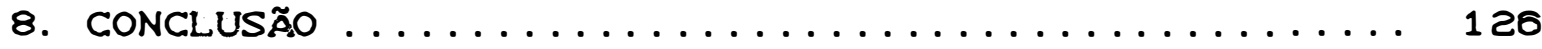

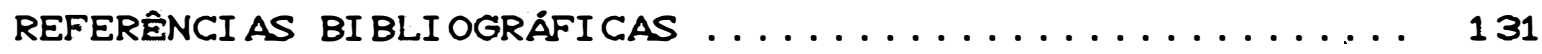

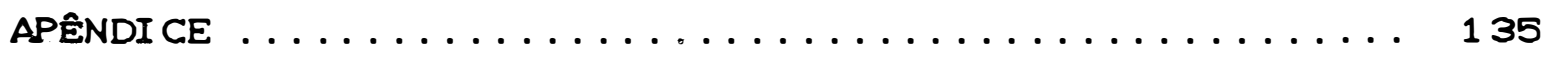


vi i.

\section{LISTA DE TABELAS}

Tabela ne

1 Unidade de Medida dos Produtos Selecionados ....

2 Fonte, Periodicidade e Perlodos dos Precos Obti-

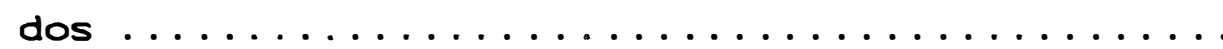

3 Varejões Existentes no Interior do Estado de São

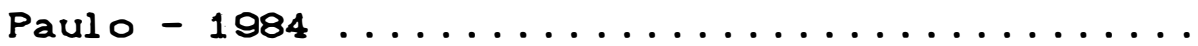

4 Evol ucão da populacão, taxa de urbanizacão e da densidade demográfica de Piracicaba ...........

5 Estabelecimentos da rede privada que comercializam hortigranjeiros em Piracicaba-SP $1989 \ldots . .$.

6 Distribuicão das unidades de abastecimento de acordo com zoneamento baseado no IPTU - Piraci-

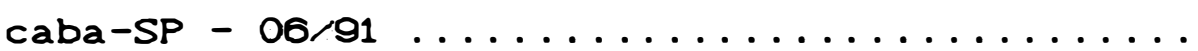

7 Vendedores por Unidade de Comercializacão e Cate goria - Piracicaba - SP Cjunho/90) ..........

8 Permissionários por Ramo de Atividade e Número de Boxes - Mercado Municipal - Piracicaba - SP Janeiror8g ...........................

9 Permissionários por Grupo de Produtos - FeirasLivres Piracicaba - SP - Janeiro/89 ......... 52

10 Permissionários e Boxes por Grupo de Produtos CEASA - Piracicaba - SP - Janeiro/89........

11 Volume comercializado - CEASA - Piracicaba SP -

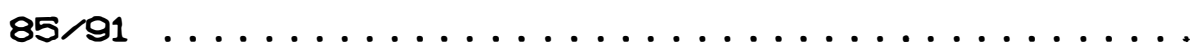

12 Procedência da Alface, Batata e Banana. CEASA Piracicaba-SP $C 02 / 88$ á $02 / 89) \ldots \ldots \ldots \ldots$ 
viii.

Tabel a ne

pág

13 Participacão das categorias de compradores na CEASA - Piracicaba - SP (1987 e 1989) ........

14 Usuários da CEASA por Categoria e Participacão no volume comercializado da CEASA de Piracicaba

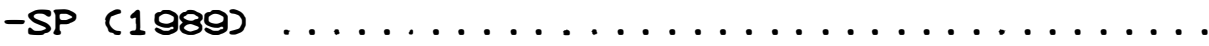

15 Data de inauguracão dos Varejões e Varejinhos

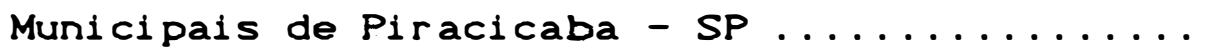

16 Permissionários/Grupo de Produtos e Categoria do Sistema Municipal de Varejões - Piracicaba-SP (31/00/91) ..........................

17 Permissionários/Gr upo de Produtos, Bancas e Categoria - Varejão Central (Ex Sorocabana)

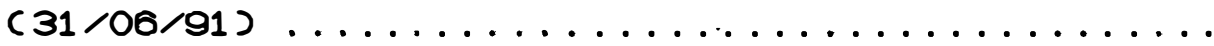

18 Permissionários/Grupo de Produtos, Bancas e Categoria - Varejão Vila Rezende (31/06/91) ....

19 Permissionários/Grupo de Produtos, Bancas e Categoria - Varejão Raposo Tavares (31/06/91) . .

20 Permissionários/Grupo de Produtos, Bancas e Categoria - Varejão Piracicamirim (31/06/91) . . .

21 Permissionários/Grupo de Produtos, Bancas e Categoria - Varejão Santa Terezinha (31/06/91) .

22 Permissionários/Grupo de Produtos, Bancas " e Categoria - Varejão Paulicéia (31/06/91) ......

23 Caracteristicas dos Usuários dos Varejões $\theta$ Varejinhos - Piracicaba-SP. - 09/91 .........

24 Classificacão das Unidades dos Varejões e Varejinhos de acordo com seus Usuários sobre Transporte Coletivo e Diversidade dos Produtos Piracicaba-SP $-09 / 91 \ldots \ldots \ldots \ldots \ldots$ 
25 Classificacão das Unidades dos Varejões e Varejinhos de acordo com seus Usuários sobre Preco e Qualidade dos Produtos - Piracicaba-SP -

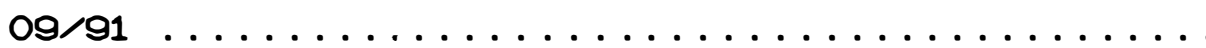

26 Coeficientes de transmissão de precos do atacado São Paulo para o atacado de Piracicaba ........

27 Equacão de transmissão de precos de alface, do atacado de São Paulo para o atacado de Piracicaba no periodo de $01 / 85$ a $12 / 90 \ldots \ldots \ldots \ldots$

28 Equacão de transmissão de precos de tomate, do atacado de São Paulo para o atacado de Piracicaba no periodo de $01 / 85$ a $12 / 90 \ldots \ldots \ldots \ldots \ldots \ldots$

29 Equacão de transmissão de precos de batata, do atacado de São Paulo para o atacado de Piracicaba no periodo de $01 / 85$ a $12 / 90 \ldots \ldots \ldots \ldots \ldots$

30 Equacão de transmissão de precos de banana, do atacado de São Paulo para o atacado de Piracicaba no periodo de $01 / 85$ a $12 / 90 \ldots \ldots \ldots \ldots \ldots$

31 Coeficientes de transmissão de precos do atacado de Piracicaba para o varejo de Piracicaba ......

32 Equacão de transmissão de precos de alface, do atacado de Piracicaba para o varejo de Piracica-

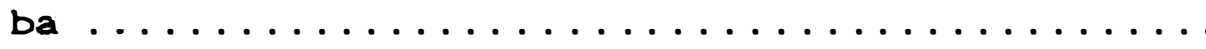

33 Equacão de transmissão de precos de tomate, do atacado de Piracicaba para o varejo de Piracica-

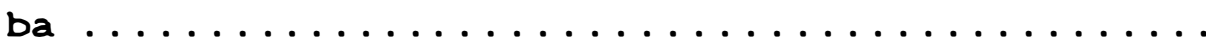

34 Equacão de transmissão de precos de batata, do atacado de Piracicaba para o varejo de Piracica-

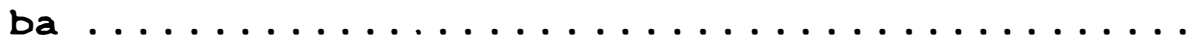


35 Equacão de transmissão de precos de banana, do atacado de Piracicaba para o varejo de Piracicabа ................................ 101

36 Coeficientes de transmissão de precos do atacado de São Paulo para o varejo de São Paulo ........ 104

37 Equacão de transmissão de precos de alface, do atacado de São Paulo para o varejo de São Paulo. 105

38 Equacão de transmissão de precos de tomate, do atacado de São Paulo para o varejo de São Paulo. 106

39 Equacão de transmissão de precos de batata, do atacado de São Paulo para o varejo de São Paulo. 107

40 Equacão de transmissão de precos de banana, do atacado de São Paulo para o varejo de São Paulo. 108

41 Margem de Comercializacão de Alface em Piracicaba - SP, nos perlodos de $85 / 90$ e $89 / 90 \ldots . . \ldots 111$

42 Margem de Comercializacão de Alface em São Paulo - SP, nos perlodos de $85 / 90$ e $89 / 90 \ldots . . . . . . .1113$

43 Margem de Comercializacão do Tomate em Piracicaba - SP, nos perlodos de $85 / 90$ e $89 / 90 \ldots \ldots \ldots 115$

44 Margem de Comercializacão do Tomate em São Paulo - SP, nos perílodos de $85 / 90$ e $89 / 90 \ldots . . . . . . .$.

45 Margem de Comercializacão da Batata em Piracicaba - SP, nos perílodós de $85 / 90$ e $89 / 90 \ldots \ldots 119$

46 Margem de Comercializacão da Batata em São Paulo - SP, nos perílodos de $85 / 90$ e $89 / 90 \ldots . . . . . . .121$

47 Margem de Comercializacão da Banana em Piracicaba - SP, nos perlodos de $85 / 90$ e $89 / 90 \ldots \ldots \ldots 123$

48 Margem de Comercializacão da Banana em São Paulo - SP, nos períodos de 85/90 e 89/90 


\section{LISTA DE FIGURAS}

Figura ne

1 áreas ocupadas com cana de acúcar - municipio de

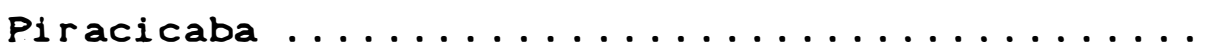

2 Áreas ocupadas com culturas anuais - municipio de Piracicaba ......................

3 Localizacão das feiras Livres no municipio de

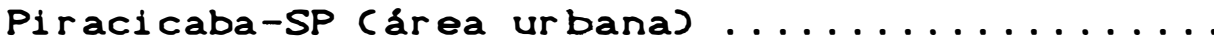

4 Nucleos Rurais e distância do centro da cidade municipio de Piracicaba ................

5 Localizacão dos Varejóes no municipio de Piracicaba-SP (área urbana) ................... 65

6 Localizacão dos Varejinhos no municipio de Pira-

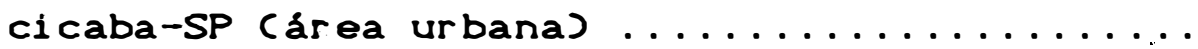

7 Quantidade comercializada CEASA X Varejóes 482 a

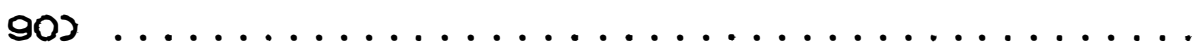

8 Quantidade comercializada CEASA X Varejóes Cjan.

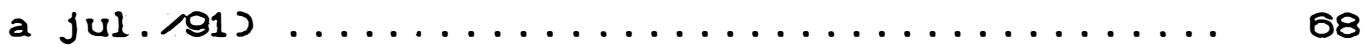

9 Quantidade comercializada - Varejinhos X Varejóes de Piracicaba (jan. a set. 91 ) ..........

10 Quantidade comercializada - Varejinhos de Piracicaba Cjan. a set. 91 ) .............. 72

11 VERDURAS $C \%$ das vendas Varejóes de Piracicaba

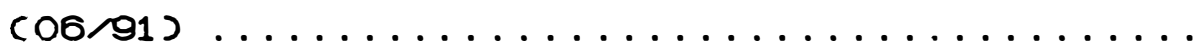

12 LEGUMES ( $\%$ das vendas Varejôes de Piracicaba $(06 / 91)$ 
xii.

Figura ne

13 TOMATE (\%) das vendas Varejões de Piracicaba

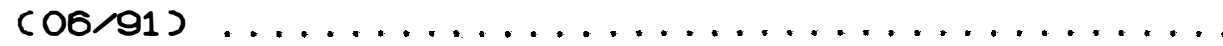

14 CEREAIS TUBERCULOS C\% das vendas Varejões de

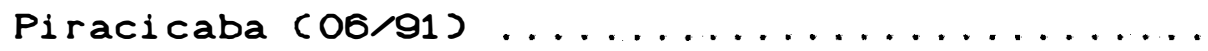

80

15 LARANJA C $\%$ das vendas Varejões de Piracicaba

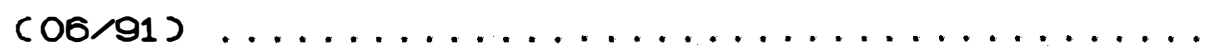

80

16 BANANA (\%) das vendas Varejões de Piracicaba

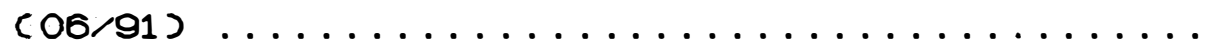

80

17 ovos (\%) das vendas Varejões de Piracicaba

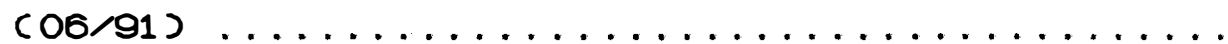

18 FRANGOS E FRIOS C\% das vendas Varejões de Pira-

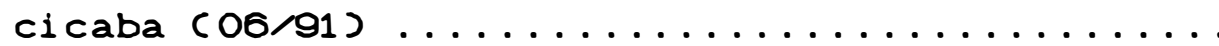

19 MIUDOS C\% das vendas Varejões de Piracicaba

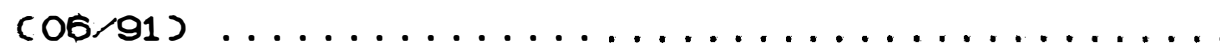

20 PEIXES $C \%$ das vendas Varejões de Piracicaba

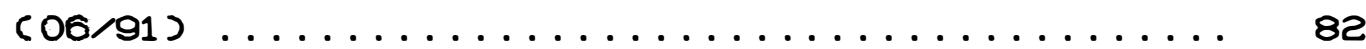

21 Comparacão dos precos da alface na CEASA, FeiraLivre e Varejão em Piracicaba, média semanal perlodo 85 a $90 \ldots \ldots \ldots \ldots \ldots \ldots \ldots \ldots . \ldots \ldots \ldots$

22 Comparacão dos precos da alface na CEASA, FeiraLivre e Varejão em Piracicaba, média anual pe-

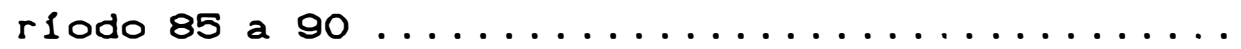

23 Comparacão dos precos do tomate na CEASA, FeiraLivre e Varejão em Piracicaba, média semanal pe-

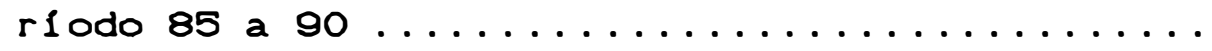

24 Comparacão dos precos do tomate na CEASA, FeiraLivre e Varejão em Piracicaba, média anual pe-

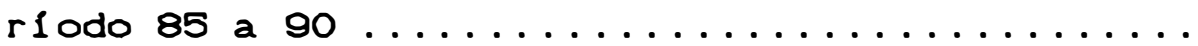

25 Comparacão dos precos da batata na CEASA, FeiraLivre e Varejão em Piracicaba, média semanal pe-

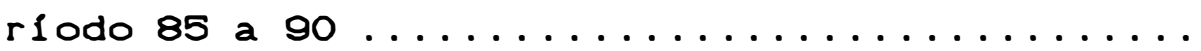


xii1.

Figura ne

pág.

26 Comparacão dos precos da batata na CEASA, FeiraLivre e Varejão em Piracicaba, média anual pe-

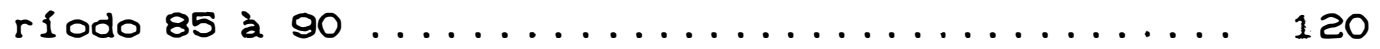

27 Comparacão dos precos da banana na CEASA, FeiraLivre e Varejão em Piracicaba, média semanal período 85 à $90 \ldots \ldots \ldots \ldots . \ldots \ldots \ldots . \ldots \ldots \ldots$

28 Comparacão dos precos da banana na CEASA, FeiraLivre e Varejão em Piracicaba, média anual período 85 à $90 \ldots \ldots \ldots \ldots . \ldots \ldots \ldots$ 
xiv.

\section{A ADMINISTRACÃO PÚBLICA MUNICIPAL E $O$ ABASTECIMENTO DE HORTIGRANJEIROS: O CASO DOS VAREJÕES MUNICIPAIS DE PIRACICABA, ESTADO DE SÃO PAULO.}

Francisco Constantino Crocomo

Orientador: Prof. Dr. Geraldo S. A. de Camargo Barros

\section{RESUMO}

Diversas são as acões do setor público no sentido de enfrentar os problemas de abastecimento al imentar no Brasil. Na década de 70 estas acôes foram mais efetivas, inclusive com medidas de expansão do comércio varejista. Os Varejões - unidades varejistas administradas pelo setor público, em locais predeterminados e com precos máximos fixados para cada produto, constituiram-se alvo de investigacão deste trabalho. Nele a experiência dos Varejões do municipio de Piracicaba, 1982 a 1990, administrados pelo setor público municipal, foi analisada através de sua insercão no Sistema dé Abastecimento da cidade, na tentativa de identificar sua atuacão e reflexos neste mercado.

Foram objeto desta análise os seguintes

produtos: Alface; Tomate; Batata e Banana. Efetuou-se a comparacão de seus precos nos Varejões e demais unidades varejistas com os precos no atacado do municipio. 
Verificou-se que as margens de comercializacão dos Varejões estão abaixo das outras unidades. Em média os Varejões obtiveram $11,5 \%$ de margem corrente mensal (11\% para Alface; $13 \%$ para o Tomate; $12 \%$ para Batata e 10\% para a Banana), enquanto as Feiras-Livres obtiveram $28,5 \%$ ( $30 \%$ para Alface; 26\% para o Tomate; $25 \%$ para a Batata e $35 \%$ para a Bananas, para o perfodo de 1985 a 1990 . Os precos máximos estabelecidos para os Varejões são fixados com base nos precos do atacado local, confirmado pelos resultados dos cálculos de elasticidade de transmissão de precos para os produtos analisados. Verificou-se também que em geral são necessárias mais de quatro semanas para a transferência total das variacões de preco do atacado para o Varejão.

Observou-se que, no periodo analisado, a administracão do setor público municipal manteve uma equipe de comerciantes para atuarem nos bairros periféricos, com a mesma filosofia dos Varejões. A quantidade comercia- lizada pelos Varejões manteve certa regularidade, o que não ocorre no atacado. Identificou-se também que os Varejões possuem razoável número de produtores que vendem no varejo, inclusive em número maior que a unidade atacadista da cidade. Conclue-se que o Sistema de Varejões, objeto principal desse estudo, conseguiu se estabelecer ao longo do periodo considerado, constituindo um canal alternativo de comercializacão para consumidores e comerciantes. 
xri.

THE MUNICIPAL PUBLIC ADMUNISTRATION AND THE SUPPLY OF HORTICULTURAL AND FRUIT PRODUCTS: THE CASE OF THE "VAREJõES OF THE CITY OF PIRACICABA, STATE OF SÃO PAULO

\author{
Francisco Constantino Crocomo \\ Adviser: Prof. Dr. Geraldo S. A. de Camargo Barros
}

SUMLARY

Several are the actions of the public sector directed to solve the problems of the food supply in Brazil. In the seventies these actions standed to be more effective reaching even the retail trade level. This study was an at tempt to analyse the "VAREJõES", which are units of retail trade operating with maximum prices established for the public sector each product. The experience of this $\dot{k}$ ind of trade at the city of Piracicaba from 1982 to 1990 was analysed as an attempt to identify its performance and its influence in other retail agents.

The products considered included Lettuce, Potato, Tomato and Banana. The price of each commodity at the "VAREJõES" and at the other retail units level were compared with the wholesale level price.

It was observed that the marketing spreads of the "VAREJõES" are smaller tham the spreads other units; on average the current monthly spread at the varejão was about $11,5 \%$ C $11 \%$ for Lettuce, $13 \%$ for Tomato, $12 \%$ for Potato, and $10 \%$ for Bananal for the $1985-1990$ period. On this same 
xvi i.

period the current monthly spread for the street market (feiras-livres) close to $28,5 \%$ (30\% for Lettuce, $26 \%$ for Tomato, 25\% for Potato, and 35\% for Bananas.

The "VAREJõES" maxi mum prices were established with basis on the local wholesale prices. This rule was corroborated by the elasticities of price transmission determined for each one of the products considered. It was also found that in general more than four weeks are necessary to total transference of the price variation from the wholesale level to the retail level (VAREJõES).

It was verified that during the Public Administration kept a trader team with the objective of acting on the surrounding regions relied on the same rundamental principles of the "VAREJõES".

It was observed also that a reasonable number of producers sell their products at the "VAREJõEs"; this number is greater than the number of producers that trade at the wholesale level. This study is results indicated that the system of "VAREJõEs" has now stablished to self as an alternative chaunel of trading for consumers and suppliers. 


\section{INTRODUĞ̃̃O}

1.1. Caracterização do Problema

Este estudo analisa a atuacão dos Varejões Municipais de Piracicaba - SP, como um canal alternativo de comercializacão de alimentos administrado pelo setor público municipal desde 1982. Informacões sobre operacionalizacão. sua insercão e reflexos no Sistema de Abastecimento da cidade, bem como a relação com politicas públicas ligadas ao setor, constituem preocupacões desta pesquisa.

A acão do setor público na implantacão dos Varejões pode ser embasada de forma sintética na afirmacão de Bessa (1984. pag. 233) : "a idéia fundamental e básica era a de criar um canal alternativo de distribuicão e outra opcão ao público consumidor na tentativa de, também simultâneamente, regular os precos de mercado".

Conforme Barros (1987, pag. 31), "O desenvolvimento de canais mais eficientes de comercializacão e a difusão de informações mais adequadas sobre os mercados, têm papel importante. Nesse campo, as atividades oficiais como centrais de abastecimento, mercados de produtor e Varejões, representam possiveis solucões sempre que estimulem práticas competitivas".

Embora o problema do abastecimento alimentar esteja envol vido com entraves de ordem macroeconômico devido ao baixo nivel de renda e com a instabilidade na politica 
agricola da esfera federal, é importante investigar o alcance do Varejão como parte de uma solucão a nível local. A realizacão desta pesquisa foi possivel gracas ao envolvimento junto ao órgão administrador do Sistema Municipal de Abastecimento da Prefeitura Municipal de Piracicaba - SP, o qual demonstrou interesse nos resultados, com vistas a avaliação de suas ações nesta área. Constatou-se também, em conjunto com este órgão da Prefeitura, que existia a necessidade da realizacão de um amplo diagnóstico sobre o setor de abastecimento alimentar da cidade, o qual foi realizado em conjunto com a ESALQ - Escola Superior de Agricultura Luiz de Queiroz, através do seu Departamento de Economia e Sociologia Rural.

A busca de informações, principalmente dos precos praticados no mercado de Piracicaba, exigiu uma revisão e organizacão dos arquivos na Prefeitura Municipal, bem como a garantia da continuidade de sua producão com boa qual i dade.

\subsection{Objeti ros}

o objetivo geral do trabalho é analisar a acão do Governo Municipal de Piracicaba iniciada em 1982, na implementacão dos varejöes municipais, como canal alternativo no abastecimento de produtos horticolas. Para tal, esta análise se darł através dos objetivos especificos: 
i) Identificar a estrutura das seguintes unidades de comercializacão", bem como possíveis interrelacões: CEASA (atacado de Piracicaba) e Feiras Livres, mercado municipal e Varejões Municipais, para Piracicaba - SP.

2) Comparar precos de 4 (quatros produtos; alface, batata. tomate e banana, praticados entre as unidades de comercializacão já citadas acima.

3) Verificar o grau de relacão dos precos das diversas unidades de varejo com o de atacado.

4) Para comparacões cóm o caso de Piracicaba, adotar o mesmo procedimento para a cidade de São Paulo, considerando CEAGESP (atacado); varejões; felras-livres (varejo) e super mer cados;

5) Analisar a integracão do atacado de Piracicaba com o de São Paulo - SP, ou seja relacionar os precos do CEASA Piracicaba em funcão daqueles praticados na CEAGESP - São Paulo.

A fim de atender aos objetivos propostos 0 presente trabalho fol organizado conforme segue: Revisão Bibliográfica sobre a questão de abastecimento alimentar e a intervencão pública e algumas avaliacões da atuacão no mercado varejista; Acão Pública no abastecimento de hortigranjeiros, com a finalidade de identificar as politicas

1 Termo usado como representalivo das diferentes modalidades de organizasāo nas vendas de horligranjeiros. É comum utilizar-se o lermo"equi pamentos" pelos lécnicos da Administragão Pública. 
desencadeadas pelo setor público brasileiro na questão e, em seguida, a caracterizacão do Sistema de Abastecimento em Piracicaba, com ênfase para as unidades que são administradas pelo setor público; Caracterizacão do Sistema Municipal de Varejôes e sua operacionalizacão pela Prefeitura Municipal de Piracicaba; Análise da politica de precos dos varejóes no mercado varejista de Piracicaba, via cálculos das elasticidades de tranismissão de precos e das margens de comercializacão em comparacão com os resultados do mercado da cidade de São Paulo - SP; por fim apresentamos as Consideracôes Finais. 


\section{REVISÃO BIBLIOGRÁFICA}

Diversos trabalhos se preocupam com o problema do abastecimento de alimentos, e diversas também são as interpretaçóes a respeito da intervencão pública nesse campo. Entretanto, especificamente para análise da atuacão de unidades de comercializacão administradas pelo setor público, os trabalhos são escassos e elaborados, na maioría dos casos, pelos próprios órgãos administradores destas. Diante deste quadro, são apresentados alguns enfoques ligados a intervencão pública no setor de abastecimento alimentar e, posteriormente, aqueles ligados à operacionalizacão das unidades de comercializacão.

Linhares (1979), em pesquisa voltada para a história do abastecimento, chama a atencão para a importância de investigacões locais e regionais, com vistas ao consumo urbano, renda gerada, hábitos de cultivo e alimentares. sem esquecer das estruturas sociais envolvidas, a politica e mentalidades. Deixa clara a relevância dos estudos sobre técnicas de comercializacão, bem como o aspecto historico. "Assim, o abastecimento pode ser encarado sobre o prisma tanto histórico-econômico própriamente dito, quanto da história politico-social, importando localizar, de um lado, o sistema agrário e, de outro, as estruturas, emergindo de ambos as necessidades de comercializacão e distribuicão" (p. 217). A criacão do Comissariado de Alimentacão Pública 
6.

em 1918 é apresentada como sendo o primeiro passo na história da intervencão pública no mercado interno. "Rompeu - tabu liberal de não ingerência no setor privado, prenunciando uma politica de abastecimento cuja eficácia foi sempre alvo de polêmicas e contra a qual se congregaram as insastifações das massas consumidoras" (p. 220).

FERRATO (1982) estuda o abastecimento de alimentos no Brasil sob o enfoque da intervencão que o Estado realiza históricamente no setor, discutindo a controvérsia metodológica, buscando entender a natureza e o caráter das intervencões. Faz referência a contradicões que emergem da relacão direta entre a interferência do Estado com o processo de acumulacão da economia, que se manifestam pelo "equilibrio instável entre o Capital Privado, a Sociedade e o Estado, e traduzidos por acões meramente tópicas, deste último Setor, além de marchas e contra-marchas da politica agricola de abastecimento " (p. 93).

As medidas politicas, o papel da comercializacão e suas interacões são abordadas dentro de alguns trabal hos.

BRANDT (1969) afirma que os estudos de comercializacão são requeridos com grande intensidade, quando da intervencão governamental. " o impacto de tais politicas sobre a producão, consumo, niveis de estoque e de precos depende, entre outras coisas, das respectivas elasticidades -preco de oferta e procura " (p.61). Faz referência também sobre a nocão do comportamento das margens, race a variacão 
em precos, quantidades, etc.

WELSH (1969) faz referência as pesquisas reali zadas pelo Instituto Agricultura Internacional de Michigan State University, relativas a Porto Rico e através do Prof. Kelly Harrison, onde se apontaram 6 classes de programas governamentais, dos quais destacamos 0 de Assistência a organizacão de comercializacão: "medidas para facilitar e encorajar certos tipos de organizacões econômicas e associacões, tais como sociedades profissionais, consórcios de pesquisa, etc., que determinadas situacões, poderão contribuir para o desempenho total da comercializacão e para - crescimento econômulco" (p. 20 ).

BARROS (1980) discute a problemática de producão de alimentos nö Brasil sob o ângulo de sinalizacóes de precos, programas de seguro rural, isso a curto prazo. Porém destaca que " os aumentos de preco, todavia, podem pesar demasiadamente sobre a classe de baixa renda. Disso resulta a ausência de alternativa, no curto prazo, a não ser um programa de subsidio de redistribuicão de renda a favor dessa classe de consumidores..." (p.32).

MALUF (1982) trata da comercializacão de Produtos Horticolas, fazendo inferências a respeito da estrutura das investigacões, que a propósito coincidiam com - ano de criacão dos varejões em Piracicaba. Faz mencão sobre a possibilidade do produtor participar diretamente do mercado atacadista, o que se efetivava de forma reduzida na época, restringindo-se ao "Mercado de Caminhőes"/ em Mogi 
8.

das Cruzes, e não nos CEASAS, sendo que a malor parte da producão era comercializada via atacadista e cooperativas, sob consignacão, e "num segundo plano, estariam as vendas à vista aos compradores que, posteriormente, revendem os produtos aos atacadistas de grandes entrepostos" (p. 78). A construcão de CEASAŚ e outras centrais de abastecimentos regionais pelo interior, descentralizou a comercializacão, segundo MALUF, o qual acrescenta,"Certamente esta tendencia deverá produzir efeltos sobre a estrutura de comercializacão vigenté e constituir em interessante campo de investigacão “ (p. 79).

MALUF (1989) chama a atencão para a necessidade de discusão e entendimento da chamada "seguranca alimentar", presente na literatura internacional, que é pouco difundida no Brasil, que tem como linha geral a necessidade de assegurar a toda a populacão a obtencão dos alimentos que necessitem. Uma politica nacional de seguranca alimentar tem um horizonte mais amplo e perspectiva de intervencão mals profunda do que os costumeiros ce muitas vezes fracassados) progressos complementares ou setoriais". Cpag. 103. O autor ressalta o merito dos programas de caráter local, e de acŏes emergencials, 1 mplementadas por diversos municipios para enfrentamento as conjunturas adversas, tais como: "propostas que estimulam a producão agricola de alguns alimentos, articuladas com determinada destinacão como, por exemplo, os mercados de produtores ou mesmo a merenda escolar. Apesar de restritas e insuficientes como 
base de uma politica global de abastecimento, elas têm o mérito de enfrentar o empobrecimento de pequenos produtores e ampliar a oferta local de alguns bens". Cpag. 10). O autor considera tais medidas, ao alcance dos municipios, 1 mportantes más não suficientes para o enfrentamento do problema al imentar.

GUIMARÃES (1969), investiga o papel das feiras-livres no abastecimento da cidade de São Paulo. Através de vasto material de pesquisa, relata a história das feiras-livres e sua importáncia no abastecimento, em termos de descentralizacão, facilidades, e também seus aspectos negativos em termos de qualidade, higiene, etc... 0 autor aponta também pára novas al ternativas de mercado que surgiam na época, e para adaptacões da própria felra-livre. .

Uma avaliacão dos varejões da clidade de São Paulo, realizada em 1984 por alunos da Faculdade de Ciências de Saúde São Camilo para a Secretaria de Agricultura e Ab́astecimento do Estado de São Paulo - Coordenadoria de Abastecimento, concluiu que a estrutura destas unidades varejistas não atendia satisfatóriamente aos consumidores, pois os precos fixados para os produtos, por classificacão, nem sempre eram obedecidas nas vendas.

Especificamente para o mercado de Piracicaba dois trabalhos foram localizados. Um relacionado ao estudo do mercado varejista, realizado por Amaro, Tsunechiro e Vansetti (1989), e outro por Silva (1984) relativo à análise e avaliacão dos varejões de Piracicaba, no seu objetivo de 
atender aos pequenos e médios produtores e consumidores.

- estudo do mercado varejista de Piracicaba. de Amaro, et al. (1989), baseou-se em pesquisa realizada em 1980, época em que ainda não existiam os varejões e o CEASA de Piracicaba. O trabal ho apresentou como objetivo a análise da organizacão dos equipamentos varejistas do comércio de produtos hortifruticolas, e alguns aspectos das práticas utilizadas nas compras e vendas dos produtos. A pesquisa envolveu análise de feiras-livres, quitandas, armazéns/mercearias, supermercados e casas de aves/ovos. Dentre os pontos mais relevantes das conclusões do trabal ho destacamos (pag. 124).

a) Existia, na época da pesquisa, uma legislacão municipal que procurava ordenar as atividades de comércio de al imentos;

b) Os comerciantes realizam suas compras, não efetuando encomendas (ou compras a distância), o que evidenciava a ralta de um "sistema eficiente" de classificacão de produtos agricolas em especial de hortifruticolas;

c) Dentre os estabelecimentos comerciais, a predominância era de firmas individuais e de caráter familiar, e muitas microempresas;

d) Os supermercados passam a predominar, inclusive com o surgimento das redes, com mais de uma loja;

e) Quanto a participacão das unidades varejistas no volume de vendas por tipo de produtos,o mercado se apresentava da seguinte forma: 
Feiras-livres: verduras, legumes em geral e ovos.

Supermercados: mamão, banana macã, cereais, al ho e aves abatidas.

Quitandas: abacaxi, banana nanica, laranja e frutas de forte sazonalidade de producão.

Armazéns e Mercearias: batata e cebola.

f) Não se identificou a existência de problemas estruturais no comércio varejista de genêros alimenticios.

g) As fontes atacadistas situavam-se na cidade e abasteciamse predominantemente em entrepostos de outras localidades, a cadà dois ou três dias.

- estudo dos varejões Municipais, realizado por Silva, et al. (1984), objetivou analisar e avaliar os servicos dos varejões, em 1984, quanto à participacão de produtores e perfil dos consumidores atendidos. O trabalho foi solicitado pela Secretaria Municipal de Agricultura e Abastecimento de Piracicaba; as caracteristicas mais importantes das conclusões deste trabalho, são as que se seguem (pag. 84 a 86 ):

a) Os consumidores em sua maioria eram de baixa renda;

b) Os produtores que participavam das vendas nos varejões apresentavam insatisfacões e grande expectativa quanto à assistência técnica agricola;

c) Tanto os vendedores como os consumidores aparentavam, de forma geral, estarem satisfeitos com os precos, a organizaça e qualidade dos produtos (para os consumidores): 
12.

d) dentre as sugestóes dos consumidores destacam-se:

- melhorar fiscalizacão dos produtos;

- maior diversificacão dos produtos;

- aumentar espaco dos varejões;

- aumentar quantidade de bancas;

- implantar mais varejôes na cidade (na época existiam 3). 


\section{MATERIAL E MËTODOS}

Descrevemos aqui os dados e informações e suas respectivas fontes, bem como os métodos a serem utilizados neste trabalho, conforme os objetivos propostos.

\subsection{Material e Fonte de Dados}

3.1.1. Caracterização das estruturas das unidades de comérclallzaçăo

Analisamos algumas caracteristicas da infraestrutura e operacionalizacão das seguintes unidades de comercialização: CEASA, varejões municipais, mercado municipal e Feiras-Livres de Piracicaba-SP. Tais análises referemse a revisão das leis e regulamentos em vigência; das quantidades médias de vendas colisponiveis só para os Varejões e CEASA); do número e categoria de comerciantes por ramo de venda (grupo de produto), bem como do tipo e participacão dos compradores. A fonte destas informacões foi a SEMA - Secretaria Municipal de Agricultura e Abastecimento de Piracicaba e CEASA - Central de Abastecimento Atacadista de Piracicaba - SP.

3.1.2. Produtos selecionados e comparaçáo de seus precos

Realizamos comparacões de precos de 4 Cquatro) produtos, conforme especificacão (Tabela 1 ). 
Tabela 1. Unidade de Medida dos Produtos Selecionados

\begin{tabular}{|c|c|c|c|}
\hline \multirow{2}{*}{ PRODUTO } & \multirow{2}{*}{ TIPO } & \multicolumn{2}{|c|}{ UNI DADE } \\
\hline & & ATACADO & VAREJO \\
\hline $\begin{array}{l}\text { Alrace } \\
\text { Lisa }\end{array}$ & Grande & $c x=4,0 \mathrm{~kg}$ & $\begin{array}{l}\text { unidade }=\operatorname{maco} \\
=0,33 \mathrm{~kg}\end{array}$ \\
\hline $\begin{array}{l}\text { Tomate } \\
\text { Envarado }\end{array}$ & $A A$ & $c x=25,0 \mathrm{~kg}$ & $\mathrm{~kg}$ \\
\hline $\begin{array}{l}\text { Batata } \\
\text { Bintje }\end{array}$ & $\begin{array}{l}\text { Lisa } \\
\text { Especial }\end{array}$ & saca $=60 \mathrm{~kg}$ & kg \\
\hline $\begin{array}{l}\text { Banana } \\
\text { Nanica }\end{array}$ & Climatizada & $c x=26.0 \mathrm{~kg} / 12 \mathrm{dz}$ & $d z$ \\
\hline
\end{tabular}

Fonte: SEMA e CEASA - Piracicaba - SP

Foram utilizados os precos dos produtos discriminados na Tabela 1, que foram comercializados nas unidades de comercializacão já descritas no item anterior, bem como os precos da CEAGESP - Companhia de Entrepostos e Armazéns Gerais de São Paulo, varejões e feiras-livies da cidade de São Paulo (ver apêndice).

A escolha destes produtos levou em consideracão os seguintes critérios:

a) maior volume comercializado (no grupo a que pertence) e

b) procedência (diferentes graus de importacão no municipio de Piracicabas.

3.1.3. Periodo, Periodicidade, Tratamento e Fonte dos precos.

Os precos foram obtidos, quando possivel, para o periodo de Janeiro de 1985 a dezembro de 1990 , registrados por semana, deflacionados pelo IGP (Indice Geral 
de Precos) "coluna $2 "$ da Fundacão Getulio Vargas, atualizados para valores de dezembro de 1990. As fontes, periodicidade e perfodos dos dados são mostrados na Tabela 2 . Tabela 2. Fonte, Periodicidade e Perlodos dos Precos Obtidos.

\begin{tabular}{|c|c|c|c|c|}
\hline $\begin{array}{l}\text { UNI DADE DE } \\
\text { COMERCI ALI ZACÃO }\end{array}$ & FONTE & PERI ODI CI DADE & \multicolumn{2}{|c|}{ PERÍODO } \\
\hline \multicolumn{5}{|l|}{ ATAC.ADO } \\
\hline $\begin{array}{l}\text { Entreposto } \\
\text { Munici pal }\end{array}$ & SEMA & Sextas-Feiras & $01 / 85$ a & $02 / 85$ \\
\hline $\begin{array}{l}\text { CEASA- } \\
\text { Piracicaba }\end{array}$ & $\begin{array}{l}\text { CEASA- } \\
\text { Piracicaba }\end{array}$ & Sextas-Feiras & $03 / 85$ a & $12 / 90$ \\
\hline CEAGESP & CEAGESP & $\begin{array}{l}\text { Quintas e } \\
\text { Sextas-Feiras }\end{array}$ & $01 / 85$ a & $12 / 90$ \\
\hline \multicolumn{5}{|c|}{ VAREJO-PI RACI CABA } \\
\hline $\begin{array}{l}\text { Varejões } \\
\text { Municipais }\end{array}$ & SEMA & Sábados & $01 / 85$ a & $12 / 90$ \\
\hline $\begin{array}{l}\text { Feiras- } \\
\text { Livres }\end{array}$ & SEMA & Médi a/Semana & $01 / 85$ a & $12 / 90$ \\
\hline $\begin{array}{l}\text { Mercado } \\
\text { Municipal ** }\end{array}$ & SEMA & Média/Semana & $03 / 89 a$ & $12 / 90$ \\
\hline \multicolumn{5}{|l|}{ VAREJO-CEAGESP } \\
\hline $\begin{array}{l}\text { Varejöes. } \\
\text { CEAGESP }\end{array}$ & CEAGESP & Sábados & $01 / 89 a$ & $01 / 90$ \\
\hline $\begin{array}{l}\text { Feiras- } \\
\text { Livres }\end{array}$ & $\operatorname{IEA}^{* * * *}$ & Médi a/Semana & $01 / 85$ a & $12 / 90$ \\
\hline Super mer cados & IEA & Médi a/Semana & $01 / 85 a$ & $12 / 90$ \\
\hline
\end{tabular}

(*) I naugurado em $03 / 85$

(*) As coletas só foram regularizadas a partir de 03/88

(**) Os precos de 1979 até 1988 foram extraviados segundo informacões da CEAGESP.

(3***) Instituto de Economia Agricola - Secretaria de Agricul tura do Estado de São Paulo

A selecão do Perlodo e Periodicidade dos precos levou em consideracão os seguintes critérios e restricões: 
a) optou-se pelos precos praticados aos sábados nos varejões, tanto de São Paulo como em Piracicaba, devido a sua maior importância em termos de quantidade comercializada, com a suposicão de que um maior número de consumidores afluem a estes mercados. Dai decorre a obtencão dos precos ás sextas-feiras no atacado de Piracicaba e São Paulo. Informacões que os varejôes dos sabados tomam por base, para fixacão de seus precos, o atacado das sextas-feiras.

b) obtiveram-se também os precos do atacado das quintasfeiras da CEAGESP, a fim de verificar a sua influencia no atacado de Piracicaba, vi a CEASA.

c) quanto aos precos de outras unidades varejistas, tanto em São Paulo como em Piracicaba, o uso de média de precos se deu exclusivamente pela disponibilidade dos mesmos desta forma.

\subsection{Margens de Comercialização}

Os precos no atacado para Piracicaba-SP e São Paulo-SP serão convertidos em unidades equivalentes ao varejo sem levar em consideracão eventuais perdas cconforme Tabela 12, para posterior determinacão das margens de comercialização. Estas serão calculadas pelo método usual:

$$
M_{v}=\frac{P_{v}-P_{a}}{P_{v}} \cdot 100
$$

onde:

$$
\begin{aligned}
& M_{v}=\text { Margem de comercializacão no varejo } \\
& P_{v}=\text { Preco no varejo }
\end{aligned}
$$




$$
P_{a}=\text { Preco no atacado }
$$

A obtenção das margens em nosso estudo permitirá o acompanhamento das mesmas para cada produto nas diferentes unidades de comercializacão, no periodo de 85 a 90 , com a possibilidade de efetuar a comparacão Piracicaba-São Paulo. Segundo BARROS (1987 pag. 42): "A principal utilizacão das medidas das margens de comercializacão refere-se ao acompanhamento de sua evolucão, propiciando avaliacão do desempenho dos mercados. Evidentemente, tal avaliacão requer - pleno contiecimento do significado da medida em questão".

- autor chama a atencão para a necessidade do conhecimento de vários fatores que podem áfetar as margens, entre os quais:

- grau de concorrência no mercado, esperando-se menores margens nos mercados mais competitivos;

- valor do produto em relacão ao seu peso ou volume;

- produtos pereciveis e produtos processados apresentam maior margem;

- mudancas tecnológicas podem reduzir as margens c como o armazenamento e transporte a granel);

- alteracão nos servicos de comercializacão, ex. : auto-servico, embalagens, etc...

- alteracóes nos precos dos insumos de comercializacão e de producão e na demanda do consumidor;

- perdas na comercializacão.

Não será levada em conta a derasagem de tempo na mensuracão das margens de comercializacão, pois a análise 
recal sobre produtos perecivels no mercado, negociados rapidamente ao consumidor final.

3.3. Relaçao de Precos entre Atacado e Varejo e entre Unidades Varejistas

\subsubsection{Comparações a serem feltas:}

a) Interacão com o mercado Paulistano CCEASA-Piracicaba e CEAGESP-São Paulo).

b) Entre Atacado (CEASA e varejão em Piracicaba-SP e outras unidades: feiras-livres e supermercados;

c) Entre Atacado (CEAGESP) e varejão em São Paulo e outras unidades (feiras-livres e mercado municipal);

\subsubsection{Procedimento estatistico}

Para medir os efeitos indicados em 3.3.1..

procederemos o ajustamento de regressão múl tipla na seguinte forma:

$$
\ln Y_{t}=a+\sum_{i=0}^{d} b_{i} \ln X_{t-i}+w_{t}+t+u_{t}
$$

onde:

$a=$ constante; $Y_{t} e X_{t}$ - representam os precos ao varejo e ao atacado, prespectivamente nos casos b) e cl descritos acima. No caso $d) X_{t}$ representa os precos do varejão $e Y_{t}$ os precos de outras unidades varejistas. No caso a) $\mathrm{X}_{t}$ representa os precos do Atacado em São Paulo e $Y_{t}$ O Atacado em Piracicaba.

$b_{i}$ - o coeficiente que representa a elasticidade parcial de transmissão de precos do periodo (t - il para o periodo 
t. Finalmente $\Sigma b_{i}$ será a elasticidade total de transmissão de precos, refletindo o efeito acumulado durante o periodo relevante de transmissão de precos.

d - número de derasagens $=4$

w - variável binária - período do Plano Cruzado C03/86 a $11 / 86=1$ e 0 para os demais períodos 2.

t - varıável tendência

$u_{t}$ - erro aleatorio

Efetua-se o ajustamento de regressão acima para a série de precos para as unidades de comercializacão em estudo, a fim de obter as elasticidades de transmissão que contemplam a derasagem de tempo de 4 semanas, aqui convencionada a fim de se realizar as comparacões necessárias, supondo que no mercado estudado, os agentes passam não alterar integralmente e/ou 1 mediatamente seus precos após alteracões no mercado de compra.

Foi necessário a aplicacão de flltragens de primeiro, segunda e de até terceira ordem no ajustamento da regressão multipla proposta, toda vez em que o teste de Durbin-Watson (DW) detectou a auto-correlacão entre residuos ${ }^{1}$.

BARROS (1988) testa um modelo teórico de transmissão de precos de batata inglesa, banana, cebola e tomate de 1972 a 1985, comercializados através do c.EAGESP.

1 Os procedimentos para o ajustamento e testes da regressão foram efetuados a través das instrucōes contidas em kASSOUf, A. L. a HOFFMANN, R. (1988) para aplicafão do "soflvare" RATS (DOAN Q LITERNMAN (15>81), bem como at ravés de HOFFMANN, R. Q VIEIRA, $S$. (1528?). 
- autor tentou verificar que niveis de mercado tendem a liderar os demais por ocasião de variacões de precos e com que intensidade tais variacões são transmitidas de um nível de mercado para outro. Constatou-se que o CEAGESP tem tomado as iniciativas de mudancas de preco, não se evidenciando que amplie sistematicamente os choques de precos. Conclui que normalmente o setor de intermediacão Catacado para o varej0), "atenúa ou quando muito se 11 mita a repassar as oscilacões de precos, depois de ocorrido tempo suficiente para os mercados se ajustarem" (pág. 117). 


\section{AC̆Ão PÚBLICA NO ABASTECIMENTO DE HORTIGRANJEI ROS ${ }^{1}$}

4.1. Aspectos da Evolução do Sistema do Abastecimento Alimentar no Brasil

- processo de industrializacão e urbanizacão do Brasil, que se iniciou basicamente na década de 40, refletiu-se em diversos setores dos principais centros urbanos do pais. Entre eles, o setor de abastecimento viu-se bastante afetado pelo fluxo de novos contigentes populacionais vindos do interior. Por outro lado, os reflexos dos surtos inflacionários e progressiva concentracão de renda fizeram com que o setor público se preocupasse e interviesse com a implantacão de mecanismos alternativos de distribuicão de alimentos.

Segundo estudo realizado pela equipe da Secretaria de Agricultura e Abastecimento Estado de São Paulo $(1982)^{2}$, a evolucão do sistema de Abastecimento Urbano no Brasil pode ser dividida em três fases.

Primeira rase: na década de 40, no período inicial do processo de industrializacão e urbanizacão do Brasil, quando predominava a agricultura na economia, a populacão em sua maioria vivia na zona rural csegundo

\footnotetext{
1 Baseado em Perez, ot al. (1982)
}

2 Perez, et al. (1882, pag. 70-82\} 
recenseamento de $1940,70 \%$ da população viviam na zona ruralJ. Não existia estrutura de mercado desenvolvida, bem como grandes pressões sobre o setor produtivo.

A maior parte dos produtos er am adquiridos "in natura" ou a granel. O sistema de distribuicão era reito sem transportes soristicados $e$, na maioria das vezes, pelos próprios produtores, ocorrendo problemas, portanto, quanto aos artigos produzidos em regiões mais distantes. Surgem as "Rodas de Compradores" dos centros comerciais que obtinham poder do "controle do fornecimento" dos produtos de acordo com interesses próprios.

Segunda fase: a década de 50 é caracterizada pelo desenvolvimento do transporte rodoviário e surgimento das indústrias de grande porte de bens de consumo duráveis. Portanto, temos uma expansão da fronteira agrícola, aumentando a oferta de alimentos. Mas, por outro lado, o crescimento demográfico traz desequilibrio entre o mercado urbano e a infra-estrutura de comercializacão.

Temos o surgimento de dois novos fatores no lugar da "Roda de Compradores": o "camioneiro", encarregado de transferir a producão agrícola para os centros urbanos; e a concorrência com as estradas de ferro, sendo possível incorporar outras áreas no abastecimento do mercado interno.

Conjuntamente, nesta rase, formam-se nos principais centros urbanos, os mercados atacadistas responsáveis pela distribuicão dos produtos ao sistema varejistas. Acumulando um poder cada vez maior na formacão dos precos, 
pois constituiam-se no poder de concentracão e redistribuicão dos produtos agrícolas nos mercados urbanos.

Terceira fase: caracterizada por transformaçes havidas no setor de abastecimento e com a acão direta do Governo, com medidas para a diferenciacão nas formas de comercial i zacão.

No principio da década de 60, realizam-se os primeiros Encontros Nacionais de Abastecimento (1961), de efeito normativo somente, sem alterar de forma concreta o planejamento giobal do setor, ou seja, sua estrutura.

Mas o crescimento das principais cidades, com modificacóes nos hábitos de consumo e outros fatores, implicaram em obsolescência dos equi pamentos existentes na época. Os mercados atacadistas com localizacão em áreas centrais estavam cada vez mais ineficientes nas operacóes de comercializacão, face a restricôes de ordem física no concernente a sua expansão, além de causar transtornos devido ao estacio namento de velculos pesados pelas ruas centrais da cidade. Outro ponto de estrangulamento era o "poder oligopolista dos atacadistas atuantes, que podiam manter suas posicôes pela falta de capacidade de expansão física da área de comercializacão desses mercados, o que impedia a entrada de novos concorrentes". Para a correcão destes problemas o Estado tenta organizar o comércio atacadista e agilizar o fluxo de comercializacão entre producão e consumo. Por sua vez, o 
24.

comércio varejista nos centros urbanos, antes constituido por armazéns, quitandas e feiras, foi substituido parcialmente pelas cadeias de supermercados.

\section{2. Planos e Programas Nacionals}

A preocupacão com problemas de comercializacão e abastecimento de produtos hortigranjeiros tem sido uma constante em nosso pals. O setor público tem demonstrado isto já há muitos anos, em diversos niveis de sua competência. Tais acões podem ser verificadas nas várias etapas da comercializacão agricola, desde a producão até o nivel de abastecimento ao consumidor rinal. Embora tais acões sempre tragam consigo grande polêmica, devido a caracterizarem-se como intervencões ao livre mercado, elas acabam ocorrendo. pois a alimentacão é uma questão prioritária na maioria dos programas governamentais.

A seguir indicamos alguns itens de Planos e Programas Nacionais voltados para a queståo do abastecimento:

a) Plano de Abastecimento Nacional (1957) - previa a construcão de Centrais de Abastecimento;

b) Plano Nacional de Abastecimento (1961) - propunha a criacão de organismos como: SUNAB CSuperintendência Nacional do Abastecimento); CoBAL (Companhia Brasileira de Alimentos); CIBRAZEM CCompanhia Brasileira de Armazenamento) e CFP (Comissão de Financiamento da Producão), com objetivos de regularizar e dinamizar as 
atividades do abastecimento;

c) Programa Estratégico de Desenvolvimento (1968) - propunha modernizacão das estruturas de comercializacão tanto no atacado como no varejo, com a prioridade para a construcão de CEASAS - Centrais de Abastecimento nas. principais concentracões demográficas do pais;

d) I Programa Nacional de Desenvolvimento (72/74) - propunha a continuidade da modernizacão e reestruturacão do Sistema de Abastecimento, com enfase para transporte, armazenamento, crédito rural e modernizacão do comércio varejista. Previa também a expansão das construcões das Centrais de Abastecimentos (CEASAS), 15 ao invés de 8, via a criacão do SINAC CSistema Nacional de Abastecimentos. Passava para a COBAL a funcão de órgão coordenador, entre ós Estado e Municipios participantes, administrando o sistema de CEASAS, Hortomercados, Redes Varejistas de distribuicão de hortigranjeiros bem como Mercados do Produtor:

e) II Plano Nacional de Desenvolvimento (75/79) - propunha a continuidade da modernizacão na comercializacão de hortigranjeiros com a construcão da Rede de Mercados Rurais;

f) III Plano Nacional de Desenvolvimento (80/85)- cria 0 sistema integrado de producão e armazenamento, transporte e comercializacão, com o objetivo de minimizar os desperdicios e perdas e garantir abastecimento 
regular internamente e para exportacão.

\subsection{Acão do Setor Público no Estado de São Paulo}

No Estado de São Paulo, a atuacão de alguns órgãos relacionados no tópico anterior, como a COBAL por exemplo, não é predominante, em virtude da existência da infra-estrutura da Secretaria de Agricultura e Abastecimento, com sua ampla rede de servicos prestados pela CEAGESP Companhia de Entropostos e Armazéns Gerais do Estado de São Paulo-SP, resultante da fusão da CAGESP - Companhia de Armazéns Gerais do Estado de São Paulo e do CEASA - Centro Estadual de Abastecimento S/A em $31 / 05 / 69$. Podemos considerar que com a implantacão do primeiro mercado atacadista do Brasil, CEAGESP, através do Governo Estadual, teve-se um modelo, ou um grande laboratório, de onde derivaram as politicas de descentralizacão com a criacão de CEASAS regionais e também as experiências com a atuacão junto ao mercado produtor e varejista que foram disseminadas por todo o pais.

Importante marco também foi a alteracão da estrutura da Secretaria da Agricultura do estado de São Paulo com a criacão da Coordenadoria de Abastecimento, em 1979, que passa para Secretaria de Agricultura e Abastecimento, com ampliacão das suas atribuicões e competência ${ }^{5}$

4 A primeira unidade em funcionamento no Brasil - 1072 em Recife-PE

5 Tal competência foi garantida pelo Decreto no. 13.023 de 01 de outubro de 1970. 
como:

- poder para atuar direta e indiretamente na producão. comercialização e distribuicão de gêneros alimenticios e no desenvolvimento das demais funcões necessárias a racionalizacão da politica estadual de abastecimento de gêneros alimenticios.

As experiências com a atuacão junto ao mercado varejista ganharam, também, conotacão de caráter de "economi a de recursos", (Conjuntura Alimentos 1985, pag. 21), pois devido aos pesados investimentios na construcão de CEASAS no pèriodo de 79-81, face à escassa disponibilidade de recursos, optou-se por alternativas mais simples e econômicas. que se juntaram a politica ineficaz do Governo Federal.

Surgiram, portanto, os varejóes como uma das alternativas de servicos, operacionalizados a nivel estadual. fundamentalmente pela CEAGESP e pelas Prefeituras em alguns municipios.

Os varejöes, inicialmente denominados mercadôes, apresentavam preponderância de produtores, passaram a incluir outras categorias, como feirantes, atacadistas, etc.. A experiências do mercado de Mogi das Cruzes resultiou na instalacão do primeiro varejão em São Pauloo, nas dependências da CEAGESP, o que mostrava que era possivel a venda a varejo em maior escala com margem de $15 \%$ sobre o preco do atacado.

- Foi o primeiro varejão a funcionar em são Paulo: 22/07/79 conforme documentasão do Departamento de Economia - CEAOESP 
28.

Os precos, portanto, eram tabel ados a varejo, atendendo $50 \mathrm{mil}$ compradores durante seis horas no dia de funcionamento. Foi consolidada, portanto, uma ação no mercado varejista. Por sua vez, o Mercado do Produtor em Mogi das Cruzes mostrou que os produtores conseguiam estruturar-se para vendas a varejo. Vendia-se em média 300 toneladas de hortigranjeiros por semana, estimando-se em $50 \mathrm{mil}$ compradores, com precos de 30 a $40 \%$ menores que os das feiras-1ivres. Setecentos e cinquenta e cinco dos seus vendedores eram produtores rurais.

Em setembro de 1980 , tivemos a inauguração do varejão Bresser (chamado também de mercadão), o primeiro de uma série de 74 até hoje instalados. Desses varejões, 28 localizavam-se, em 1984, na Região Metropolitana de São Paulo e 51 no interior (ver Tabela 3), acrescentado-se mais 5 em Campinas, operacionalizados pela rede COBAL. Apresentamos adiante mais alguns detalhes sobre a operacionalizacão e critérios básicos para a implantacão dos varejões. 
29.

Tabela 3. Varejões Existentes no Interior do Estado de São Paulo 1984.

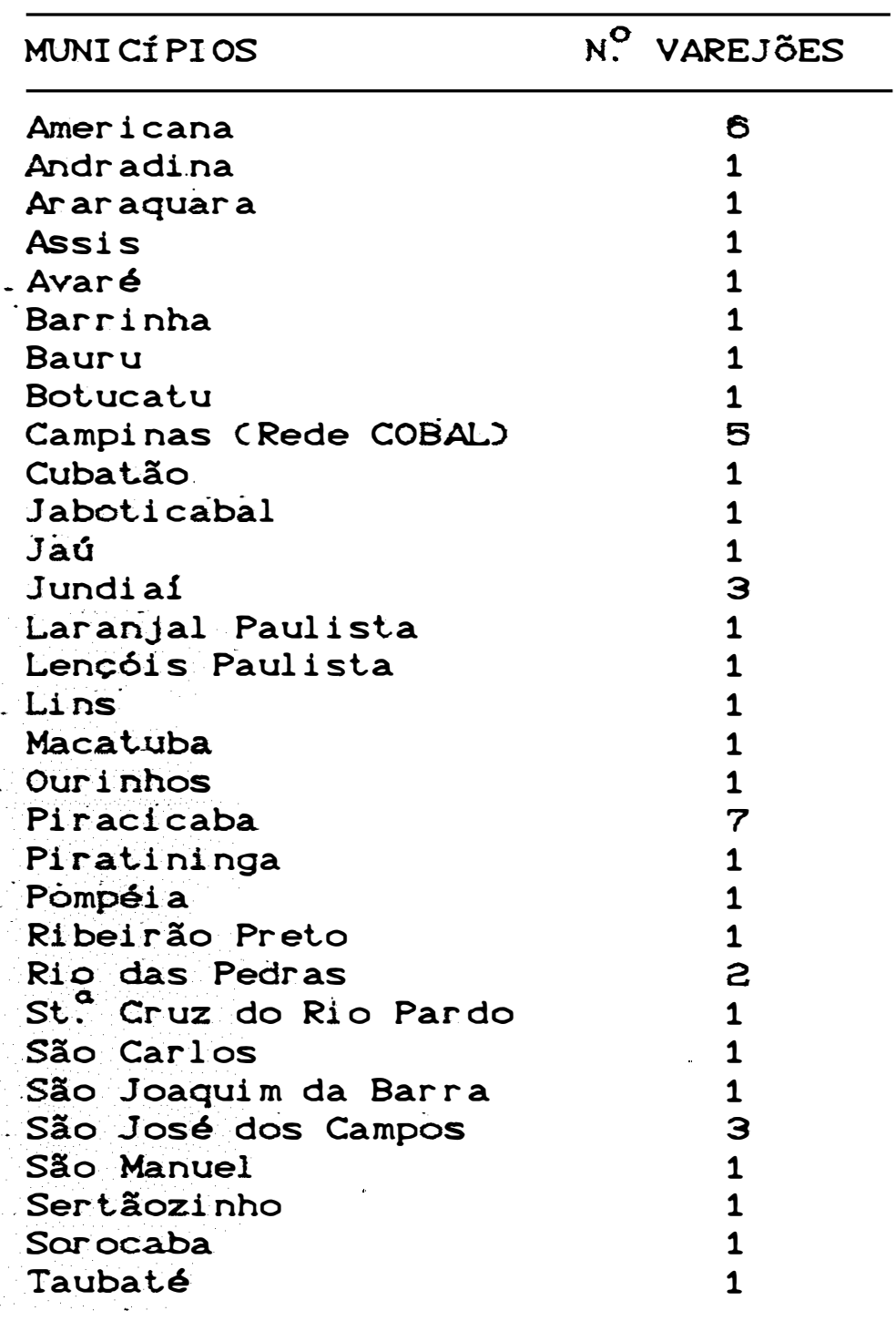

Fonte: CEAGESP - Companhia de Entrepostos e Armazéns Gerais de São Paulo

\section{4. Acão das Prefelturas}

A intervenção a nivel municipal tem se pautado pela atuacão nas fases finais de comercializacão, especificamente na comercialização de hortigranjeiros. A legislação 
municipal delega ao poder público o poder de atuar direta e indiretamente no estimulo e manutencão de feiras, na construção e administracão de mercados municipais, entrepostos e similares.

Conforme equipe técnica do Programa de Regionalizacão de Producão e Consumo de Alimentos - PROCALI? ..."vem se observando cada vez mais uma atuação a nível municipal nestas questões, o que se reflete na criacão de unidades técnicas nas Prefeituras as quais passaram a atuar no setor de abastecimento através de Assessoria, Divisões, Departamentos, Coordenadorias ou Secretarias Municipais de Agricultura e Abastecimento".

Descreveremos a seguir as principais caracteristicas das diferentes modalidades de comercializacão no Setor de Abastecimento Alimentar em São Paulo", experiência que vem sendo acumulada pelo Estado, com enfase para a modalidade varejões. Ressalta-se que tais prögramas devem levar em conta as caracteristicas da realidade local:

SACOLÃO: Venda de hortigranjeiros a preco único por quilo. Sua iniciativa é comunitária, portanto, pode ser criada e administrada por qualquer comunidade, associacões, etc. .

7 Manual de Equipamentos Varejistas (1001, pag. 1)

8 Manual de Equipamentos Varejistas (10s) 
SACOLÃo VOLANTE: Comercializa hortigranjeiros, cereais e industrializados não pereciveis a precos controladós, através de equipamentos volantes que se deslocam para atender locais de concentracão de popul ação de baixa renda e carentes de unidades de venda varejista. Os precos são controlados de acordo com o Atacado, são fixados precos por quilo diferenciados para cada módulo Chortigranjeiros; e cereais e industrializadoss.

COMBOIO DE ALIMENTOS: Caminhöes, peruas e outros velculos de Atacadistas, Feirantes ou Produtores, que comercializam, no varejo, produtos básicos e hortigranjeiros em locais préviamente escolhidos. Os precos são fixados em médi a $15 \%$ aci ma do mercado atacadista.

FEIRA DO PRODUTOR: Comercializa produtos agricolas da indústria caseira de alimentos e artesanal, operada pelos proprios produtores em pequenos municipios, com a finalidade de escoamento de produção dos pequenos agricultores locais. Existe a participacão da comunidade urbana e rural tanto para sua instalacão como na operacionalizacão. Os precos são fixados de 10 a $20 \%$ inferiores aos das feiras-livres.

C.AMPANHAS: Comercializacão de um produto agricola em pontos de venda ao público, espaco público privilegiado quanto ao fluxo de pessoas e acesso ao consumidor final, com precos de 15 a $20 \%$ inferiores aos praticados no mercado varejista. Situacão alternativa de comercializacão para escoamento de um produto agricola. 
32.

CESTA BÁSICA: Formacão e venda de cesta de produtos básicos para a alimentacão mensal de uma família. o setor público age como agênciador junto aos fornecedores, quanto ao acompanhamento sistemático da composicão, preco e qual idade da Cesta.

NUTRICESTAS: Cesta formada por atacadistas, composta de sete produtos hortigranjeiros que variam de semana a semana, com preco único.

GRUPO DE COMPRAS: Reunião de familiares, amigos, vizinhos, colegas de trabalho, Associacões, etc. para efetuar compras no mesmos varejistas obtendo descontos devido a escala. o setor público pode incentivar tal organizacão, contribuindo inclusive na organizacão e cotacão de precos.

COOPERATIVAS DE CONSUMO: SOciedade de pessoas com instalacões adequadas para distribuir bens e servicos a seus associados, sem objetivo de lucros. O Setor Público deve facilitar o acesso as informacões para a organizacão de tais Cooperativas. Tem o papel de agir como "regulador de precos de mercado", diretamente ao seu associado e indiretamente à populacão regional pela compressão dos precos de outras unidades de comercializacão de rede privada.

VAREJõES: Ésta modalidade de comércio varejista tem por objetivo colocar a disposicão da populacão gêneros alimenticios mais baratos, com precos no máximo $15 \%$ acima daqueles praticados no atacado do dia anterior, normalmente com base nas cotacões do CEAGESP. Para outros 
tipos de produtos, que não são comercializados na CEAGESP, deve estabelecer-se uma margem que garanta precos abaixo do comércio varejista.

Os permissionários devem ser preferencialmente produtores, porém, conforme o caso, principalmente na impossibilidade de contar com produtores de alguns produtos na região, pode-se admitir a participacão de outros agentes, desde que as regras estabelecidas sejam cumpridas.

A classificacão dos produtos acompanha os mesmos requisitos exigidos pelos Mercado Atacadista, a fim de atender a todos os níveis de renda da populacão. A escala de vendas é bem maior do que a das feiras-livres, garantindo assim sua viabilidade para os vendedores, mesmo praticando precos inferiores aos das feiras-livres e mercados.

Informacões sobre Operacionalização dos varejões Normalmente o mercado funciona no periodo de 6 horas; com quatro fiscais e um chefe de operacão que devem verificar a observância dos precos máximos fixados para cada produto; impedir a presença de vendedores não credenciados; atender os consumidores; abrir e fechar o movimento; distribuir folheto para obtencão da quantidade comercializada no dia (romaneios). Cada banca deve ter afixada as tabelas de precos máximos dos produtos conforme sua espécie e qualidade. Requisitos e procedimentos básicos para a 1 mplantação do Varejão

Conforme o Manual de Equipamentos Varejistas - PROCAlI (1991, pag. 28), os requisitos básicos para 
1 mplantacão do varejão são:

a) Existência de producão hortigranjeira no municlpio e cidades vizinhas;

b) Densidade demográfica suficiente para fornecer escala ao equipamento; co empreendimento só se justifica em cidades de porte médio cuja densidade demográfica garanta uma demanda potencial que o viabilize economi camente. J

c) Instalacão do varejão em local de fácil acesso à popul acão consumidora, principalmente àquela de baixo poder aquisitivo;

d) Fiscalizacão e classificacão dos produtos com base nas mesmas classificacóes adotadas no atacado, fixando o 1 imite, em média, de $15 \%$ acima dos precos no mercado atacadista para os produtos, conforme sua classificacão;

e) Comercializacão em unidades - padrão: quilos, dúzias, pés, evitando-se "montes", "bacias";

f) Para produtos que não constem da pauta de comercializacão da CEAGESP, deve ser estabelecida margem que garanta precos inferiores ao mercado varejista local;

g) Planejamento prévio incluindo dados referentes ao municlpio, com indicacão de locais mais adequados para a instalacão do varejão que reuna as seguintes condicóes: acesso fácil, proximidade de áreas de grande concentracão de populacão, equipamentos varejistas instalados nos locais indicados e em sua área de 
35.

influência ;

h Orientacão e assistência técnica da CEAGESP e Coordenadoria de Abastecimento - CAB. 
5. O MUNICIPIO DE PIRACICABA E O SISTEMA DE ABASTECIMENTO dE HORTI GRANJEIROS

5.1. Principals Caracteristicas Sócio-Econômicas do Municiplo de Piracicaba - SP.

5.1.1. Área e producão agrícola

- Municipio de Piracicaba conta com uma área de $142 \mathrm{mil}$ hectares, da qual cerca de $88 \%^{1}$ são ocupadas pela zona rural, 13^ posicão dentre as áreas rurais dos municipios do estado de São Paulo, segundo o censo de 1980.

A producão agricola municipal está centrada na cana de acúcar que, segundo estimativas do IBGE-1987, ocupou $81 \%^{2}$ da área cultivada com os principais produtos, seguida do milho e do arroz com 6,2 e $2,7 \%$, respectivamente. A pecuária ocupa quase a totalidade do restante da zona rural.

A cultura de cana situa-se nas melhores terras, região leste conforme (Figura 1), tanto em termos de localizacão como de produtividade. Evidentemente toda a infra-estrutura sucro-alcooleira do municipio, importante para seu crescimento e desenvolvimento, implica em sérias restricões que se somam ás dificuldades normais de producão e comercializacão de alimentos. Especificamente com relacão

1 Conforme Cadastro Técnico da Prefeitura Municipal de Piracicaba (1001)

2 Total da d́rea cultivado pelos principais produtos $=56.483$ ha 
aos produtos hortigranjeiros a producão é praticamente restringida a verduras (folhas), efetuada em geral nas piores terras, com baixa tecnologia, uso intensivo de mão-de-obra e através de pequenos produtores (Figura 2 ).

Quanto a estrutura fundiária, segundo o IBGE-(1985), $84 \%$ dos estabelecimentós de até 100 hectares ocupavam 25\% da área rural do município, contra $16 \%$ de estabelecimentos de mais de 100 hectares que abrangem 0 restante, $75 \%$, da área cultivada. A concentração de grandes propriedades relaciona-se com a exploracão da grande cultura comercial de cana-de acúcar.

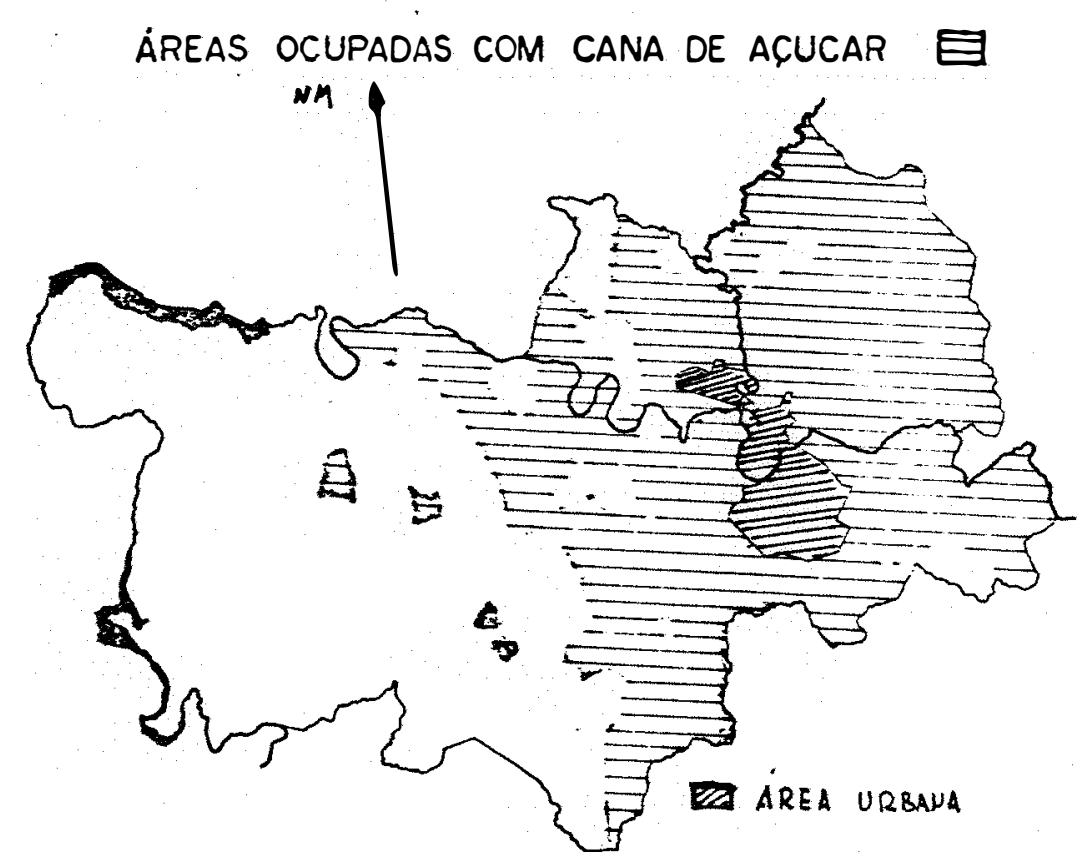

Figura 1. Áreas ocupadas com cana de acúcar - municipio de Piracicaba - Fonte: Cadastro Técnico SEMA - 1991. 


\section{ÁREAS OCUPADAS COM CULTURAS ANUAIS}

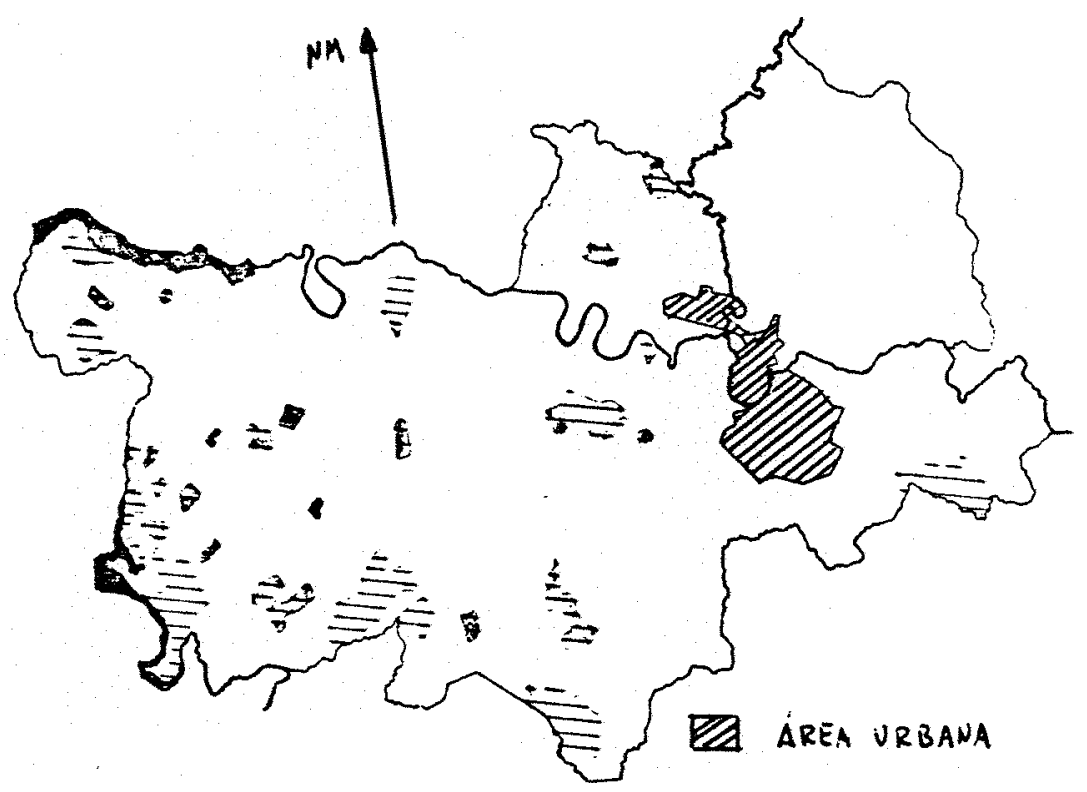

Figura 2. Areas ocupadas com culturas anuais - municipio de Piracicaba - Fonte: Cadastro Técnico SEMA - 1991.

\subsubsection{Aspectos sócio-econômicos}

A área urbana conta com 62.799 residências, 7.010 imóveis comerciais e 410 industriais. A cidade possui 52 núcleos de favelas na periferia, com aproximadamente 20 mil habitantes, com um indice de confinamento de 4 a 5 pessoas por habitacão segundo a Prefeitura Municipal de Piracicaba.

Piracicaba vem experimentando elevacão na taxa de urbanizacão de sua populacão, atingindo $96,5 \%$ em 1991 . 
segundo estimativas de SEADE - CFundacão de Sistema Estadual de Análise de Dados), a exemplo da densidade demográfica que elevou-se para 213 habitantes por $\mathrm{km}^{2}$ em 1991 contra 151 em 1990, conforme Tabel a 4:

Tabela 4. Evol ução da populacão, taxa de urbanização e da densidade demográflca de Piracicaba.

$1950-1991$

\begin{tabular}{|c|c|c|c|c|c|}
\hline \multirow{2}{*}{ ANO } & \multicolumn{3}{|c|}{ POPULACÃ̃O } & \multirow{2}{*}{$\begin{array}{c}\text { Taxa de ur } \\
\text { banizacão } \\
(\%)\end{array}$} & \multirow{2}{*}{$\begin{array}{l}\text { Densidade } \\
\text { demográfica } \\
\mathrm{Hab} / \mathrm{km}^{2}\end{array}$} \\
\hline & TOTAL & URBANA & RURAL & & \\
\hline 1950 & 81.281 & 46.894 & 34.387 & 57,7 & 57 \\
\hline 1960 & 116.190 & 82.303 & 33.887 & 70,8 & 82 \\
\hline 1970 & 152.505 & 127.818 & 24.687 & 83,8 & 107 \\
\hline 1980 & 214.394 & 197.988 & 16.406 & 92,3 & 151 \\
\hline 1991 & 302.733 & 292.137 & 10.596 & 96,5 & 213 \\
\hline
\end{tabular}

Fonte: 1. FIBGE: Censos Demográficos $1950 / 1980$

2. FIBGE: Esti mativa da Populacão para 1991

3. SEADE: Estimativa da Taxa de Urbanizacão para 1991 in: NEGRI, Barjas (1991, pag. 33)

\subsubsection{Renda da Popul ação}

Piracicaba possuia em 1980 uma renda "percapita" de US\$2500 contra US\$1700 da média do país; caracterizando-se, como uma cidade de renda relativamente elevada. Porém cerca de 50\% dos cidadãos mais pobres possuiam, em 1980, menos de $16 \%$ da renda, enquanto os $5 \%$ mals ricos detinham $25 \%$ da renda gerada pela cidade. CCenso de 1980 - IBGEJ. 
5.2. Breve Histórico da Comercialização de Hortigranjeiros em Piracicaba-SP

A organização do comércio de hortigranjeiros na cidade de Piracicaba comeca a ser delimitada historicamente na fundação do mercado municipal, ocorrida em 5 de julho de 1888. Neste local atuavam produtores atacadistas e varejistas. o termo "organizacão" foi utilizado aqui no sentido de concentracão e arrumacão disciplinada, em local estratégico, diverso daquilo que vinha ocorrendo espalhado pela cidade. Segundo Leandro (1961, pag. 235), o que existia na época antes do mercado municipal "... eram "Quartos" nas principais ruas da cidade, Rua da Palma (hoje Tiradentes) e Rua dos Pescadores (hoje Prudente de Moraes, onde os sitiantes levavam suas mercadoria nos lombos de burros (cargueiros) onde afluiam as donas de casa, as mucanas, os escravos, os retalhistas e, especialmente os acambarcadores, que naqueles tempos também punham suas manguinhas de fora. Haviam também as transacões de porta em porta, espécies de mascateacão, sistema primitivo, sem estabilidade de preco".

A instalacão do mercado municipal se deu devido à reinvindicacão da comunidade, após longas discussơes sobre sua aprovacão e localizacão, que ocorriam na Câmara Municipal. Evidenciava-se na época a existência de alguns problemas, tais como:

- higiene na manipulacão dos produtos alimentares;

- monopólio de alguns produtos;

- fluxo de comerciantes nas ruas da cidade, causando 
transtornos à circulacão da população, etc.

Acreditava-se que com o funcionamento de um mercado bem localizado, regulamentado e especializado no comércio de alimentos, poder-se-ia solucionar tais problemas, e ainda constituir-se em um dos elementos fundamentais para... "progresso material e moral das cidades populosas, em que a concorrência de novos habitantes faz aumentar de di a em dia o consumo de alimentos....".

Quanto às regul amentaçóes para o funcionamento do mercado municipal, desde sua fundacão, teve-se a seguinte evol ução". :

- primeiro regulamento foi aprovado a 8 de abril de 1888 pela Lei Provincial ne 84. Seguiram-se ainda mais três regulamentos publicados, respectivamente, em 1914 , 1967 e 1974; e também diversas leis que ainda vigoram. De acordo com os dois primeiros regulamentos, era possivel. através do próprio municipal, o conhecimento por parte da administracão pública da quantidade e precos de alimentos comercializados na cidade, tanto aqueles produzidos no Municipio como aqueles importados, uma vez que o mercado municipal era tido como centralizador das operacóes que envolviam as atividades de abastecimento e comercialização..."

3 Edilorial da "Gazela de Piracicaba" - edicão 11/08/1882, in Leandro (1001, pag. 235)

4 Sinopse das leis do Mercado Municipal - SEMA (1000) 
À medida que a cidade se expandia, surgiam as feiras-1ivres, que eram abastecidas no mercado municipal. Elas foram regulamentadas pela primeira vez pela lei Municipal ne 175 de 5 de dezembro de 1923. As feiras-livres desempenham um importante papel para a populacão devido a sua dispersão entre os diversos bairros da cidade, promovendo uma distribuicão ágil dos produtos alimenticios. Destaca-se aqui um Canal de Comercializacão que possui a caracteristica especifica de varejo, diferenciando-se das caracteristicas do mercado municipal até então.

Com a Instalação de un Entreposto Municipal. em 1974, Grganizado e administrado pela Prefeitura Municipal, localizado em Santa Terezinha, bairro afastado do centro da cidade aproximandamente $8 \mathrm{~km}$. o objetivo foi tirar da praca de frente ao mercado municipal o movimento intenso de caminhões, temos o primeiro Mercado Atacadista do genêro na cidade, ou seja especialista no atacado de hortigranjeiros criado e regulamentado oficialmente ${ }^{5}$. Os estabelecimentos locals, tanto os de ponto fixo (quitandas, etc...), como os móveis (feiras, ambulantes) passaram a abastecer-se no Entreposto Municipal.

Em 1982 a Administracão Municipal implanta o Sistema de Varejões, reflexo de politicas da esfera federal e estadual, questão em que nos deteremos com mais atencão no próximo capitulo pois refere-se ao nosso alvo de

5 Portaria ne 477, de 07/11/74-Prefeitura Municipal de Piracicaba-sp Decreto ne 2.003, de 13/11/75 - Prefeitura Municipal de Piracicaba-SP 
investigacão.

Em marco de 1985 foi inaugurada a CEASA Centro de Abastecimento S/A, regional de Piracicaba-SP, administrada pela Secretaria de Agricultura e Abastecimento, via CEAGESP - Companhia de Entrepostos e Armazéns Gerais de São Paulo-SP, reflexo da politica federal, conforme Programa Governamental - 1968 já citado na Introdução deste trabalho. A maioria dos CEASA'S regionais foram construidos no periodo de 1975 a 80 , cerca de 50 em todo o pais, com o objetivo de melhorar a eficiência a partir de ganhos de escala de operacões, as condicões higiênico-sanitárias, a localizacão e de propiciar maior concentracão dos comerciantes, incentivar a producão local, etc...

"Acreditava-se que com uma mel horia de eficiên cia haveria uma reducão Ifquida e certa nos precos finais. No entanto, observou-se que as vantagens foram absorvidas quase que exclusivamente por atacadistas, grandes Cooperativas e firmas agro-comerciais que aumentaram sua escala de atuacão, contribuindo para maior oligopolizacão do mercado" Conjuntura Alimentos (1985, pag. 9).

- antigo Entreposto Municipal foi desativado e - Mercado atacadista passou a operar na CEASA na Rodovia do Acúcar, km 10 - Bairro Taquaral. Todo o processo para a instalacão, desde a construcão até a transferência de permissionários (do Entreposto para CEASA), causou grande polêmica principalmente pelos problemas quanto a: localizacão, horário de funcionamento e infra-estrutura, entre 
outros, conforme Pereira, (1990) relata em suas conclusões (páginas 91 a 96) e que serão comentadas no item reservado ao CEASA neste capitulo, inclusive com a decretacão de lei de protecão do mercado ${ }^{\circ}$

Piracicaba conta atualmente, além destes canais de comercializacão já descritos ( 1 mercado municipal, 18 feiras-livres, 1 CEASA, 6 varejöes municipais e 11 varejinhos móveis), com uma grande rede privada de estabelecimentos para comercializacão de hortigranjeiros, conforme mostra a Tabela 5.

Tabela 5. Estabelecimentos da rede privada que comercializam hortigranjeiros em Piracicaba-SP 1989.

\begin{tabular}{clcl}
\hline QUANT. & TIPO & QUANT. & TIPO \\
\hline 2 & Sacolões & 129 & Armazéns \\
15 & Avicolas & 175 & Mercearias \\
11 & Peixarias & 64 & Supermercados (4gdes) \\
131 & Acougues & 64 & Atacadistas de Cereais \\
109 & Quitandas & 2 & Atacadistas de Pescado \\
\hline
\end{tabular}

Fonte: Cadastro da Receita da Prefeitura Municipal de Piracicaba - Informacoes de 09/89

Existem portanto inúmeras opcões para o consumidor da cidade e da região. A populacão vem sentindo várias adaptacões destes servicos, tanto pelo setor público como

\footnotetext{
- Lei, Municipal ne 2.421 de 17/11/80 - proibia a comercializasão por atacado de hortigranjeiros fora do CEASA (a ser instalado). Tal lei foi revogada em 00/12/82 pela Lei Municipal 2. 493.
} 
pelo privado. Podemos verificar, através da Tabela 6 , a localizacão destas unidades de comercializacão conforme a zona venal $^{7}$ para cobranca do IPTU. Imposto Predial e Territorial Urbano.

Tabela 6. Distribuicão das unidades de abastecimento de acordo com zoneamento baseado no IPTU - Piracicaba-SP - 06/91

\begin{tabular}{|c|c|c|c|c|c|c|c|}
\hline \multirow[t]{2}{*}{ EQUI PAMENTOS } & \multicolumn{7}{|c|}{ ZONAS } \\
\hline & \multicolumn{2}{|c|}{ ALTA } & \multicolumn{2}{|c|}{ I NTERM. } & \multicolumn{2}{|c|}{ BAI XA } & \multirow{2}{*}{$\frac{\text { TOTAL }}{\text { nưmero }}$} \\
\hline PRI VADOS & número & $\%$ & nưmero & $\%$ & número & $\%$ & \\
\hline Acougue & 54 & 45.4 & 32 & 26.9 & 33 & 27.7 & 119 \\
\hline Aves e ovos & 3 & 30.0 & 5 & 50.0 & 2 & 20.0 & 10 \\
\hline Ar mazem & 40 & 43.5 & 17 & 18.5 & 35 & 38.0 & 92 \\
\hline Cerealista & 15 & 36.6 & 14 & 34.1 & 12 & 29.3 & 41 \\
\hline Mercearia & 48 & 33.1 & 48 & 33.1 & 49 & 33.8 & 145 \\
\hline Pei xaria & 2 & 22.2 & 4 & 44.4 & 3 & 33.3 & 9 \\
\hline Quitandà & 15 & 48.4 & 4 & 12.9 & 12 & 38.7 & 31 \\
\hline Super mer cado & 15 & 28.3 & 18 & 34.0 & 20 & 37.7 & 53 \\
\hline \multicolumn{8}{|l|}{ PÚBLI COS } \\
\hline Feira Livre & 12 & 70.6 & 3 & 17.6 & 2 & 11.8 & 17 \\
\hline Varejão & 1 & 16.7 & 2 & 33.3 & 3 & 50.0 & 6 \\
\hline Varejinho & - & - & 1 & 9.1 & 10 & 90.9 & 11 \\
\hline Merc. Munic. & 1 & 100.0 & - & - & - & - & 1 \\
\hline TOTAL & 208 & 38.50 & 148 & 27.66 & 181 & 33.83 & 535 \\
\hline
\end{tabular}

Fonte: Di agnóstico sobre o Abastecimento Alimentar no Municipio de Piracicaba (1991)

7 Padrão de construcão das habitaç̃es 
46.

5. 3. Caracterizaçáo das Unidades de Comercializaçáo de Hortigranjelros Sob a Acão Pública Municipal

Neste item nos preocuparemos somente com a caracterizacão dos equipamentos ligados à esfera pública, mesmo sabendo da importância da rede particular, especialmente no advento das instal acões dos supermercados, os quais demarcaram a chamada modernizacão no mercado, tanto na novidade do auto-servico, como na possibilidade de integracão vertical junto à producão, constituindo-se em um grande segmento do mércado.

Cerca de 371 vendedores se distribuem nas unidades de comercializacão administradas pelo Setor Público em Piracicaba; CEASA, felras-livres, varejão e mercado municipal, sendo que $23 \%$ destes possuem mais de um ponto de venda, conforme Tabela 7 . 
Tabela 7. Vendedores por Unidade de Comercializacão e Categoria Piracicaba - SP (junhor90)

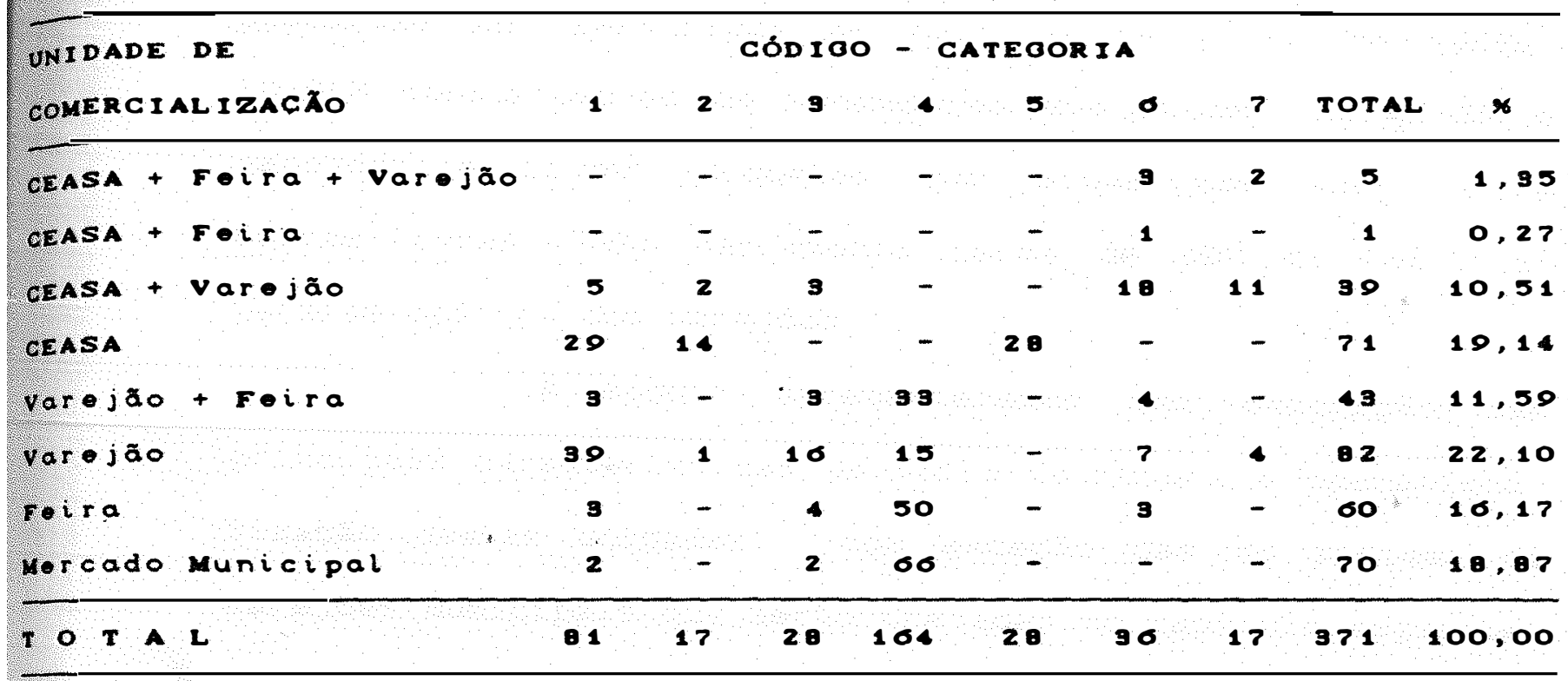

\begin{tabular}{|c|c|}
\hline Cób I 00 & CATEOORIA \\
\hline 1 & Produtor \\
\hline 2 & Produtor/Atacadista \\
\hline $\mathbf{9}$ & Produtor/varojista \\
\hline 4 & varejista \\
\hline 5 & Atacadista \\
\hline 6 & Varejista/Alacadista \\
\hline 7 & Produtorlatacadista/varejiota \\
\hline
\end{tabular}

Fonte: Diagnóstico sobre o Abastecimento Alimentar no Municipio de Piracicaba (1991)

A maior participacão de vendedores se dá no sistema municipal de varejões com $45,5 \%$ do total de vendedores na rede administrada pela esfera pública, contra $31,26 \%$ para CEASA, 29,38\% para Feiras-livres e $18,87 \%$ para o mercado municipal. A nai or participacão de produtores se dá também nos varejões segui da do CEASA, 47 e $34 \%$ respecti vamente.

Estas porcentagens resultaram das agregacões, para cada ponto de venda, elou grupo de ponto de venda onde 
48.

a modalidade esta presente.

Destacamos também que, dos $23 \%$ dos permissionários que participam de mais de um ponto de venda, $10,51 \%$ constituem-se de vendedores que atuam no CEASA e varejões e $11,59 \%$ daqueles que atuam nos varejões e feiras-1ivres. Isto representa cerca de $49 \%$ do total de permissionários dos varejões.

A seguir apresentaremos uma descricão das principais caracteristicas da infra-estrutura e operacionalizacão destas unidades, com excecão das do sistema de varejões municipais que serão tratadas no capltulo seguinte.

\subsubsection{Mercado Municipal}

A SEMA administra o mercado municipal de Piracicaba, quanto à manutencão e limpeza; observacão de horários de funcionamento e controle de permissão dos comerciantes. Não exerce nenhum controle sobre os precos.

A localizacão do mercado municipal é central, vem desempenhando importante papel no abastecimento da cidade". devido a sua localizacão, boa diversificacão e qualidade dos produtos, bem como pelo tempo de permanência do comércio ctodos os di as da semana, inclusive aos sábados, domingos e feriados com horários especiais). Possui de forma geral, um nivel de precos mais elevado que 0 das feiras-livres e os varejões.

- A sema presume que o Mercado Municipal atende especialmente o consumidor de média e alta renda 
49.

Os 145 boxes são ocupados pelo sistema de permissão (vide Tabela 8) sob o pagamento de taxa mensal. Os vendedores Julgam-se também com o direito de negociar seus pontos, a valores expressivos ${ }^{\circ}$. Estes procedimentos inviabilizam a aplicacão de polfticas da SEMA na setorizacão dos boxes, que possam of erecer produtos em quantidade suficiente e de certa forma dificultar a formacão de Oligopól los.

- abastecimento é efetuado nas madrugadas na praca situada a frente de suas instalacôes, por Atacadistas e Produtores; que aproveitam para realizar transacóes com outros tipos de varejistas, como quitandeiros, feirantes, ambulantes, etc... Este procedimento é chamado de "mercado paralelo" pelos administradores da CEASA local, e.é frequentemente combatido por eles, embasados em um possível "desvirtuamento" do mercado atacadista que supostamente deveria ser centralizado para "formacão de precos".

Isto reproduz, de certa forma, a funcão que o mercado municipal desempenhou durante longo tempo: o de "ponto de encontro" de produtores, atacadistas e varejistas. - fato de estar localizado no centro da cidade exerce fortes motivos para que as transacóes continuem a ocorrer na sua praca fronteirica.

- A venda de pontos é uma pratica antiga, constituindo-se em um problema dificil de ser contornado entre a Administracão Municipal $\theta$ a Associacão dos Permissionários do Mercado Municipal, devido a aspectos legais 
Não existem registros sobre o volume comercia11zado, porém deduz-se que tenha uma boa participacão no total comercializado do municipio.

Tabela 8. Permissionários por Ramo de Atividade e Número de Boxes - Mercado Municipal - Piracicaba - SP - Janeiro/89.

\begin{tabular}{|c|c|c|c|c|}
\hline \multirow{3}{*}{$\begin{array}{l}\text { RAMOS DE } \\
\text { ATI VIDADE } \\
\text { Frutas/Verduras/ }\end{array}$} & \multicolumn{2}{|c|}{ PERMISSI ONÁRI OS } & \multicolumn{2}{|c|}{ BOXES } \\
\hline & NÚMERO & $\%$ & NÚMERO & $\%$ \\
\hline & 22 & 31,43 & 63 & 43,45 \\
\hline $\begin{array}{l}\text { Armazens/Secos } \\
\text { Mol hados }\end{array}$ & 11 & 15,72 & 17 & 11.72 \\
\hline Casa de Carnes & 7 & 10,00 & 10 & 6,90 \\
\hline $\begin{array}{l}\text { Café/Pastel/ } \\
\text { Lanches }\end{array}$ & 5 & 7.14 & 6 & 4,14 \\
\hline Tabacaria & 5 & 7.14 & 5 & 3,45 \\
\hline Aves/Oros. & 4 & 5.71 & 8 & 5,52 \\
\hline Floricultura & 4 & 5,71 & 10 & 6,90 \\
\hline Mercearia & 4 & 5,71 & 11 & 7,59 \\
\hline $\mathrm{Brinq}$. Ntil. Dom. & 3 & 4,29 & 3 & 2,07 \\
\hline Casa de Massas & 1 & 1,42 & 2 & 1,37 \\
\hline Padaria & 1 & 1,43 & 2 & 1.37 \\
\hline Pei xaria & 1 & 1,43 & 4 & 2,76 \\
\hline Bol achas & 1 & 1,43 & 3 & 2,07 \\
\hline Caca e Pesca & 1 & 1,43 & 1 & 0,69 \\
\hline$T \circ I A L$ & 70 & 100,00 & 145 & 100,00 \\
\hline
\end{tabular}

Fonte: Cadastro de Permissionários e Felrantes - SEMA (1989) 
51.

\subsubsection{Felras-Livres}

As felras-11vres, com ampla tradicão em todos os municipios brasileiros, encontram também em Piracicaba uma boa aceltacăo da populacão, mas apresentam tendênclas decrescentes em expressåo e qualidade, provavelmente pela sua 1 moblilidade frente a modernizacão de outras unidades varejistas, e em Piracicaba também devido a 1 mplantacão do Sistema de Varejôes Munlcipals ${ }^{10}$.

- municipio possul 18 feiras instaladas na cldade, com malor adensamento na reglåo central Cvide Figura 3) em locais "consagrados" pela demanda, que hoje garantem pelo menos sua continuidade.

Os felrantés, em número de 94 (Tabela 9 ), distribuem-se na comercializacão nos diferentes balrros, Cao longo da semana de 2 as sextas-felras - das 5:00 as 12:00 horas). Cabe a Administracão Municipal efetuar o Cadastramento a cobranca do uso de solo dos comerciantes. A SEMA mantém a flscalizacão quanto a aspectos de permissão e dos locals de cada banca, qualidade dos produtos, horários de Inicio e fim das feiras e o controle do trânsito no local.

Os feirantes de Piracicaba não possuem uma assoclacão de classe, o que, de certa forma, diflcultou a modernizacão de seus servicos, como por exemplo: apresentam frequentemente problemas de higiene e qualidade dos produtos

10 Os Varejōes Municipais podem ser caracterizados como uma feira "moder nizada" devido as suas instalaçes adequades e selorizacso de produ= tos (conforme descrevemos no item o deste trabalho). 
52.

e desorganizacão quantos aos critérios de grupos de composicão dos produtos e disposicão das bancas; conflitos com os moradores nos locals onde as feiras são instaladas.

Não existe controle de quantidade comercializada, e os comerciantes em sua grande maioria, possuem uma pequena escala de vendas para cada produto, obrigando-os a manter elevadas margens de comercializacão. Podemos acrescentar, também aqui, as dificuldades no abastecimento até o CEASA local, que năo possue uma boa localizacão e seu horário de runcionamento é exclusivamente nas manhãs, coincidindo com o momento de realizacão das feiras, fazendo com que recorram ao "mercado paralelo", descrito no item anterior, ou mesmo no recebimento dos produtos no próprio local da comercializacão.

Tabela 9. Permissionários por Grupo de Produto - FeirasLivres Piracicaba - SP - Janeiror89.

\begin{tabular}{lrc}
\hline GRUPOS DE PRODUTO & \multicolumn{2}{c}{ PERMISSIONÁRIOS } \\
\hline Frutas verduras e legumes & 50 & 53,20 \\
Cereaís-Mercearia & 9 & 9,57 \\
Frios, carnes e ovos & 11 & 11,70 \\
Salgados & 6 & 6,38 \\
Bolachas & 2 & 2,13 \\
Utilidades domésticas & 4 & 4,26 \\
Calcados e confeccões & 6 & 6,38 \\
Miudezas em geral & 1 & 1,06 \\
Flores & 1 & 1,06 \\
Diversos & 4 & 4,26 \\
\hline T O I A L & 94 & 100,0 \\
\hline
\end{tabular}

Fonte: Cadastro de Permissionários e Feirantes - SEMA (1989) 

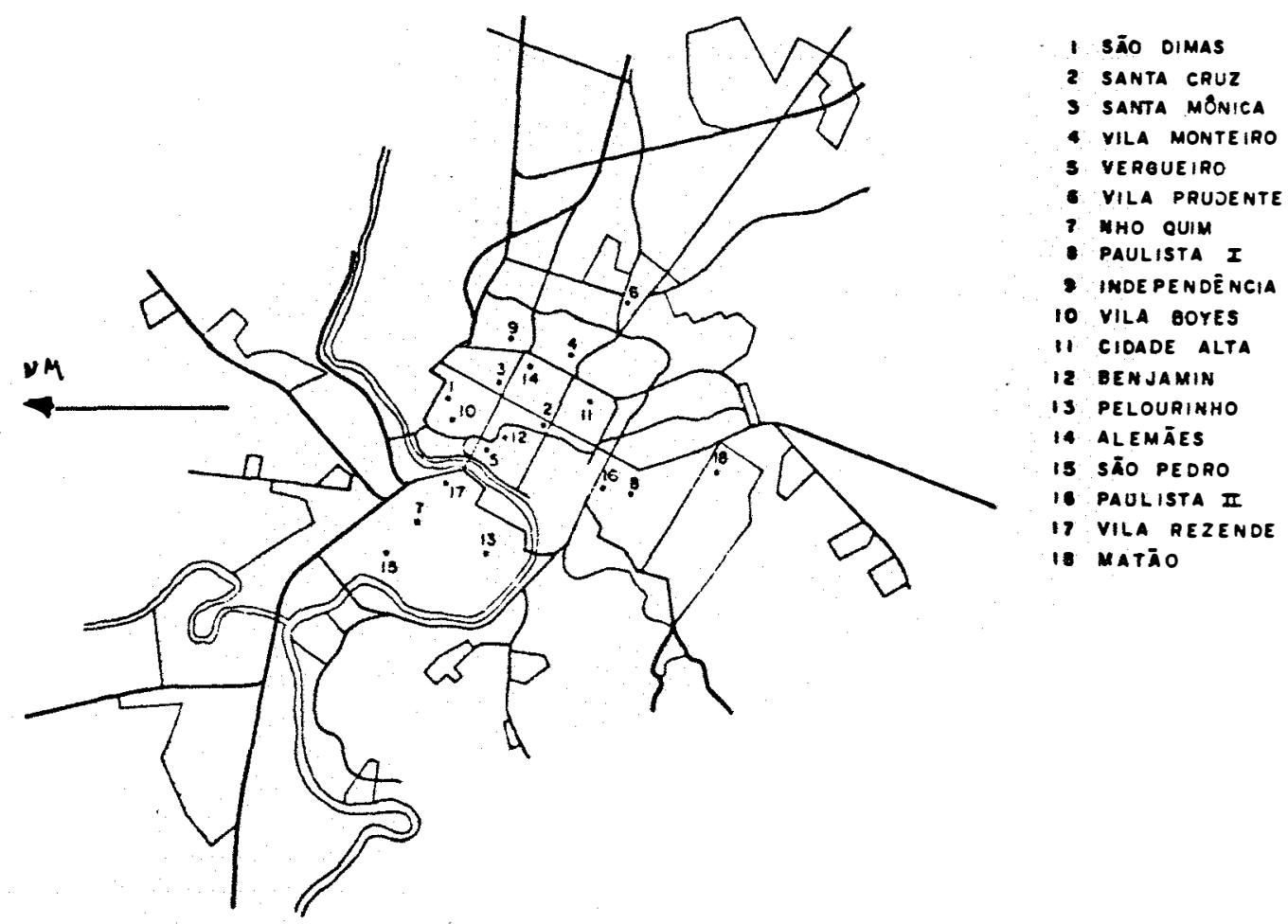

18 MATÃO

Figura 3 - Localizacao das feiras Livres no municipio de Piracicaba - SP (área urbana) - Fonte: Cadastro Técnico SEMA - 1991

5.3.3. CEASA - Piracicaba-SP - Companhia de Entrepostos e Armazéns Gerais de Săo Paulo Regional de Piracicaba

A CEAGESP inaugurou em marco de 1985 a CEASA-Piracicaba, localizada no bairro Taquaral, zona rural distante $16 \mathrm{~km}$ do município, com área de $52.830 \mathrm{~m} ; 7080 \mathrm{~m}$ de construção e 4.050 m destinadós à comercialização.

- mercado atacadista funciona às segundas, quartas e sextas-feiras; observando os seguintes horários: is 5: 30 hs inicia-se a comercializacão (sem velculos) até 
às 9:00 horas, sendo que sómente a partir das 6:30 liberada a entrada de velculos para carga.

Vendedores

Na CEASA podem operar produtores, representantes de produtores e comerciantes, em base mensal ou diária. distribuidos em boxes, módulos e o pátio, mediante pagamento de taxa estipulada conforme área. As exigências, segundo as normas existentes nó regulamento, são:

a) Produtor: apresentar atestado de producão;

b) Firma: registro comercial.

Conforme Tabela 10, em janeiro de 1989, 94 permissionários mensalistas atuavam neste mercado, onde se nota a malor participacão no grupo de Verduras e Legumes com cerca de $45 \%$ de permissionários e $37 \%$ dos boxes e módulos, . seguido do grupo de Frutas e de Tomate. Observa-se também a maior participacão de Produtores no Grupo de Verduras e Legumes; a participacão de produtores na comercializacão do Ceasa-Piracicaba se dá quase que exclusivamente neste grupo, sendo que 95\% deles pertencem ao municiplo de Piracicaba segundo cadastros da CEASA. 
Tabela 10. Permissionários por Grupo de Produto Categoria e Boxes - CEASA - Piracicaba - SP - Janeirio/89

\begin{tabular}{|c|c|c|c|c|c|c|}
\hline \multirow{2}{*}{$\begin{array}{l}\text { GRUPOS DE } \\
\text { PRODUTOS }\end{array}$} & \multicolumn{2}{|c|}{ PERMISSIONÁRIOS } & \multicolumn{2}{|c|}{ BOXES } & \multirow{2}{*}{$\begin{array}{l}\text { CATEOORIA DO } \\
\text { COMERCIANTE }\end{array}$} & \multirow{2}{*}{$\begin{array}{l}\text { PERMIS. } \\
\text { PRODUTOR }\end{array}$} \\
\hline & NÚMERO & x & NƯMERO & x & & \\
\hline Frutas & 25 & 20,50 & 48 & 94,20 & 29 & 2 \\
\hline verduras/legumes & 42 & 44,60 & 52 & 97,14 & $\boldsymbol{\theta}$ & 94 \\
\hline Tomate & 10 & 10,04 & 20 & 14,90 & 9 & 1 \\
\hline $\begin{array}{l}\text { Coreais, batala, } \\
\text { cobola, alho }\end{array}$ & 15 & 15,90 & 10 & 12,06 & 14 & 1 \\
\hline $\begin{array}{l}\text { Diversos (embala- } \\
\text { gense conservas) }\end{array}$ & - & 2,13 & $\mathbf{2}$ & 1,49 & 2 & - \\
\hline T 0 T A L & 24 & 100,00 & 140 & 100,00 & 50 & 98 \\
\hline
\end{tabular}

Fonte: Cadastro de Permissionários CEASA (1989)

Yol une de comerciallzacão

- volume médio mensal de comercializacão no período de 85 a 89 atingiu cerca de 3.600 toneladas, apresentando significativa melhora em 1990, com 5.829 toneladas e nos cinco primeiros meses de 1991 com 5.155 toneladas, conforme Tabela 11:

Tabela 11. Volume Comercializado - CEASA Piracicaba - 85/91

\begin{tabular}{llc}
\hline ANO & VOLUME( $t)$ & MEDI A MENSAL $(t)$ \\
\hline 1985 & 31.109 & 3.111 \\
1986 & 48.531 & 4.119 \\
1987 & 47.674 & 3.973 \\
1988 & 41.269 & 3.439 \\
1989 & 41.309 & 3.436 \\
1990 & 69.952 & 5.829 \\
1991 (*) & 25.773 & 5.155 \\
\hline
\end{tabular}

Fonte: CEAGESP - Boletim Mensal

(*) até maio 
56.

A CEASA de Piracicaba apresentou uma queda sensivel na participacão do volume comercializado de rede estadual de Ceasa Regionais, de 49 l ugar em 1987 passou para 58 e 78 respectivamente em 1988 e 1989 , conforme boletim estatisticos mensais da CEAGESP.

\section{Procedêncla de produtos}

A maior parte dos produtos para abastecimento de Piracicaba vem de fora, devido as características da producão agropecuária do município. Isto é demonstrado pelas estatísticas da CEASA local, para alguns produtos, conforme Tabela 12:

Tabela 12. Procedencia da Alface, Batata e Banana Comercializados na CEASA - Piracicaba-SP (O2/88 á 02/89).

\begin{tabular}{lcc}
\hline & \multicolumn{2}{c}{ Participacão Porcentual no Volume Comercializado } \\
\cline { 2 - 3 } PRODUTO & Micro Região & Outras \\
& Acucareira de Piracicaba & Regióes \\
\hline Alface & 78,37 & 21,62 \\
Batata & 29,29 & 70,71 \\
Banana Nanica & 36,84 & 63,16 \\
\hline
\end{tabular}

Fonte: CEAGESP - Boletim Mensal

(*) Base na quantidade em toneladas.

\section{Compradores}

Não existem estatisticas permanentes sobre a participacão dos compradores, que afluem até o mercado atacadista do CEASA, quanto a sua categoria, procedência, etc.. Porém, recorremos a algumas pesquisas esporádicas do 
57.

CEASA e de SEMA, que tracam algumas caracteristicas do perfil destes compradores, mostradas nas Tabelas 13 e 14:

Tabela 13. Participacão das categorias de compradores no CEASA de Piracicaba-SP - 1987 e 1989.

\begin{tabular}{lccc}
\hline CATEGORI A & \multicolumn{3}{c}{ Participacão ( \% ) } \\
\hline Ambulante & 20 & 1989 \\
Quitanda & 38 & 25 \\
Restaurante & - & 10 \\
Supermercado & 13 & 15 \\
Feirantes & 29 & 10 \\
Atac. outras regiões & - & 25 \\
Outras & - & 10 \\
\hline
\end{tabular}

Fonte: Pereira (1990, pág. 71 )

Tabela 14. Usuários da CEASA por Categoria e Párticipacão no Volume Comercializado - Piraicaba-SP 1989.

Permissionários

Varejão

11

21

Felrantes

Permissionários

Mercado Municipal

Outros (*)
07

36
0,5

8,0

2,0

14,5

Fonte: Diagnóstico sobre o Abastecimento Alimentar no Municipio de Piracicaba (1991)

(*) Supermercados, Quitandas, Restaurantes e Pessoas Fisicas.

Conforme análise de Pereira, (1990) sobre a

CEASA de Piracicaba, evidenciam-se vários problemas na atuacão deste mercado que tem origens na falta de melhor tratamento das informacões contidas no diagnóstico realizado 
em $1978^{11}$, que teve como principal fonte, o Entreposto Municipal - do bairro Algodoal - mercado atacadista tradicional.

A CEASA acabou sendo construida em local não adequado, tanto pela distância das unidades de comercializacão da cidade, como das cidades vizinhas. "Uma Central de Abastecimento não pode ser instalada de forma artificial dentro de um sistema de comercializacão". (Pereira, 1990, pág. 875. Talvez o aproveitamento das instalacões do Entreposto Municipal fosse mais adequado e de menor gasto para os cofres públicos. Dois dos principais indicadores de que a CEASA de Piracicaba não vem desempenhando a contento o seu papel, é a comparacão do volume comercializado com o antigo Entreposto Municipal que decresceu de $53,8 \%$ por vendedor e a queda de $8,9 \%$ no número de vendedores (1978 em comparação a 1989 .

Encontram-se algumas justificativas para a queda do volume comercializado e menor participacão do CEASA Piracicaba na rede da CEAGESP, no relatório de avali acão da CEAGESP ${ }^{\text {i2 }}$ real izado em 1989 :

- "Mercado Paralelo" em frente ao mercado municipal. diminui de 20 a $30 \%$ do movimentacão da CEASA cinclusive com atuacão de alguns permissionários da CEASAD.

- Atuacão dos varejões de Piracicaba, que absorvem pro-

11 Cenoesp, Avaliação do comércio alacadista de Piracicaba mimeografado (1978).

12 CEAOESP (1909) 
59.

dutores e atacadistas da CEASA, na venda direta aos consumi dores.

- Atuacão de venda no Atacado nos varejóes de Piracicaba.

- Os permissionários da CEASA, também atuam no varejo, atacado e semi-atacado, em outras unidades de comercia1 ização da esfera pública e/ou mesmo particular.

- Proximidade e importância da CEASA - Campinas, com relacão à região. 
6. ADMINISTRAç̃o muNicipal DE PIRACICABA E O SISTEMA DE YAREJÕES

Nesta parte procura-se identificar as origens do Sistema de Comercializacão do tipo varejão, o qual, como já descrevemos, tem ligacóes fortes com a lidéla de Feira do Produtor: como a do mercado de caminhões de Mogi das Cruzes e Mercadão Bresser. Especificamente para Piracicaba realizamos algumas entrevistas com pessoas ligadas a implantacão de tal sistema na cidade e obtivemos algumas informacóes consideradas importantes para nossa análise e que serão discutidas neste capitulo.

A Idéia da implantação teve fortes influências no sentido de traduzir-se em uma opcão a mais para o consumidor de hortigranjeiros, com garantia de precos "realmente mais baixos" do que outras unidades de comercializacão do gênero na cidade, mercado municipal, feiras-livres, etc.. 1 Banco de Dados existente na época (1981) realizava cálculos da Cesta Básica conforme metodologia do IEA, e evidenciava que os precos dos alimentos na cidade encontravam-se em patamares altos.

1 Segundo entrevista realizada com oabriel Ferrato dos Santos, assessor do Gabinete do Prefeito em 1901 e um dos fundedores do sistema de varejżes em Piracicaba. 
61.

A existência do Entreposto Municipal Ccitado no capitulo anterior serviu de modelo para a implantacão do Sistema. Foi executado um amplo diagnóstico da producão e abastecimento de hortigranjeiros na cidade via o Entreposto, pois ele contava quase que com a totalidade de atacadistas e produtores da cidade. Este diagnóstico identificou que Piracicaba produzia quase que exclusivamente verduras e dependia muito de produtos de outras regióes. Isto reforcou ainda mais a idéia da implantacão dos varejóes, no sentido de criar-se mals uma opcão para o Produtor, bem como para os Atacadistas, mas com vendas diretas ao consumidor $e$ com escal a adequada ${ }^{2}$.

Tais ratos somados às acóes do Governo do estado nas décadas de 70 e 80 , levaram a implementacão dos varejóes em Piracicaba, atraves da Administracão Municipal. Importante marco na história da implantacão deste novo sistema de abastecimento, naquela época (1982), foi a participacão da Coordenadoria de Obras e Servicos Rurais da Prefeltura Municipal que ao implementar acôes diretas no abastecimento, transformou-se em Secretaria Municipal de Agricultura e Abastecimento, em 1984. A Coordenadoria tratava exclusivamente de questóes de obras e Servicos Rurais, enquanto que as atividades de controle de permissão

2 Informacões de luiz Henrique Peres, da secretaria de AgriculturaEstado de são Paulo IEA - e que participou do processo de criacão dos Varejões em São Paulo, e de certa forma manteve contalo com Gabriel Ferrato dos Santos, durante a fundacão dos varejões em Piracicaba. 
nas feiras-livres e mercado no Entreposto Municipal cabiam a Secretaria de Finanças, atividades estas meramente burocráticas. A Administração Municipal passou então a administrar uma razoável parcela das unidades de comercialização na cidade.

\subsection{Varejão Sorocabana a Experiência Piloto}

A primeira unidade de comercializacão do tipo "varejão municipal" em Piracicaba, iniciou-se com a experiência do varejão da Sorocabana em 24/06/82, localizado em um antigo e desativado armazém de acúcar na Estação da Estrada de Ferro Sorocabana, próximo ao terminal de ônibus urbano, e também da zona central da cidade. "Surgiram logo os primei-

ros problemas: produtores com medo de perder sua fréguesia no mercado municipal, não aceitavam oferecer seus produtos no local. Ainda assim, fol organizado o primeiro varejão municipal da cidade, inicialmente com 3 bancas; uma de tomate, outra de frutas e outra de legumes. O exito foi total e em menos de 2 horas for am vendidos todos os produtos. Na segunda semana apareceram 4 bancas; na terceira o número passou para 50 sendo $80 \%$ de comerciantes e $20 \%$ de produtores" (Silva, 1984, pág. 38).

Com a experiência piloto, roi importante a discussão de qual seria a filosofia do Sistema de varejôes na cidade. Discutiu-se a nova relacão entre produtor e comerciante, a necessidade de controlar os precos e qualidade dos produtos, a fim de oferecer melhores opcóes para a 
63.

popul ação. Com a nova filosofia implantada, a relaç̃o de produtores passou de 20 para $73 \%$ em relacão aos comerciantes. A Secretaria passou a incrementar a assistência técnica e servicos de infra-estrutura na zona rural cestradas, pontes. acudes, etc.J. Foram criados os núcleos rurais ${ }^{3}$ cuja a distribuição do municipio é mostrada na figura 4.

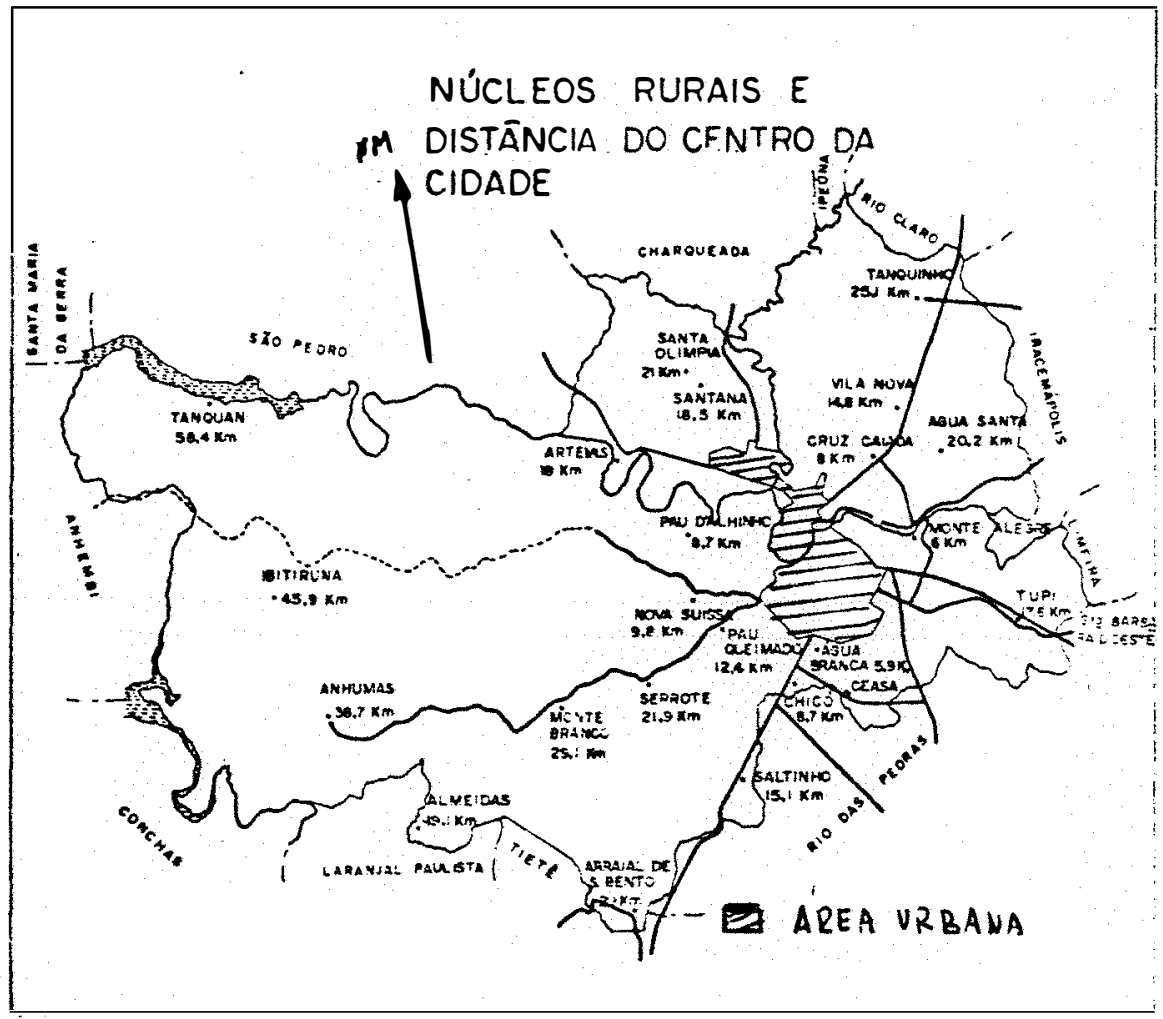

Figura 4.. Nucleos Rurais e distáncia do centro da cidade municipio de Piracicaba - Fonte: Cadastro Técnico SEMA - 1991

Para complementar a estrutura varejista, foram criados mais 5 varejões espalhados pela cidade (Figura 5 ), além dos varejinhos (Figura 6), que constituem pequenas

3 Bairros-sedes onde os produlores da regiäo, bairros vizinhos, encontram-se para promover suas reinvidicasōes junto a SEMA. 
64.

feiras que se realizam nos bairros da periferia com a mesma filosofia dos varejões, ou seja; são praticados os mesmos precos dos varejões, garante-se a participacão de pelo menos um vendedor para cada variedade de produtos. Assemelham-se às feiras porque não são localizados em lugares fechados, mas nas ruas de determinados bairros que possa atender o maior número da populacão da região. No próximo item descrevemos mais informacões sobre sua operacional izacão.

As Figuras 5 e 6 comparadas com a localizacão das feiras-livres (Figura 3), sugerem uma distribuicão planejada, ou seja os varejões e varejinhos parecem estrategicamente localizados no municipio. 


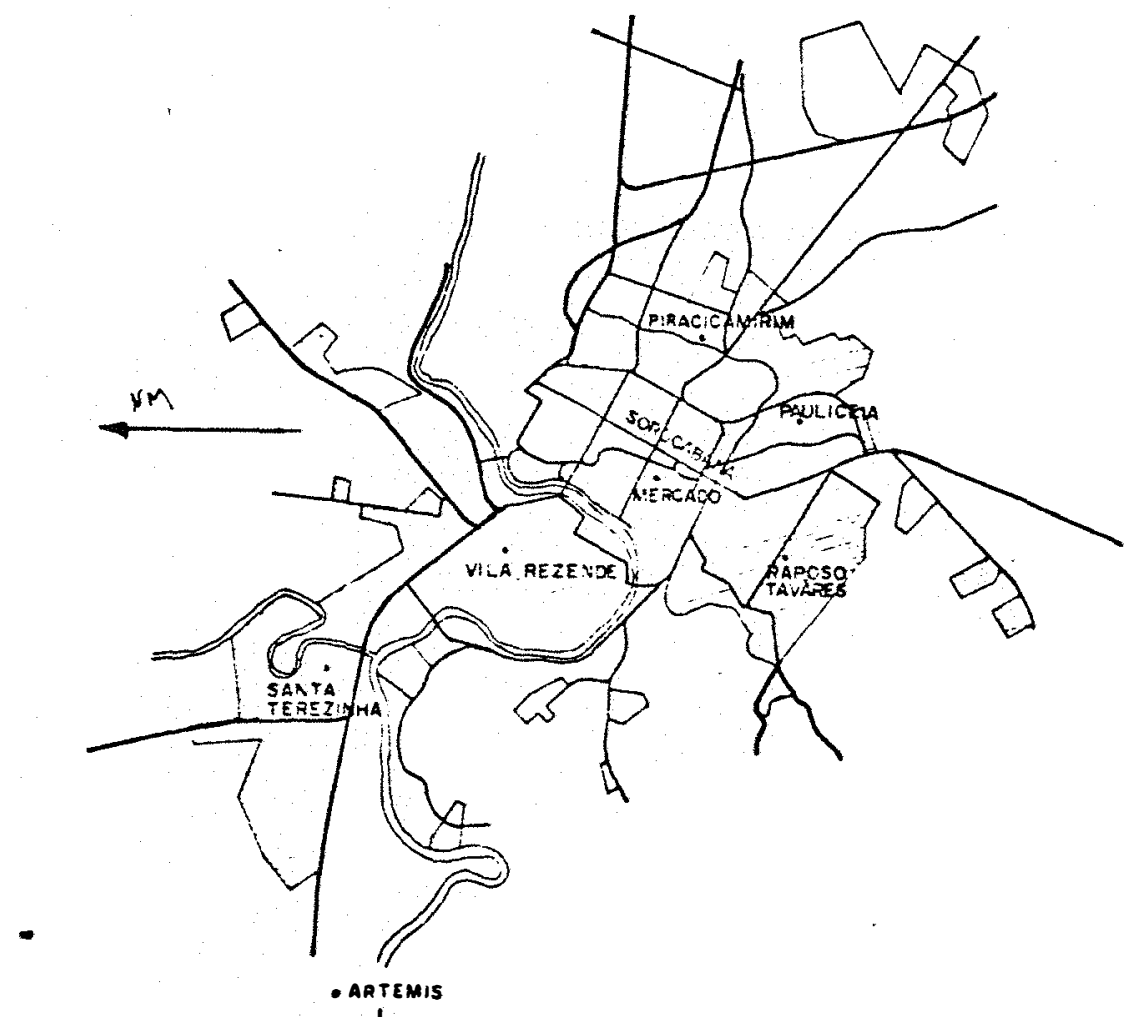

Figura 5 - Localização dos Varejôes no municipio de Piracicaba (área urbana) - Fonte: Cadastro Técnico SEMA - 1991 .

VARE JINHOS

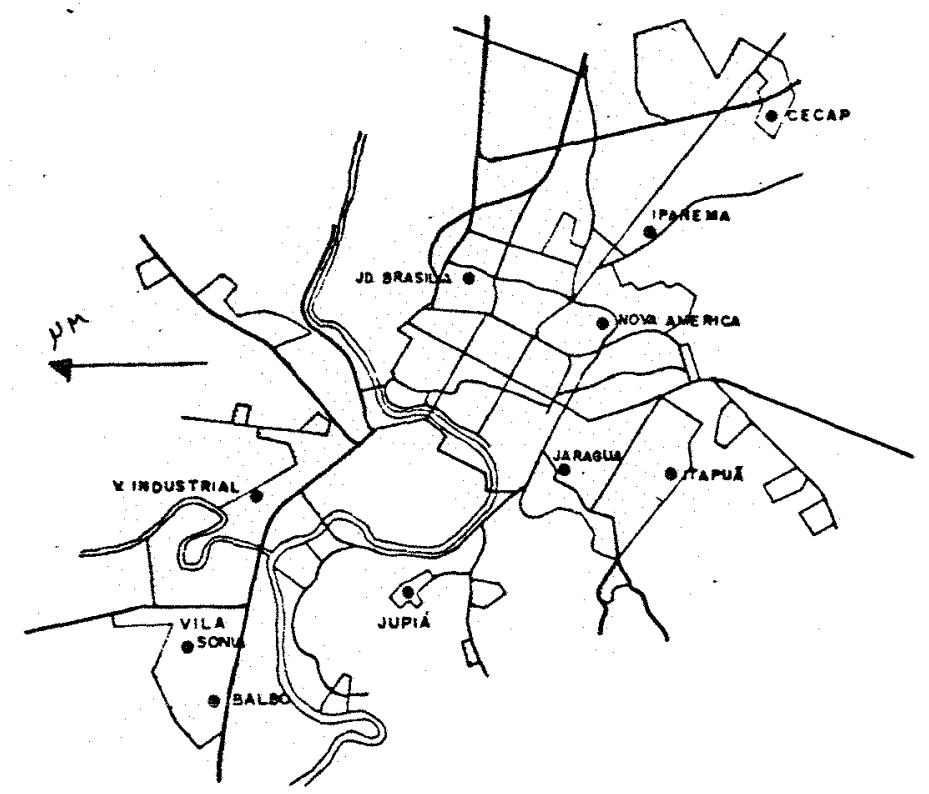

Figura 06 - Localização dos Varejinhos no municipio de Piraclcaba (área urbana) - Fonte: Cadastro Técnico SEMA - 1991. 


\subsection{Infra-Estrutura e Operacionalizacáo do Sistema Munt-} cipal de Varejões de Piracicaba-SP

A Secretairia Municipal de Agricultura e abastecimento SEMA possui um corpo de funcionários que atua diáriamente na administracão dos varejóes, tanto no que concerne a sua estrutura cnúmero de vendedores cadastrados e bancas, grupo de produtos, etc.J, mas principalmente na elaboracão dos precos máximos, ás quintas e sextas feiras, com base nas coletas efetuadas na CEASA (segundas, quartas e sextas feiras, dias em que existe comercializacão no atacado), nas feiras-livres (diariamente), mercado municipal (quartas e sextas feiras) e supermercados (quintas e sextas feiras). Os precos dos varejöes devem ser fixados no máximo em 20\% acima do atacado e devem estar abaixo ou no mesmo patamar (em alguns casos) com relacão a outras unidades de varejo da cidade.

As tabelas de precos máximos são amplamente divulgadas na imprensa local e no local da comercializacão, com a vantagem de o consumidor conhecer o preco antes de realizar suas compras, ou mesmo usá-las como referencial naquelas realizadas em outros locais.

Os produtores locais e da região têm também a oportunidade de colocar seus produtos de época, realizar promoç̃es, etc. através das 18 unidades de comerciallzacão

- Independentemente de serem ou nāo cadastrados no sistema Municipal de Abastecimento 
(7 varejões e 11 varejinhos). Iécnicos da SEMA acredi tam que a producão de hortigranjeiros em Piracicaba, principalmente a de folhas, tem se mantido gracas a estas possibilidades de vendas que também se somam as das grandes lojas de supermercados, e de outras em grandes escala.

Os varejões têm registrado um volume regular de vendas, desde sua implantacão, inclusive se comparado ao vol ume da CEASA local, conforme se pode observar nos figuras 07 e 08. Isto ocorre até 1989, em 1990 verificamos que o vol ume comercializado da CEASA aumentou consideravelmente.

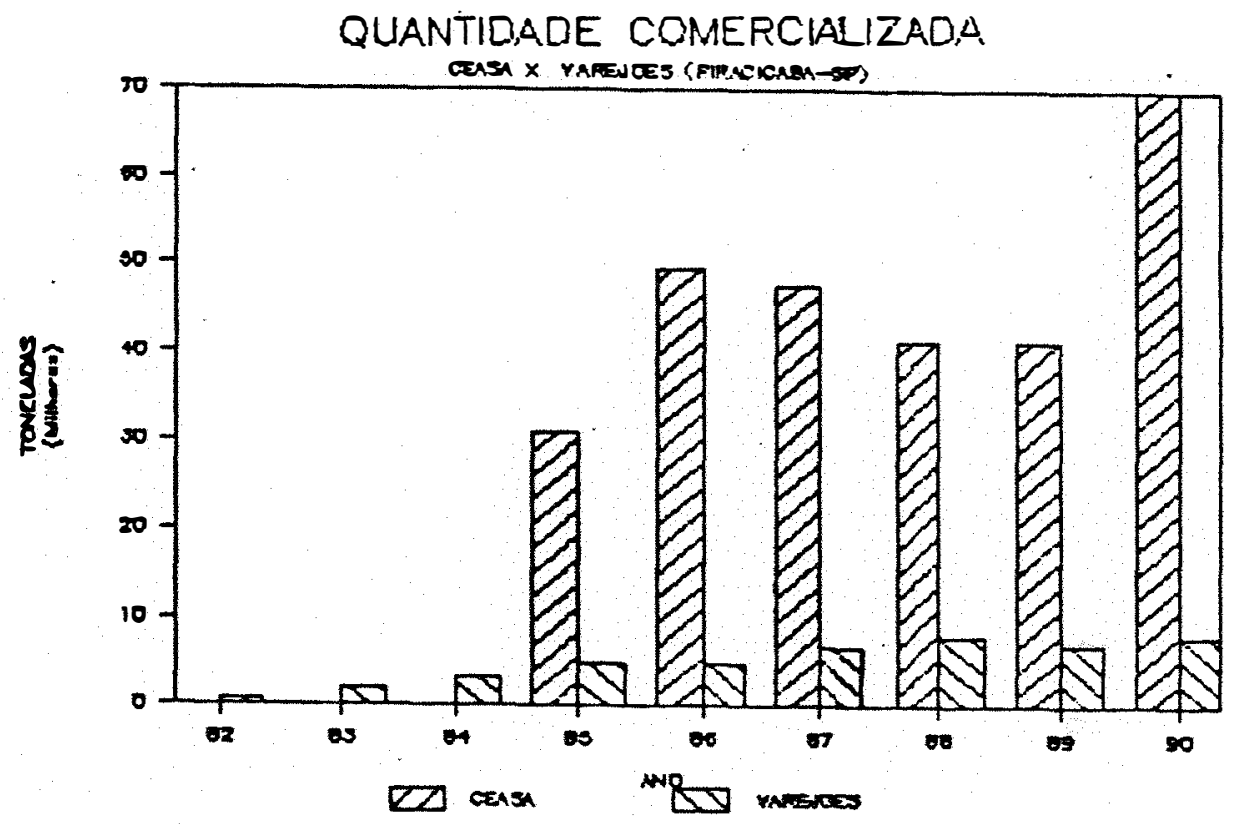

Figura 07 - Quantidade comercializada CEASA X varejões C82 a $90)$ - Fonte: CEAGESP Boletim Mensal do Interior e SEMA Boletim Mensal. 
68.

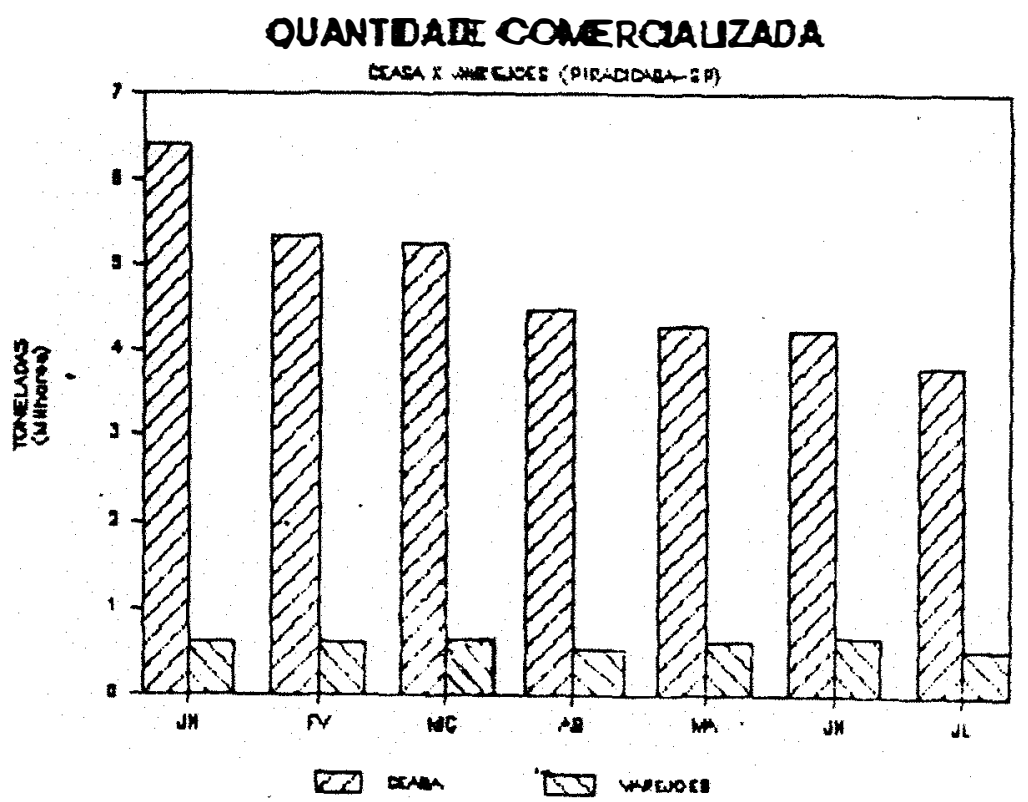

Figura 8. Quantidade comercializada CEASA X Varejoes Cjan. a jul. $/ 91$ ) - Fonte: CEAGESP Boletim Mensal do Interior e SEMA Boletim Mensal

Segundo informacões do SEMA, os varejões de Piracicaba-SP apresentam as seguintes caracteristicas:

a) Localizaç̃o em pontos estratégicos para garantir o maior fluxo de pessoas possivel;

b) Infra-estrutura com barracão coberto, cercas, banheiros e prédio para administração (feiras confinadas);

c) Venda setorizada, isto é os permissionários só podem comercializar produtos de um mesmo setor, por exemplo, verduras e legumes; frutas tropicais e frutas finas; ovos e aves, peixes e carnes/miudos, cereais e tubérculos, etc. .

d) Possui um número importante de produtores na composição de permissionários; 
89.

e) A admissão de permissionários e a atribuicão de bancas estão vinculadas a uma "Permissão de Uso"que pode ser remunerada e a um regulamento de conduta do permissionário;

f) Os produtos são comercializados a precos controlados, isto é, com base numa cotacão de precos no atacado (CEASAS - Piracicaba) com rixacão de margem bruta de comercializacão (até no máximo de 20\%, comparando-se aos precos das feiras-livres, supermercados e mercado municipal;

g) Equipe de fiscais com conhecimento técnico de classificacão de produtos (curso dado pelo CEAGESP), para atuação na cotação e aplicacão de tabelas, conferindo precos e qualidade.

6.2.1. Cronologia das implantacões dos varejões e varejinhos em Piracicaba-SP.

Ocorreram inauguraçoses em quase todos os anos após 1982 (ano de inauguracão da primeira unidade), exceto em 1990 conforme mostrado na Tabela 15. Nota-se também que ocorreram 08 desativacóes de varejinhos, bem como um bom número de inauguracóes no ano de 1991. Isto decorre das constantes tentativas de solidificar estas "feiras" em áreas da periferia, que normalmente apresentam pouca escala de venda, pelo baixo poder aquisitivo da populacão. Estas instalacőes ocorrem, segundo informacões da SEMA, por solicitacão da populacão destes bairros, após discussão com os Permissionários e a própria SEMA. 
Tabela 15. Data de Inauguracão dos Varejôes e Varejinhos Municipais de Piracicaba - SP.

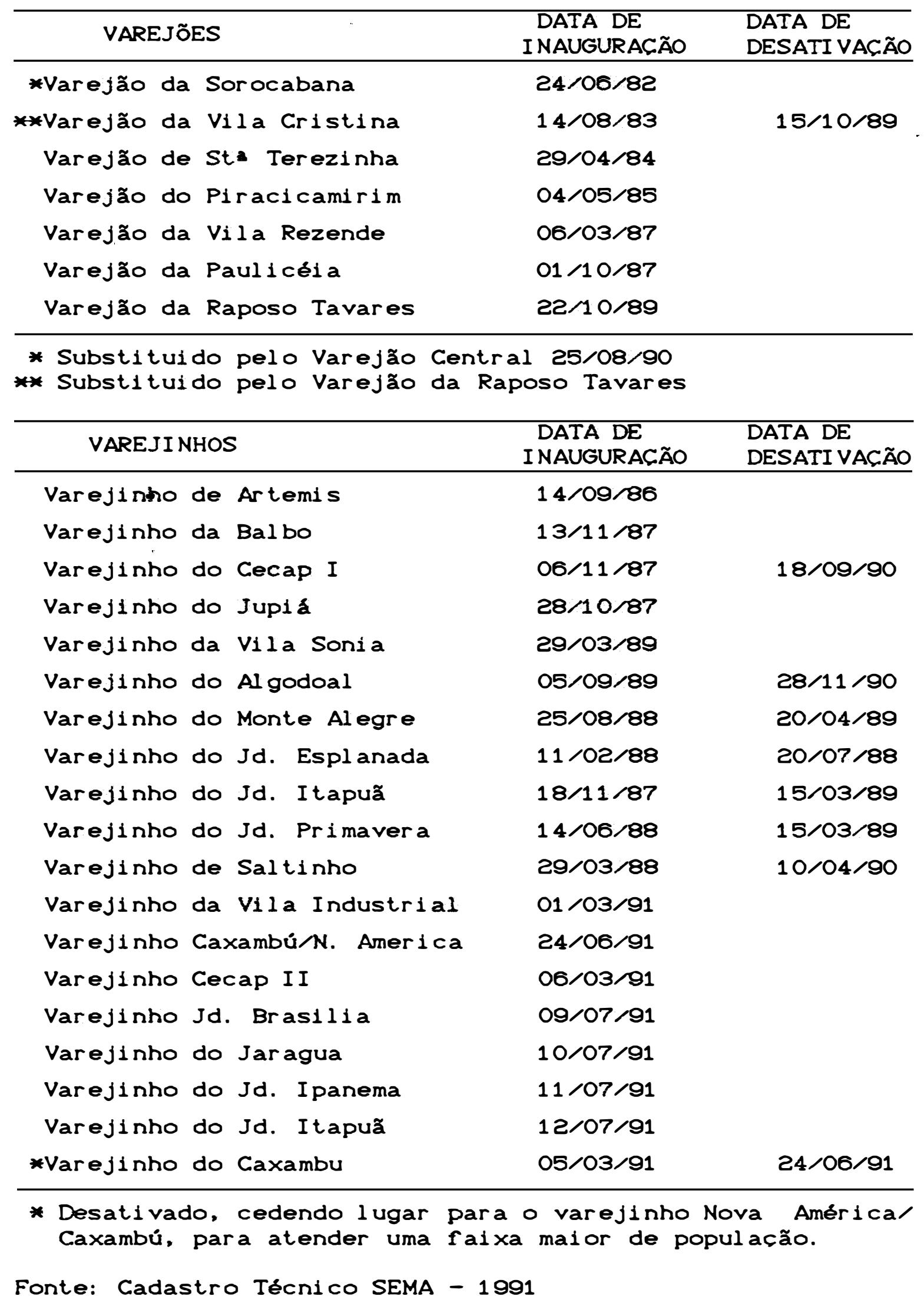


o que vem sendo feito é a tentativa de melhorar a localizaçao dos varejinhos, para que atendam um número de consumidores suficiente para solidificacão da unidade. Vem sendo utilizada também, junto aos Permissionários, a justificativa de que alguns varejoes e mesmo alguns varejinhos apresentam-se vantajosos e que podem compensar menores ganhos daqueles instalados em bairros periféricos de baixa "demanda. Os varejinhos realizavam suas vendas quinzenalmente e a partir de 1991 passaram a operar todas as semanas, o que tem incrementado o volume comercializado (ver Figura 9 e 10s, o que de certa forma aponta para sua solidificacão no Sistema Municipal de Abastecimento.

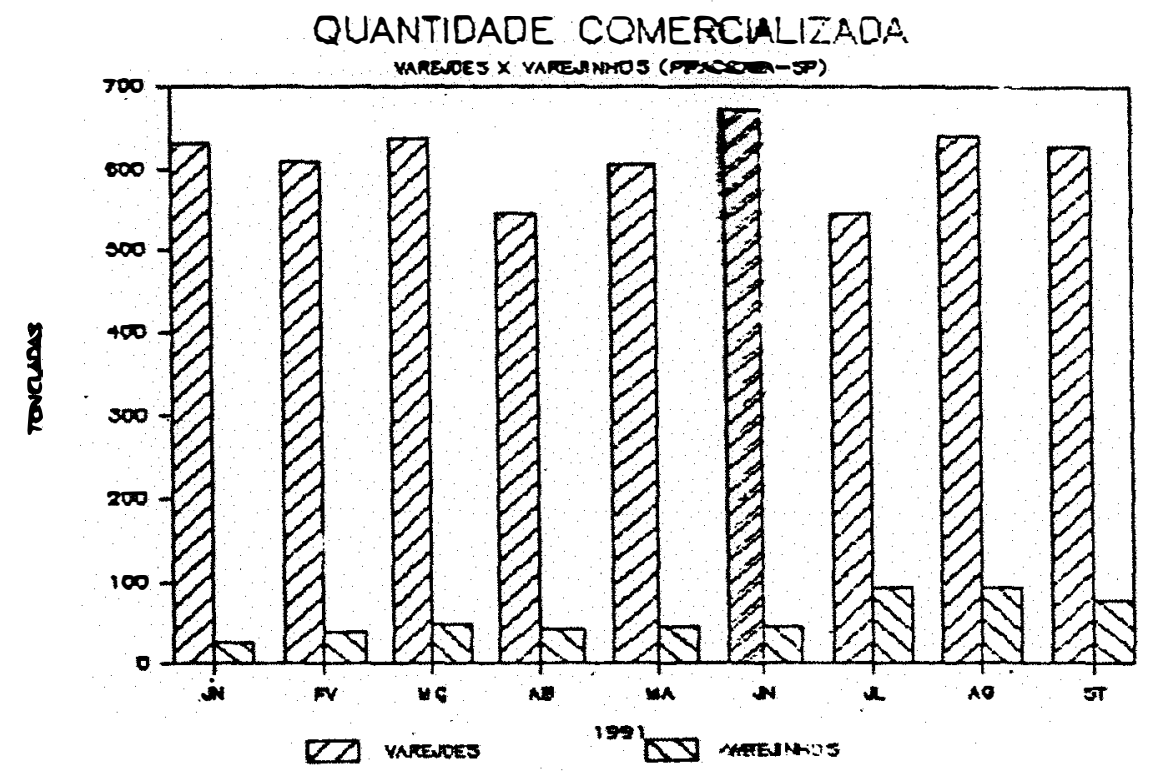

Figura 9. Quantidade comercializada - Varejinhos X Varejóes de Piracicaba (jan. a set. $/ 91$ ).

Fonte: SEMA - Boletim Mensal 


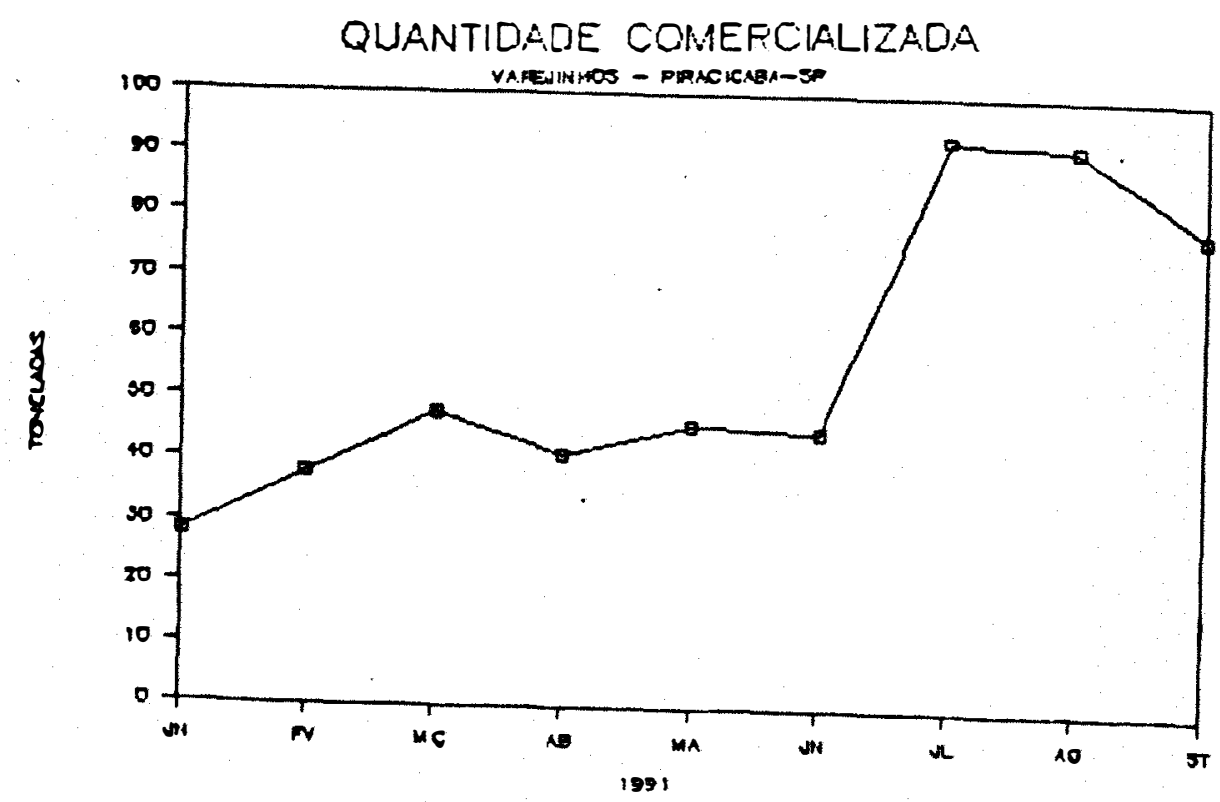

Figura 10. Quantidade comercializada - Varejinhos de Piracicaba CJan. a set. 91 ).

Fonte: SEMA - Boletim Mensal

6.2.2. Aspectos da Estrutura e Operacionalização do Sistema Municipal dos Varejôes

Elaboramos algumas tabelas e gráficos que demonstram aspectos da estrutura e operacionalização das unidades de comercializacão estudadas e que serão a seguir discutidos.

A Tabela 16 mostra a distribuicão dos Permissionários para cada grupo de produto. Também registra a categoria dos vendedores: Produtor, Comerciante ou Produtor/Comerciant $e^{5}$.

5 Parte do que leva para comercializar \& comprado no Alacado ou de outros produtores 
73.

- Sistema Municipal de varejões possui 151 Permissionários que estão distribuidos nas unidades de comercializaçao e 49\% são Produtores, 46\% são Comerciantes e 5\% Produtores/Comerciantes. A maior participacão dos Produtores $186 \%$ encontra-se no grupo de Verduras.

Tabela 16. Permissionários e Grupo de Produtos do Sistema Municipal de Varejões - Piracicaba-SP ( $31 / 06 / 91)$.

\begin{tabular}{|c|c|c|c|c|c|}
\hline \multirow{2}{*}{$\begin{array}{l}\text { ORUPOS DE } \\
\text { PRODUTOS }\end{array}$} & \multicolumn{2}{|c|}{ PERMISSIONARIO } & CATEOORIA & \multicolumn{2}{|c|}{ DO PERMISSIONARIO } \\
\hline & $\mathrm{N}^{2}$ & $x$ & PROD. & COMERC. & - PROD. CCOM. \\
\hline verduras & 64 & 42.98 & 04 & - & - \\
\hline Legumes & $\mathbf{8}$ & 5.90 & - & $\boldsymbol{8}$ & - \\
\hline Tomate & 0 & 5.00 & - & $\sigma$ & 3 \\
\hline Banana & 0 & 5.00 & $\mathbf{3}$ & $\mathbf{5}$ & 1 \\
\hline Laranja & $\mathbf{8}$ & 5. 90 & 4 & $\mathbf{3}$ & 1 \\
\hline \multicolumn{6}{|l|}{ Mamão/Abacaxi/ } \\
\hline Melancia & 4 & 2.04 & - & 4 & - \\
\hline Frutas finas & 10 & 0.02 & - & 10 & - \\
\hline \multicolumn{6}{|l|}{ cereais } \\
\hline ruberculos & $?$ & 4.69 & 1 & 4 & 2 \\
\hline$P \bullet i \times \theta s$ & 5 & 3. 31 & 1 & 4 & - \\
\hline ovos & 5 & 9. 91 & 1 & 4 & - \\
\hline Frangos/Frios & $\mathbf{8}$ & 5. 90 & - & $\boldsymbol{\theta}$ & - \\
\hline Miudos & 1 & 0.06 & - & 1 & - \\
\hline Pastel & 8 & 5.90 & - & 8 & - \\
\hline Diversos & 5 & 9. 91 & - & 4 & 1 \\
\hline
\end{tabular}

Fonte: SEMA - Boletim Mensal (1991)

Quanto à participação dos Permissionários nas unidades de Comercializacão, destaca-se o varejão Central (Tabela 17), com aproximadamente 45\% de Permissionários e 35\% das Bancas no Grupo de Verduras, maior indice de parti- 
cipação deste grupo. Em todas unidades de comercialização o Grupo de Verduras é o de maior participacão (ver Tabelas 17 a 25).

Nos demais grupos de produtos a distribuicão encontra-se razoável mente equilibrada, até no máximo $10 \%$ do total de vendedores e de bancas em cada unidade.

Cabe esclarecer que o quadro de cada unidade de comercializacão é fixo, e é montado de acordo com a demanda apresentada pelos consumidores de cada região e pela disponibilidade de vendedores. Esta composicão deve estar sendo sempre revista. A administracão dos varejôes procura atribuir, sempre que possivel, mais de um vendedor por grupo de produtos na tentativa de que ocorra alguma concorrência entre eles. 
76.

Tabela 10. Permissionários orupode Produto, Banca categoria-varejão Raposo Tavares - Piracicaba - SP - $91 / 00 / 01$

\begin{tabular}{|c|c|c|c|c|c|c|c|}
\hline \multirow{2}{*}{$\begin{array}{l}\text { ORUPOS DE } \\
\text { PRODUTOS }\end{array}$} & \multicolumn{2}{|c|}{ PERMIS. } & \multicolumn{2}{|c|}{ BANCAS } & \multicolumn{2}{|c|}{ CATEGORIA } & PERMISSIONARIO \\
\hline & $\overline{N^{2}}$ & 9 & $\overline{N^{2}}$ & $\%$ & PROD. & COMERC. & PROD./COMERC. \\
\hline verduras & 11 & 20.20 & 10 & 23.45 & 11 & - & - \\
\hline Løgumes & $\mathbf{3}$ & 7.14 & 5 & 0.17 & - & $\mathbf{3}$ & - \\
\hline Tomate & $\mathbf{3}$ & 7.14 & 0 & $7 \cdot 40$ & - & 1 & 2 \\
\hline Banana & 4 & 0.52 & 7 & 8. 04 & - & $\mathbf{3}$ & 1 \\
\hline Laranja & $\mathbf{3}$ & 7.14 & 8 & 0.87 & $\mathbf{3}$ & - & - \\
\hline \multicolumn{8}{|c|}{ Mamao/Abacaxi/ } \\
\hline Melancia & 1 & 2.98 & 2 & $2 \cdot 46$ & - & 1 & - \\
\hline $\begin{array}{l}\text { Frutas finas } \\
\text { cereais }\end{array}$ & $\mathbf{9}$ & 7.14 & $\mathbf{8}$ & 9.87 & - & $\mathbf{9}$ & - \\
\hline Tuberculos & 4 & 0.52 & 10 & 12.94 & - & 2 & 2 \\
\hline$P \bullet i x \bullet \mathbf{s}$ & 1 & 2.98 & 2 & 2.40 & - & 1 & - \\
\hline ovos & $\mathbf{2}$ & 4.70 & 4 & 4.99 & 1 & 1 & - \\
\hline Frangos/Frios & $\mathbf{9}$ & $7 \cdot 14$ & $\boldsymbol{0}$ & $7 \cdot 40$ & - & $\mathbf{9}$ & - \\
\hline Miudos & 1 & 2.38 & 1 & 1.29 & - & 1 & - \\
\hline$P a s t \in l$ & 2 & 4.70 & 2 & $2 \cdot 40$ & - & 2 & - \\
\hline Diversos & 1 & 2.98 & 1 & $1 \cdot 23$ & - & - & 1 \\
\hline T O $T$ A $A$ & 42 & $100 \%$ & 81 & $100 \%$ & 15 & 21 & 0 \\
\hline
\end{tabular}

FONTE: SEMA - Boletim Mensal

Tabela 20. Permissionários orupo de Produto, Banca calegoria-varejāo Piracicamirim - Piracicaba-SP - 91/00/01

\begin{tabular}{|c|c|c|c|c|c|c|c|}
\hline \multirow{2}{*}{$\begin{array}{l}\text { ORUPOS DE } \\
\text { PRODUTOS }\end{array}$} & \multicolumn{2}{|c|}{ PERMIS. } & \multicolumn{2}{|c|}{ BANCAS } & \multicolumn{2}{|c|}{ CATEGORIA } & \multirow{2}{*}{$\frac{\text { PERMISSIONARIO }}{\text { PROD./COMERC. }}$} \\
\hline & $N^{2}$ & 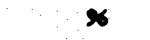 & $\mathbf{N}^{2}$ & $\%$ & PROD. & COMERC. & \\
\hline verduras & 0 & 25.00 & 15.5 & 21.98 & 9 & - & - \\
\hline Legumes & 2 & 5.55 & 0 & 0.51 & - & 2 & - \\
\hline Tomate & 2 & 5.55 & 4 & 5.07 & - & 1 & 1 \\
\hline Banana & 4 & $11 \cdot 11$ & 8 & $11 \cdot 34$ & - & $\mathbf{3}$ & 1 \\
\hline Laranja & $\mathbf{9}$ & 8. $\mathbf{3} \mathbf{9}$ & $\mathbf{8}$ & $11 \cdot 34$ & 2 & 1 & - \\
\hline \multicolumn{8}{|l|}{ Mamão/Abacaxi/ } \\
\hline Melancia & & & & & & & . \\
\hline Frutas finas & $\mathbf{3}$ & 8. 99 & $\mathbf{8}$ & $11 \cdot 34$ & - & $\mathbf{3}$ & - \\
\hline Tuberculos & 2 & 5.55 & 4 & 5. 67 & - & 2 & - \\
\hline$P \bullet i x \in 8$ & 1 & 2.77 & 2 & 2.83 & - & 1 & - \\
\hline ovos & 2 & 5.55 & 5 & 7.00 & - & 2 & - \\
\hline Frangos/Frios & 4 & $11 \cdot 11$ & 5 & 7.09 & - & 4 & - \\
\hline Miudos & 1 & 2.72 & 1 & $1 \cdot 41$ & - & 1 & - \\
\hline Pastel & 2 & 5.55 & 2 & 2.83 & - & 2 & - \\
\hline Diversos & 1 & 2.77 & 2 & 2.89 & - & 1 & - \\
\hline
\end{tabular}

FONTE: SEMA - BOLEtim MOnBal 
7.5.

rabela 17. Permissiondrios o orupo de Produlo, Banca e Categoria-varejão central (Ex sorocabanal - Piracicaba-sp-a1/00/01

\begin{tabular}{|c|c|c|c|c|c|c|c|}
\hline \multirow{2}{*}{$\begin{array}{l}\text { ORUPOS DE } \\
\text { PRODUTOS }\end{array}$} & \multicolumn{2}{|c|}{ PERMIS. } & \multicolumn{2}{|c|}{ BANCAS } & \multicolumn{2}{|c|}{ CATEGORIA } & \multirow{2}{*}{$\begin{array}{l}\text { PERMISSIONARIO } \\
\text { PROD. /COMERC. }\end{array}$} \\
\hline & $\mathbf{N}^{2}$ & $x$ & $\mathrm{~N}^{2}$ & $x$ & PROD. & COMERC. & \\
\hline verduras & 42 & 44.20 & 57.5 & 34.43 & 42 & - & - \\
\hline Legumes & 5 & 5.20 & 0. 5 & 5.68 & - & 5 & - \\
\hline Tomate & 9 & 0. 47 & 15 & 8. $\$ 8$ & - & $\boldsymbol{\sigma}$ & $\mathbf{9}$ \\
\hline Danana & 5 & 5.20 & 8 & 4.78 & - & 4 & 1. \\
\hline Laranja & 4 & 4.21 & 12 & 7.18 & 4 & - & - \\
\hline \multicolumn{8}{|l|}{ Manão/Abacaxi / } \\
\hline Melancia & 4 & 4.21 & 8 & 4.78 & - & 4 & - \\
\hline $\begin{array}{l}\text { Frulas finas } \\
\text { cereais }\end{array}$ & 5 & 5.25 & 15 & 8. 98 & - & 5 & - \\
\hline Tubercul.os & 6 & 6.31 & 13 & 7.78 & 1 & $\mathbf{3}$ & 2 \\
\hline$P \bullet i x \in 8$ & 4 & 4.21 & 8 & 4.78 & 1 & $\mathbf{3}$ & - \\
\hline OV0.8 & 2 & 2.10 & 0 & 3.59 & - & 2 & - \\
\hline Frangos/Frios & 4 & 4.21 & $\mathbf{8}$ & 4.78 & - & 4 & - \\
\hline Miudos & 1 & 1.05 & 2 & 1. 18 & - & 1 & - \\
\hline$P a=l \cdot l$ & $\mathbf{3}$ & 3.15 & $\mathbf{3}$ & 1.79 & - & $\mathbf{3}$ & - \\
\hline Diversos & 1. & 1.05 & 2 & 1. 10 & - & - & 1 \\
\hline
\end{tabular}

FONTE: SEMA - Boletim Mensal

rabela 18. Permissionarios - orupo de Produlo, Banca calegoria-varejãovila Rezende - Piracicaba - SP - 31/06/81

\begin{tabular}{|c|c|c|c|c|c|c|c|}
\hline \multirow{2}{*}{$\begin{array}{l}\text { ORUPOS DE } \\
\text { PRODUTOS }\end{array}$} & \multicolumn{2}{|c|}{ PERMIS. } & \multicolumn{2}{|c|}{ BANCAS } & \multicolumn{2}{|c|}{ CATEOOR IA } & \multirow{2}{*}{$\begin{array}{c}\text { PERMISSIONARIO } \\
\text { PROD. /COMERC. }\end{array}$} \\
\hline & $\mathbf{N}^{2}$ & $x$ & $\mathbf{N}^{2}$ & $x$ & PROD. & COMERC. & \\
\hline verduras & 23 & 92.98 & 37.5 & 20.91 & 29 & - & - \\
\hline Legumes & $\mathbf{3}$ & 4.22 & 10 & 7.01 & - & $\mathbf{9}$ & - \\
\hline Tomale. & 6 & 8. 45 & 12 & 8. 42 & - & 4 & 2 \\
\hline Banana & 5 & 7.04 & 10 & 7.01 & 1 & 4 & - \\
\hline Laranja & 4 & 5.63 & 12 & 8.42 & $\mathbf{3}$ & 1 & - \\
\hline \multicolumn{8}{|l|}{ Mamão/Abacaxi/ } \\
\hline Melancia & 4 & 5. 63 & 8 & 5.01 & - & 4 & - \\
\hline $\begin{array}{l}\text { Frutas finas } \\
\text { coreais }\end{array}$ & 5 & 7.04 & 17 & 11.92 & - & 5 & - \\
\hline ruberculos & 5 & 7.04 & 12 & 0. 42 & 1 & $\mathbf{3}$ & 1 \\
\hline$P \bullet i x \in 8$ & 2 & 2.81 & 4 & 2.80 & - & 2 & - \\
\hline ovos & $\mathbf{3}$ & 4.22 & 0 & 4.21 & - & 2 & 1 \\
\hline Frangos/Frios & 5 & 7.04 & 6 & 4.21 & - & 5 & - \\
\hline Miudos & 1 & 1.40 & 1 & 0.70 & - & 1 & - \\
\hline Pastel & $\mathbf{3}$ & 4.22 & $\mathbf{3}$ & $2 \cdot 10$ & - & $\mathbf{8}$ & - \\
\hline Diversos & 2 & 2.81 & 4 & 2.80 & - & 1 & 1 \\
\hline $\mathbf{T} \quad \mathbf{O} \quad \mathbf{T} A \mathbf{L}$ & 71 & $100 \%$ & 142.5 & $100 \%$ & 28 & $3 \mathbf{8}$ & 5 \\
\hline
\end{tabular}

FONTE: SEMA - Boletim Mensal 
Tabola 21. Permissionários orupo de Produto, Banca catogoria-varejãosanta Torezinha - Piracicaba - SP- 31/00/91

\begin{tabular}{|c|c|c|c|c|c|c|c|}
\hline \multirow{2}{*}{$\begin{array}{l}\text { ORUPOS DE } \\
\text { PRODUTOS }\end{array}$} & \multicolumn{2}{|c|}{ PERMIS. } & \multicolumn{2}{|c|}{ BANCAS } & \multicolumn{2}{|c|}{ CATEGORIA } & \multirow{2}{*}{$\frac{\text { PERMISSIONARIO }}{\text { PROD. /COMERC. }}$} \\
\hline & $\mathbf{N}^{2}$ & $x$ & $\mathbf{N}$ & $x$ & PROD. & COMERC. & \\
\hline verduras & 10 & 28.57 & 10 & 25.00 & 10 & - & - \\
\hline L・gumes & 2 & 5.71 & 4.5 & 7.00 & - & 2 & - \\
\hline Tomate & 2 & 5.71 & 4 & 0.00 & - & - & 2 \\
\hline Banana & 5 & 14.28 & 10 & 10.00 & 2 & $\mathbf{9}$ & - \\
\hline Laranja & $\mathbf{3}$ & 0.57 & 5.5 & 9.00 & 1 & 2 & - \\
\hline & \multicolumn{7}{|c|}{ Mamão/Abacaxi/ } \\
\hline Frutas finas & 2 & 5.71 & 7 & 11.00 & - & 2 & - \\
\hline Cereais & & & & & & & \\
\hline Tuberculos & $\mathbf{3}$ & 0.57 & 5 & 8.00 & - & $\mathbf{3}$ & - \\
\hline$P \bullet i x \in \mathbf{s}$ & 1 & 2.85 & 2 & 8.00 & - & 1 & - \\
\hline OV०8 & 1 & 2.85 & 2 & 8.00 & - & 1 & - \\
\hline Frangos/Frios & $\mathbf{9}$ & 8.57 & 4 & 0.00 & - & $\mathbf{9}$ & - \\
\hline Miudos & - & - & - & - & - & - & - \\
\hline Pastel & 2 & 5. 71 & 2 & 9.00 & - & 2 & - \\
\hline Diversos & 1 & 2.85 & 2 & 3.00 & - & 1 & - \\
\hline $\begin{array}{lllll} & \mathbf{O} & \mathbf{T} & \mathbf{A} & \mathbf{L}\end{array}$ & 35 & $100 x$ & 04 & $100 x$ & 13 & 20 & 2 \\
\hline
\end{tabular}

Tabola 22. Pormissionários orupo de Produto, Banca catogoria-varejão Paulicêia-Piracicaba-SP-31/00/81

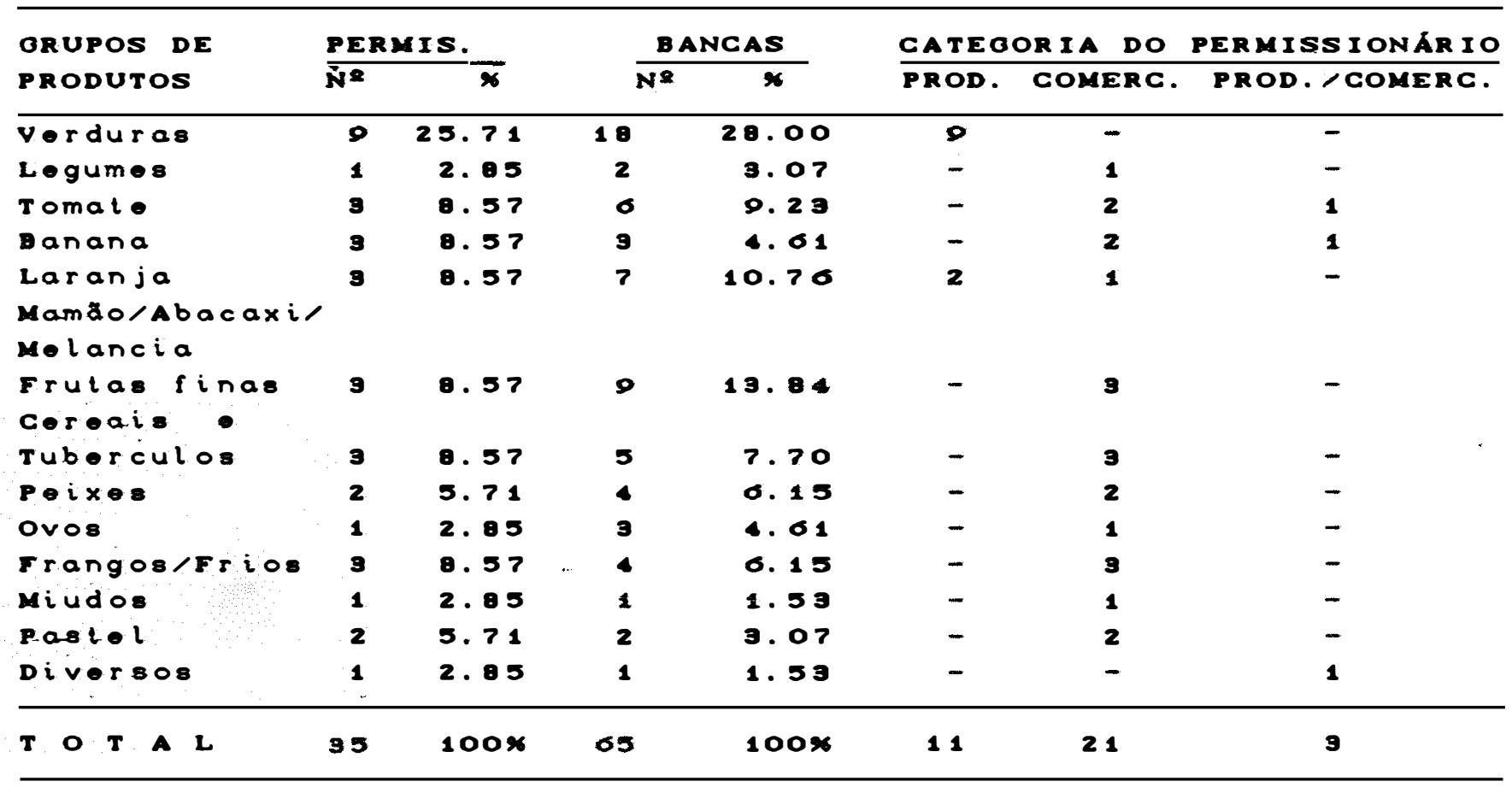

FONTE: SEMA - BOL tim MOnBal 
78.

As Figuras 11 a 20 mostram a participacão de cada unidade nas vendas por grupo de produto. Eles contribuem para o acompanhamento do volume de produtos vendidos em cada região onde estão instalados os varejões. Entendemos que para a análise desta participacão deve-se levar em consideracão três fatores:

a) a capacidade de vendas de cada permissionário, boa comunicacão, bom atendimento, etc., o que cria uma relacão forte com os consumidores: a efetivacão da "freguesia".

b) No volúme de vendas existe a possibilidade de ocorrer um parcela que é destinada a pequenos varejistas, tais como: quitandeiros, feirantes, etc.. Segundo os técnicos da SEMA isto decorre da dificuldade que os varejistas da rede privada local experimentam no deslocamento até o CEASA devido a necessidade de percorrer girande distância ${ }^{\circ}$.

c) Os costumes e as caracteristicas peculiares dos compradores, de acordo com o bairro ou regiao que residem, no consumo de hortigranjeiros.

- Apesar de constituir-se em unidedes de comercializacão de caráter varejista, os varejôes podem estar servindo também como ponto de entre ga alacadista (tanto pelos produtores como comerciantes). Cabe d SEMA garantir que haja quantidade suficiente para atender o varejo, inclusive para que se possibilite um certo grau de concorrência dentro dos varejôs 


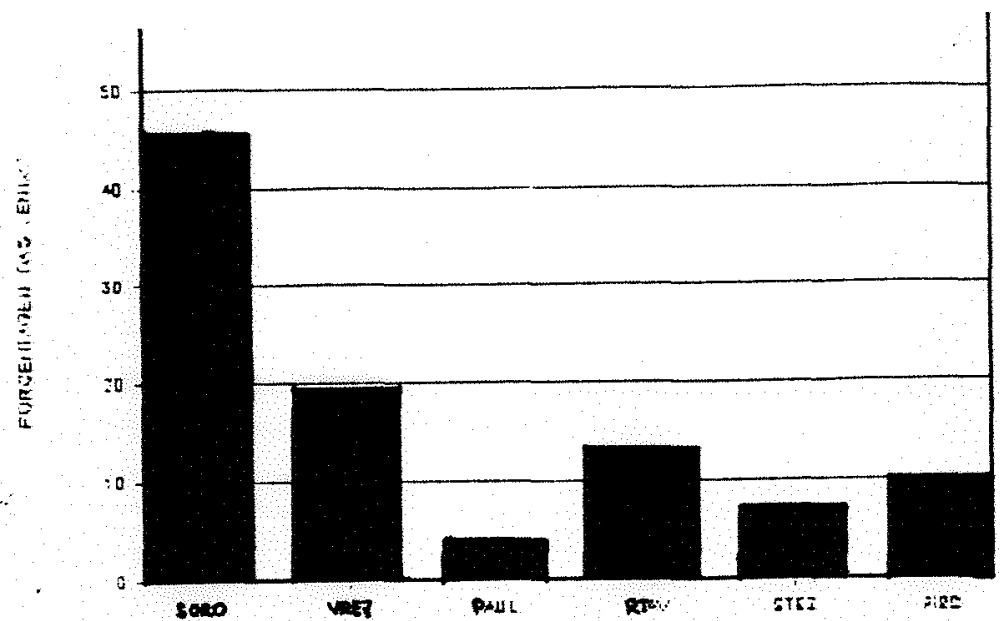

79.

LEEDAA (SIO. IS 2 26):

SORO - SOROCABANA VREZ - VILA REZENDE

PAUL - PAULICEIA

RTAV - RAPOSO TAVARES

STEZ - SANTA TEREZI NHA

PIRC - PIRACICANIRIM

Figura 11 - VERDURAs $\{\%\rangle$ das vendas varejöes de piracicaba $(06 / 01\rangle$.

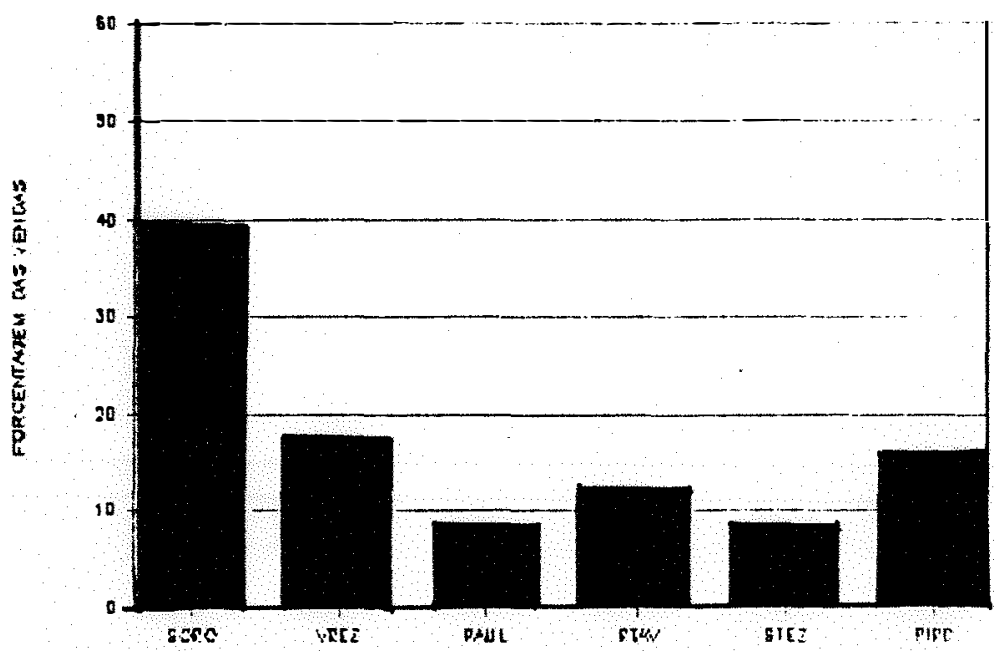

Figura 12 - Leoumes $(x)$ das vendas varejôes de Piracicaba $(06 / 01)$.

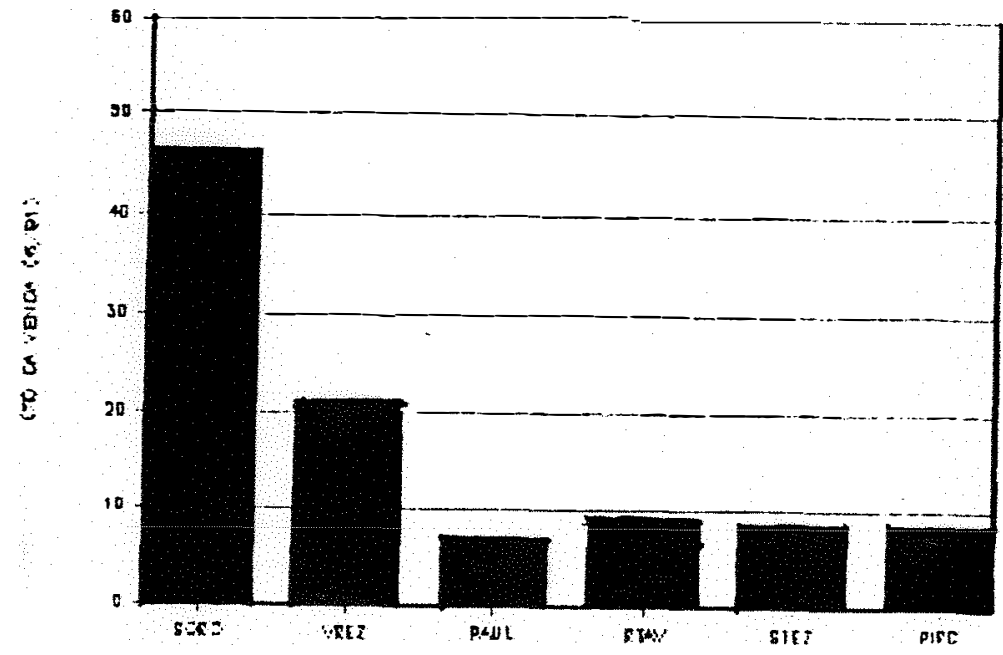

Figura 13 - TOMATE $(x)$ das vendas varejöes de Piracicaba $(\operatorname{co} / 01)$. 


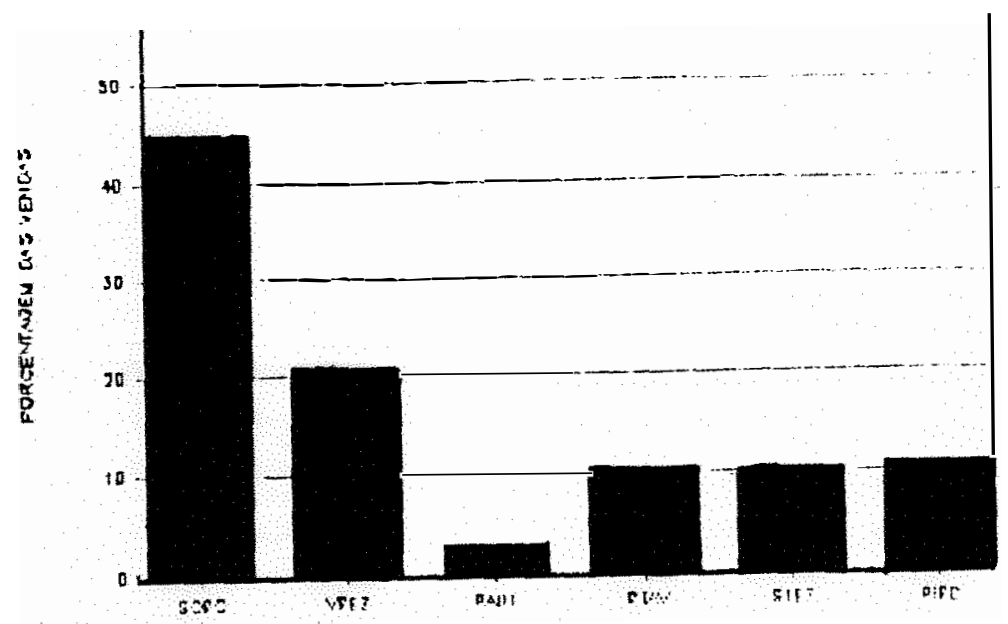

80.

Figura 14 - CEREAIS TUBERculos $(\%)$ das vendas varejöes/piracicaba $(00 / 01)$.

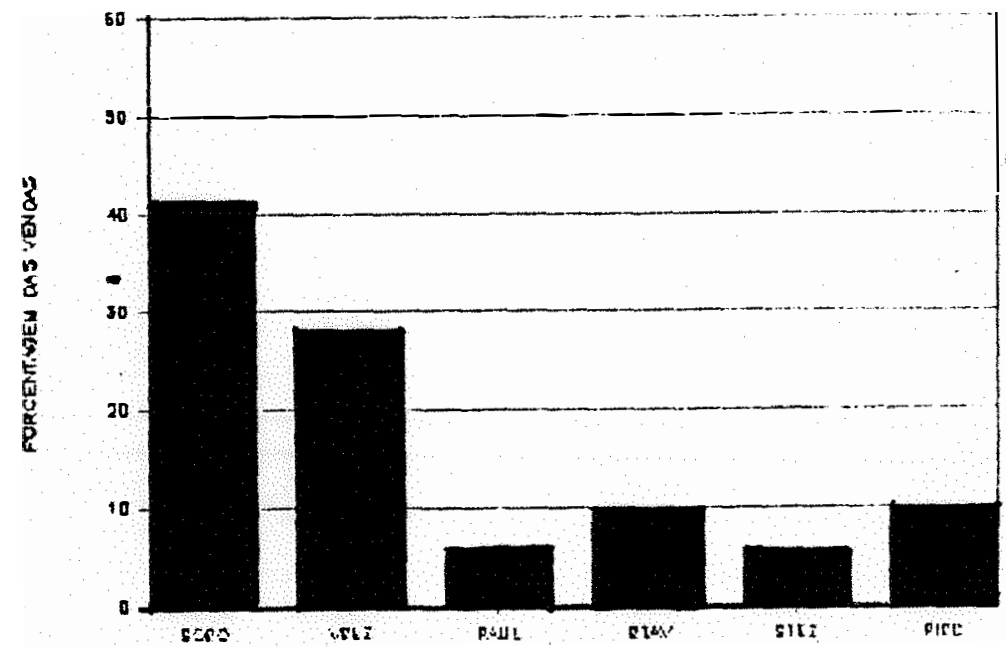

Figura 15 - LARANJA (\%) das vendas varejöes de Piracicaba (06/01).

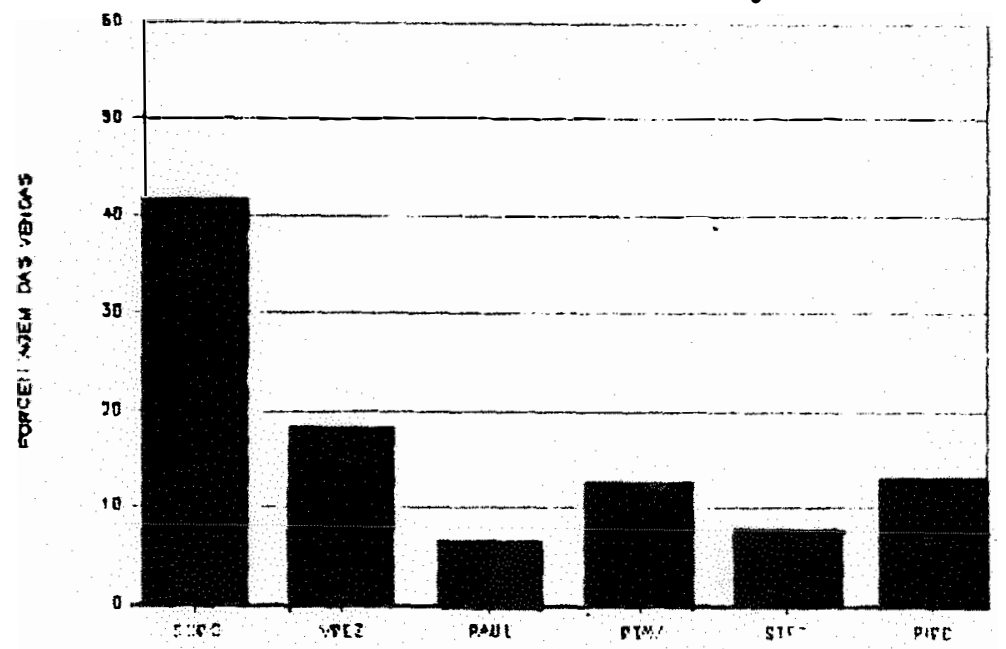

Figura 16 - BANANA $(\%)$ das vendas varejöes de Piracicaba $(00 / 81)$. 


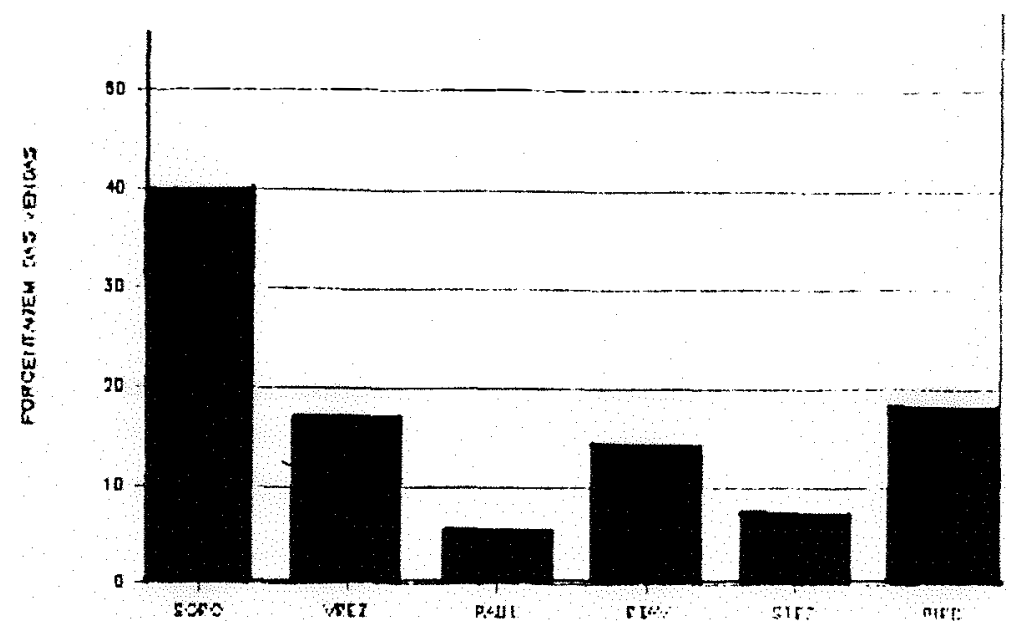

81.

Figura 17 - ovos ( $($ ) das vendas varejôes de Piracicaba (co/o1).

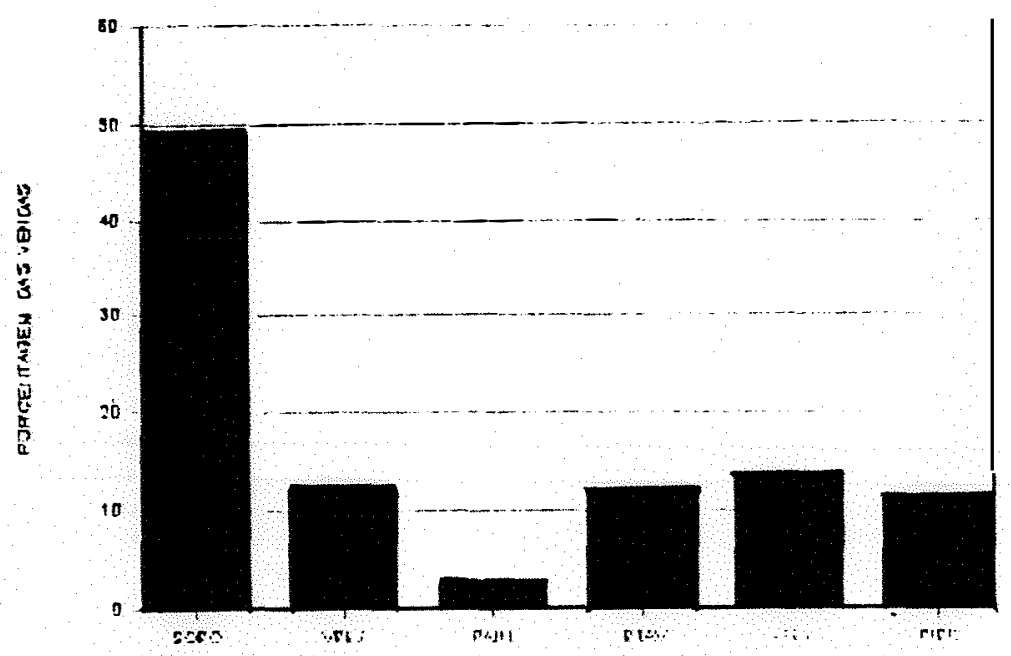

Figura 18 - Franoos E Fros (*) das vendas varejões de piracicaba $(00 / 01)$.

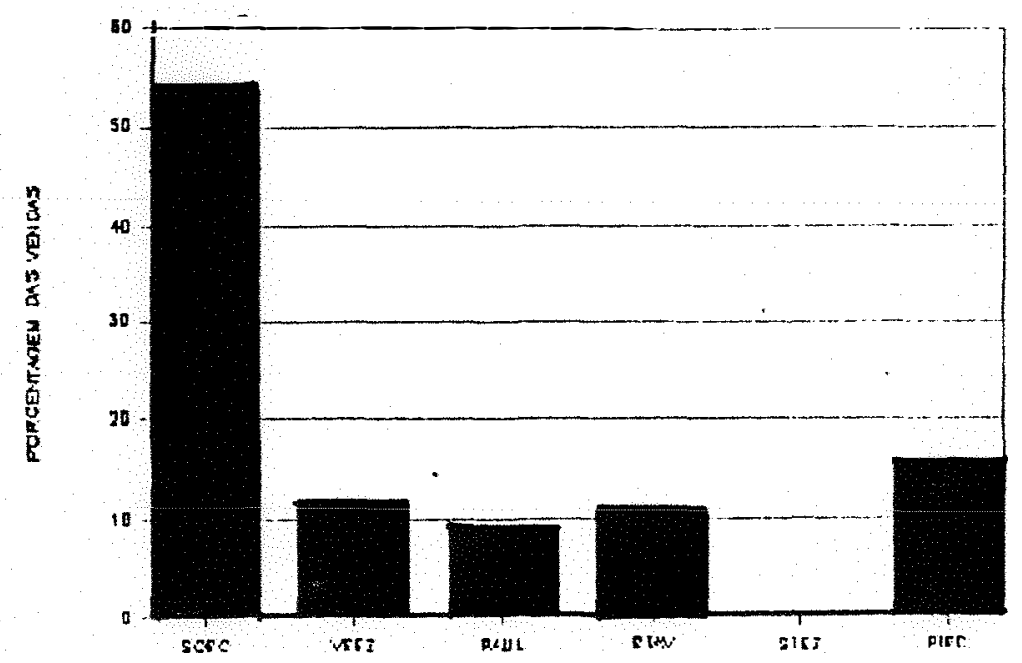

Figura 18 - MIUdos (\%) das vendas varejôes de Piracicaba (00/91). 


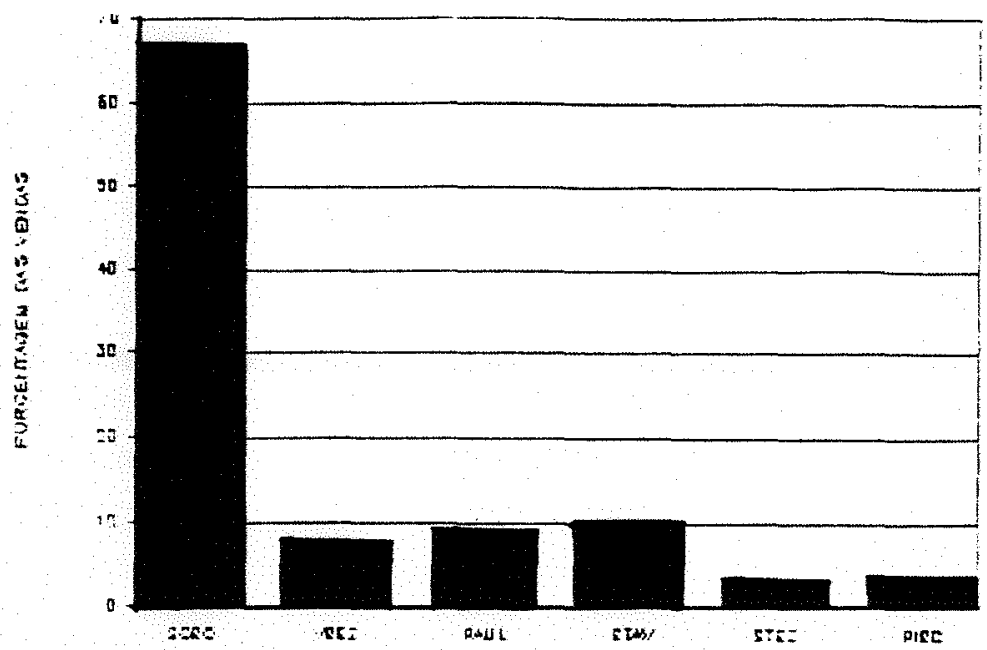

82.

Figura 20 - PEIXEs (\%) das vendas varejöes de Piracicaba (06/O1).

Caracteristicas dos usuários dos Varejões

A SEMA realiza frequentemente pesquisas para avaliação da performance dos varejôes. Efetuamos a tabulacão de algumas destas informaçóes para 10 varejinhos Móveis e 3 varejöes, conforme Tabela 23, a pesquisa mostra que em média $79 \%$ possuem o hábito de efetuar suas compras todas as semanas, e que $78 \%$ dos entrevistados deslocam-se a pé até os locais de compra, abaixo desta média encontram-se todos os varejôes considerados; $22 \%$ para o varejão Piracicamirim 66\% Santa Terezinha e 38\% Sorocabana. O varejão do Piracicamirim possui maior participacão no número de consumidores que utilizam-se de veiculos próprios; $71 \%$ contra 25\% de Santa Terezinha e 35\% da Sorocabana. Aqueles que se utilizam de transporte coletivo (ônibus) representam em média $14 \%$ nos varejôes e $6 \%$ nos varejinhos.

Quanto ao número de bairros atendidos, notamos que as unidades cobrem vários deles, especialmente os varéjôes, devido a sua localizacão estratégica e sua solidifi- 
83.

cacão como mercado permanente e instalacões fixas. Quanto aos varejinhos móveis, a maíoria atende no máximo 7 bairros. com excecão do varejinho Sonia que atende aproximadamente 17 bairros, devido a sua localizacão; ele é instalado no terminal de onibus urbano no Bairro vila Sonia, onde existe adensamento populacional elevado se comparado a outras regiǒes.

Tal pesquisa inclui também uma questão para identificacão de nivel de renda dos consumidores das unidades de comercializacão, porém solicita a profissão de quem esta comprando. Isto não dá a idéia da renda ramiliar. porque normalmente as compras são feitas pelas donas de casa, o que ficou evidente na tabulacão das respostas com a grande maioria para donas de casa.

Tomando por base as respostas efetuadas em outras profissões, podemos identificar que em todos os varejinhos e nos varejores de Santa Terezinha e Sorocabana, a maioria dos compradores pertencem à Classe Média Baixa. A malor incidência está relacionada com profissốes que requerem esforco bracal, com excecão do varejão Piracicamirim com profissôes de nivel médio e até superior. 
84.

Tabela 23. Caracteristicas dos Usuários dos Varejões e Varejinhos de Piracicaba-SP. 09/91

\begin{tabular}{|c|c|c|c|c|c|c|c|}
\hline \multirow{2}{*}{ UNIDADE } & \multirow{2}{*}{$\begin{array}{l}N^{\circ} \text { BAIRROS } \\
\text { ATENDIDOS }\end{array}$} & \multicolumn{3}{|c|}{ TRANSPORTE } & \multicolumn{3}{|c|}{ FREQUENNCIA } \\
\hline & & 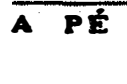 & ONIBUS & $\begin{array}{l}\text { VEICULO } \\
\text { PROPRIO }\end{array}$ & $\begin{array}{l}\text { TODA } \\
\text { SEMANA }\end{array}$ & $\begin{array}{l}\mathbf{B X} \\
\text { MESS }\end{array}$ & $\begin{array}{l}\text { MENOS } \\
\text { 9X MÊS }\end{array}$ \\
\hline \multicolumn{8}{|l|}{ VAREJÕES } \\
\hline Piracicamirim & 29 & 22 & 7 & 71 & 58 & 10 & 29 \\
\hline sta Terezinha & 15 & 00 & D & 25 & 82 & 0 & ○ \\
\hline sorocabana & 79 & $3 \mathbf{8}$ & 27 & 35 & 70 & 10 & 11 \\
\hline \multicolumn{8}{|l|}{ VAREJINHOS } \\
\hline $\begin{array}{l}\text { N. Amb́rica } \\
\text { Caxambú }\end{array}$ & 7 & 92 & 4 & 4 & 80 & 4 & 10 \\
\hline Jupid & 1 & 93 & 4 & $\mathbf{3}$ & 94 & $\mathbf{3}$ & 3 \\
\hline sonia & 17 & 88 & 4 & 8 & 70 & 7 & 14 \\
\hline cecap & 7 & 90 & 4 & - & 9 3 & 10 & 7 \\
\hline Caxambú & 6 & 88 & 10 & 2 & 84 & 7 & 0 \\
\hline Balbo & 4 & 91 & 0 & $\mathbf{3}$ & 87 & 7 & 0 \\
\hline v. Industrial & 4 & 80 & 0 & 5 & 74 & 20 & 0 \\
\hline I panema & $\mathbf{3}$ & 91 & 0 & $\mathbf{3}$ & 68 & 5 & 27 \\
\hline média & - & 78 & $\boldsymbol{\theta}$ & 14 & 70 & 10 & 11 \\
\hline
\end{tabular}

Fonte: SEMA - Pesquisa de Opiniåo (1991)

Quanto à opinião dos consumidores sobre preco, qualidade e diversidade dos produtos comercializados nos varejões e varejinhos, a pesquisa demonstra boa aceitacão, conforme mostrados nas Tabelas 24 e 25.

Preços praticados: Em média 45\% consideram o nivel dos precos praticados como bons, contra $28 \%$ ótimo, $25 \%$ regular e $2 \%$ como ruim.

Diversidade dos Produtos: Em média $47 \%$ consideraram a diversidade dos produtos como boa; $29 \%$ como 
Stima; $21 \%$ como regular e $3 \%$ como $r$ uim.

Qualidade: Em media $51 \%$ consideram a qualidade dos produtos como boa; $35 \%$ otima; $13 \%$ como regular e $1 \%$ como ruim.

Destacamos que entre as unidades pesquisadas, - varejinho de Vila Sonia apresentou um dos melhores indices de aceitacão. A metade dos consumidores do varejão da Sorocabana consideram os produtos de stima qualidade, porém 44\% consideram seus precos regulares.

- varejão do Piracicamirim apresenta um perfil de consumidor de renda relativamente mais el evada que outras unidades -pesquisadas, inclusive devido a sua localizacão, onde existe grande incidência da classe média. Isto fica evidenciado pela malor utilizacão de veículos nas compras e com a menor frequência. 
86.

Tabela 24. Classificacão das Unidades dos Varejōes e Varejinhos de Acordo com as opiniões dos Usuários sobre Transporte Coletivo e Diversidade dos Produtos Piracicaba -SP - 09/91

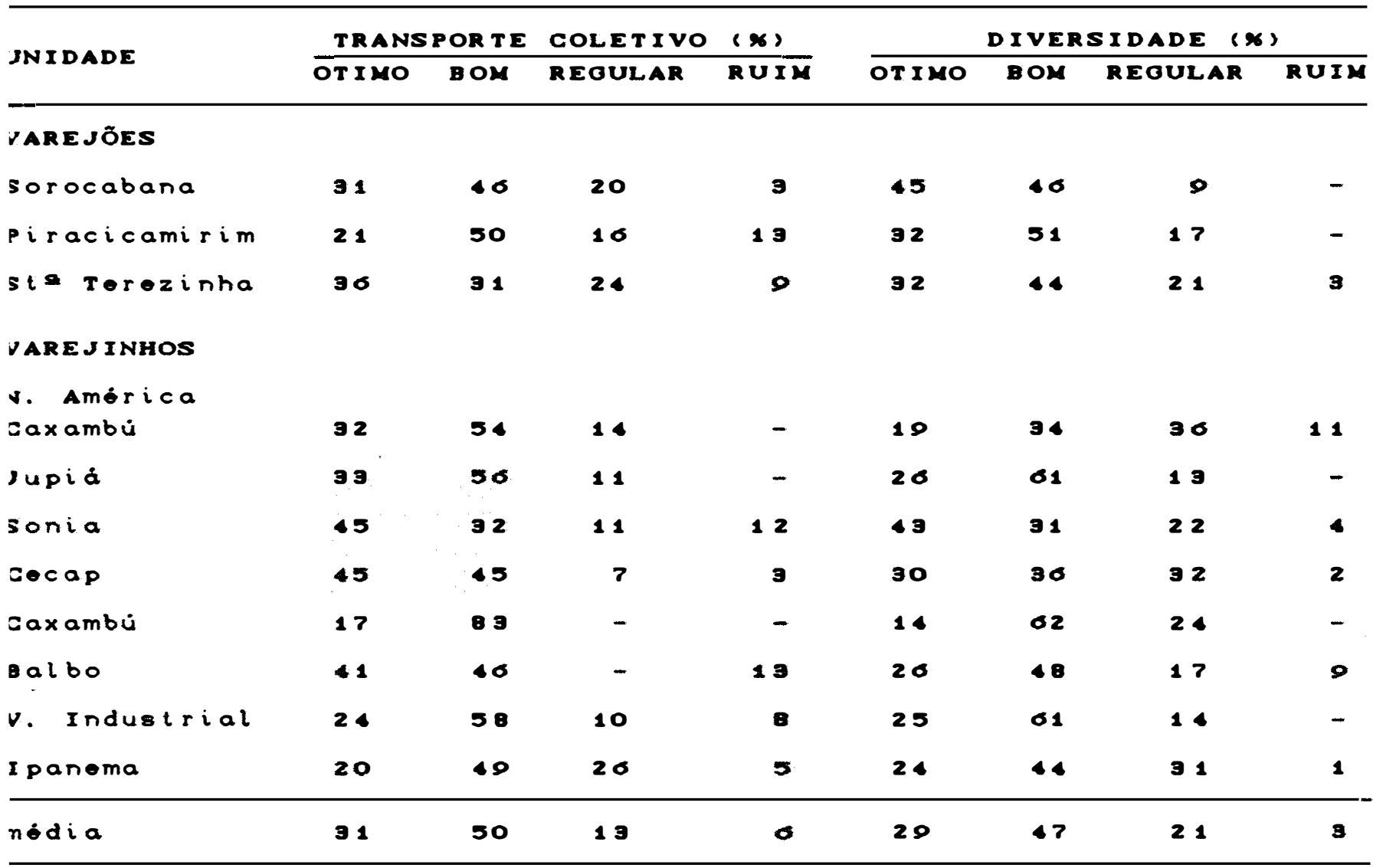

Fonte: SEMA - Pesquisa de Opinião (1991) 
87.

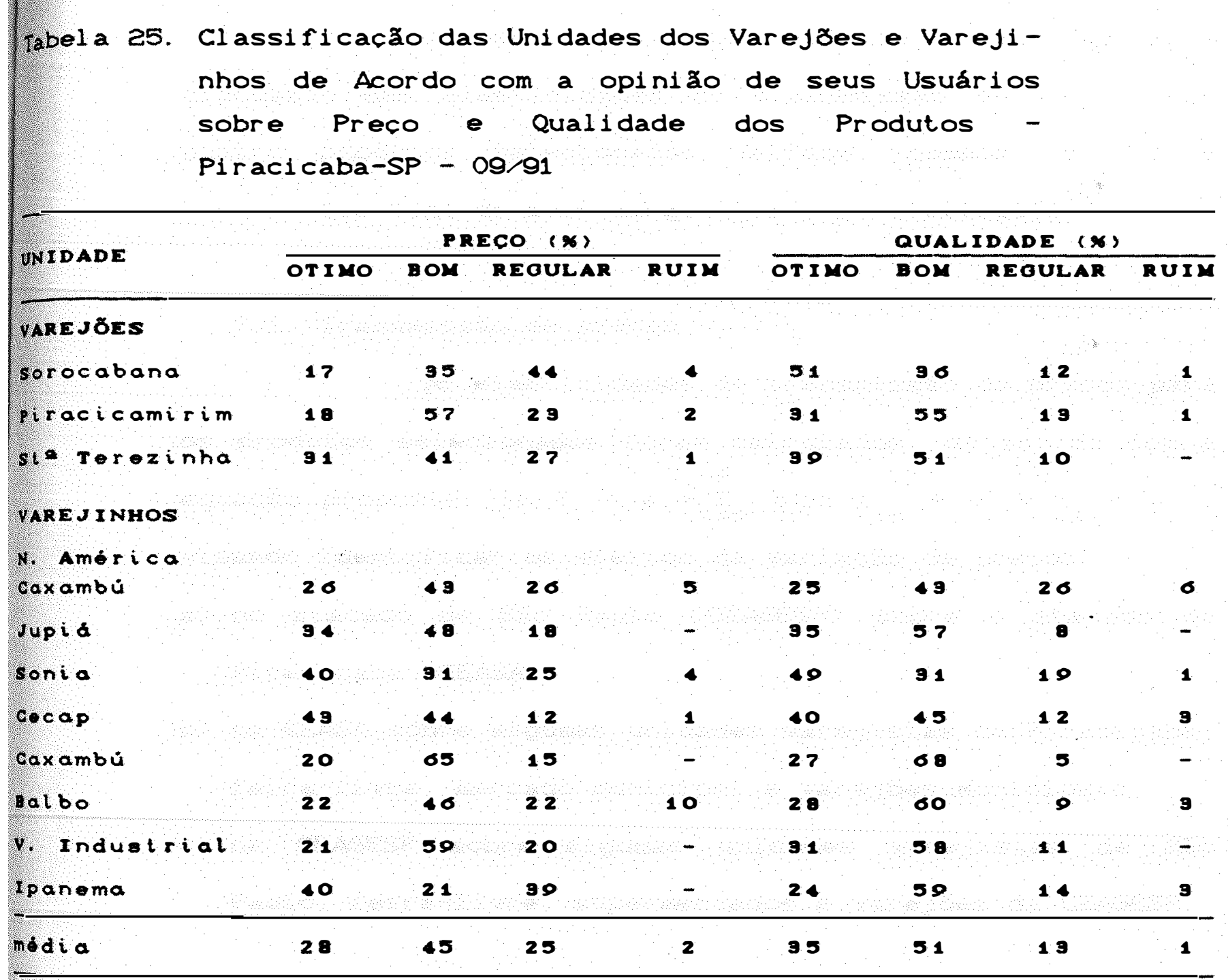

Fonte: SEMA - Pesquisa de Opinião (1991) 
88.

\section{ANÁlisE DA POLítica DE PREçOS DOS VAREJõEs DE PIRACICABA} Apresentamos neste capitulo os resultados e discussão das elasticidades de transmissão de precos dos quatro produtos selecionados; alface, tomate, batata e banana, bem como de suas margens de comercializacão.

\subsection{Transintssão de precos}

As elasticidades de transmissão de precos para os produtos selecionados for am calculados, de acordo com a equacão proposta: $\ln Y_{t}=a+\sum_{i=0}^{d} b_{i} \ln X_{t-i}+w_{t}+t_{t}+u_{t}$, visando identificar os efeitos da variacão de precos:

a) no atacado de São Paulo (CEAGESP) sobre o atacado de Piracicaba CCEASA ;

b) na CEASA sobre algumas unidades varejistas de Piracicaba; feira-livre, mercado municipal e varejós Municipais;

c) na CEAGESP sobre algumas unidades varejistas de São Paulo, reira-livre, supermercados e varejöes da CEAGESP.

7.1.1. Efeito das yariacóes de precos do atacado de Sáo Paulo sobre o atacado de Piracicaba Os coeficientes de elasticidade de transmissão de precos apurados para os produtos selecionados para detectar influências do atacado das quintas e sextas-feiras de São Paulo sobre o atacado das sextas-reiras em Piracicaba, aparecem na Tabela 26 para todos os produtos. Os 
89.

testes econométricos para as equacóes estimadas para cada produto encontram-se nas Tabelas 27, 28, 29 e 30.

\subsubsection{Análise da transmissão de precos por produto}

\section{Alface}

A alface apresenta o menor coeficiente de transmissão; para cada 10\% de variacão dos precos no atacado de São Paulo ocorreu uma variacão de 1 mediato em média de $3,5 \%$ no atacado de Piracicaba $(3,4 \%$ da quinta-feira e $3,6 \%$ da sexta-felral. Se esta variacão de $10 \%$ persistir por 4 semanas a transmissão para Piracicaba será de $5,5 \%$ em média (5,7\% da quinta-feira e $5,4 \%$ da sexta-feira).

\section{Tomate}

Para cada 10\% de variacão no preco do tomate no atacado em São Paulo ocorrerá uma transmissão no mesmo momento de, em média, 4,9\% C $5,0 \%$ da quinta-feira e 4,7\% da sexta-feira) e de cerca de $8,1 \%(8,0 \%$ da quinta-feira e $8,1 \%$ da sexta-feiral se esta variacão persistir por 4 semanas.

\section{Batata}

Apresenta a maior transmissão, para cada $10 \%$ de variacão no preço do atacado em São Paulo ocorrerá uma variação de $5,6 \% \quad 5,8 \%$ da quinta-feira e $5,4 \%$ da sexta-feira), em média, de 1 mediato e de $8,9 \%(9,0 \%$ da quinta-feira e $8,8 \%$ da sexta-feiral em 4 semanas, se a variacão de $10 \%$ em São Paulo, persistir. 


\section{Banana}

- preco de banana no atacado de Piracicaba sofrerá uma variacão em média de $4,8 \%$ de i mediato face a uma variacão de $10 \%$ do atacado em São Paulo (5,0\% da quintaffeira e 4,7\% da sextaffeiras; e de $7,3 \%$ se esta variacão persistir por 4 semanas.

Tabela 26. Coeficientes de transmisssão de precos do atacado São Paulo para o atacado de Piracicaba

\begin{tabular}{|c|c|c|c|c|c|c|c|}
\hline \multirow{2}{*}{ PRODUTO } & YARI AVEL & \multicolumn{5}{|c|}{$\begin{array}{l}\text { COEFICIENTE DE VAR. INDEP ENDENTEC bH) } \\
\text { NO DE DEFASAGENS (d) }\end{array}$} & \multirow{2}{*}{$\sum_{d=0}^{d=4}$} \\
\hline & DEP. INDEP. & 0 & 1 & 2 & 3 & 4 & \\
\hline Al face & $C P_{2}$ & $\begin{array}{l}0.34 \\
0.30\end{array}$ & $\begin{array}{l}0.20 \\
0.22\end{array}$ & $\begin{array}{l}0.04 \\
0.02\end{array}$ & $\begin{array}{l}-0.03 \\
-0.02\end{array}$ & $\begin{array}{r}0.02 \\
-0.04\end{array}$ & $\begin{array}{l}0,57 \\
0,54\end{array}$ \\
\hline Tomale & $\begin{array}{l}C P_{2} \\
C P_{1}\end{array}$ & $\begin{array}{l}0.50 \\
0.47\end{array}$ & $\begin{array}{l}0.22 \\
0.18\end{array}$ & $\begin{array}{l}0.03 \\
0.08\end{array}$ & $\begin{array}{c}-0.001 \\
0.01\end{array}$ & $\begin{array}{r}-0,00 \\
0,07\end{array}$ & $\begin{array}{l}0.80 \\
0.81\end{array}$ \\
\hline Batata & $C P$ : & $\begin{array}{l}0.58 \\
0.54\end{array}$ & $\begin{array}{l}0.14 \\
0.18\end{array}$ & $\begin{array}{l}0,08 \\
0,08\end{array}$ & $\begin{array}{l}0.07 \\
0.04\end{array}$ & $\begin{array}{l}0.03 \\
0.00\end{array}$ & $\begin{array}{l}0.80 \\
0.88\end{array}$ \\
\hline Banana. & $C P_{1}$ & $\begin{array}{l}0.50 \\
0.46\end{array}$ & $\begin{array}{l}0,13 \\
0,10\end{array}$ & $\begin{array}{l}0,003 \\
-0,01\end{array}$ & $\begin{array}{l}0,01 \\
0.002\end{array}$ & $\begin{array}{l}0.00 \\
0.12\end{array}$ & $\begin{array}{l}0.73 \\
0.73\end{array}$ \\
\hline
\end{tabular}

\footnotetext{
$C_{t}$ - preco ao atacado de Piracicaba - SP

$E_{1}$ - preco ao atacado de São Paulo - SP - as quintas-feiras $E_{2}$ - preco ao atacado de São Paulo - SP - às sextas-feiras
} 
$\theta 1$.

Tabela 27. Equacão de transmissão de precos de alface ${ }^{1}$ do atacado de São Paulo para o atacado de Piracicaba no periodo de $01 / 85$ à $12 / 90^{2}$.

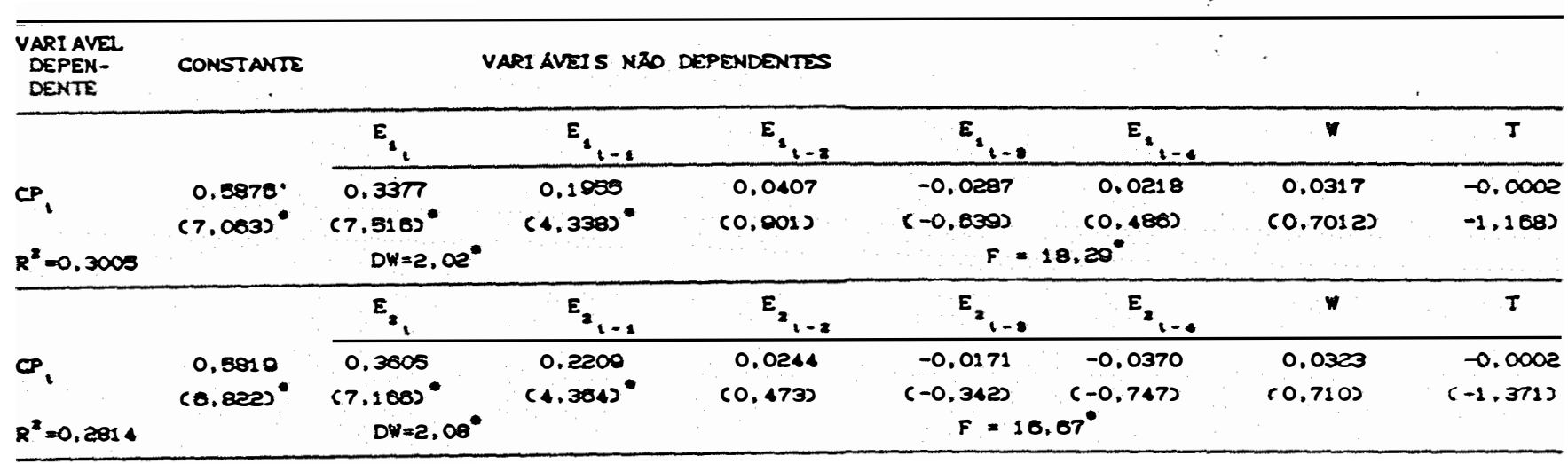

(1) com aplicacão de uma filtragem de primeira ordem

(2) os valores do teste $t$ estão entre parênteses cnivel de significância bilateral )

(*) $1 \%$ - nível de significância.

$C_{t}$ - preco ao atacado de Piracicaba - SP

E - preco ao atacado de São Paulo - SP - ás quintas-feiras

$E_{2}$ - preco ao atacado de São Paulo - SP - ás sextas-feiras 
92.

Tabela 28. Equacão de transmissão de precos de tomate ${ }^{1}$, do atacado de São Paulo para o atacado de Piracicaba no periodo de $01 / 85$ à $12 / 90^{2}$.

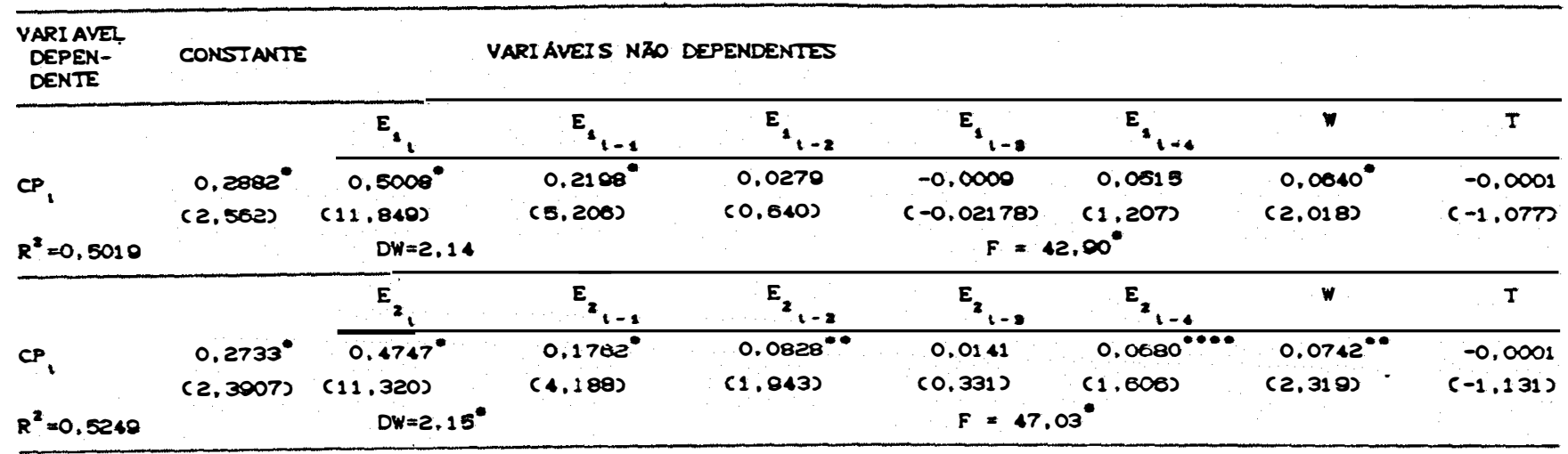

(1) com aplicacão de uma filtragem de primeira ordem

(2) os valores do teste $t$ estão entre parênteses cnivel de significância billateral)

(*) $1 \% ;(* *) 5 \% ;(* * *) 10 \% ;(* * * *) 20 \% ;-$ nivel de significância a

C.P $P_{t}$ - preco ao atacado de Piracicaba - SP

$E_{1}$ - preco ao atacado de São Paulo - SP - ás quintas-feiras

$E_{2}$ - preco ao atacado de São Paulo - SP - ás sextas-feiras 
83.

Tabela 29. Equacão de transmissão de precos da batata ${ }^{1}$ do atacado de São Paulo para o atacado de Piracicaba no periodo de $01 / 85$ à $12 / 90^{2}$.

\begin{tabular}{|c|c|c|c|c|c|c|c|}
\hline $\begin{array}{l}\text { VARI AVEL } \\
\text { DEPEN- } \\
\text { DENTE }\end{array}$ & CONSTANTE & & VARI AVEIS NAO & DEPENDENTES & & & \\
\hline & & $E_{1}$ & $E_{1-1}$ & $E_{1,2}$ & $\varepsilon_{1,0}$ & $\nabla$ & $\mathbf{T}$ \\
\hline \multirow{2}{*}{$C P}$, & 0.0325 & $0.5823^{\circ}$ & $0.1370^{\circ}$ & $0.0783^{\circ 00}$ & $0.0738^{\circ} \quad 0.02500$ & $0.0845^{\circ}$ & 0.0001 \\
\hline & $(0,360)$ & (נהטאל.010) & $(2.5 / 10)$ & (נنלts. (1.) & $(1.372) \quad(0.446)$ & $(2.520)$ & $(1.234)$ \\
\hline \multirow[t]{2}{*}{$R^{2}=0.3023$} & & $D W=2.10$ & & & $F=27.48^{\circ}$ & & \\
\hline & & $E_{2}$ & $E_{2-1}$ & $E_{2,-2}$ & $E_{2, \ldots}$ & $w$ & $T$ \\
\hline \multirow[t]{2}{*}{$\mathbf{C P}_{\mathbf{I}}$} & 0.0010 & $0,5400^{\circ}$ & $0,1504^{\circ}$ & $0.084 \cdots$ & 0,0620 & $0,0030^{\circ}$ & 0,000004 \\
\hline & $(0.407)$ & $(10.802)$ & $(3.155)$ & $(1.083)$ & $(0.745) \quad(1.200)$ & $(2,003)$ & (1.025) \\
\hline$R^{2}=0,3030$ & & $D W=2.15^{\circ}$ & & & $F=27.20^{\circ}$ & & \\
\hline
\end{tabular}

(1) com aplicacão de uma filtragem de primeira ordem para E, e de segunda para $E_{2}$.

(2) os valores do teste $t$ estão entre parênteses cnível de significância bilateral J

(*) $1 \% ;(* *) \quad 5 \% ;(* * *) 10 \% ;(* * * *)$ 20\%:-nivel de significância

$C_{1}$ - preco ao atacado de Piracicaba - SP

$E_{1}$ - preco ao atacado de São Paulo - SP - às quintas-feiras

$E_{2}$ - preco ao atacado de São Paulo - SP - às sextas-feiras 
94.

Tabela 30. Equacão de transmissão de precos da banana ${ }^{1}$ do atacado de São Paulo para o atacado de Piracicaba no periodo de $01 / 85$ à $12 / 90^{2}$.

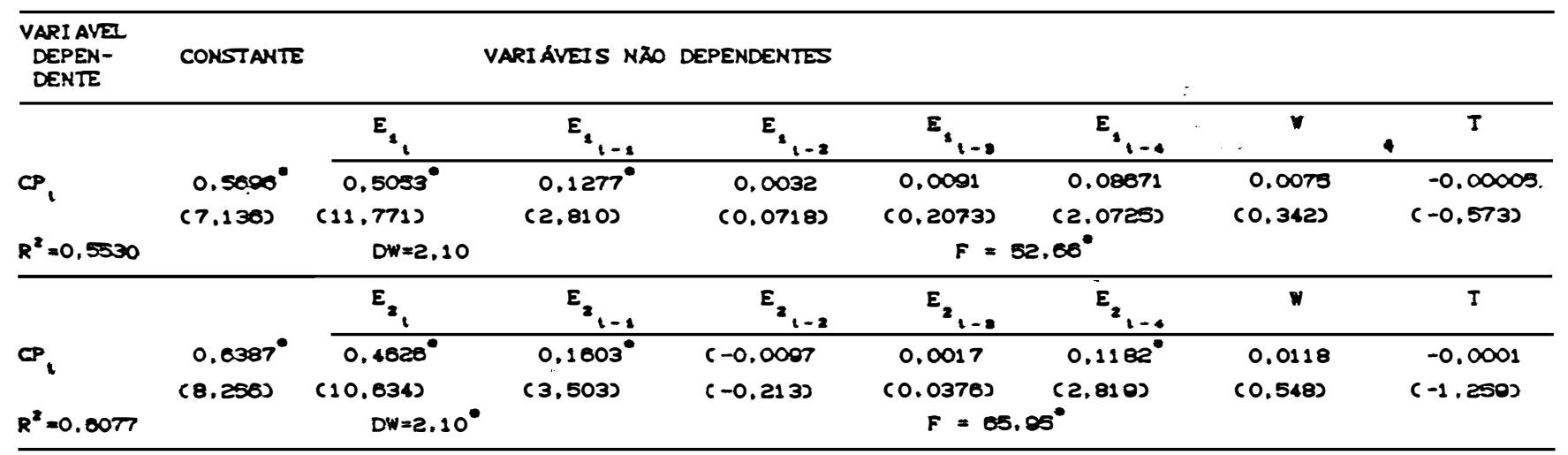

(1) com aplicacão de uma filtragem de primeira ordem

(2) os valores do teste $t$ estão entre parênteses cnível de significância bilateral)

(*) $1 \% ;(* *) 5 \% ;(* * *) 10 \% ;(* * * *) 20 \% ;-$ nivel de significância

$C P_{1}$ - preco ao atacado de Piracicaba - SP

$E_{1}$ - preco ao atacado de São Paulo - SP - ás quintas-feiras

$E_{2}$ - preco ao atacado de São Paulo - SP - ás sextas-feiras 
95. 7.1.2. Efeitos das variacões de precos do atacado
sobre unidades varejistas

7.1.2.1. Para Piracicaba - SP

Conforme Tabel as 31, 32, 33, 34 e 35, podemos

verificar que as varlacóes de precos do atacado de Piracicaba são transferidos em maior porcentagem para os varejôes, de imediato, e que a transferência em quatro semanas é menor para tomate e batata e malor para alface e banana em comparacão com o mercado municipal e feiraslivres. Os testes econométricos para as equacões estimuladas para cada produto encontram-se nas Tabelas 32, 33, 34 e 35.

Alface

Para cada variacão de $10 \%$ nos precos do alface no atacado de Piracicaba ocorre uma transferência de $5,1 \%$ para os varejôes e de 3,0\% para a feira-livre e mercado municipal, de imediato. Ocorrerá uma transferência de $8,6 \%$ para os varejóes, $8,0 \%$ e $7,5 \%$ para as feiras e mercado municipal respectivamente, se a variacão de $10 \%$ no atacado de Piracicaba persistir por 4 semanas.

\section{Tomate}

Para cada variacão de $10 \%$ nos precos do tomate no atacado de Piracicaba ocorre uma transferência de 6, 3\% para os varejôes, $4,5 \%$ para as felras e $5,1 \%$ para o mercado municipal, de 1 mediato. Se a variacão de $10 \%$ do atacado permanecer por 4 semanas a transferência será de 9, 3\% para os varejôes $10 \%$ para o mercado municipal e 9,6\% para as feiras-1ivres. 
96.

\section{Batata}

- atacado transfere, de cada $10 \%$ de variacão do preco da batata, $7,4 \%$ para os varejóes, $4,7 \%$ para as feiras e 5,3\% para o mercado municipal de imediato. Se o aumento de $10 \%$ permanecer por 4 semanas ocorrerá uma transferência de 9,2\% para os varejốes e de mais de $10 \%$ para as feiras e mercado municipal.

\section{Banana}

Para cada 10\% de variacão dos preços da banana no atacado ocorrerá uma tranferência de imediato de $5,9 \%$ para os varejơes, $4,0 \%$ e $5,2 \%$ para as feiras e mercados municipal respectivamente. Ocorrerá uma transferência após quatro semanas, se o aumento de $10 \%$ persistir neste periodo, de $8,2 \%$ para os varejôes e de $5,2 \%$ e $6,4 \%$ para as feiras e mercado municipal respectivamente.

Constatamos, também, através da Tabela 31 , que as feiras-livres, dentre as unidades varejistas consideradas, apresentam os menores indices de transmissão de imediato. Isto é promovem variacóes, de preços, menores no primeiro momento, passando a distribui-las nas outras semanas seguintes. 
97.

Tabela 31. Coeficientes de transmisssão de precos do atacado de Piracicaba para o varejo de Piracicaba

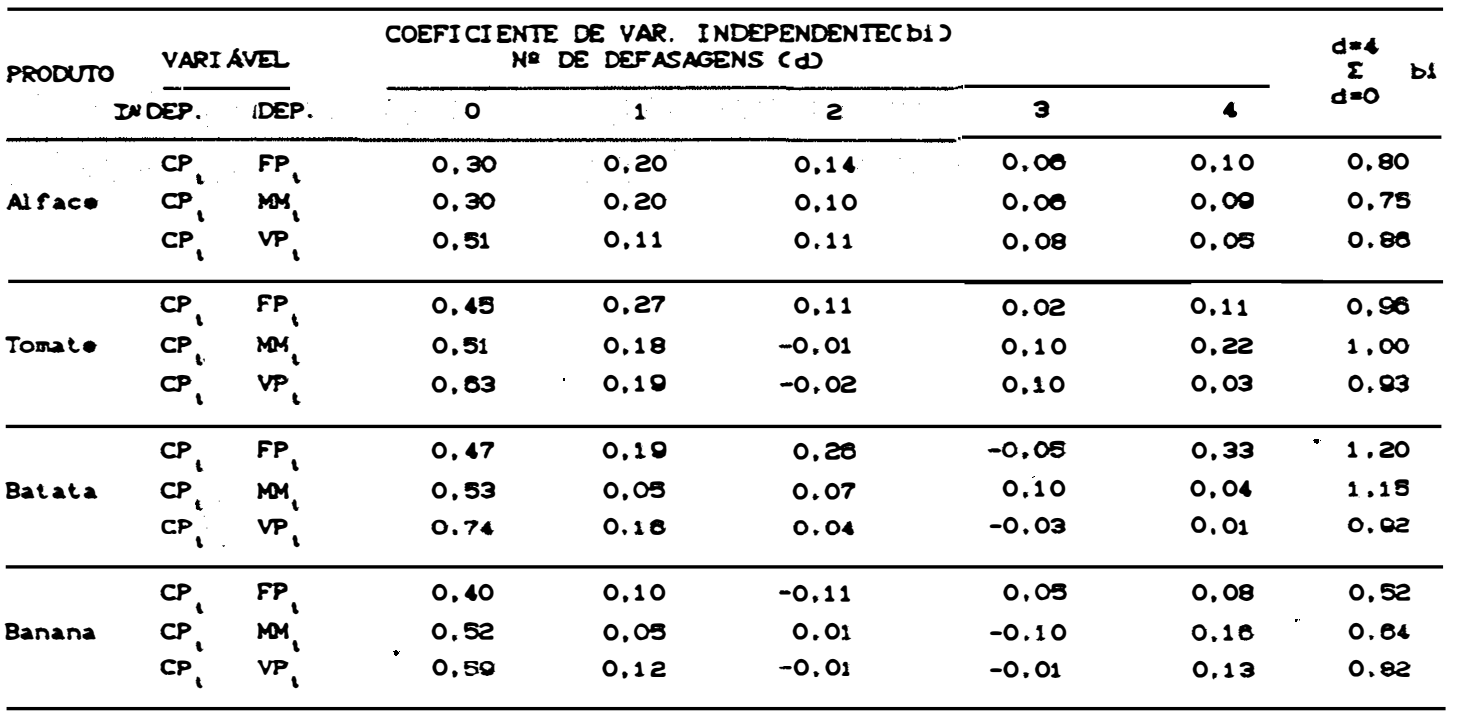

CP $P_{t}$ - preco ao atacado de Piracicaba - SP

$F P_{t}$ - preco na feira-livre de Piracicaba - SP

$M M_{t}$ - preco no mercado municipal de Piracicaba - SP

VP $P_{t}$ - preco no varejão de Piracicaba - SP 
98.

Tabela 32. Equacão de transmissão de precos de alface ${ }^{1}$ do atacado de Piracicaba para o varejo de Piracicaba ${ }^{2}$.

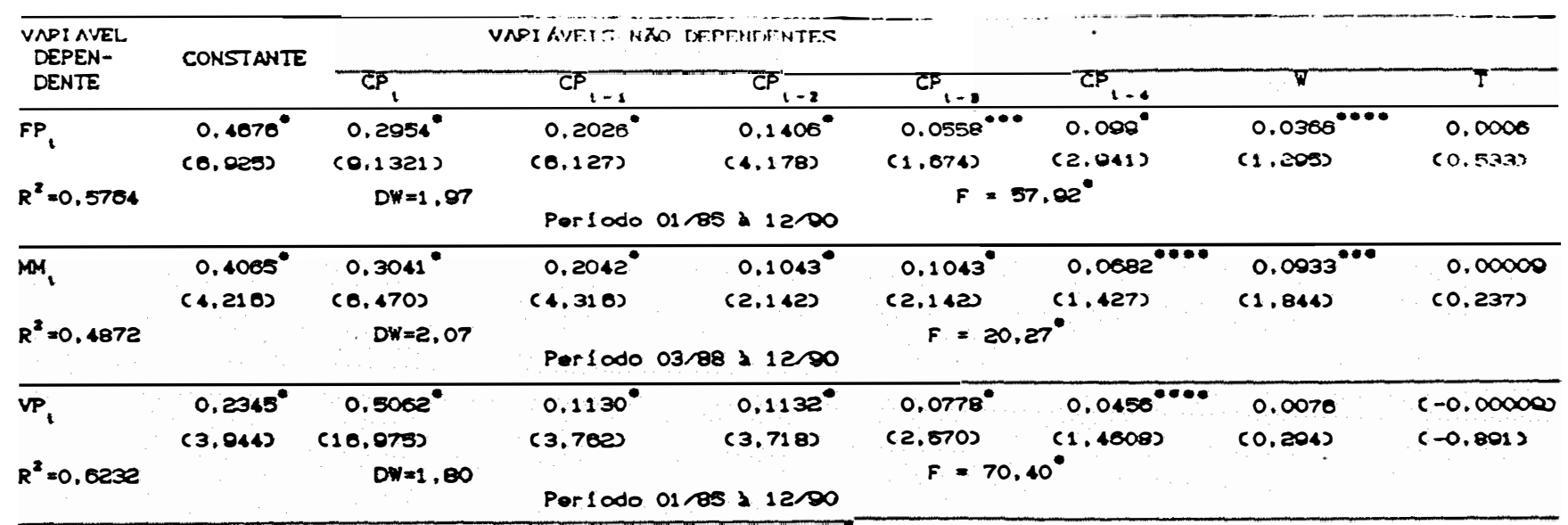

(1) com aplicação de uma filtragem de primeira ordem

(2) entre parênteses estão os valores para o teste $t$ cnivel de significância bilateral s

(*) $1 \% ;(* *) 5 \% ;(* * *) 10 \% ;(* * * *) 20 \% ;-$ nivel de significância a

CP - preco ao atacado de Piracicaba - SP

$F_{1}$ - preco na feira-livre de Piracicaba - SP

$M M_{t}$ - preco no mercado municipal de Piracicaba - SP

VP, - preco no varejão de Piracicaba - SP 
99.

Tabela 33. Equacão de transmissão de precos de tomate ${ }^{1}$ do atacado de Piracicaba para o varejo de Piracica$\mathrm{ba}^{2}$.

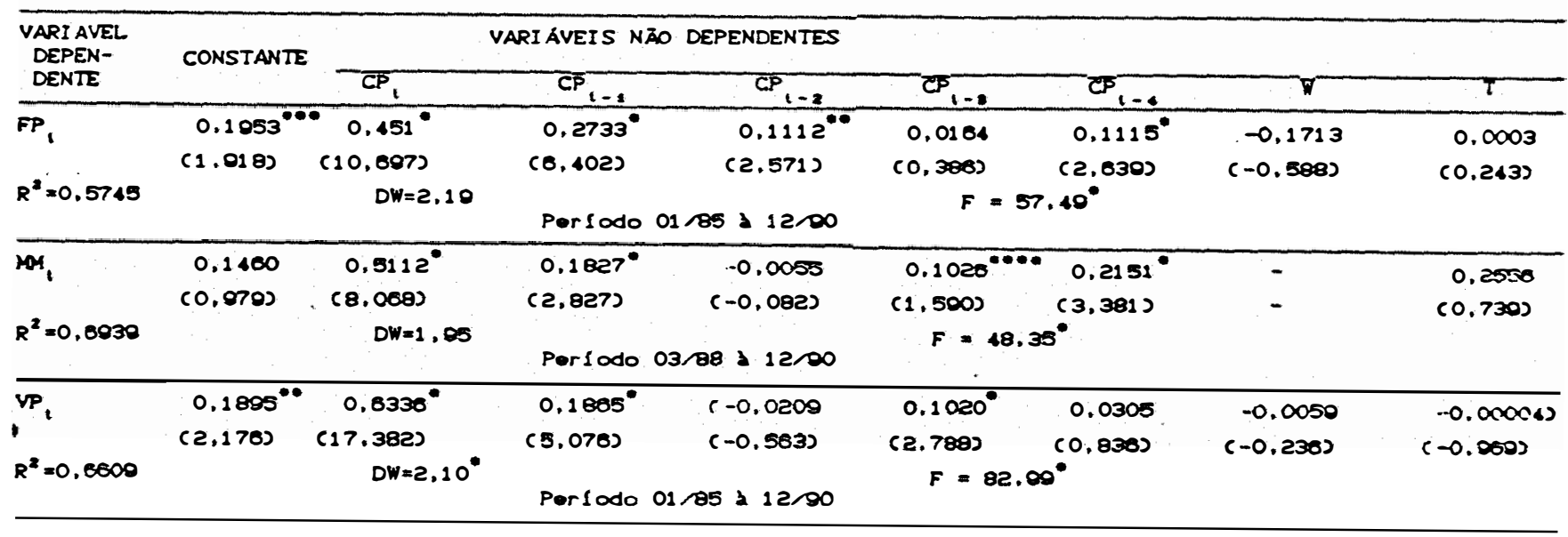

(1) com aplicacão de uma filtragem de primeira ordem

(2) entre parênteses estão os valores para o teste $t$ Cnível de significância bilateral)

(*) $1 \% ;(* *) \quad 5 \% ;(* * *) 10 \% ;(* * * *) \quad 20 \% ;-$ nivel de significância

$C_{i}$ - preco ao atacado de Piracicaba - SP

$F P_{l}$ - preco na feira-livre de Piracicaba - SP

$M_{t}{ }^{2}$ - preco no mercado municipal de Piracicaba - SP

$V P_{t}$ - preco no varejão de Piracicaba - SP 
100.

Tabela 34. Equação de transmissão de precos de batata ${ }^{1}$ do atacado de Piracicaba para o varejo de Piracica$\mathrm{ba}^{2}$.

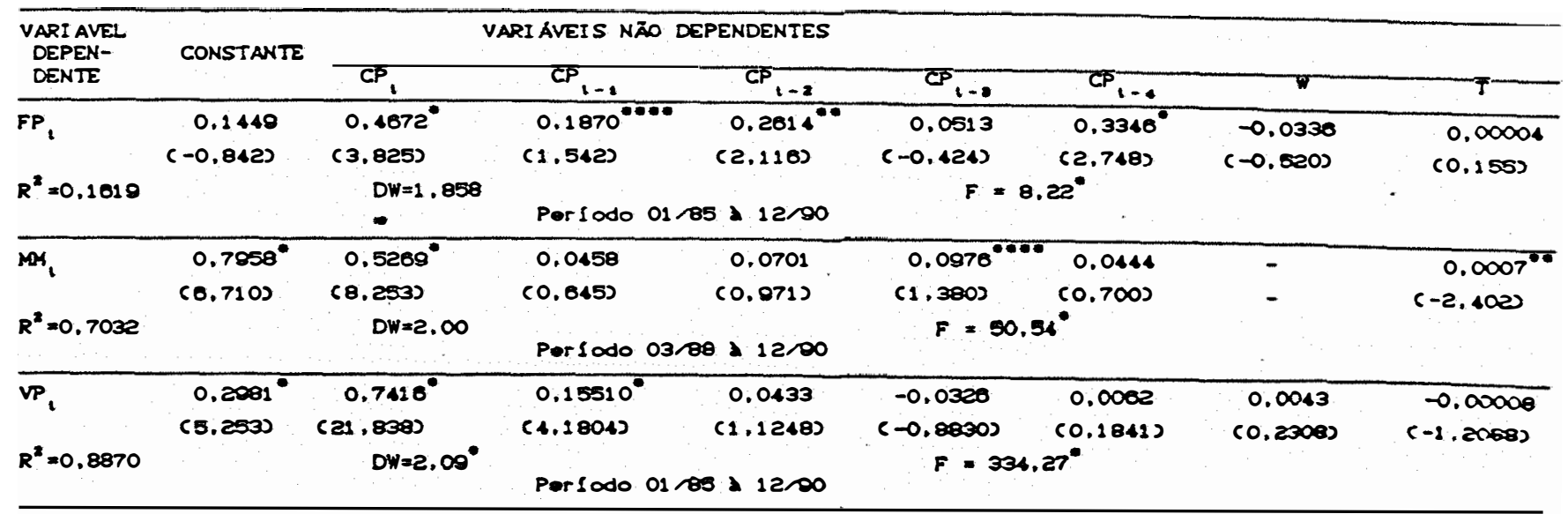

(1) com aplicacão de uma filtragem de primeira ordem

(2) entre parênteses estão os valores para o teste $t$ CnÍvel de significância bilateral)

(*) $1 \% ;(* *) 5 \% ;(* * *) 10 \% ;(* * * *) \quad 20 \% ;-$ nível de significância

$C P_{\ell}$ - preco ao atacado de Piracicaba - SP

$F P_{t}$ - preco na feira-livre de Piracicaba - SP

$M M_{t}$ - preco no mercado municipal de Piracicaba - SP

$V P_{t}$ - preco no varejăo de Piracicaba - SP 
101.

Tabela 35. Equacão de transmissão de precos de banana ${ }^{1}$ do atacado de Piracicaba para o varejo de Piracica$\mathrm{ba}^{2}$.

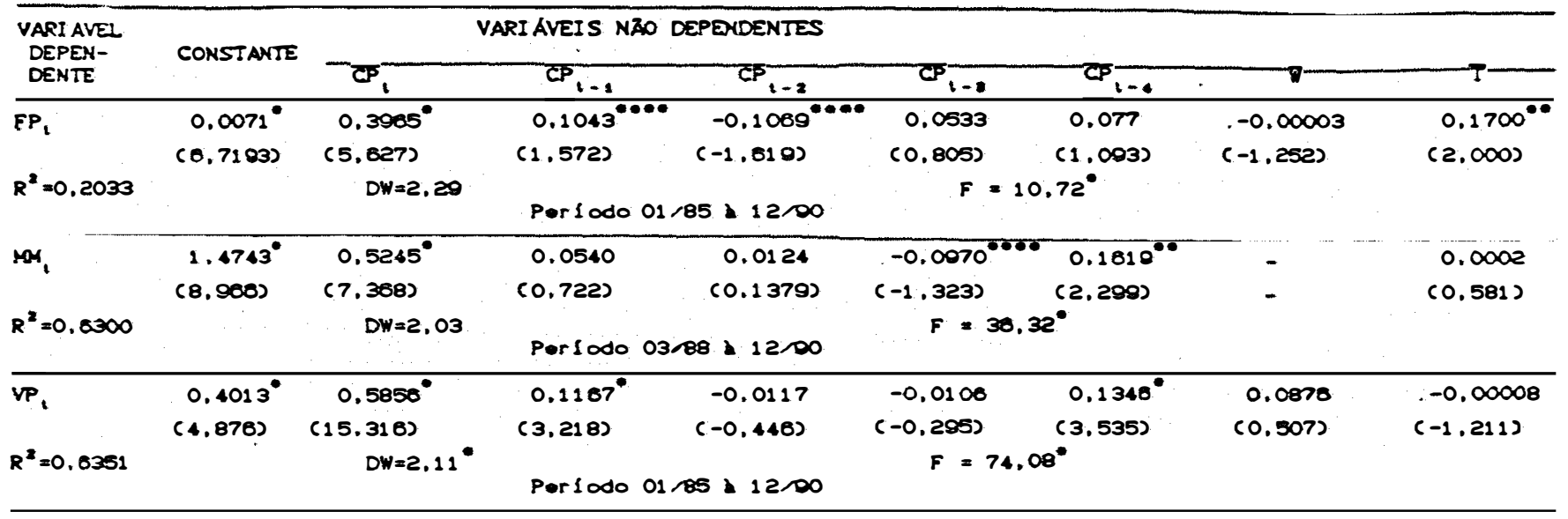

(1) com aplicacão de uma filtragem de primeira ordem para $M M_{t} e P_{t} e$ de segunda para FP

(2) entre parênteses estão os valores para o teste $t$ cnivel de significância bilateral)

(*) $1 \% ;(* *) 5 \% ;(* * *) 10 \% ;(* * * *) 20 \% ;-n f$ vel de significância

CP - preco ao atacado de Piracicaba - SP

FP $P_{t}$ - preco na feira-livre de Piracicaba - SP

$M M_{t}$ - preco no mercado municipal de Piracicaba - SP

$V_{P_{t}}$ - preco no varejão de Piracicaba - SP 
102.

\subsubsection{Para Såo Paulo - SP}

A exemplo dos varejöes de Piracicaba os varejões de São Paulo recebem em maior magnitude, de imediato, as variacões ocorridas no atacado, se compararmos seus indices de elasticidade de transmissão com os das feiras-livres e supermercados, (Tabelas 36, 37, 38, 39 e 40).

As transferências das variacões do atacado em 4 semanas, apresentam maior porcentagem para os varejões, em três produtos, sendo excecão a Batata com a menor transferência (72\%).

\section{Alface}

Para cada variacão de $10 \%$ no atacado de São Paulo ocorrerá uma transferência imediata de $6 ; 5 \%$ nos varejões, $2,1 \%$ nos supermercados $e 2,5 \%$ nas feiras-livres, enquanto que se a variacão do atacado persistir por quatro semanas ocorrerá uma transferência de 8,6\% para os varejões, $7,1 \%$ para os supermercados e 6,4\% para as feiras-1ivres.

\section{Tomate}

Para cada variacão de $10 \%$ no atacado de São Paulo ocorrerá uma transferência imediata de $5,6 \%$ nos varejões, $4,7 \%$ nos supermercados e 4,1\% nas feiras-livres. Se esta variacão do atacado persistir por 4 semanas a transferência será de $8,7 \%$ nos varejões, $6,9 \%$ nos supermercados e $7,4 \%$ nas feiras-1ivres. 
103.

\section{Batata}

Uma variacão de $10 \%$ no atacado de São Paulo se refletirá em uma variacão imediata de $5,0 \%$ nos varejões, $3,6 \%$ nos supermercados $e 2,7$ nas feiras. Se a variacão do atacado permanecer por 4 semanas, a transferência será de $7,2 \%$ para os varejões, 9,9\% para os supermercados e 9,6\% para as feiras.

\section{Banana}

Para cada variação de $10 \%$ no atacado de São Paulo, ocorrerá uma transferência imediata de $3,8 \%$ para os varejões, 2,6\% para os supermercados e 3,7\% para as feiras. Persistindo esta variacão do atacado por 4 semanas, ocorrerá uma transferência de $6,4 \%$ para os varejões, $4,6 \%$ para os supermercados e de 3,9\% para as feiras. 
104

Tabela 36. Coeficiente de transmissão de precos do atacado de São Paulo para o varejo de São Paulo.

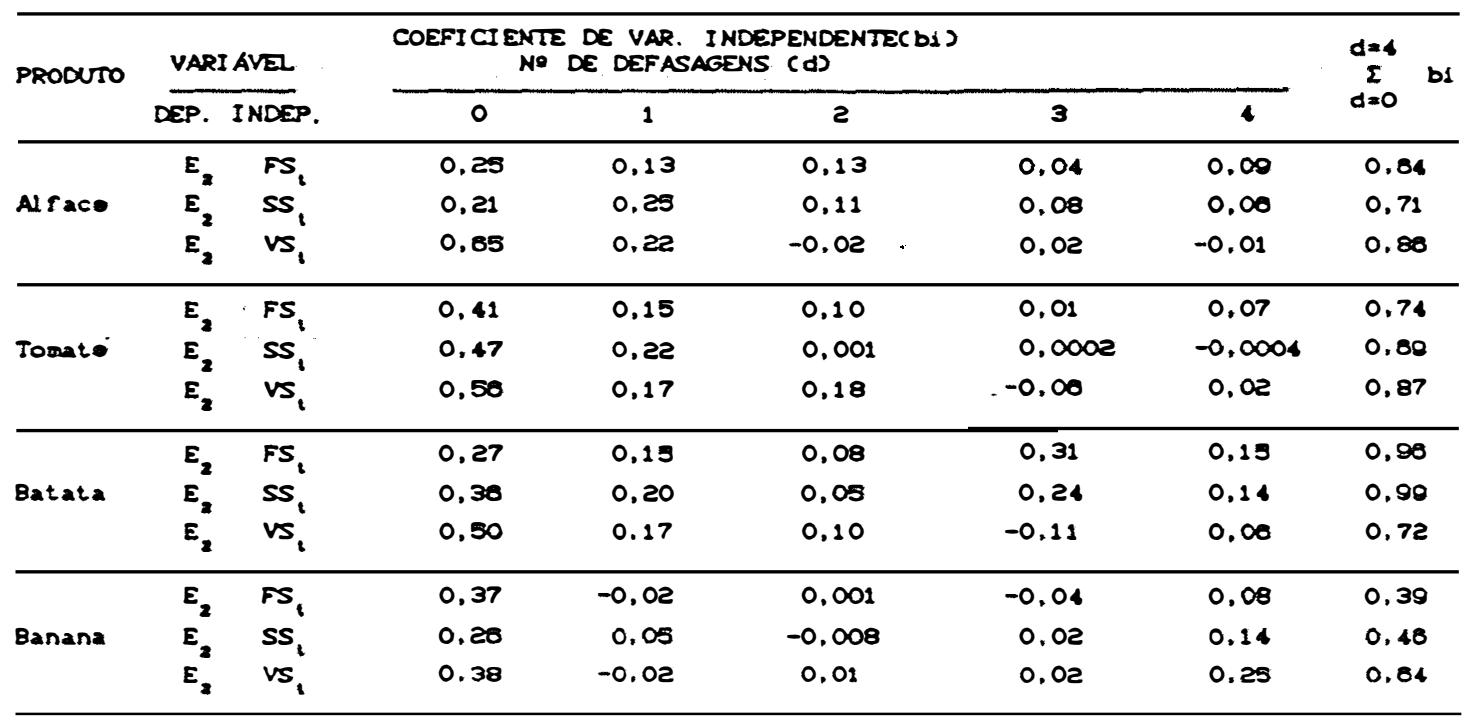

$E_{2}$ - preco ao atacado de São Paulo - SP ás sextas-feiras

FS ${ }_{\ell}$ - preco na reira-livre de São Paulo - SP

$S S_{t}$ - preco no supermercado de São Paulo - SP

$V S_{t}$ - preco no varejão de São Paulo - SP 
Tabela 37. Equacão de transmissão de precos da al face ${ }^{1}$ do atacado de São Paulo para o varejo de São Pauloz.

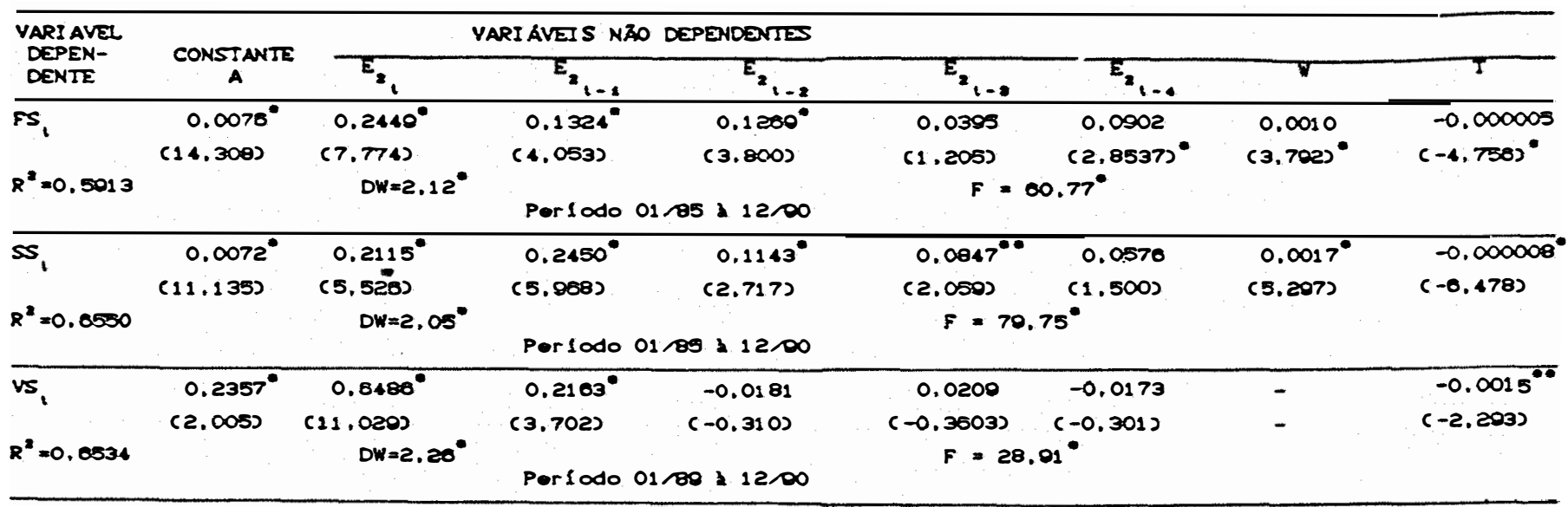

(1) com aplicacão de uma filtragem de primeira ordem para vS e de segunda para $S S_{t}$ e $F S_{t}$

(2) entre parênteses estão os valores para o teste $t$ Cnivel de significância bilateral)

(*) $1 \% ;(* *) 5 \% ;(* * *) 10 \% ;(* * * *) 20 \% ;-$ nivel de significância

$E_{2}$ - preco ao atacado de São Paulo - SP ás sextas-feiras

$F S_{t}$ - preco na feira-livre de São Paulo - SP

$S S_{\ell}$ - preco no supermercado de São Paulo - SP

VS $S_{\ell}$ - preco no varejão de São Paulo - SP 
106.

Tabela 38. Equacão de transmissão de precos da tomate ${ }^{1}$, do atacado de São Paulo para o varejo de São Paulo ${ }^{2}$.

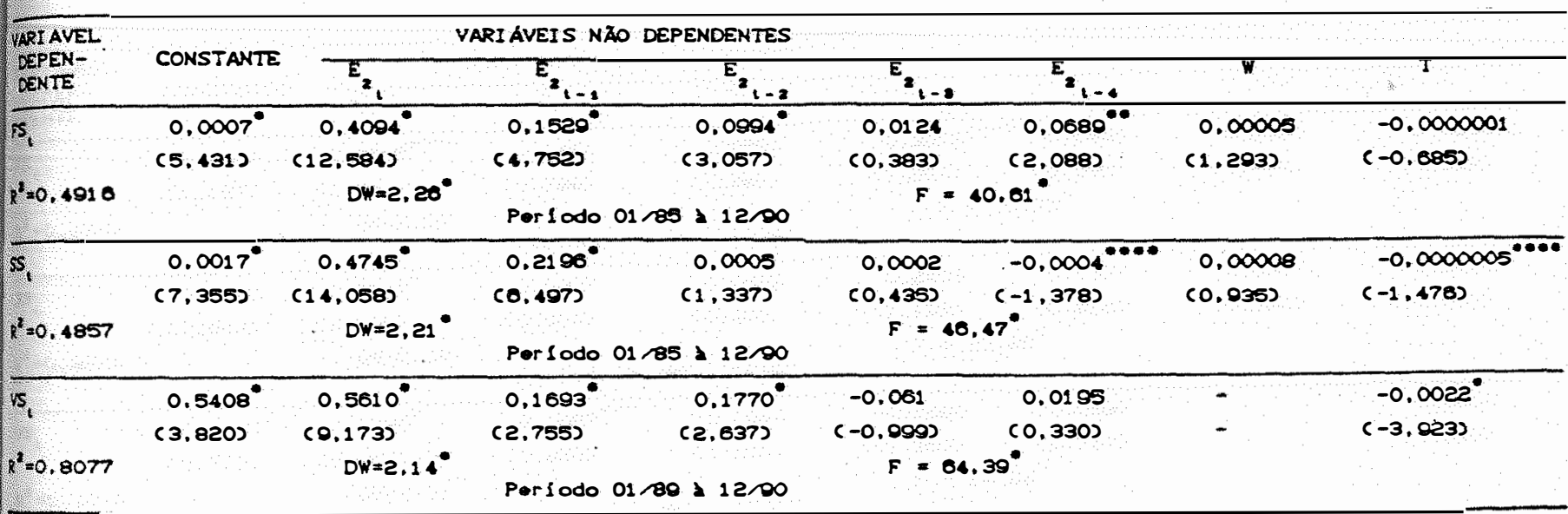

(1) com aplicacão de uma filtragem de primeira ordem

(2) entre parênteses estão os valores para o teste $t$ cnivel de significância bilaterals

(*) $1 \% ;(* *) 5 \% ;(* * *) 10 \% ;(* * * *) 20 \% ;-n f$ vel de significância

$E_{2}$ - preco ao atacado de São Paulo - SP ás sextas-feiras

$F S_{1}$ - preco na feira-livre de São Paulo - SP

$S S_{l}$ - preco no supermercado de São Paulo - SP

$V S_{t}$ - preco no varejão de São Paulo - SP 


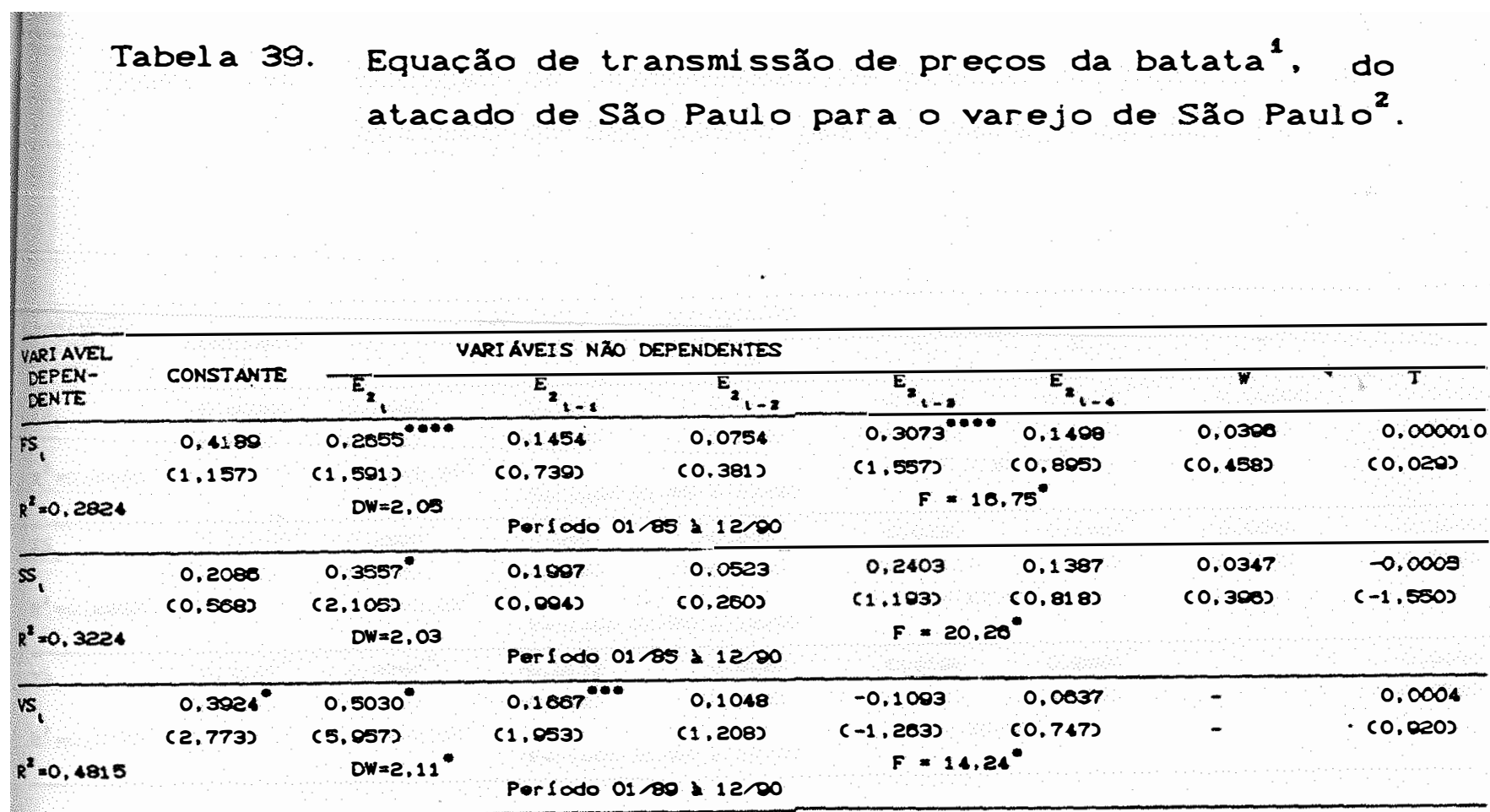

(1) com aplicacão de uma filtragem de primeira ordem para VS e de segunda para $F S_{t}$ e $S S_{t}$

(2) entre parênteses estão os valores para o teste $t$ cnIvel de significância bilateral)

(*) $1 \% ;(* *) \quad 5 \% ;(* * *) 10 \% ;(* * * *)$ 20\%;-nivel de significância

E. - preco ao atacado de São Paulo - SP ás sextas-feiras

FS - preco na feira-livre de São Paulo - SP

SS

VS - preco no varejão de São Paulo - SP 
108.

Tabel a 40. Equacão de transmissão de precos da banana ${ }^{1}$, do atacado de São Paulo para o varejo de São Paulón.

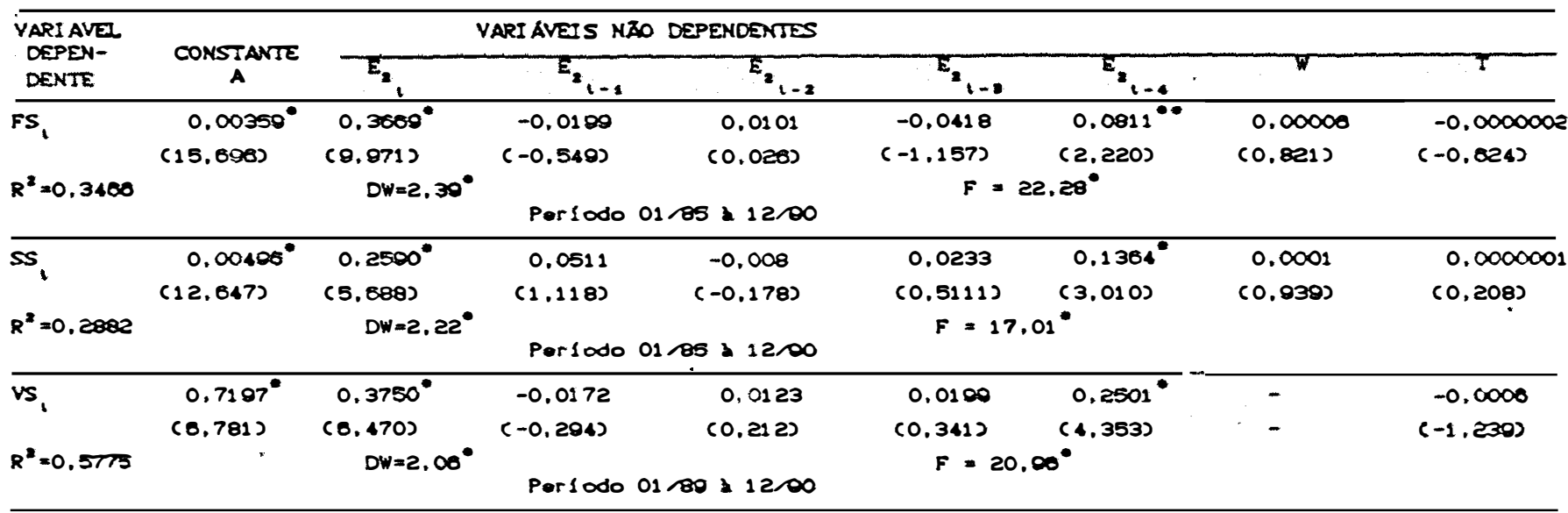

(1) com aplicação de uma filtragem de primeira ordem para VS e de segunda para FS $S_{t} S_{t}$

(2) entre parênteses estão os valores para o teste $t$ Cnível de significância bilateral

(*) $1 \% ;(* *) 5 \% ;(* * *) 10 \% ;(* * * *) \quad 20 \% ;-n i v e l$ de significância

$E_{2}$ - preco ao atacado de São Paulo - SP ás sextas-feiras

$F_{l}$ - preco na feira-livre de São Paulo - SP

$S S_{1}$ - preco no supermercado de São Paulo - SP

VS $S_{l}$ - preco no varejão de São Paulo - SP 
109.

\subsection{Margens de Comercialização}

Foram calculadas margens de comercializacão dos varejistas, para Piracicaba e São Paulo, para cada produto selecionado, conforme modelo proposto:

$$
M_{v}=\frac{P_{v}-P_{a}}{P_{v}} \cdot 100
$$

As menores margens em Piracicaba ocorreram nos varejôes e supermercados ${ }^{1}$.

As magnitudes das margens calculadas evidenciaram as práticas de fixacão de precos, para os produtos considerados, nos varejőes. Os varejões de Piracicaba têm seus precos máximos fixados em até 20\% do Atacado CCEASA locall e sempre inferiores aos do mercado municipal e feiras, enquanto que para São Paulo os precos são calculados até $15 \%$ acima do atacado (CEAGESP).

A seguir apresentamos as margens através das tabelas e gráficos com alguns comentários. Esclarecemos que os resultados foram apresentados para dois periodos diferentes (1985 a 1990 e 1989 a 1990) a fim de possibilitar comparacóes com o mercado municipal para Piracicaba e dos varejões de São Paulo, os quais não possuem série completa de precos no período de 1985 a 1988.

1 Não existe sórie completa de precos dos Supermercados de Piracicaba-SP, de 1002 ats 1000 . 


\section{Alface}

Conforme Tabela 41 para Piracicaba, as margens de comercializacão dos varejões para o período de 89 a 90 , considerando a média mensal, situaram-se em cerca de $6 \%$ contra $24 \%$ do mercado municipal e 30\% das feiras Livres. Para o período de 1985 - 90 os varejões apresentaram em média uma margem de $11 \%$ contra os mesmos $30 \%$ das feiras. A Figura 21, mostra a média semanal dos precos dos varejões. feiras e CEASA no período de 1985 - 90, e a Figura 22 demonstra as médias anuais dos precos destas unidades neste período. Nota-se a maior proximidade dos precos dos varejões aos do CEASA, do que o das reiras.

A Tabela 42 mostra as margens para alface no mercado de São Paulo, para as unidades de comercializacão selecionadas. As margens negativas para os varejões fazem supor que pode não estar havendo compatibilidade entre as classificacões apresentadas entre as tabelas de precos dos varejões e as do CEAGESP, apesar de constar a mesma denominacão. Já para os supermercados, esta prática pode ser justificada pela própria caracteristica das unidades de comercializacão, que obtem outros tipos de rendimento, ora pela venda de outras mercadorias com margens superiores, ora pela própria negociacão nas formas de pagamento com seus fornecedores. 
Tabela 41. Margem mensal de Comercializaç̃o da Alface em P1racicaba - SP, nos perfodos de $1985 / 90$ e $1989 / 90$. Margem relativa $(\%$

\begin{tabular}{|c|c|c|c|c|c|c|}
\hline \multirow[t]{2}{*}{ MÊS } & \multicolumn{2}{|c|}{ FEI RA-LI VRE } & \multicolumn{2}{|c|}{ VAREJ ÃO } & \multirow{2}{*}{$\begin{array}{l}\text { MERCADO } \\
1985 / 90\end{array}$} & \multirow{2}{*}{$\begin{array}{l}\text { MUNI CI PAL } \\
1989 / 90\end{array}$} \\
\hline & $1985 / 90$ & $1989 / 90$ & $1985 / 90$ & $1989 / 90$ & & \\
\hline JAN & 29 & 28 & 17 & 19 & - & 22 \\
\hline FEV & 26 & 35 & 13 & 21 & - & 22 \\
\hline MAR & 25 & 16 & 7 & 1 & - & 20 \\
\hline$A B R$ & 30 & 28 & 10 & 3 & - & 28 \\
\hline MAI & 29 & 33 & 9 & 4 & - & 30 \\
\hline JUN & 37 & 37 & 17 & 23 & - & 41 \\
\hline JUL & 36 & 27 & 6 & -12 & - & -4 \\
\hline AGO & 39 & 25 & 14 & 4 & - & 8 \\
\hline SET & 20 & -14 & -9 & -63 & - & -15 \\
\hline OUT & 36 & 44 & 27 & 27 & - & 48 \\
\hline NOV & 35 & 49 & 10 & 24 & - & 45 \\
\hline DEZ & 20 & 43 & 13 & 14 & - & 42 \\
\hline MÉDI A & 30 & 30 & 11 & 6 & - & 24 \\
\hline
\end{tabular}


PRECO REAL ALFACE (1985/90)

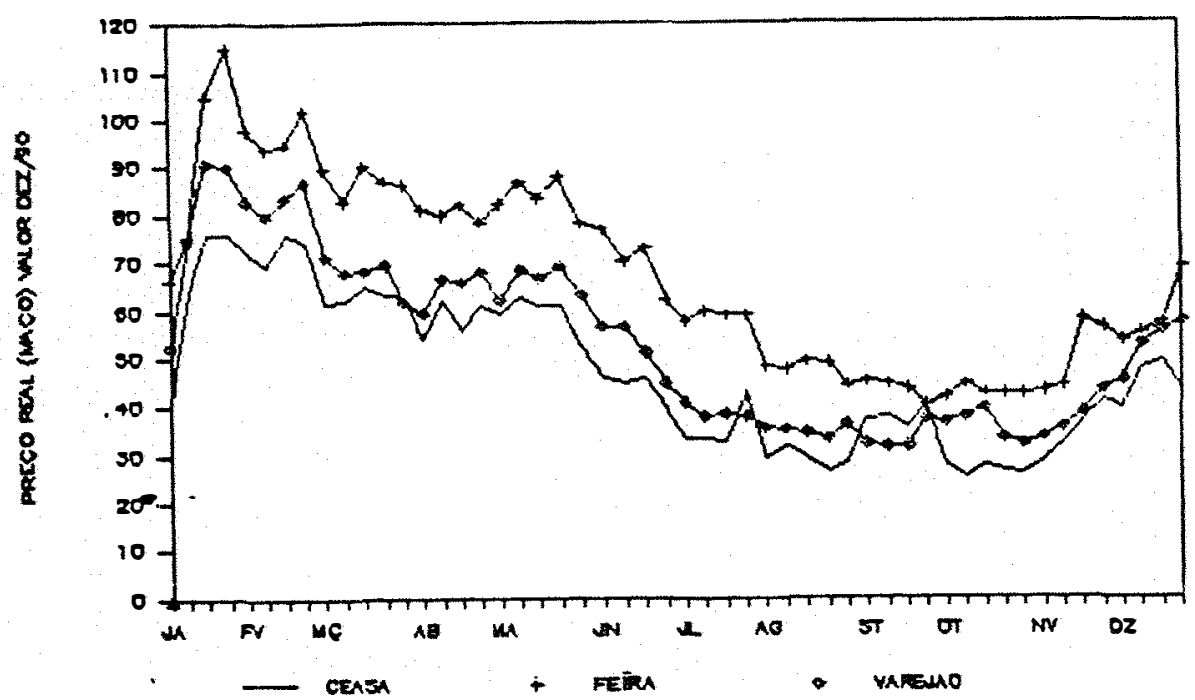

Figura 21. Comparacão dos precos da alface no CEASA, reiralivre e varejão em Piracicaba, média semanal período 1985 - 90 .

PRECO REAL ALFACE (1985/90)

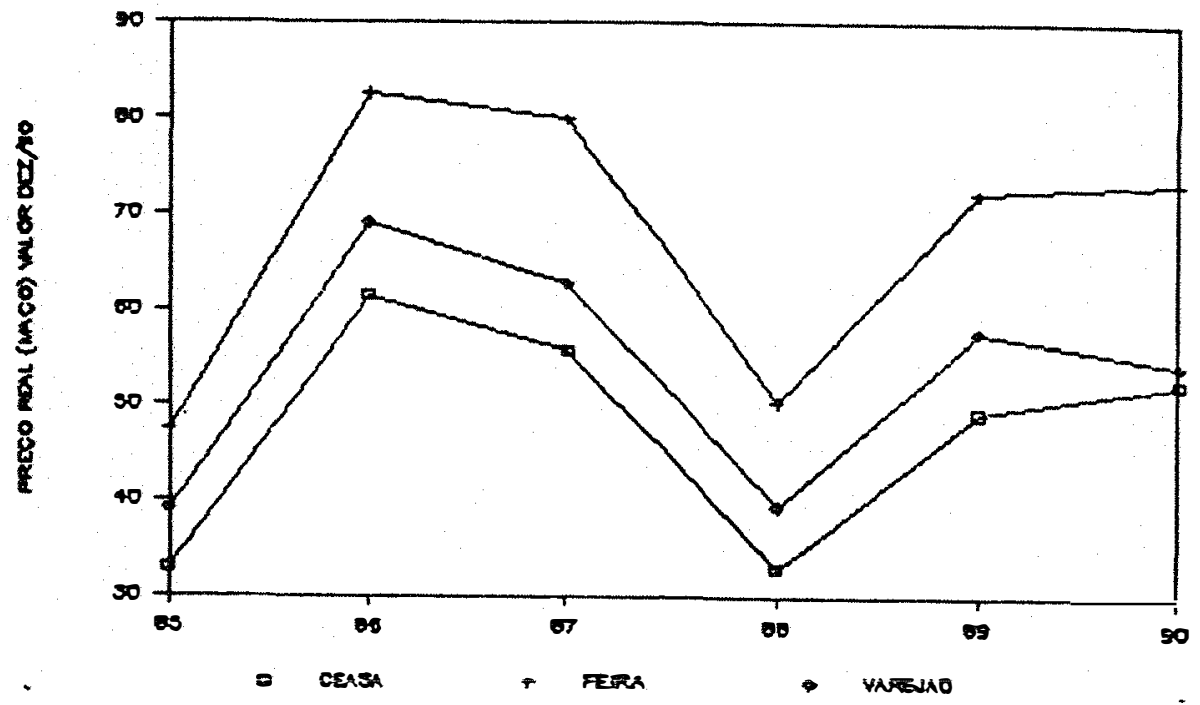

Figura 22. Comparacão dos precos da alface no CEASA, feiralivre e varejão em Piracicaba, média anual período 1985 - 90 . 
Tabela 42. Margem mensal de Comercializacão da Al face em São Paulo - SP, nos períodos de 1985/90 e 1989/90. Margem relativa (\%)

\begin{tabular}{lcccccc}
\hline MESS & \multicolumn{2}{c}{ FEI RA-LI VRE } & \multicolumn{2}{c}{ VAREJ ÃO } & \multicolumn{2}{c}{ SUPERMERCADO } \\
& $1985 / 90$ & $1989 / 90$ & $1985 / 90$ & $1989 / 90$ & $1985 / 90$ & $1989 / 90$ \\
\hline JAN & 2 & -16 & - & -15 & -20 & -36 \\
FEV & 13 & 23 & - & -51 & 2 & -3 \\
MAR & 18 & -8 & - & -30 & 16 & -25 \\
ABR & 32 & 16 & - & 7 & 26 & -4 \\
MAI & 12 & 17 & - & -3 & 8 & 7 \\
JUN & 23 & 29 & - & -8 & 20 & 22 \\
JUL & 37 & 2 & - & -25 & 30 & -9 \\
AGO & 44 & 11 & - & -28 & 34 & - \\
SET & 34 & -1 & - & -33 & 19 & -19 \\
OUT & 31 & 3 & - & -28 & 17 & -15 \\
NOV & 32 & 9 & - & -35 & 10 & -26 \\
DEZ & 13 & 6 & - & -49 & -6 & -25 \\
MÉDI A & 24 & 8 & - & -24 & 13 & -11 \\
\hline
\end{tabular}


114.

\section{Tomate}

A Tabela 43, demonstra que os varejôes de Piracicaba, para o período de 1989 - 90, considerando a média mensal, obtiveram cerca de $10 \%$ de margem contra $28 \%$ do mercado municipal e $29 \%$ das feiras-1ivres. Para o periodo 1985 - 90, obtiveram 13\% de margem em média contra 26\% das feiras-livres.

A Tabela 44. para o mercado de São Paulo. mostra margens de menor magnitude do que aquel as registradas em Piracicaba, ricando as feiras-livres com o maior percentual, 16\%, contra $9 \%$ dos supermercados e $1 \%$ para os varejöes. 
Tabel a 43. Margem mensal de Comercializacão do Tomate em Piracicaba - SP, nos períodos de $1985 / 90$ e $1989 / 90$. Margem relativa C\%

\begin{tabular}{|c|c|c|c|c|c|c|}
\hline \multirow[t]{2}{*}{ MÊS } & \multicolumn{2}{|c|}{ FEI RA-LI VRE } & \multicolumn{2}{|c|}{ VAREJ ÃO } & \multirow{2}{*}{$\begin{array}{l}\text { MERCADO } \\
1985 / 90\end{array}$} & \multirow{2}{*}{$\begin{array}{l}\text { MUNI CI PAL } \\
1989 / 90\end{array}$} \\
\hline & $1985 / 90$ & $1989 / 90$ & $1985 / 90$ & $1989 / 90$ & & \\
\hline JAN & 24 & 29 & 18 & 13 & - & 28 \\
\hline FEV & 21 & 25 & 12 & 17 & - & 21 \\
\hline MAR & 25 & 25 & 12 & 17 & - & 24 \\
\hline$A B R$ & 24 & 24 & 13 & 7 & - & 17 \\
\hline MAI & 31 & 37 & 15 & 15 & - & 33 \\
\hline JUN & 35 & 41 & 15 & 13 & - & 31 \\
\hline JUL & 31 & 39 & 9 & 6 & - & 31 \\
\hline$A G O$ & 31 & 39 & 10 & 13 & - & 32 \\
\hline SET & 33 & 47 & 17 & 33 & - & 44 \\
\hline OUT & 28 & 32 & 13 & 15 & - & 37 \\
\hline NOV & 16 & 5 & 8 & -6 & - & 21 \\
\hline DEZ & 14 & 32 & 10 & -18 & - & 14 \\
\hline MÉDI A & 26 & 29 & 13 & 10 & - & 28 \\
\hline
\end{tabular}


PRECO REAL TOMATE (1985/90)

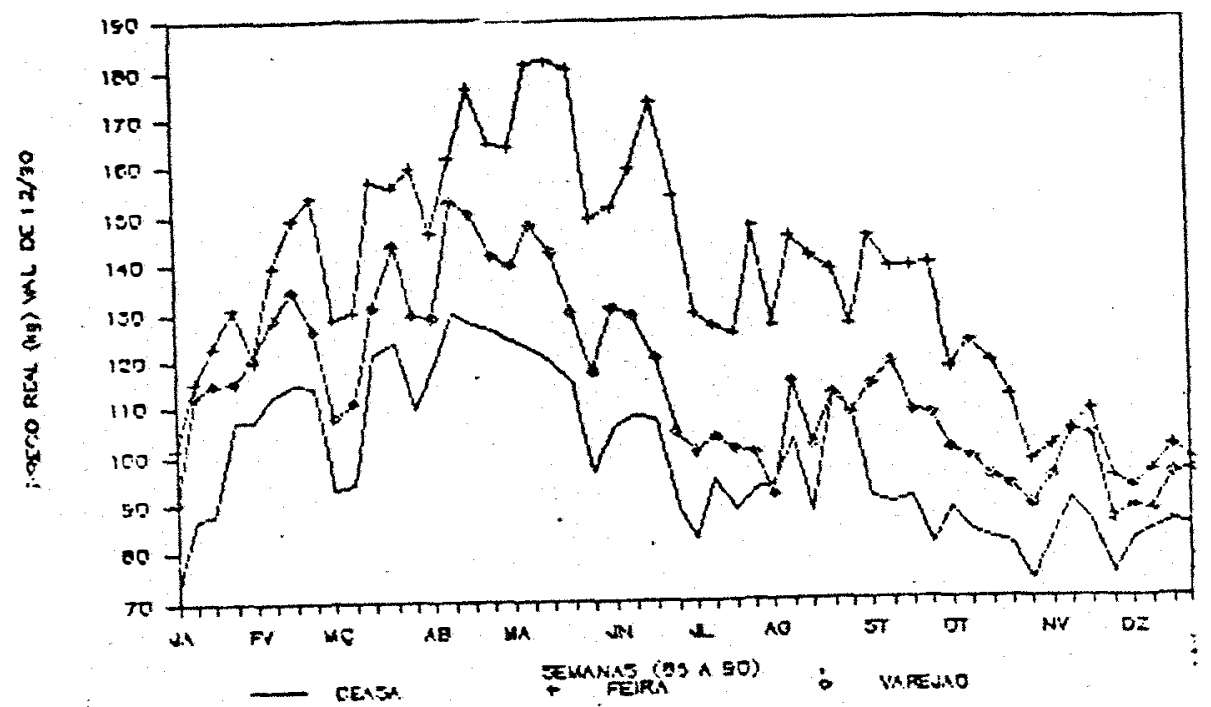

Figura 23. Comparacão dos precos do tomate no CEASA, feiralivre e varejão em Piracicaba, média semanal período 1985 - .90.

PREGO REAL TOMATE (1985/90)

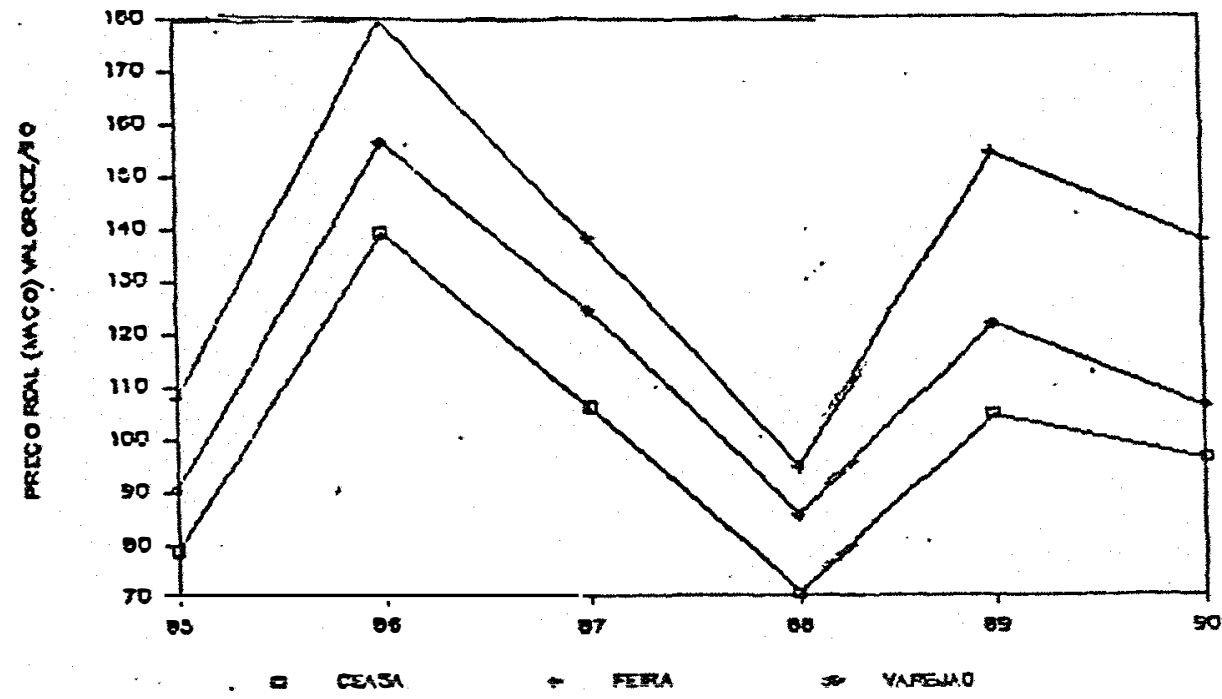

Figura 24. Comparacão dos precos do tomate no CEASA, feiralivre e varejão em Piracicaba, média anual periodo 1985 - 90 . 
Tabela 44. Margem mensal de Comercializacão do Tomate em São Paulo - SP, nos perílodos de $1985 / 90$ e $1989 / 90$. Margem relativa C\%

\begin{tabular}{lcccccc}
\hline MES & \multicolumn{2}{c}{ FEI RA-LI VRE } & \multicolumn{2}{c}{ VAREJÃO } & \multicolumn{2}{c}{ SUPERMERCADO } \\
& $1985 / 90$ & $1989 / 90$ & $1985 / 90$ & $1989 / 90$ & $1985 / 90$ & $1989 / 90$ \\
\hline JAN & 23 & 22 & - & -1 & 13 & 6 \\
FEV & 15 & 25 & - & 6 & 4 & 16 \\
MAR & 14 & 3 & - & -12 & 7 & 5 \\
ABR & 14 & 15 & - & -2 & 3 & 8 \\
MAI & 21 & 22 & - & 13 & 14 & 18 \\
JUN & 27 & 25 & - & 6 & 22 & 26 \\
JUL & 15 & 8 & - & -11 & 9 & 4 \\
AGO & 10 & 8 & - & 0 & 8 & 9 \\
SET & 11 & 9 & - & 14 & 8 & 7 \\
OUT & 10 & 12 & - & -5 & 2 & -2 \\
NOV & 14 & 18 & - & -1 & 4 & 2 \\
DEZ & 17 & 31 & - & 9 & 7 & 15 \\
& 16 & 16 & - & 1 & 9 & 9 \\
MÉDI A & 16 & & & & & \\
\hline
\end{tabular}


118

\section{Batata}

A Tabela 45, para Piracicaba, registra que a margem de comercializacão de Batata para o periodo de 89 a 90 foi de $11 \%$ nos varejóes, $33 \%$ no mercado municipal e 35\% nas reiras-livres. Para o periodo de 85 a 90 os varejóes apresentaram $12 \%$ de margem contra $25 \%$ das feiras.

Para o mercado de São Paulo, conforme Tabela 46. observamos margens de maior magnitude, com excecão daquelas praticados nos supermercados. Os varejöes obtiveram $14 \%$ de margem contra $37 \%$ das feiras $10 \%$ nos supermercados para o período de 89 a 90. 
Tabela 45. Margem mensal de Comercialização da Batata em Piracicaba - SP, nos perlodos de $1985 / 90$ e $1989 / 90$. Margem relativa $6 \%$

\begin{tabular}{|c|c|c|c|c|c|c|}
\hline \multirow[t]{2}{*}{ MÊS } & \multicolumn{2}{|c|}{ FEI RA-LI VRE } & \multicolumn{2}{|c|}{ VAREJ ÃO } & \multicolumn{2}{|c|}{ MERCADO MUNICIPAL } \\
\hline & $1985 / 90$ & $1989 / 90$ & $1985 / 90$ & $1989 / 90$ & $1985 / 90$ & $1989 / 90$ \\
\hline JAN & 29 & 41 & 15 & 24 & - & 48 \\
\hline FEV & 34 & 48 & 14 & 21 & - & 34 \\
\hline MAR & 33 & 43 & 11 & 18 & - & 35 \\
\hline$A B R$ & 21 & 25 & 8 & 2 & - & 30 \\
\hline MAI & 30 & 44 & 14 & 20 & - & 36 \\
\hline JUN & 28 & 43 & 7 & -3 & - & 20 \\
\hline JUR & 27 & 43 & 13 & 18 & - & 35 \\
\hline AGO & 19 & 31 & 14 & 13 & - & 42 \\
\hline SET & 10 & 2 & 5 & -15 & - & -4 \\
\hline OUT & 4 & 31 & 11 & 9 & - & 54 \\
\hline NOV & 40 & 40 & 15 & 15 & - & 31 \\
\hline DEZ & 30 & 27 & 14 & 10 & - & 31 \\
\hline MÉDI A & 25 & 35 & 12 & 11 & - & 33 \\
\hline
\end{tabular}


PREGO REAL BATATA (1985/90)

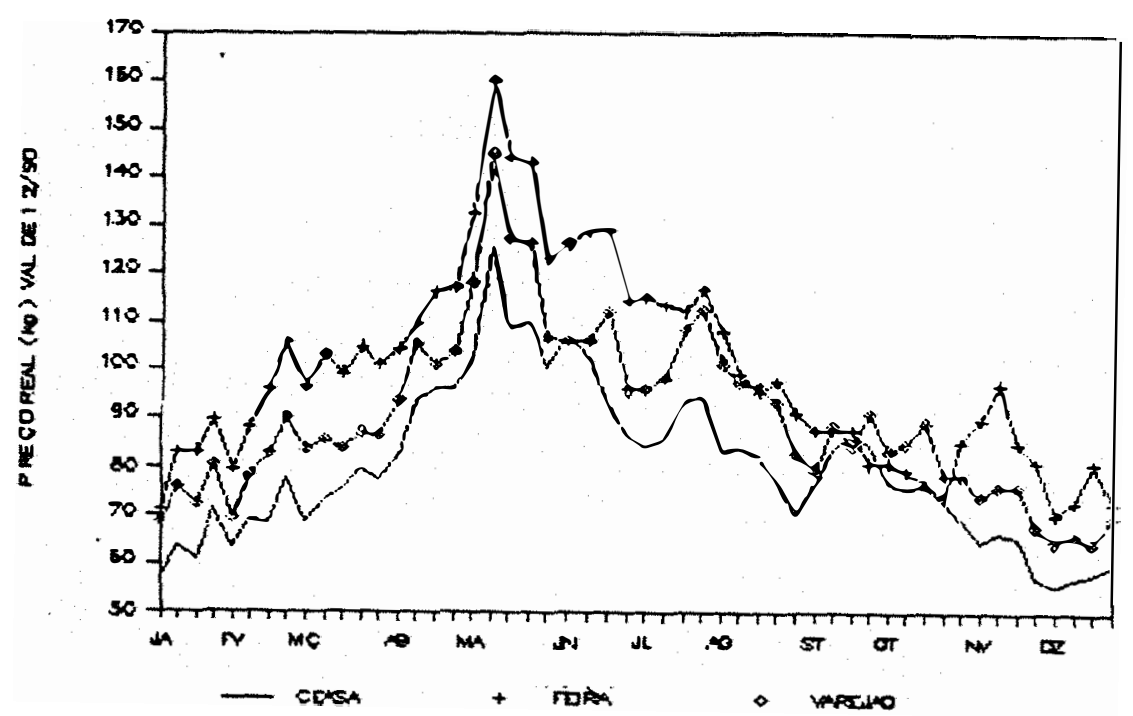

Figura 25. Comparacão dos precos da batata no CEASA, feiralivre e varejão em Piracicaba, média semanal período 1985 - 90 .

PRECO REAL BATATA (1985/90)

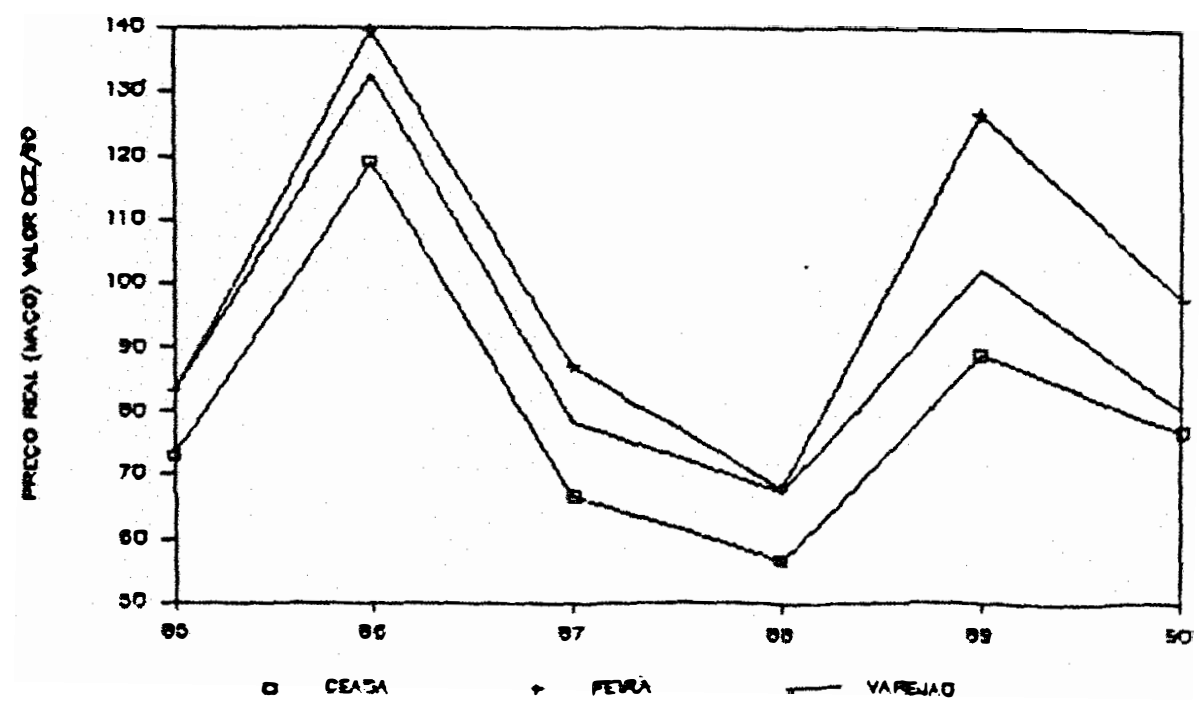

Figura 26. Comparacão dos preços da batata no CEASA, feiralivre e varejão em Piracicaba, média anual período 1985 à 90 . 
Tabela 46. Margem mensal de Comercialização da Batata em São Paulo - SP, nos perílodos de $1985 / 90$ e $1989 / 90$.

Margem relativa $C \%$

\begin{tabular}{|c|c|c|c|c|c|c|}
\hline \multirow[t]{2}{*}{ MES } & \multicolumn{2}{|c|}{ FEI RA-LI VRE } & \multicolumn{2}{|c|}{ VAREJÃO } & \multicolumn{2}{|c|}{ SUPERMERCADO } \\
\hline & $1985 / 90$ & $1989 / 90$ & $1985 / 90$ & $1989 / 90$ & $1985 / 90$ & $1989 / 90$ \\
\hline JAN & 49 & 30 & - & 17 & 30 & 15 \\
\hline FEV & 42 & 62 & - & 32 & 22 & 26 \\
\hline MAR & 41 & 60 & - & 27 & 23 & 27 \\
\hline ABR & 40 & 54 & - & -4 & 14 & 13 \\
\hline MAI & 31 & 30 & - & 20 & 11 & 12 \\
\hline JUN & 38 & 32 & - & 8 & 23 & 13 \\
\hline JUL & 26 & 19 & - & 4 & 15 & 3 \\
\hline AGO & 28 & 47 & - & 10 & 10 & 11 \\
\hline SET & 17 & 15 & - & 2 & 15 & -12 \\
\hline OUT & 29 & 28 & - & 21 & 5 & 5 \\
\hline NoV & 43 & 36 & - & 10 & 15 & 12 \\
\hline DEZ & 36 & 29 & - & 18 & 8 & -1 \\
\hline MÉDI A & 35 & 37 & - & 14 & 16 & 10 \\
\hline
\end{tabular}




\section{Banana}

Os varejôtes de Piracicaba, conforme Tabela 47. obtiveram margens de cerca de $9 \%$, contra $36 \%$ no mercado municipal e 38\% nas feiras-1ivres, no periodo de 89 a 90 . Para o período de 85 a 90 os varejões fixaram em média $10 \%$ e as feiras-livres $35 \%$.

Para São Paulo, conforme a Tabela 48, os varejões fixaram em $17 \%$ suas margens e as feiras $32 \%$ e supermercado em 28\% para o período de 89 a 90 . Já no período de 85 a 90 os varejões tiveram 10\% de margem contra 25\% nos supermercados e $31 \%$ nas feiras. 
Tabela 47. Margem mensal de Comercializacão da Banana em Pi- SP, nos períodos de $1985 / 90$ e $1989 / 90$.

Margem relativa C\%

\begin{tabular}{|c|c|c|c|c|c|c|}
\hline \multirow[t]{2}{*}{ MÊS } & \multicolumn{2}{|c|}{ FEI RA-LI VRE } & \multicolumn{2}{|c|}{ VAREJÃO } & \multicolumn{2}{|c|}{ MERCADO MUNI CI PAL } \\
\hline & $1985 / 90$ & $1989 / 90$ & $1985 / 90$ & $1989 / 90$ & $1985 / 90$ & $1989 / 90$ \\
\hline JAN & 39 & 47 & 10 & 13 & - & 46 \\
\hline FEV & 48 & 59 & 14 & 10 & - & 43 \\
\hline MAR & 42 & 53 & 11 & 14 & - & 34 \\
\hline$A B R$ & 40 & 49 & 11 & 3 & - & 28 \\
\hline MAI & 39 & 44 & 11 & 11 & - & 40 \\
\hline JUN & 39 & 42 & 14 & 14 & - & 36 \\
\hline JUR & 31 & 31 & 11 & 9 & - & 28 \\
\hline AGO & 33 & 35 & 6 & 2 & - & 28 \\
\hline SET & 26 & 19 & 8 & 11 & - & 33 \\
\hline OUT & 21 & 21 & 5 & 5 & - & 33 \\
\hline NOV & 31 & 32 & 10 & 8 & - & 38 \\
\hline DEZ & 32 & 26 & 10 & 10 & - & 39 \\
\hline MÉDI A & 35 & 38 & 10 & 9 & - & 36 \\
\hline
\end{tabular}


PRECO REAL BANANA (1985/90)

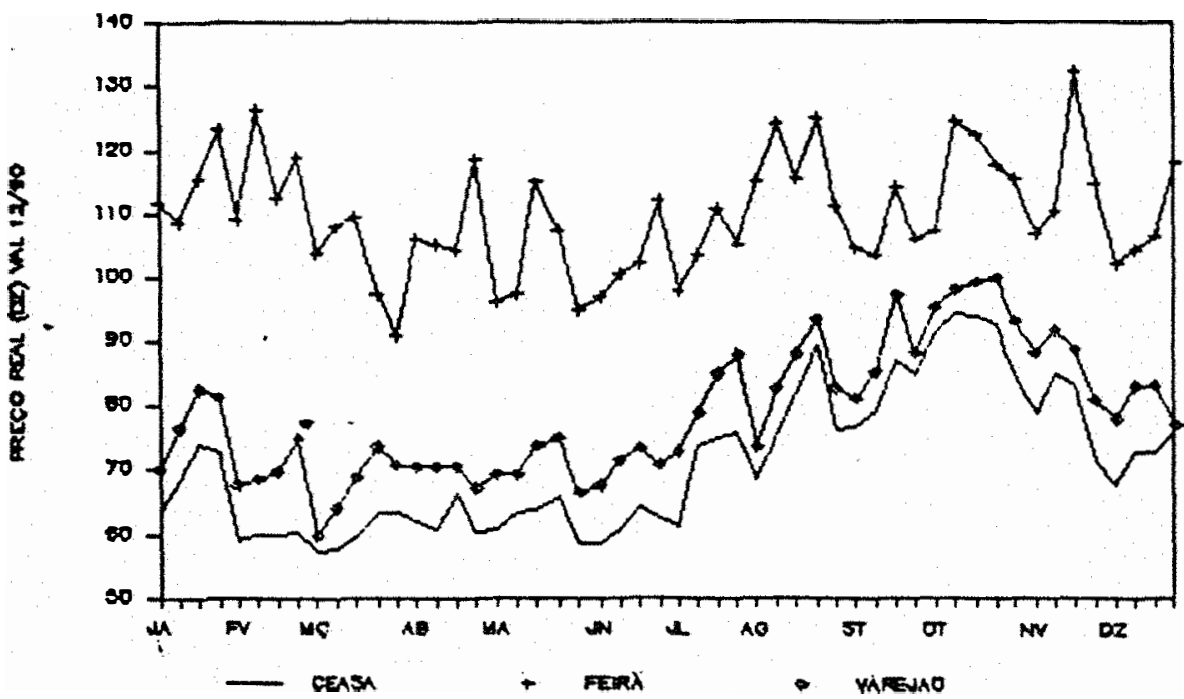

Figura 27. Comparacão dos precos da banana no CEASA, feiralivre e varejão em Piracicaba, média semanal perído 1985 - 90 .

PRECO REAL BANANA (1985/90)

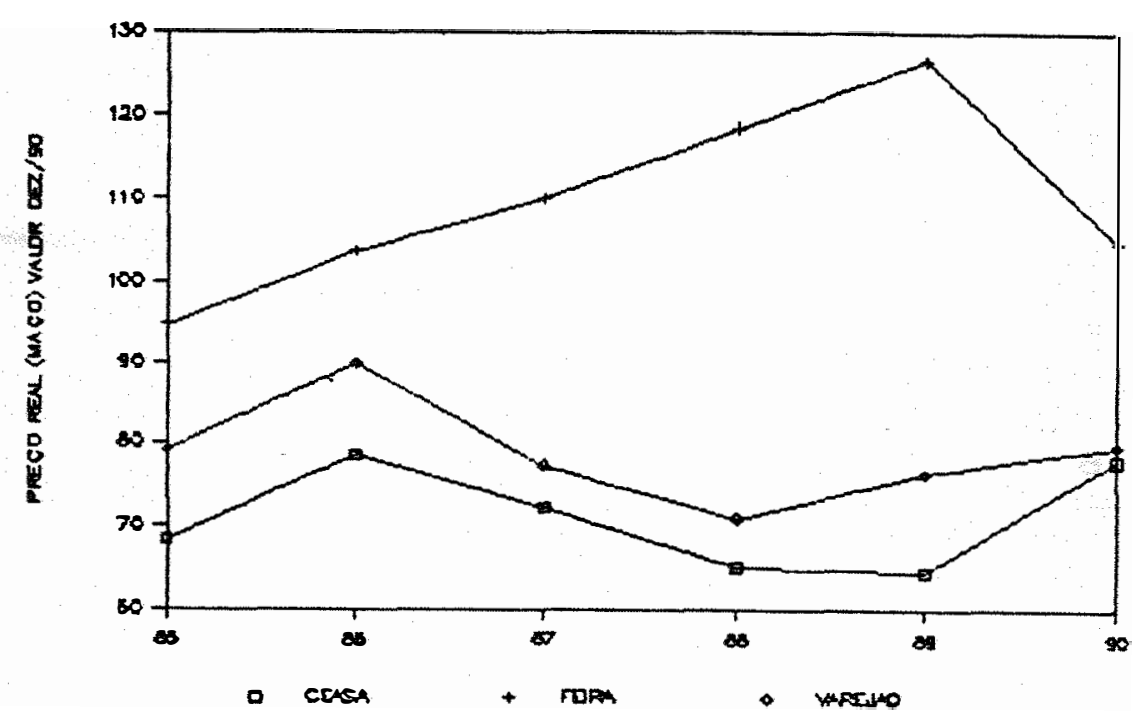

Figura 28. Comparacão dos precos da banana no CEASA, feiralivre e varejão em Piracicaba, média anual perlodo 1985 - 90 . 
Tabela 48. Margem mensal de Comercializacão da Banana em São Paulo-SP, nos perlodos de $1985 / 90$ e $1989 / 90$. Margem relativa C\%

\begin{tabular}{|c|c|c|c|c|c|c|}
\hline \multirow[t]{2}{*}{ MES } & \multicolumn{2}{|c|}{ FEIRA-LI VRE } & \multicolumn{2}{|c|}{ VAREJ ÃO } & \multicolumn{2}{|c|}{ SUPERMERCADO } \\
\hline & $1985 / 90$ & $1989 / 90$ & $1985 / 90$ & $1989 / 90$ & $1985 / 90$ & $1989 / 90$ \\
\hline JAN & 31 & 42 & - & 22 & 24 & 35 \\
\hline FEV & 40 & 43 & - & 22 & 36 & 40 \\
\hline MAR & 39 & 40 & - & 18 & 31 & 33 \\
\hline$A B R$ & 30 & 20 & - & -11 & 21 & 5 \\
\hline MAI & 39 & 36 & - & 33 & 33 & 30 \\
\hline JUN & 38 & 32 & - & 26 & 32 & 29 \\
\hline JUL & 33 & 28 & - & 13 & 28 & 26 \\
\hline$A G O$ & 29 & 31 & - & 13 & 24 & 29 \\
\hline SET & 22 & 27 & - & 16 & 16 & 25 \\
\hline OUT & 18 & 24 & - & 12 & 13 & 25 \\
\hline NOV & 27 & 28 & - & 18 & 20 & 30 \\
\hline $\mathrm{DEZ}$ & . 30 & 38 & - & 20 & 26 & 35 \\
\hline MÉDI A & 31 & 32 & - & 17 & 25 & 28 \\
\hline
\end{tabular}


126.

\section{CONCLUSÕES}

É patente o problema do abastecimento alimentar no Brasil. Os estudiosos no assunto, em sua grande maioria, relacionam o problema com caracteristicas de ordem macroeconômica e estrutural.

Porém, algumas iniciativas do setor público no sentido de implementar acóes locais, respeitando-se as peculiaridades de cada região, são aceitas e até recomendadas. Verifica-se que no histórico das açôes do setor público no Brasil existem vários Planos e Programas, que tentaram organizar o setor de abastecimento alimentar. Destaca-se aqui a criação da CEAGESP e suas Centrais Regionais, que de certa forma centralizam as operacões de atacado e tentam servir de parâmetros para os precos de hortigranjeiros.

A criação dos varejôes parece ter se dado como desdobramento dos servicos da CEAGESP, para dar conta também, de uma parte do mercado varejista. Além desse canal alternativo de varejo, o Governo do Estado de São Paulo oferece outras modalidades aos municipios, de acordo com suas necessidades e peculiaridades.

Especificamente para Piracicaba, suas caracteristicas de produção agricola concentrada na cana de acúcar. a elevada taxa de urbanizacão e o grande e diversificado mercado consumidor. parecem ter contribuido favorávelmente para o estabelecimento dos varejôes. 
127.

É fundamental também associarmos a implementacão dos varejões em Piracicaba com o contexto de seu sistema de abastecimento. A acão do setor público na comercializacão de hortigranjeiros pode ser notada desde a criacão do mercado municipal em 1888. E fol através do mercado municipal que o sistema de abastecimento, com a administracão do setor público, se desdobrou; as feiras-livres que não deixam de ser bracos do setor varejista do mercado municipal. A criacão do Entreposto municipal (1974), que, de certa forma, transferiu o segmento atacadista do mercado municipal para um local mais adequado, teve como objetivo evitar transtorno para o tránsito no centro da cidade.

Até a década de 70 a acão do setor públ1co preocupa-se com regulamentacões que permitissem a utilizacão de uso do solo. No advento da implantacão dos varejões (1979 em São Paulo e 1982 em Piracicaba), identifica-se uma caracteristica diferente na acão do setor público. Os varejões consolidam-se como uma opcão a mais no sistema varejista de hortigranjeiros, ou seja um "canal alternativo" que proporciona mais possibilidades para produtores, atacadistas e varejistas colocarem suas mercadorias, desde que obedecam a tabela de precos máximos para suas vendas, e ao mesmo tempo maior número de alternativas para os consumidores nas suas compras.

Neste trabalio, apresentou-se as principais caracteristicas de infra-estrutura e operacionalizacão da 
128.

CEASA, Feiras e mercado municipal de Piracicaba. Isto possibilitou a comparacão de suas caracteristicas àquelas dos varejões. Estes apresentam-se como "Feiras Confinadas", com localizacão estratégica, ou seja previamente planejada C50\% encontram-se em zona de baixo padrão de construcão e 33,3\% em zona de construcão intermediárias, com setorizacão de produtos, diversificacão de produtos, vendas em escala e distribuicão dos vendedores que possibilite concorrência abaixo do preco máxi mo fixado.

Destaca-se também a possibilidade dos varejöes substituirem uma parcela da comercializacão do atacado. realizada no antigo Entreposto municipal, conforme avaliacão da própria C.EAGESP. Esclarecese que esta possibilidade leva em conta a transferência de vendas no atacado para. vendas a varejo.

Quanto às opiniones dos consumidores a respeito dos varejôes, existe uma boa aceitacão quanto ao preco, qualidade e diversificacão dos produtos. Quanto ao perfil dos consumidores, a pesquisa efetuada pela SEMA não permi te identificar de forma segura o nível de renda. A pesquisa identifica, também, grande porcentagem de pessoas que frequentam toda a semana os varejões, bem como as que deslocam-se a pé até o local de compra, boa aceitacão quanto ao sistema de transporte coletivo. Isto demonstra, através desta amostra, que os varejôes possuem uma clientela cativa e são bem localizados. 
Identificou-se também, na politica de fixacão de precos máximos nos varejões, que existe uma forte relacão com os precos da CEASA local, com transferência imediata de uma parcela maior das variacões ocorridas no atacado, do que outras unidades varejistas estudadas, porém com margens de comercial 1̇ação inferiores.

- presente trabalho sujeri que o atacado de Piracicaba tem seus precos relativamente associados aos do atacado de São Paulo, e que os precos das sextas-feiras do atacado de Piracicaba estão associados, quase que na mesma proporcão, com os das quintas e sextas-feiras do atacado de São Paulo. Constatou-se também que o mercado varejista aqui estudado tanto para Piracicaba como para São Paulo, não transfere de imediato as alteracões de preco do mercado atacadista, assim como ocorre na integracão do atacado de Piracicaba com o de São Paulo. Ratificando a conclusão de Barros (1988) que o setor de intermediacão, e aquí também o varejista, "atenua as oscilacões de precos, transferindo-as apos determinado perfodo de tempo. Destaca-se neste trabal ho que a Alface apresenta o menor impacto de transmissão na integracão com o atacado de São Paulo, para cada $10 \%$ de variacão do preço de São Paulo a oscilacão em Piracicaba roi, em média, 5,5\%, em quatro semanas, seguida da Banana (7.3\%); Tomate $(8,1 \%$; Batata $(8,9 \%)$

Enfim, este trabalho preocupou-se com a investigacão desta "alternativa" no contexto do abastecimento de hortigranjeiros em Piracicaba reconhecendo ocorrer 
algumas solucões para alguns problemas locais; tais como: pequena producão hortigranjeira no local, as Feiras e mercado municipal não enfrentavam muitos concorrentes, a não ser quitandas e algumas mercearias; os supermercados até então não mantinham abastecimento de hortigranjeiros de forma regular.

É interessante, portanto, que o setor público mantenha um leque de opcões, inclusive com experiências como estas dos varejões, para que sejam devidamente aproveitadas pelos municipios, de acordo com suas caracteristicas e necessidades locais. Entendemos, também, que os varejões em Piracicaba devem merecer atencão do setor público, no sentido de sua adaptacão e modernizacão, já que encontram-se estabelecidos no sistema de abastecimento da cidade. Porém com cuidados no sentido de evitar privilégios aos vendedores.

Como já foi descrito ao longo do trabalho, esta alternativa não soluciona o problema da má distribuicão de renda ou problemas da politica agricola, mas os atenua e oferece para uma parcela da populacão o acesso a alguns produtos necessários a sua alimentacão. 


\section{REFERENCI AS BIBLIOGRÁFICAS}

AMARO, A. A; TSUNECHIRO, A; VANSETTI, M. C. R. Abastecimento de Centros Urbanos: Estudo do Mercado Varejista de Piracicaba. Agricultura em São Paulo. Boletim Técnico do Instituto de Econômia Agrícola, São Paulo, 36(1): 99-125, 1989.

BESSA, Eledil. A Acão do Estado no Setor Varejista in: Anais do I Seminário Nacional: "Experiências de Abastecimento em grandes cidades". SAACAB. São Paulo, 1984.

BARROS, G.S. de C. . Economia da Comercializacão Agricola. FEALQ/ESALQ/USP, Piracicaba. 1987.

BARROS, G.S. de C. Os três desafios à Agricultura Brasileira Piracicaba, Departamento de Economia e Sociologia Rural, ESALQ/USP, 1980. (Série Pesquisa ne 41 )

BARROS, G.S. de C. Transmissão de precos pela Central de Abastecimento de São Paulo. Brasil. In IV Semi nário sobre Problemas e Perspectivas da Agricultura Brasileira. Piracicaba, 1988, Anuais USP-ESALQ. FEALQ. 1988.

BRANDT, S. A. Curso de Pós-Graduação de Comercializacão Agricola. Vicosa, UFV, 1969. $146 \mathrm{p}$.

CADASTRO DE PERMISSIONÁRIOS. CEASA. Piracicaba SP 1989.

CADASTRO DE PERMISSIONÁRIOS E FEIRANTES. SEMA. PI racicaba SP 1989. 
132.

C.ADASTRO TÉCNICO DA PREFEI TURA MUNICIPAL DE PIRACICABA. Piracicaba SP. 1991.

CEAGESP - Avaliacão do Comércio Atacadista de Piracicaba, mi meograf ado: p. 24, 1978.

CEAGESP - Boletim Mensal do Interior (vários números). São Paulo SP.

CEAGESP - Questionários aplicados nas C.EASAS Regionais, mi meografado, 1989.

CONJUNTURA ALIMENTOS. São Paulo: SAACAB, V. 1 , ne 4 , dez. 1985. $55 \mathrm{p}$.

DI AGNÓSTICO SOBRE O ABASTECIMENTO ALIMENTAR NO MUNICIPIO DE PIRACICABA. Convênio Departamento de Economia e Sociologia Rural (ESALQ/USP)e SEMA - Prefeitura Municipal de Piracicaba (dados preliminares). Piracicaba - SP. 1991

FERRATO, G.A. Abastecimento de Alimentos a Intervencão do Estado e a Reproducão da Forca de Trabalho. São Paulo, 1982. CMestrado-Fundacão Getúlio Vargas, Escola de Administracão de Empresas de São Paulos.

GUIMARÃES, 0 . O papel das Feiras-Livres no abastecimento da cidade de São Paulo. São Paulo, 1969. CMestrado - USP, Inatitulo de Geografia).

HOFFMANN, R. \& VIEIRA, S. Análise de regressão: uma introducão à econometria. 2 ed. São Paulo, Hucitec, 1977.

KASSOUF, A.L. e HOFFMANN, R. Introducão ao RATS. Piracicaba. Departamento de Economia e Sociologia Rural/ESALQ-USP. 1988. 61 p. Série Estudos no 29. 
LEANDRO, L. De Piracicaba para Piracicaba, subsidios para a história da cidade Piracicaba, Edicão do Jornal de Piracicaba, 1961 .

LINHARES, M.Y.L.S. História do abastecimento, uma problemática em questão (1530-1918). Brasilia. Biblioteca Nacional de Agricultura, 1979.

MALUF, R.S. Algumas questões teórico - metodológías no estudo da comercializacão agricola. Campinas, 1982. (Mestrado-Universidade de Campinas).

MALUF, R.S. Panorama e Mitos no Abastecimento. Såo Paulo: INAPP. Instituto Nacional de Administracão e Politicas Públicas. 1989 . 12 p. mi meo.

MANUAL DE EQUI PAMENTOS VAREJISTAS. Uma Proposta Viável. São Paulo: SAACAB e Prefeitura Municipal. PROCALI - Programa de Regionalizacão da Producão e Consumo de Alimentos, V. 1. ne 1, 1991. 72 p. Edicão Especial.

NEGRI. Barjas. Evolução da Populacão. Taxa de urbanizacão e da Densidade Demografica de Piracicaba, Piracicaba, 1. ago. 1991 . pag. 33.

PEREIRA, M.T. Análise da Politica de Centrais de Abastecimento. $O$ caso de Piracicaba. Piracicaba 1990. Mestrado em Economia Agrária. ESALQ/USP.

PEREZ, L: H: et al. Abastecimento no Estado de São Paulo. Secretaria de Agricultura e Abastecimento/FAO. São Paulo. 1982. 165 p.

SEMA. Boletim Mensal. (vários números). Piracicaba-SP.

SEMA. Pesquisa de Opinião 1991. Piracicaba - SP. 
SILVA, M.P. et al. VAREJõES DE PIRACI CABA - UMA INI CI ATIVA MUNICIPAL PARA ATENDER AOS INTERESES DOS PEQUENOS E MÉDIOS PRODUTORES E CONSUMI DORES. Piracicaba. Faculdade de Servico Social. 1984. 86p.

SINOPSE DAS LEIS DO MERCADO MUNICIPAL DE PIRACICABA. Relatório de Pesquisa. SEMA - Secretaria Municipal de Agricultura e Abastecimento e DESR - Departamento de Economia e Sociologia Rural da Escola Superior de Agricultura Luiz de Queiroz. ESALQ/USP. mimeo 08 pag., 1980.

WELSH, R.S. O papel da comercializacão no Desenvolvimento Econômico. Série Pesquisa ne 04 Piracicaba. ESALQ. 1969. 
135.

A $P \hat{E} \mathbf{N} I C E$ 


\section{PREGO REAL - ALFACE (1985 - 90) - VALOR REAL DE DEZ/90}

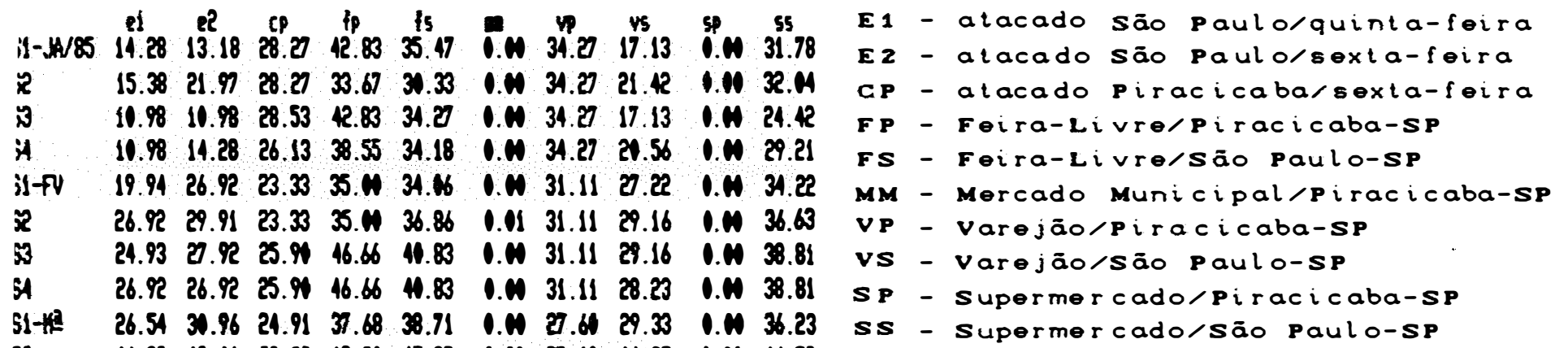

$\begin{array}{llllllllllll}52 & 41.23 & 48.66 & 22.98 & 12.3 & 45.27 & 0.40 & 27.60 & 41.85 & 0.4 & 46.58\end{array}$

$\begin{array}{lllllllllll}53 & 48.66 & 48.66 & 51.75 & 64.66 & 44.78 & 0 . N & 44.85 & 46.58 & 0 . N & 61.62\end{array}$

$\begin{array}{lllllllllll}51 & 39.81 & 39.81 & 57.48 & 69.01 & 55.89 & 0.1 & 59.34 & 37.95 & 0.4 & 59.31\end{array}$

$\begin{array}{lllllllllll}55 & 26.54 & 30.96 & 57.48 & 69.01 & 57.27 & 0.1 & 59.34 & 29.33 & 0.01 & 60.86\end{array}$

$\begin{array}{lllllllllll}S 1-A B & 28.88 & 28.88 & 42.92 & 61.52 & 51.71 & 0 . N & 53.41 & 27.35 & 0 . N & 43.18\end{array}$

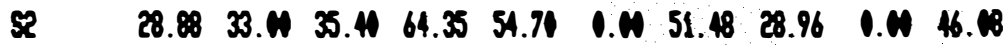

$\begin{array}{lllllllllll}53 & 28.88 & 24.75 & 32.18 & 57.92 & 45.31 & 1 . N & 51.48 & 24.13 & 1 . N & 39.96\end{array}$

$\begin{array}{llllllllllll}54 & 37.13 & 37.13 & 38.61 & 57.92 & 45.11 & \text { O.N } & 51.48 & 37.4 & 0 . N & 47.75\end{array}$

$\begin{array}{lllllllllll}51-\text { - } & 26.79 & 26.79 & 25.07 & 56.72 & 48.72 & 0 . N & 11.79 & 25.37 & 0 . N & 44.31\end{array}$

$\begin{array}{lllllllllll}52 & 26.79 & 22.96 & 32.36 & 50.75 & 45.43 & 0.11 & 41.79 & 22.39 & 0.01 & 47.31\end{array}$

$\begin{array}{llllllllllll}53 & & 26.79 & 26.79 & 12.27 & 53.73 & 19.37 & 0.0 & 11.79 & 25.37 & 0.01 & 44.66\end{array}$

$\begin{array}{lllllllllll}51 & 19.14 & 22.96 & 37.31 & 51.45 & 49.61 & 0 . N & 11.79 & 22.39 & 0 . N & 45.67\end{array}$

55 $\quad \begin{array}{lllllllllll}30.62 & 31.62 & 30.81 & 51.11 & 4.60 & \text { O.N } & 41.79 & 25.37 & \text { O.N } & 41.78\end{array}$

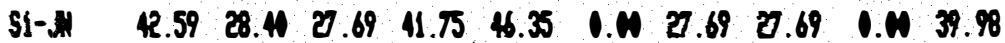

$\begin{array}{llllllllllll}52 & 42.59 & 46.11 & 33.22 & 45.4 & 58.91 & \text { O.N } & 38.76 & 22.15 & \text { N.4 } & 59.47\end{array}$

$\begin{array}{lllllllllllll}53 & 35.49 & 35.49 & 46.12 & 52.99 & 58.25 & \text { O.N } & 44.3 & 45.68 & \text { N.N } & 88.98\end{array}$

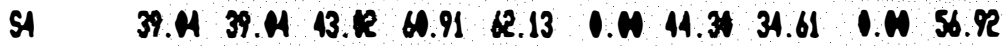

$\begin{array}{lllllllllllllllll}51-l & 29.33 & 29.33 & 33.85 & 51.83 & 61.46 & \text { O.N } & 40.67 & 35.58 & \text { N.N } & 51.95\end{array}$

$\begin{array}{llllllllllll}52 & 29.33 & 29.33 & 25.42 & 50.83 & 56.01 & \text { O.N } & 40.67 & 35.58 & \text { N.N } & 55.51\end{array}$

$\begin{array}{lllllllllllllll}53 & 35.84 & 32.58 & 38.12 & 51.83 & 61.71 & \text { O.N } & 40.67 & 33.4 & \text { I.N } & 58.35\end{array}$

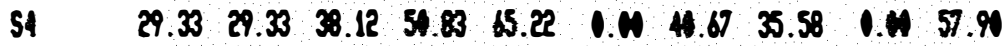

$\begin{array}{lllllllllllllll}\text { SI-A6 } & 31.44 & 31.44 & 18.55 & 4.13 & 61.09 & \text { O.N } & 35.67 & 35.67 & \text { O.N } & 47.71\end{array}$

$\begin{array}{llllllllllllllll}52 & 35.72 & 25.72 & 24.75 & 4.75 & 57.21 & \text { O.N } & 35.67 & 31.21 & \text { N.N } & 50.17\end{array}$

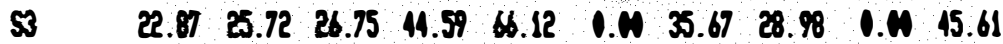

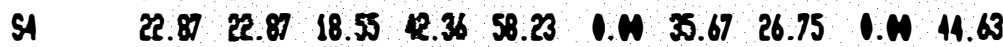

$\begin{array}{lllllllllllllllll}55 & 22.87 & 22.87 & 26.4 & 12.36 & 53.68 & \text { O.N } & 35.67 & 31.21 & \text { I.N } & 11.56\end{array}$

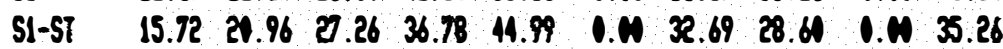

$\begin{array}{llllllllllllllllll}52 & 21.96 & 26.19 & 27.26 & 36.78 & 48.67 & \text { N.N } & 32.69 & 32.69 & \text {.N. } & 37.35\end{array}$

$\begin{array}{lllllllllllll}53 & 26.19 & 26.19 & 27.26 & 38.22 & 17.12 & \text { O.N } & 32.69 & 28.61 & \text { O.M } & 37.35\end{array}$

$\begin{array}{lllllllllllllllll}54 & 15.72 & 15.72 & 24.52 & 4 & 4.86 & 48.87 & \text { O.N } & 32.69 & 21.43 & \text { I.N } & 13.36\end{array}$

$\begin{array}{lllllllllllllll}51-07 & 14.41 & 14.11 & 21.99 & 35.59 & 12.75 & \text { 1.N } & 29.97 & 18.73 & \text { N.N } & 36.34\end{array}$

$\begin{array}{llllllllllllll} & 5 & 12.01 & 14.41 & 24.99 & 37.47 & 39.75 & \text { O.N } & 29.97 & 18.73 & \text { I.N } & 34.43\end{array}$

$\begin{array}{lllllllllllllll}53 & 16.81 & 21.62 & 31.21 & 35.59 & 13.39 & \text { N.N } & 33.72 & 29.97 & \text { O.N } & 32.63\end{array}$

$\begin{array}{llllllllllll}54 & 21.81 & 20.81 & 24.99 & 41.21 & 11.70 & 0.10 & 33.72 & 26.23 & \text { O.N } & 34.89\end{array}$

$\begin{array}{llllllllllllllll}55 & 18.73 & 18.73 & 24.95 & 35.59 & 45.71 & \text { N.N } & 33.72 & 22.48 & \text { N.N } & 34.84\end{array}$

$\begin{array}{lllllllllllllll}51+\text { W } & 26.83 & 27.17 & 24.45 & 29.34 & 41.27 & 0.01 & 29.34 & 19.56 & 1.10 & 29.67\end{array}$

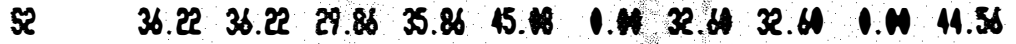

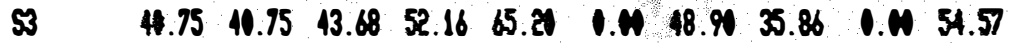

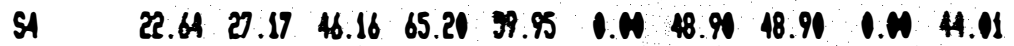

$\begin{array}{lllllllllll}S 1-D 2 & 24.01 & 32 . N & 43.24 & 57.59 & 54.72 & \text { O.N } & \text { 13.28 } & 34.56 & \text { I.N } & 39.18\end{array}$

$\begin{array}{lllllllllll}52 & 40 . N & 48 . N & 54.72 & 54.72 & 58.17 & 0 . N & 43.21 & 46.08 & 0 . N & 53.90\end{array}$

$53 \quad 36 . N 10 . N \quad 48.1157 .5959 .38$ 1.N 51.84 40.32 $\quad$ O.N 58.63

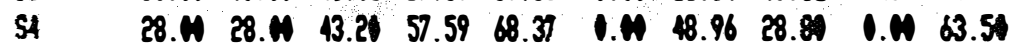


PRECO REAL - ALFACE (1985 - 90) - VALOR REAL DE DEZ/90

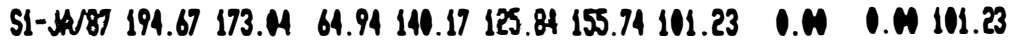

$52 \quad 129.78 \quad 173.4103 .88151 .07131 .64147 .95113 .69$

$53 \quad 108.15129 .78 \quad 96.56 \quad 140.17145 .77124 .59 \quad 98.12$

$54 \quad 129.78 \quad 95.17 \quad 77.87 \quad 155.74142 .03 \quad 132.38 \quad 93.44$

SI-FV $\quad 170.61 \quad 170.61 \quad 113.69136 .49124 .05136 .49122 .84$

S2 $\quad 170.61151 .65113 .69136 .49118 .21177 .43122 .84$

$53 \quad 83.1194 .78136 .49154 .14131 .57170 .61136 .49$

$54 \quad 68.24 \quad 68.21136 .49163 .78119 .70171 .61136 .49$

$51-12 \quad 59.34 \quad 59.34118 .69 \quad 118.6914 .33118 .69118 .69$

$52 \quad 39.56 \quad 65.94 \quad 69.19 \quad 112.75 \quad 92.22 \quad 118.69 \quad 71.21$

$53 \quad \quad \quad 59.31 \quad 59.31 \quad 59.31 \quad 112.75 \quad 89.49 \quad 118.69 \quad 65.28$

S4 $\quad \begin{array}{llllllll}59.34 & 59.34 & 54.36 & \text { IN.88 } & \pi 7.74 & 94.95 & 59.34\end{array}$

S1-Al $\quad 49.12 \quad 19.12 \quad 37.07 \quad 84.01 \quad 98.84 \quad 84.01 \quad 39.54$

S2 $\quad \begin{array}{llllllll}11.18 & 11.18 & 11.22 & 88.96 & 82.73 & 79.07 & 19.12\end{array}$

$\begin{array}{llllllll}53 & 54.91 & 54.91 & 82.33 & 79.97 & 76.11 & 88.96 & 88.96\end{array}$

$\begin{array}{llllllll}54 \quad 54.91 & 68.64 & 65.93 & 93.90 & 94.29 & 168.72 & 74.13\end{array}$

$\begin{array}{llllllll}51-14 & 60.26 & 75.32 & 77.47 & 77.47 & 78.09 & 168.46 & 77.47\end{array}$

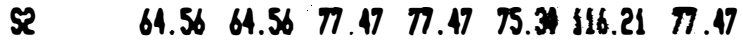

$53 \quad 75.32 \quad 86.089 .41116 .2170 .65116 .21$ IN.71

$54 \quad 107.41107 .60 \quad 77.47112 .33166 .83112 .33$ IN. 11

$55 \quad 154.64154 .6496 .84112 .33122 .64112 .33116 .21$

S1-NI $\quad 119.68 \quad 111.13 \quad 76.93 \quad 107.71$ IM.57 $\quad$ O.M 98.48

$52 \quad 85.48 \quad 85.48 \quad 61.55 \quad 98.48103 .71 \quad$ O.M 73.86

$53 \quad \begin{array}{lllllllllll}58.48 & 119.68 & 51.27 & 86.17 & 94.72 & 0.11 & 73.86\end{array}$

S4 111.13 1R.58 11.05 B6.17 1M4.88 O.N 55.39

$\begin{array}{llllllllllll}51-l & 54.73 & 51.73 & 46.89 & 44.74 & 98.23 & 0.1 \% & 50.67\end{array}$

$52 \quad 46.91 \quad 54.73 \quad 37.55 \quad 56.29 \quad 77.41 \quad$ O.M 45.41

$\begin{array}{lllllllllll}53 & 39.19 & 46.91 & 25.78 & 56.29 & 78.98 & \text { O.M } & 28.15\end{array}$

54 31.21 31.27 21.11 53.48 65.11 I.N 22.5

$55 \quad 31.27 \quad 31.27 \quad 18.75 \quad 53.48 \quad 61.92$

$\begin{array}{lllllll}51-46 & 22.45 & 26.94 & 22.46 & 53.87 & 59.26\end{array}$

$\begin{array}{llllll}52 & 29.93 & 29.93 & 26.94 & 51.18 & 58.56\end{array}$

$\begin{array}{llllll}53 & 26.94 & 26.94 & 26.94 & 43.10 & 58.31\end{array}$

$\begin{array}{lllllll}\text { S4 } & 26.94 & 26.94 & 17.94 & 40.40 & 61.90\end{array}$

$\begin{array}{llllll}\text { SI-ST } & 20.78 & 21.78 & 24.94 & 4.89 & 53.71\end{array}$

S

5

SA

S1-0

20

2

SA

S4

25

2

53

S4

SI-DI

52

5

SA

55

O.N O.N 114.62

O.N O.N 102.79

O.M O.N IN. 9

O.M O.N 95.54

O.N O.N 97.86

I.N O.N 107.14

O.N O.N 168.64

O.N O.N 96.61

O.N O.M 8.35

O.N O.N 88.29

O.N O.N 78.10

O.M O.A 55.45

O.N O.N 66.62

O.M O.N 52.48

O.M O.M $\quad 0.16$

O.M O.M 69.84

O.N O.N 62.13

O.M O.M 70.50

O.M $\quad$ O.N 87.54

O.N $\quad$ O.N 125.66

O.N O.M 99.83

I.N $\quad$ O.N 92.32

O.M I.M 87.21

O.N $\quad$ O.N 88.60

O.N O.N 89.99

O.N O.N 77.91

O.N O.N 54.61

O.N $\quad$ O.N 62.71

O.N O.N 59.15

$\begin{array}{lllll}\text { O.N } & 26.94 & \text { O.M } & O . M & 56.51 \\ \text { O.N } & 26.94 & O . M & 0 . M & 5.52\end{array}$

$\begin{array}{lllll}\text { O.M } & 26.94 & \text { O.N } & \text { O.M } & \text { R. } 24\end{array}$

$\begin{array}{lllll}0 . N & 26.94 & 0 . N & 0 . N & 52.69\end{array}$

$\begin{array}{llllll}\text { O.N } & 39.90 & \text { O.N } & \text { O.N } & 38.65\end{array}$

$\begin{array}{lllllllllll}16.62 & 16.62 & 24.94 & 39.9 & 51.62 & \text { O.N } & 24.94 & \text { O.N } & \text { I.N } & 32.32\end{array}$

16.62 $16.62 \quad 24.94 \quad 39.90 \quad 51.52 \quad$ O.N $24.94 \quad$ O.N $\quad$ O.N 36.11

$\begin{array}{llllllllllllll}21.78 & 21.78 & 24.94 & 37.4 & 53.46 & \text { O.N } & 24.94 & \text { O.N } & \text { O.N } & 30.87\end{array}$

$\begin{array}{lllllllllll}31.16 & 31.16 & 35.9 & 35.9 & 13.21 & \text { O.N } & 35.9 & \text { O.N } & \text { I.N } & 31.60\end{array}$

$\begin{array}{llllllllllllll}24.93 & 31.16 & 35.9 & 39.14 & 42.63 & \text { O.N } & 35.9 & \text { O.M } & \text { I.N } & 34.82\end{array}$

16.21 $16.21 \quad 39.06 \quad 44.87 \quad 38.86$ I.N 35.9 O.N $\quad$ O.N 31.86

$\begin{array}{llllllllllll}18.70 & 24.93 & 39.4 & 44.87 & 38.54 & \text { O.N } & 35.9 & \text { O.N } & \text { O.N } & 27.61\end{array}$

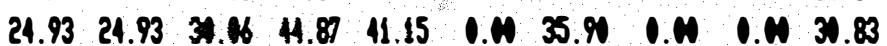

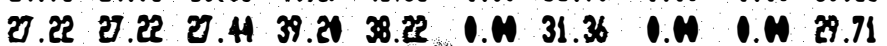

$\begin{array}{llllllllllllll}19.60 & 16.33 & 31.36 & 39.21 & 37.89 & \text { O.M } & 35.28 & \text { O.M } & \text { N.N } & 26.85\end{array}$

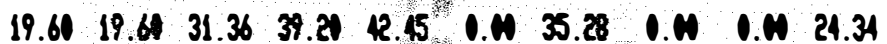

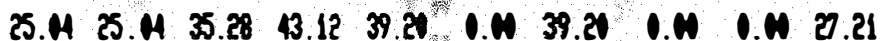

$\begin{array}{lllllllllllll}18.79 & 18.79 & 30.44 & 4.59 & 33.83 & \text { O.N } & 33.83 & \text { O.N } & \text { O.N } & 26.65\end{array}$

$\begin{array}{llllllllllll}18.79 & 18.79 & 35.44 & 43.97 & 41.71 & 0 . N & 33.83 & \text { O.N } & \text { O.N } & 31.36\end{array}$

$\begin{array}{llllllllllll}37.58 & 21.61 & 43.97 & 50.74 & 37.21 & \text { O.N } & 50.74 & \text { O.N } & \text { O.N } & 30.21\end{array}$

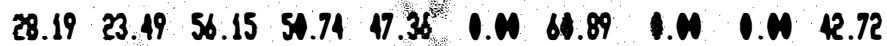

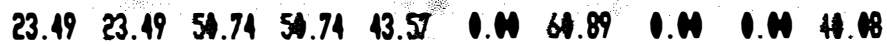


138.

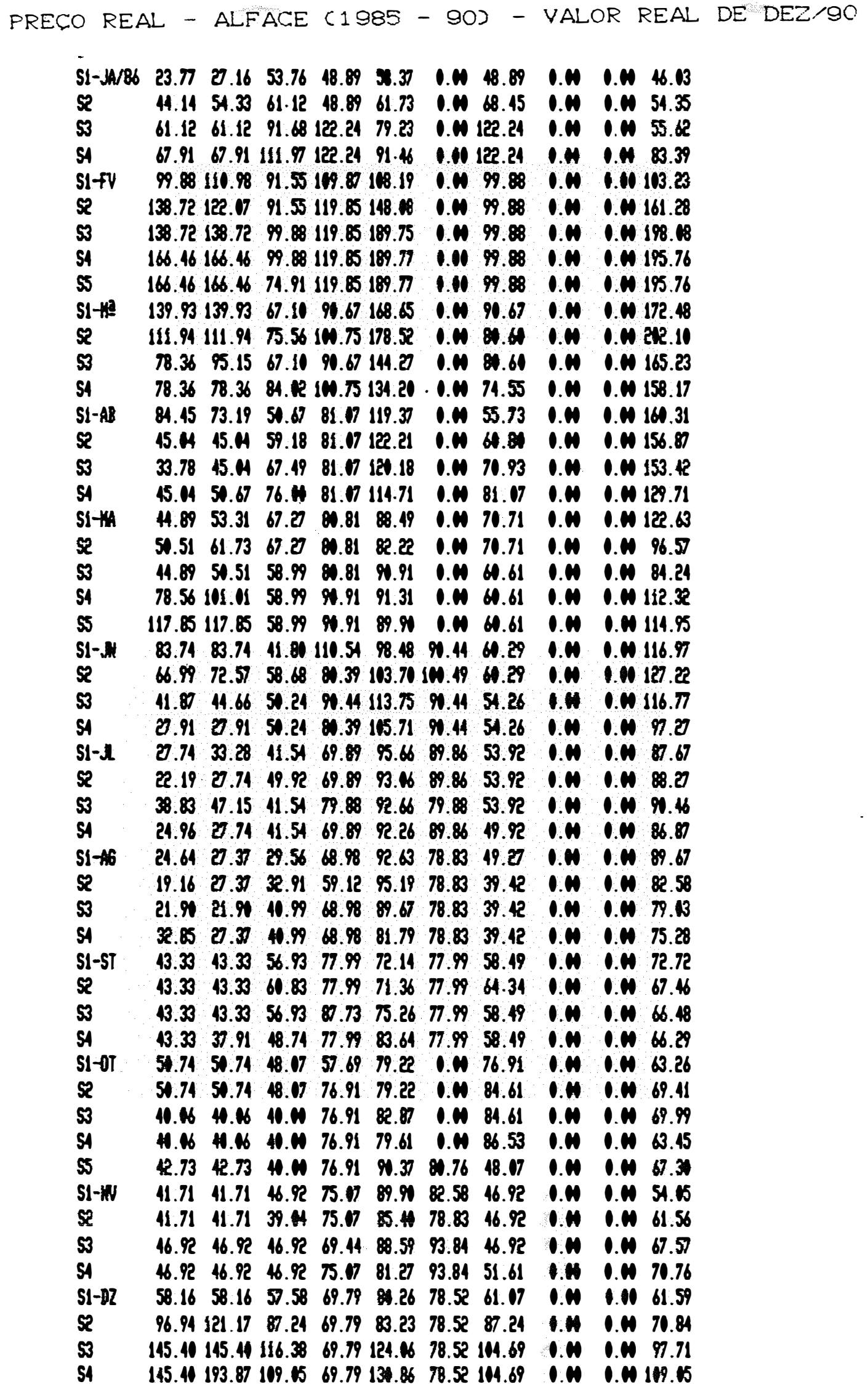




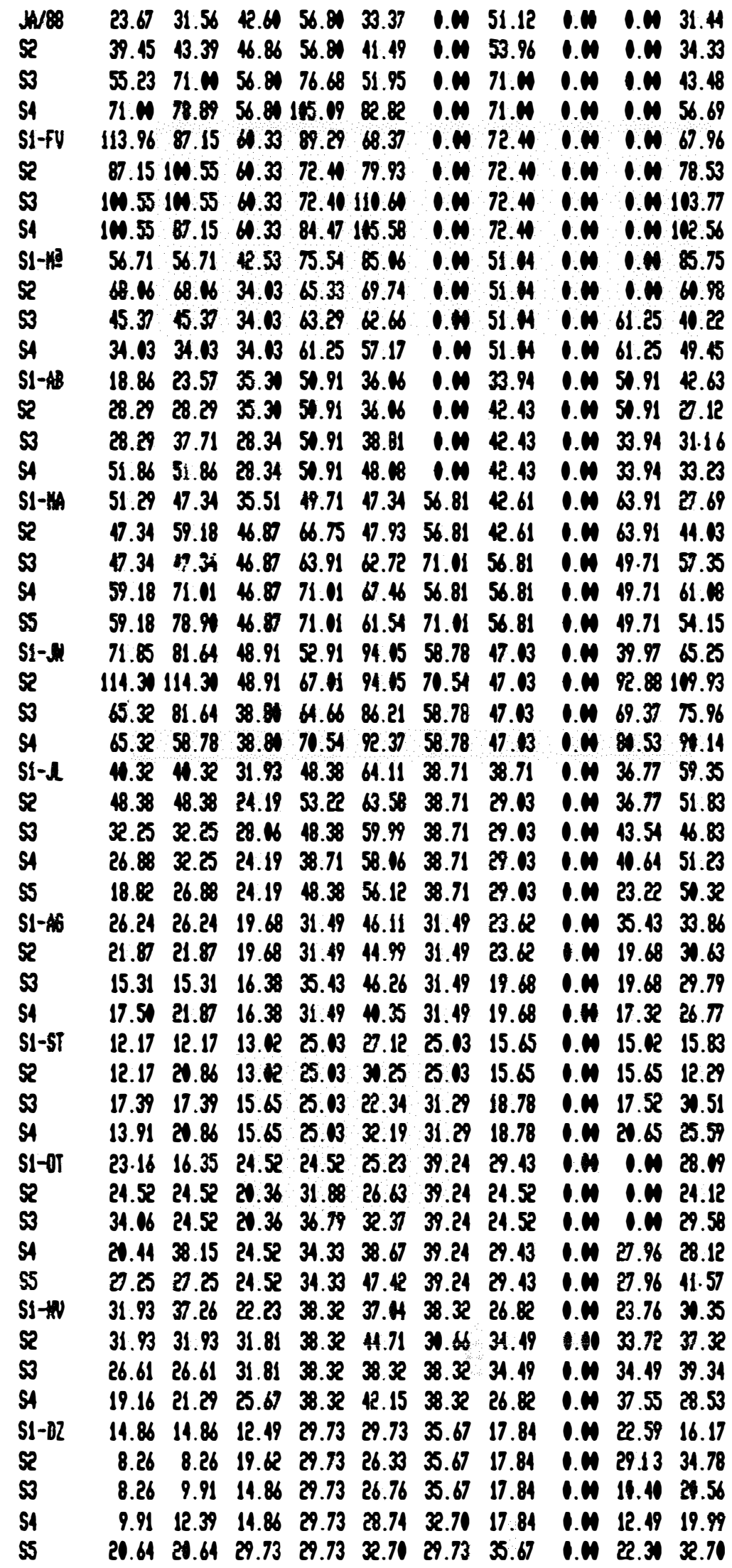


PRECO REAL - ALFACE (1985 - 90) - VALOR REAL DE DEZ 90

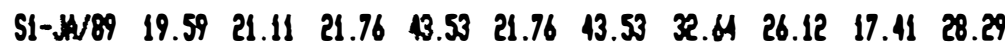

$\begin{array}{lllllllllll}52 & 36.13 & 21.15 & 65.29 & 80.05 & 39.47 & 65.29 & 87.15 & 26.12 & 32.64 & 23.94\end{array}$

$\begin{array}{lllllllllllll}53 & 71.82 & 41.35 & 89.23 & 168.81 & 60.94 & 168.81 & 168.81 & 43.53 & 31.82 & 58.76\end{array}$

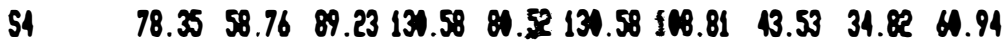

SIfV $\quad 82.92 \quad 81.76 \quad 97.33136 .26107 .06 \quad 1.0116 .81 \quad 38.93 \quad 31.15 \quad 42.83$

$\begin{array}{lllllllllll}52 & 99.98 & 52.56 & 79.81 & 116.84 & 97.33 & 0.1 & 97.33 & 38.93 & 31.15 & 68.13\end{array}$

$\begin{array}{llllllllllll}53 & 99.98 & 97.33 & 79.81 & 97.33 & 107.6 & 0.4 & 97.33 & 38.93 & 31.15 & 85.65\end{array}$

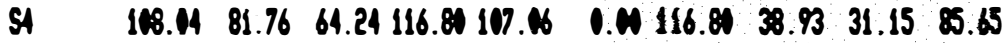

$\begin{array}{llllllllllll}51-12 & 77.71 & 78.46 & 76.59 & 112.49 & 82.21 & 112.09 & 93.41 & 37.36 & 93.41 & 69.12\end{array}$

$\begin{array}{llllllllllll}52 & 77.71 & 93.41 & 93.41 & 112.49 & 78.46 & 112.19 & 93.41 & 37.36 & 93.41 & 60.25\end{array}$

$\begin{array}{lllllllllllllll}53 & 77.71 & 93.41 & 93.41 & 112.09 & 74.73 & 112.09 & 93.41 & 84.07 & 93.41 & 85.93\end{array}$

$\begin{array}{llllllllllll}54 & 67.44 & 78.46 & 93.41 & 112.09 & 84.01 & 112.09 & 93.41 & 84.07 & 93.41 & 74.73\end{array}$

$\begin{array}{lllllllllll}\text { SI-AB } & 59.13 & 74.58 & 88.79 & 124.31 & 90.57 & 106.55 & 88.79 & 79.91 & 0.4 & 9.57\end{array}$

$\begin{array}{lllllllllllll}58 & 59.13 & 58.61 & 88.79 & 124.31 & 95.89 & 16.55 & 88.79 & 97.67 & 0.4 & 83.46\end{array}$

$\begin{array}{llllllllll}53 & 59.13 \quad 74.58 & 88.79 & 124.31 & 101.22 & 16.55 & 88.79 & 97.67 & 0.14 & 87.01\end{array}$

$\begin{array}{llllllllllll}54 & 59.13 & 58.60 & 72.81 & 115.43 & 95.89 & 16.55 & 88.79 & 97.67 & 0.41 & 87.01\end{array}$

$\begin{array}{lllllllllll}55 & 59.13 & 58.60 & 72.81 & 124.31 & 92.34 & 106.55 & 88.79 & 77.67 & 0.11 & 92.34\end{array}$

$\begin{array}{llllllllllll}51-14 & 43.61 & 2.51 & 78.71 & 125.94 & 70.84 & 94.46 & 78.71 & 62.97 & 0.4 & 75.57\end{array}$

$\begin{array}{llllllllllll}52 & \quad 13.61 & 56.67 & 78.71 & 110.21 & 85.01 & 110.21 & 78.71 & 70.84 & 0.40 & 70.84\end{array}$

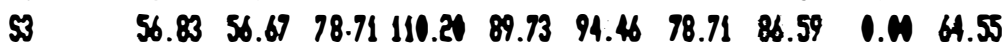

$\begin{array}{lllllllllll}S 1 & 13.61 & 43.61 & 64.55 & 125.94 & 89.29 & 125.94 & 78.71 & 62.97 & 0.01 & 89.73\end{array}$

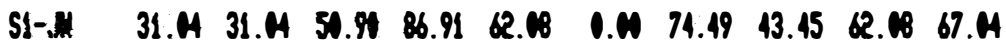

$\begin{array}{lllllllllll}52 & 33.52 & 34.39 & 40.79 & 86.91 & 68.29 & 0.4 & 74.49 & 43.45 & 19.66 & 54.63\end{array}$

$\begin{array}{lllllllllll}53 & 41.34 & 41.34 & 4.97 & 86.91 & 64.84 & 0.01 & 74.49 & 49.66 & 49.66 & 59.59\end{array}$

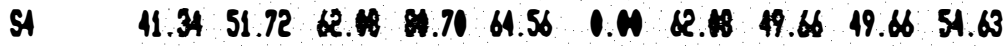

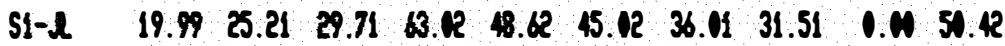

$\begin{array}{llllllllllllll}50 & 25 . N & 45.12 & 29.71 & 45.12 & 45.12 & 45.12 & 36.01 & 36.01 & \text { O.N } & 4.51\end{array}$

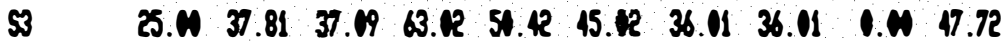

$\begin{array}{lllllllllllllll}54 & 37.51 & 37.81 & 36.91 & 72.13 & 51.42 & 49.52 & 45.02 & 45.02 & \text { O.N } & 48.62\end{array}$

$\begin{array}{llllllllllll}55 & 37.51 & 37.81 & 36.91 & 72.13 & 42.32 & \text { O.N } & 45.12 & 45.12 & \text { O.N } & 46.82\end{array}$

$\begin{array}{lllllllllllll}51-16 & 21.48 & 32.98 & 26.38 & 32.98 & 36.94 & 32.98 & 32.98 & 26.38 & 31.66 & 34.96\end{array}$

$\begin{array}{lllllllllll}52 & 32.98 & 41.32 & 27.4 & 32.98 & 41.55 & 32.98 & 32.98 & 36.28 & 31.66 & 36.94\end{array}$

$\begin{array}{llllllllllll}53 & 55.23 & 54.94 & 27.4 & 32.98 & 52.63 & 32.98 & 32.98 & 46.17 & 36.28 & 44.85\end{array}$

$\begin{array}{lllllllllll}54 & 32.98 & 27.48 & 27.4 & 39.57 & 54.13 & 32.98 & 32.98 & 26.38 & 36.28 & 42.21\end{array}$

$\begin{array}{lllllllllll}\text { SI-ST } & 19.78 & 25.69 & 19.47 & 23.74 & 33.39 & 23.74 & 23.74 & 23.74 & \text { O. } 10 & 25.64\end{array}$

$\begin{array}{llllllllllll}\text { S2 } & \quad & 19.78 & 29.68 & 19.47 & 28.49 & 33.71 & 28.49 & 23.74 & 28.49 & \text { 1.N } & 26.59\end{array}$

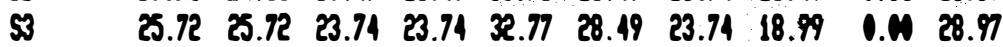

S1 $\quad \begin{array}{llllllllll}25.72 & 29.68 & 19.47 & 28.49 & 38.46 & 28.49 & 23.74 & 26.12 & \text { O.N } & 33.39\end{array}$

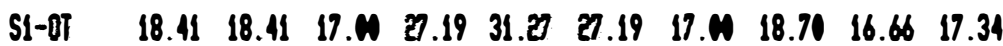

$\begin{array}{lllllllllll}52 & 14.16 & 17 . & 13.94 & 21.19 & 33.31 & 23.79 & 17 . & 18.70 & 16.66 & 21.41\end{array}$

$\begin{array}{lllllllllll}53 & 14.16 & 14.16 & 13.94 & 23.79 & 32.29 & 27.19 & 17 . \omega & 17 . N & 16.66 & 23.79\end{array}$

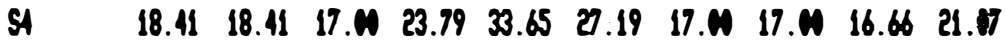

$\begin{array}{lllllllllll}55 & 18.41 & 17 . \omega & 17 . \omega & 23.79 & 17 . \omega & 27.19 & 17 . & 17 . \omega & 16.66 & 32.29\end{array}$

$\begin{array}{lllllllllll}S 1-N & 9.81 & 11.78 & 11.78 & 18.84 & 24.97 & 18.84 & 11.78 & 11.78 & 0 . N & 18.37\end{array}$

$\begin{array}{lllllllllll}52 & 11.78 & 14.76 & 15.55 & 18.84 & 23.56 & 23.56 & 14.13 & 11.78 & 0.01 & 17.69\end{array}$

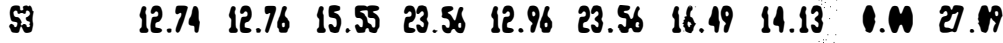

$\begin{array}{lllllllllll}54 & 14.72 & 19.63 & 21.04 & 23.56 & 26.02 & 23.56 & 18.84 & 11.78 & 0.01 & 18.37\end{array}$

$\begin{array}{lllllllllll}51-D 2 & 13.14 & 13.13 & 32.84 & 39.42 & \text { 21. } 54 & 31.53 & 28.38 & 12.61 & \text { O.N } & 13.72\end{array}$

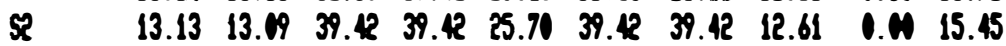

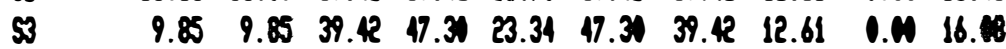

$\begin{array}{lllllllllll}54 & 13.13 & 13.09 & 31.53 & 55.18 & 47.31 & 47.34 & 39.42 & 15.77 & \text { O.W } & 22.23\end{array}$

$\begin{array}{llllllllllllllllll}55 & \quad 16.42 & 19.71 & 31.53 & 55.18 & 55.18 & 63.07 & 39.42 & 23.65 & \text { O.N } & 22.07\end{array}$ 
PRECO REAL - ALFACE (1985 - 90) - VALOR REAL DE DEZ'90

\begin{tabular}{|c|c|c|c|c|c|c|c|c|c|c|}
\hline$-3 / 49$ & $\begin{array}{r}11.47 \\
76.40 \\
114.65\end{array}$ & 95.94 & $\begin{array}{l}38.25 \\
76.40 \\
91.72\end{array}$ & $\begin{array}{r}4.21 \\
73.38 \\
137.58\end{array}$ & $\begin{array}{l}31.83 \\
47.42 \\
6971\end{array}$ & $\begin{array}{r}36.69 \\
64.21 \\
137.58\end{array}$ & $\begin{array}{r}45.86 \\
91.72 \\
110.97\end{array}$ & $\begin{array}{l}27.52 \\
73.38 \\
91.72\end{array}$ & O.M & $\begin{array}{l}22.84 \\
8.44\end{array}$ \\
\hline 54 & 95.51 & 114.65 & 91.72 & 137.58 & 8.59 & 137.58 & 111.07 & $1 N 89$ & 0 & 79.52 \\
\hline $\mathrm{SI}+\mathrm{FV}$ & 44.51 & 66.78 & 4.50 & 8.14 & 69.45 & Q1.14 & 53.43 & 58.77 & & \\
\hline & 66.78 & 44.50 & 44.51 & 80.14 & 69.67 & 89.14 & 53.43 & 48.18 & $\omega$ & 6.73 \\
\hline 53 & 44.51 & 55.65 & 53.43 & 80.14 & 75.71 & 80.14 & 64.11 & 42.74 & O.N & 22.40 \\
\hline S4 & 66.78 & 66.78 & 57.86 & 89.14 & 85.48 & 9.14 & 64.11 & 58.77 & O.N & 0.63 \\
\hline 55 & 42.96 & 49.11 & 31.91 & 73.66 & 55.66 & 44.21 & 35.36 & 44.21 & $0 . N$ & .93 \\
\hline $51-x^{2}$ & 85.92 & 85.92 & 85.92 & 73.66 & 74.99 & 58.93 & 73.66 & 73.66 & $0 . N$ & 5.66 \\
\hline 52 & 85.92 & 73.66 & 73.66 & 88.4 & 66.97 & 103.13 & 73.66 & 73.66 & & \\
\hline 5 & 61.38 & 59.42 & 73.66 & 88.40 & 77.05 & 113.13 & 73.66 & 58.93 & & 3.16 \\
\hline SA & 85.92 & 98.22 & 73.66 & 88.4 & 85.45 & 103.13 & 73.66 & 73.66 & & 44.82 \\
\hline 55 & 88.21 & 99.25 & 66.17 & 79.40 & $\pi .76$ & P2.63 & 66.17 & 66.17 & & 8.4 \\
\hline$S 1-A B$ & 82.71 & 82.71 & 77.18 & 79.40 & 82.34 & 105.87 & 66.17 & 66.17 & & 61.38 \\
\hline$\vec{x}$ & 66.17 & 66.17 & 66.17 & 92.63 & 81.60 & 15.87 & 66.17 & 52.93 & & 4.93 \\
\hline & 88.21 & 99.25 & 66.17 & 79.4 & 8.13 & 105.87 & 66.17 & 66.17 & & \\
\hline & 60.66 & $91 . N$ & 60.66 & 84.93 & 69.50 & 84.93 & 60.66 & 60.66 & & \\
\hline-14 & 89.88 & 80.88 & 60.66 & 97.16 & 76.85 & 84.93 & 60.66 & 67.94 & & 5.45 \\
\hline 5 & 04.66 & 70.76 & 60.66 & 72.81 & T3.22 & 84.93 & 64.66 & 48.53 & v & 5.52 \\
\hline & 101.09 & 01.12 & 60.66 & 72.81 & 97.16 & 81.93 & 69.66 & 84.93 & O.N & 1.36 \\
\hline & 9.73 & 92.74 & 6.36 & 77.90 & 84.98 & 77.90 & 55.64 & $\pi .90$ &. $\mathbf{N}$ & 2.19 \\
\hline$-\mu$ & 74.19 & 74.19 & 55.64 & 55.64 & 74.19 & 66.77 & 55.64 & 48.7 & & 8.17 \\
\hline & 74.19 & 55.64 & 6.36 & 55.64 & 74.19 & 66.77 & 4.52 & 44.22 & O.N & 3.3 \\
\hline & 55.64 & 55.64 & 37.10 & 55.64 & 71.83 & 66.77 & 41.52 & 41.52 & $\boldsymbol{n}$ & 6.11 \\
\hline & 46.36 & 55.64 & .10 & 55.64 & 72.34 & 66.77 & 44.52 & 33.39 & & 2.4 \\
\hline & 49.25 & $41 . M$ & 32.84 & 68.95 & 61.55 & .10 & 39.40 & 39.40 & & 0.98 \\
\hline$-\boldsymbol{l}$ & 11.M & 11.M & 32.84 & 68.95 & 59.10 & 9.10 & 39.4 & 29.55 & & 5.84 \\
\hline & 57.45 & 57.47 & & & & & 39.4 & & & \\
\hline & & & & & & & & & & \\
\hline & 137.84 & 0.84 & $\begin{array}{l}56.14 \\
58.11\end{array}$ & 69.78 & $\begin{array}{r}104.01 \\
98.86\end{array}$ & $\begin{array}{l}45.01 \\
52.34\end{array}$ & $\begin{array}{l}5.01 \\
52.34\end{array}$ & $\begin{array}{l}18.51 \\
78.51\end{array}$ & & \\
\hline & 58.14 & 58.14 & 36.34 & 69.78 & 103.89 & 52.34 & 52.34 & 52.34 & & 5.45 \\
\hline 5 & 36.31 & 43.61 & .34 & 69.78 & 74.54 & 43.61 & 13.61 & 34.89 & & .58 \\
\hline 54 & 51.89 & 72.69 & .06 & 52.34 & 68.91 & 43.61 & 13.61 & 52.34 & & 1.76 \\
\hline & 78.18 & 65.17 & 18 & 62.46 & 61.68 & & 31.23 & 54.65 & & \\
\hline SI-ST & 32.53 & 45.55 & 8.18 & 54.65 & 56.60 & 46.85 & 31.23 & 46.85 & & 4.65 \\
\hline 52 & 71.56 & 97.59 & 78.18 & 54.65 & 60.9 & 46.85 & 31.23 & 62.46 & & 1.31 \\
\hline & 52.15 & 62.46 & .18 & 51.65 & 65.58 & .65 & 31.23 & 39.04 & & \\
\hline SA & 45.59 & $57 . N$ & 22.89 & 11.13 & 59.16 & 47.87 & 27.36 & 34.28 & & 51.43 \\
\hline $31-0 T$ & 3..21 & $57 . N$ & २2.89 & 47.87 & 52.61 & 47.87 & 34.21 & 47.87 & & 49.84 \\
\hline & 35.56 & 57.11 & 22.89 & 11.03 & 53.35 & & 34.21 & 41.03 & & 41.69 \\
\hline 5 & 57.11 & 68.39 & २2.81 & 34.21 & 52.85 & 47.87 & 34.21 & 43.77 & 0.1 & 44.51 \\
\hline & 68.39 & 68.39 & 22.89 & 47.87 & 56.18 & 54.71 & 11.13 & 43.77 & & 13.69 \\
\hline $51+w$ & 33.97 & 48.53 & 29.11 & 58.23 & 33.97 & 46.58 & 40.76 & 34.94 & & 6.98 \\
\hline 5 & 72.79 & 72.79 & 38.82 & 58.23 & 72.79 & 58.23 & 46.58 & 34.94 & & 19 \\
\hline 53 & 72.79 & 72.79 & 48.52 & 116.46 & 72.79 & 116.46 & 46.58 & 52.41 & & \\
\hline S4 & 48.53 & 63.19 & $0 / .75$ & & 49.69 & & 69.88 & 40.76 & & \\
\hline SI-BI & 41.67 & 50.11 & 16.67 & $89 . N$ & $51 . N$ & & St.M & $35 . N$ & & 9.83 \\
\hline Se & SN.N & $\alpha$ & 16. & & $45 . N$ & 70 & 60.1 & $35 . \omega$ & . & \\
\hline $\begin{array}{l}53 \\
54\end{array}$ & $54 . M$ & 75.1 & .3 & & $54 . N$ & & 60.N & & & \\
\hline & & & & & & & & & & \\
\hline
\end{tabular}




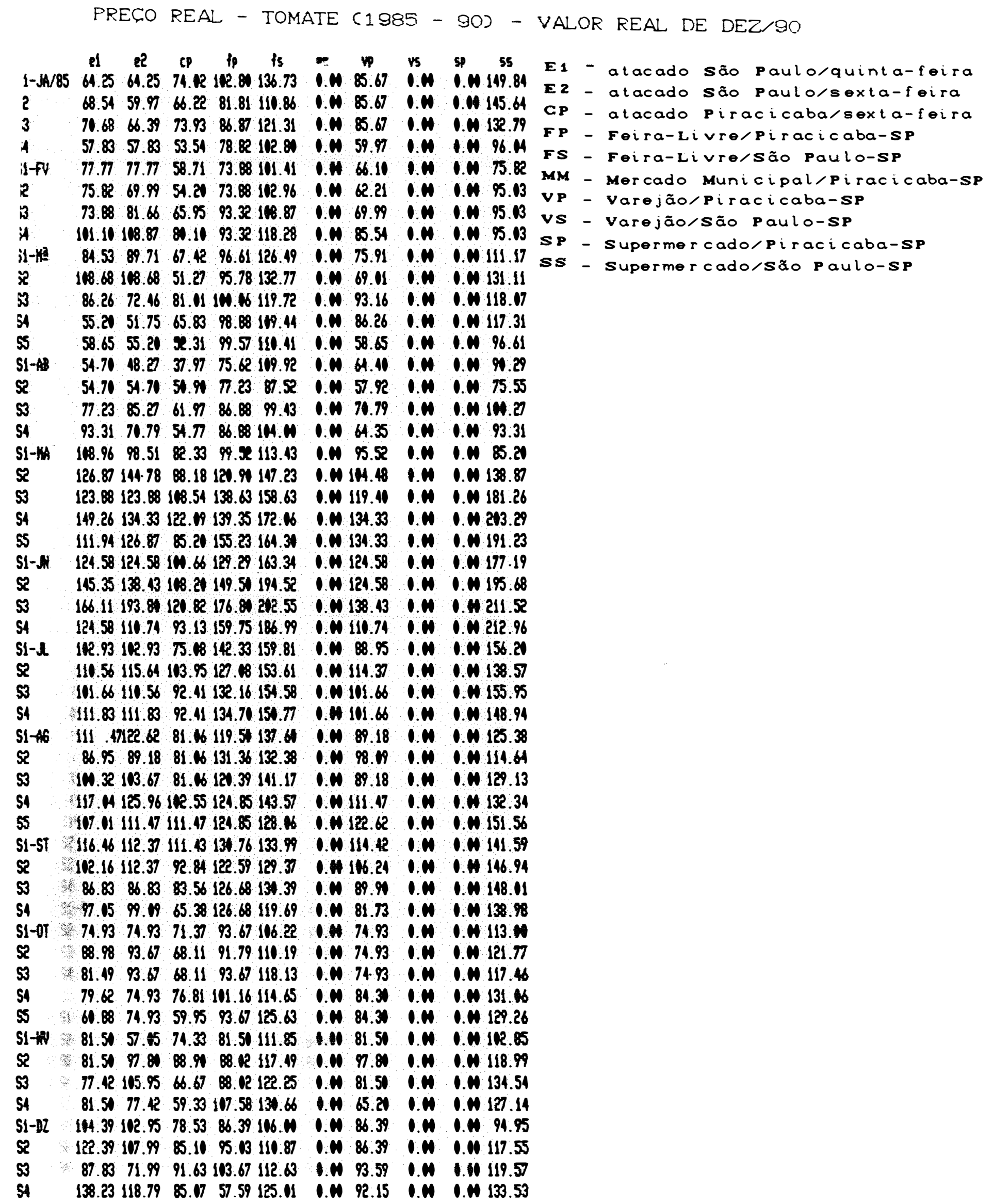


PRECO REAL - TOMATE (1985 - 90) - VALOR REAL DE DEZ.90

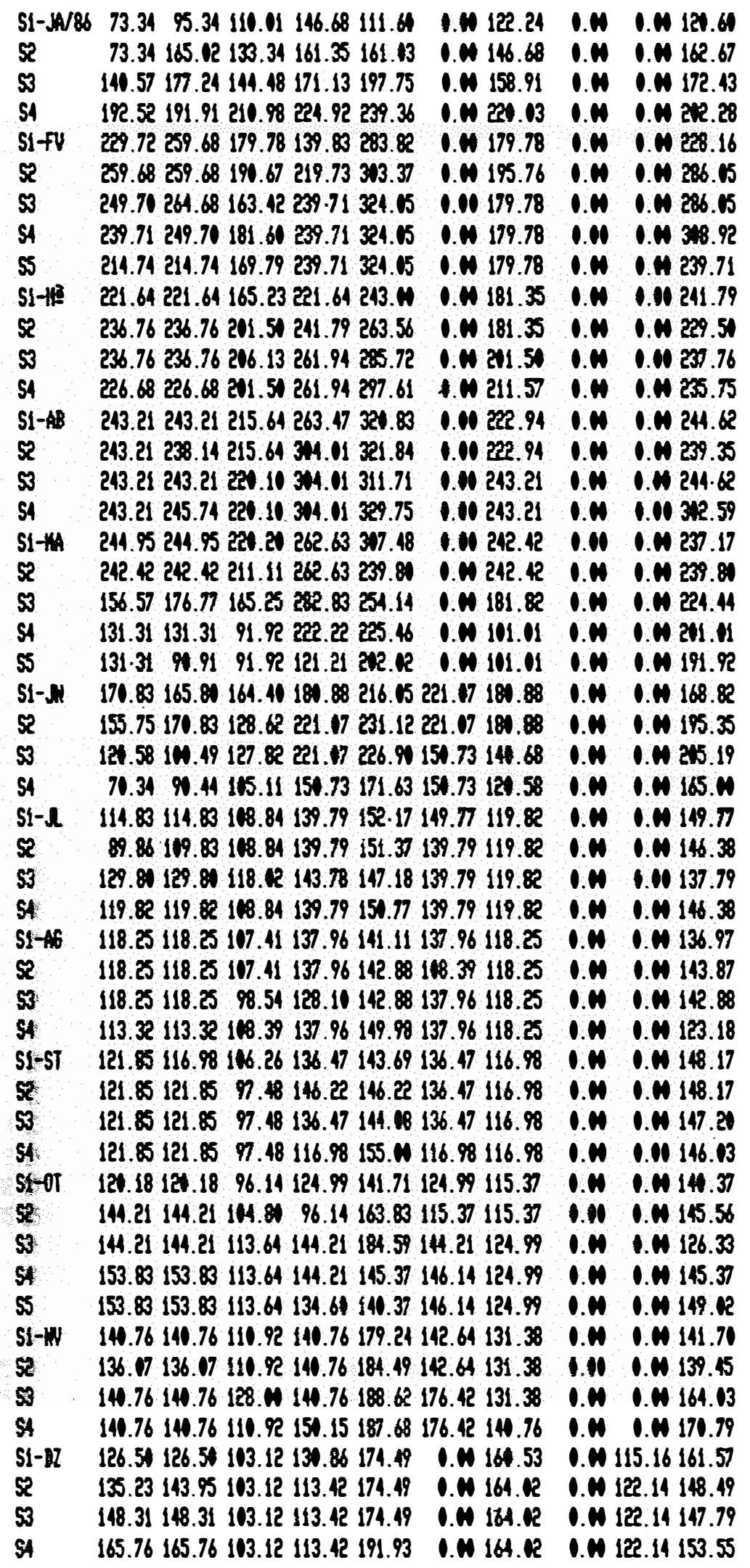


$\begin{array}{lllll}51-\$ 487147.95116 .89166 .21 & 124.59164 .88 & 1.00155 .74\end{array}$

$\begin{array}{llllllll}52 & \quad 147.85 & 147.85 & 77.87 & 124.59 & 197.17 & \mathbf{1} . \mathrm{N} & 155.74\end{array}$

$\begin{array}{llllllll}53 & 132.38 & 132.38 & 77.87 & 124.59 & 171.31 & \mathbf{1 . N} & 155.74\end{array}$

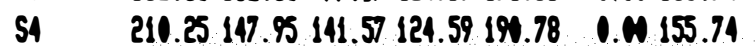

SI-FV 214.97 214.97 24. 24324.73 232.03 163.78232 .03

Se $\quad 259.32$ 259.32 244.73 245.68 266.15 259.32 232.03

$53 \quad 397.10259 .32 \quad 24.73225 .21296 .45259 .32232 .03$

$54 \quad 232.03259 .32155 .05252 .5429 .03245 .68170 .61$

S1-He $\quad 172.10172 .10 \quad 92.93124 .02192 .51189 .91 \mathrm{NN} .88$

$52 \quad 172.10172 .42 \quad 97.21139 .56213 .31172 .10106 .82$

$53 \quad 219.57219 .57161 .77201 .77225 .39172 .10178 .03$

S4 255.18255 .18 178.03 178.03 261.11 189.90 213.64

S1-AB $\quad 192.74$ 222.39 $134.82 \quad 172.97227 .33 \quad 192.74177 .91$

S2 $\quad 266.87$ 266.87 170.70 158.14 240.48 177.91197 .68

$53 \quad 291.58266 .87143 .81182 .85233 .86247 .11237 .22$

$54 \quad 192.74217 .45166 .25227 .22247 .10197 .68197 .68$

S1-11 $\quad 170.44$ 123.95 $133.79147 .21232 .41 \quad$ O.N 154.94

$52 \quad 143.32168 .46105 .67147 .27180 .7496 .84116 .21$

$53 \quad 131.70147 .2188 .01116 .21171 .29 \quad 0.41$ IN.71

$54 \quad 170.44170 .4488 .01116 .21161 .76$

$55 \quad 170.44154 .94$ 105.67 139.45 2M. 24

S1- $13 \quad 138.48 \quad 123.10 \quad 78.35110 .79159 .66$

52 $\quad 89.24 \quad 89.24 \quad 55.95 \quad 98.48 \quad 158.98$

$53 \quad 110.7914 .63 \quad 64.3214 .63125 .84$

S4 IH. 63 IM.63 69.92 92.32142 .48

S1-l $\quad 166.96 \quad 9.07 \quad 46.05 \quad 92.89112 .59$

S2 $\quad 78.81 \quad 81.63 \quad 51.17 \quad 92.89168 .82$

$53 \quad 76.481 .63 \quad 51.1784 .41103 .92$

S4 $\quad 76.0181 .63 \quad 63.95 \quad 67.55104 .37$

55 $\quad 92.89123 .65 \quad 76.79 \quad 92.89166 .96$

51-\$6 118.52 156.23 110.17 129.29 124.29

$52 \quad 156.23185 .86122 .15154 .84158 .22$

53 $\quad 148.15145 .1597 .94161 .61164 .11$

S4 121.21 145.45 122.15145 .45153 .91

SI-ST $\quad 159.59137 .15 \quad 113.21 \quad 114.71 \quad 161.19$

52 $\quad 124.68137 .55102 .74134 .66167 .07$

$53 \quad \quad \quad \quad 139.15144 .63 \quad 99.75139 .64162 .09$

S4 II2.21 122. 9999.75139 .64162 .88

S1-0T $\quad 103.21 \quad 132.37 \quad 61.47 \quad 125.64117 .79$

$52 \quad 105.45 \quad 65.25 \quad 77.18 \quad 125.64166 .57$

$53 \quad 121.15121 .1571 .34112 .18$ 112.18

S4 $\quad 87.54 \quad 98.72 \quad 71.34112 .18104 .68$

S5 $\quad$ IN.96 IN.96 71.34112 .18 1M.23

$5 !-N \quad 115.84125 .4481 .36109 .76107 .37$

$52 \quad \quad 107.87125 .4488 .97199 .76124 .11$

53 $\quad 137.20145 .4106 .63109 .76133 .91$

$54 \quad 145.04145 .4105 .84137 .20129 .83$

SI-D2 $\quad 93.12116 .70 \quad 76.79118 .39131 .08$

S2 $\quad 104.86 \quad 116.70 \quad 76.79 \quad 101.48118 .39$

53. $\quad$ I68.24 $123.47 \quad 76.79118 .39135 .34$

$54 \quad 91.33108 .24 \quad 76.79125 .16 \quad 126.85$

55
1.N IN.71

O.N 131.70

O.N IN. 63

1.N 89.01

1.N 83.09

O.1 89.01

1.10 56.29

I.N 61.92

1.N1 56.29

I.N 61.92

1.N 61.92

1.0086 .19

1.N1 129.29

I.N 115.82

1. 1113.13

I.N 99.75

I.N 99.75

O.N 99.75

1.N 14.73

O.M 76.28

1.N 8.77

1.N 76.28

O.N 89.74

O.N 89.74

1.N 8.24

1.01101 .92

I. 1133.28

I.N133.28

T.N 101.48

I.N 94.71

O.N 67.65

1.4 91.33

O.N 84.57
O.N 107.46140 .63

O.N 91.89138 .61

O.N 101.23140 .48

O. 155.74162 .41

O.N $\quad 0.01145 .36$

O.N I.N 240.22

1.N 1.0238 .62

1.N I.N 281.85

O.N O.N 197.73

O.N I.N 167.59

O.N O.N 213.43

-.N 1.4238 .19

O.N O.N 214.58

O.N O.N 181.37

O.N I.N 272.01

I.N I.N 219.13

O.N O.N 165.17

O.N O.N 151.07

O.N O.N 118.07

O.N O.N 148.13

O.N O.M 147.35

O.N O.M I28. 33

O.N O.N IEA.R

O.N O.N IBB.79

O.N O.N 14.78

O.N I.N 88.19

O.N O.N B..2)

O.N O.N 82.53

O.N I.M 82.31

O.N O.N 84.05

O.N O.N 168.55

I.N O.N 118.25

I.N O.N 168.51

O.N O.N 174.76

I.N O.N 127.23

I.N I.N 127.23

O.N O.N 146.33

O.N I.N 135.95

O.N O.N 99.39

O.N O.N 86.73

O.N O.N IM. I1

O.N O.N 94.32

O.N O.N $94 . N$

O.H O.M 81.85

O.N O.N 107.

I.N I.N 128.38

1.01 O.N 126.81

O.N O.N I H.21

O.N I.N 101.61

I.N I.N IN. 19

O.N O.N 110.48

O.N $\quad . N 180.48$ 
PRECO REAL - TOMATE (1985 - 90) - VALOR REAL DE DEZ/9O

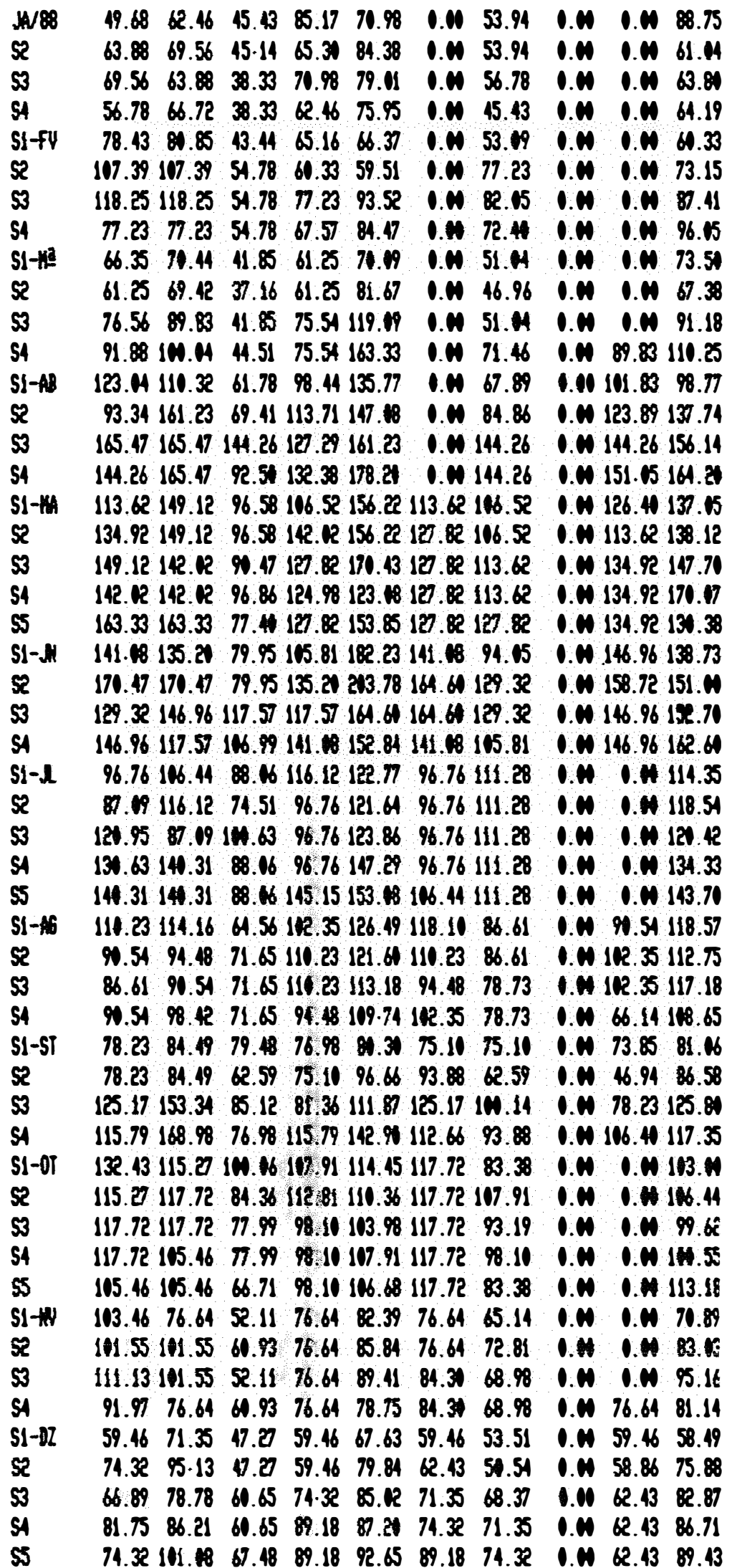


PRECO REAL - TOMATE (1985 - 90) - VALOR REAL DE DEZ/90

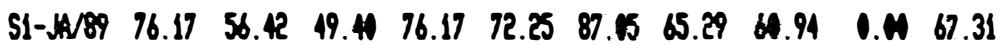

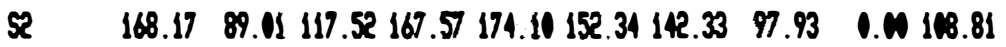

$53 \quad 187.16237 .22117 .52174 .10176 .28174 .10141 .46174 .10 \quad 0.0167 .57$

$54 \quad 171.93217 .63117 .52174 .10262 .39167 .57 \quad 119.70174 .10 \quad 0.0195 .87$

SIfV $\quad 141.52 \quad 145.99 \quad 105.12 \quad 155.73 \quad 171.31 \quad 136.26 \quad 126.53 \quad 136.26 \quad$ O.N 163.51

$52 \quad 159.23 \quad 141.52 \quad 114.85155 .73 \quad 198.55 \quad 136.26 \quad 145.99145 .99 \quad$ O. $N$ 157.67

$53 \quad 153.78194 .66157 .67194 .66 \quad 246.34175 .19184 .93194 .66 \quad$ O.N 198.55

$54 \quad 153.78194 .66157 .67194 .66210 .23194 .66184 .93194 .66 \quad$ N.W 214.13

S1-He $\quad 147.58 \quad 186.81 \quad 143.85215 .49211 .76 \quad 196.15186 .81 \quad 196.15162 .53 \quad 217.36$

S2 $\quad 195.29$ 221.44 168.13 224.18 224.18 224.18 245.19 196.15 $\quad$ I.4 216.70

$53 \quad 254.74$ Z54.63 186.81 261.51 224.18 229.78 224.18 229.78 N.N 246.59

$54 \quad 297.03297 .13215 .49261 .54276 .48252 .21212 .86229 .78 \quad$ O.N 265.22

SI-AB $\quad 159.82 \quad 159.82159 .82 \quad 266.37237 .96231 .85$ 213.09 213.09 213.09 239.85

52 $\quad 159.82$ 249.54 177.58 213.49 232.63 213.09 159.82 213.09 213.09 221. 27

$53 \quad 185.57$ 225.53 177.58 213.09 251.39 213.09 213.09 218.12 213.09 246.83

$54 \quad 242.15$ 225.53 177.58 234.85 245. 6 213.09 195.34 218.42 213.09 207.31

$55 \quad 241.51225 .53195 .31266 .37268 .14231 .05234 .85218 .42213 .4 \mathrm{cos} .80$

S1 $178.89178 .84173 .17236 .14245 .99221 .4241 .66221 .4 \quad 1 . N 266.05$

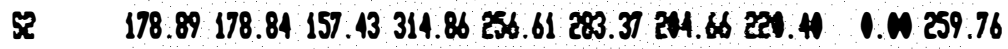

33 $\quad 178.89178 .84157 .43263 .37255 .03$ 251.88 24..66 212.53 N.N 284.22

S4 $\quad 143.10128 .78157 .43283 .37251 .88 \quad 299.11125 .94181 .14 \quad$ N.N 251.31

S1-M 112.86112 .86111 .74 223.48 $192.41173 .82 \quad 124.15142 .78148 .99192 .4$

$52 \quad 101.56101 .56 \quad 111.74186 .23197 .41173 .22124 .15142 .78148 .99186 .23$

$53 \quad 84.55 \quad 73.36 \quad 95.60186 .23186 .23161 .4124 .15 \quad 93.12148 .99181 .27$

$54 \quad 56.3756 .13 \quad 95.60186 .23161 .4124 .15111 .74 \quad 93.12 \quad 121.67 \quad 157.68$

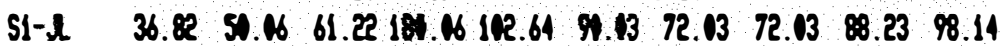

$52 \quad 53.21 \quad 36.82 \quad 61.22 \quad 168.41110 .74 \quad 90.13 \quad 72.03 \quad 63.12 \quad 90.03 \quad 81.93$

$53 \quad 53.21 \quad 53.21 \quad 69.32 \quad 135.05116 .24 \quad 96.03 \quad 81.03 \quad 67.52 \quad 90.03 \quad 90.83$

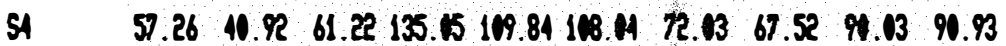

$55 \quad 57.62 \quad 57.26 \quad 53.12 \quad 135.05 \quad 118.84116 .4 \quad 67.52 \quad 67.52 \quad 90.03 \quad 97.23$

$\begin{array}{llllllllllllll}51-46 & 31.31 & 29.98 & 39.57 & 98.94 & 71.17 & 65.96 & 46.17 & 52.77 & 56.6 & 52.11\end{array}$

$\begin{array}{lllllllllllllllll}52 & 44.97 & 44.97 & 35.62 & 79.15 & 78.49 & 65.96 & 65.96 & 62.66 & 58.70 & 60.68\end{array}$

$\begin{array}{llllllllllll}53 & & 44.97 & 53.95 & 50.79 & 65.96 & 89.04 & 65.96 & 59.36 & 59.36 & 58.70 & 75.85\end{array}$

$\begin{array}{lllllllllllllll}51 & 65.96 & 65.96 & 50.79 & 65.96 & 93.4 & 65.96 & 59.36 & 65.96 & 58.70 & 87.06\end{array}$

$\begin{array}{llllllllllllll}\text { SI-ST } & 73.37 & 49.62 & 38.46 & 17.49 & 69.90 & 17.49 & \$ 2.74 & 56.98 & 85.47 & 63.16\end{array}$

$\begin{array}{llllllllllllll}58 & 97.11 & 79.86 & 64.58 & 71.23 & 79.31 & 85.47 & 71.23 & 90.22 & 85.47 & 90.70\end{array}$

$53 \quad 97.11$ 103.52 $75.51 \quad 71.23 \quad 91.17 \quad 71.23 \quad 71.23 \quad 71.23 \quad 81.73 \quad 98.31$

$54 \quad 194.22 \quad 172.66 \quad 85.95 \quad 85.47 \quad 166.21 \quad 85.47 \quad 56.98128 .21 \quad 75.98165 .25$

S1-0T IN.11 168.99 77.16101 .97104 .69 \& .88 IN.97 146.16 O.N 118.97

$52 \quad 139.02 \quad 123.99 \quad 69.34 \quad 81.98121 .01 \quad 101.9794 .78$ 135.97 $\quad$ O.N 124.07

53 $\quad 115.88115 .88 \quad 77.16 \quad 101.97 \quad 160.41 \quad 95.18 \quad 81.98 \quad 130.97 \quad$ I.N 139.36

$54 \quad 115.88168 .15 \quad 69.31101 .97134 .87 \quad 95.1878 .18135 .97 \quad$ I.N 121.01

$55 \quad 115.91 \quad 168.09 \quad 63.90 \quad 84.98 \quad 117.27 \quad 101.97 \quad 78.18 \quad 129.17 \quad$ O.N 123.05

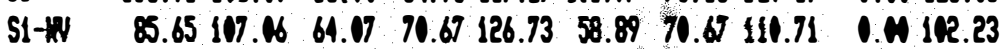

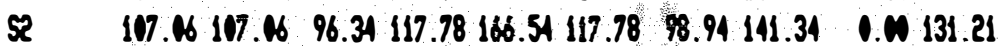

$53 \quad 133.94107 .4101 .29141 .34148 .64141 .34115 .42141 .34 \quad$ O.N 158.53

$54 \quad 139.19117 .78$ 106.N 141.31 175.26 141.31 $124.85153 .11 \quad$ O.N 117.26

$\begin{array}{lllllllllll}51-02 & 71.66 & 71.66 \quad 63.07 & 94.61 & 113.05 & 94.60 & 77.26 & 86.72 & 70.95 & 106.74\end{array}$

$52 \quad 71.66 \quad 71.66 \quad 56.76 \quad 94.64114 .31 \quad 94.61 \quad 70.95 \quad 94.60 \quad 70.95101 .22$

$53 \quad 89.57 \quad 71.66 \quad 55.1594 .64101 .54110 .37$ 78.84 $94.64 \quad$ O.N IN.59

$\begin{array}{llllllllll}54 & 114.66 & 93.03 & 70.95 & 94.60 & 128.34 & 110.37 & 86.72 & 94.60 & 1.4112 .89\end{array}$

$55 \quad 114.63114 .66 \quad 70.95110 .37189 .21110 .37162 .49134 .02 \quad 1 . N 149.31$ 
PRECOO REAL - TOMATE (1985 - 90) - VALOR REAL DE DEZ/90

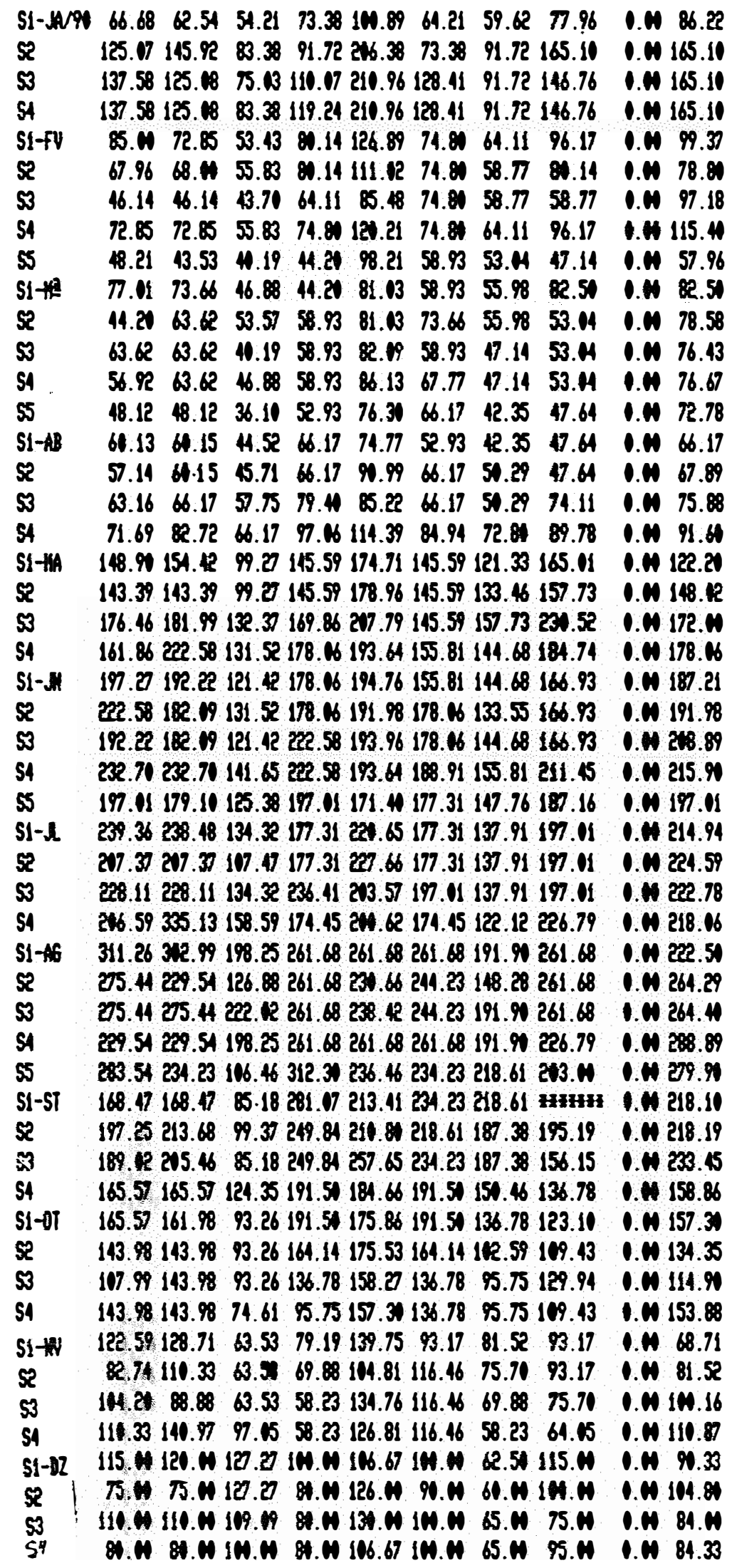


PRESO REAL - BATATA (1985 - 9O) - VALOP REAL DE DEZ $9 O$

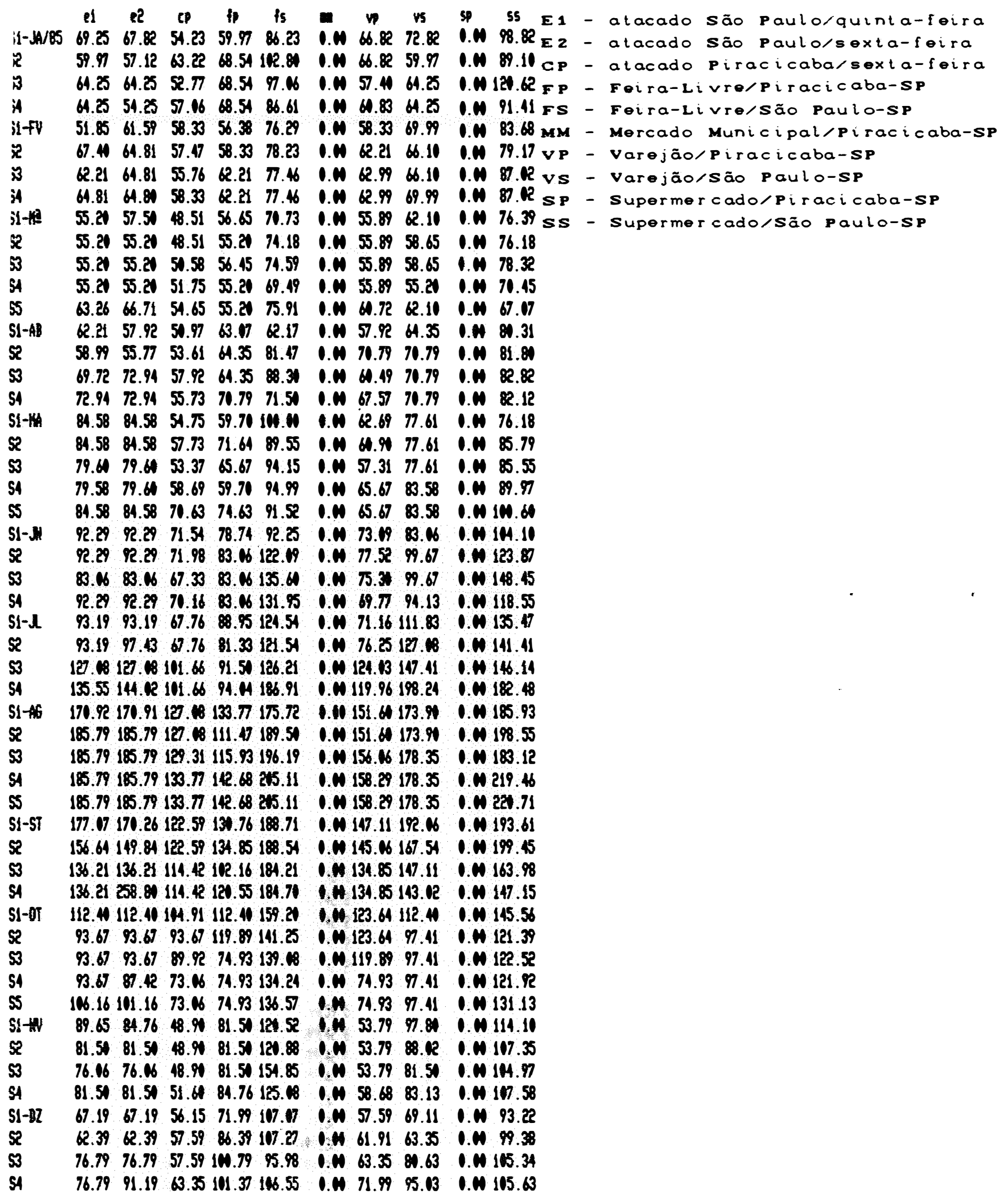




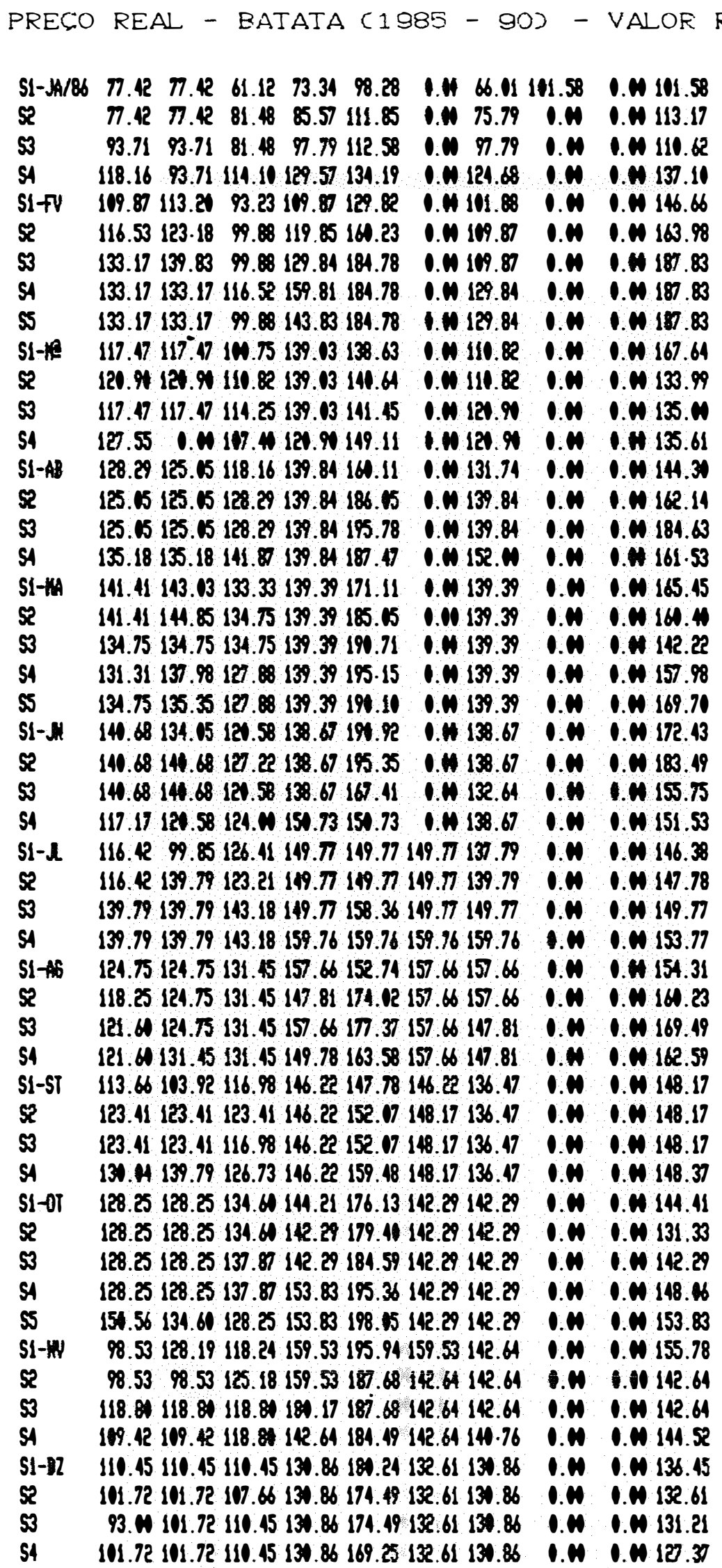


PRESO REAL - BATATA (1985 - 90) - VALOR REAL DE DEZ/90

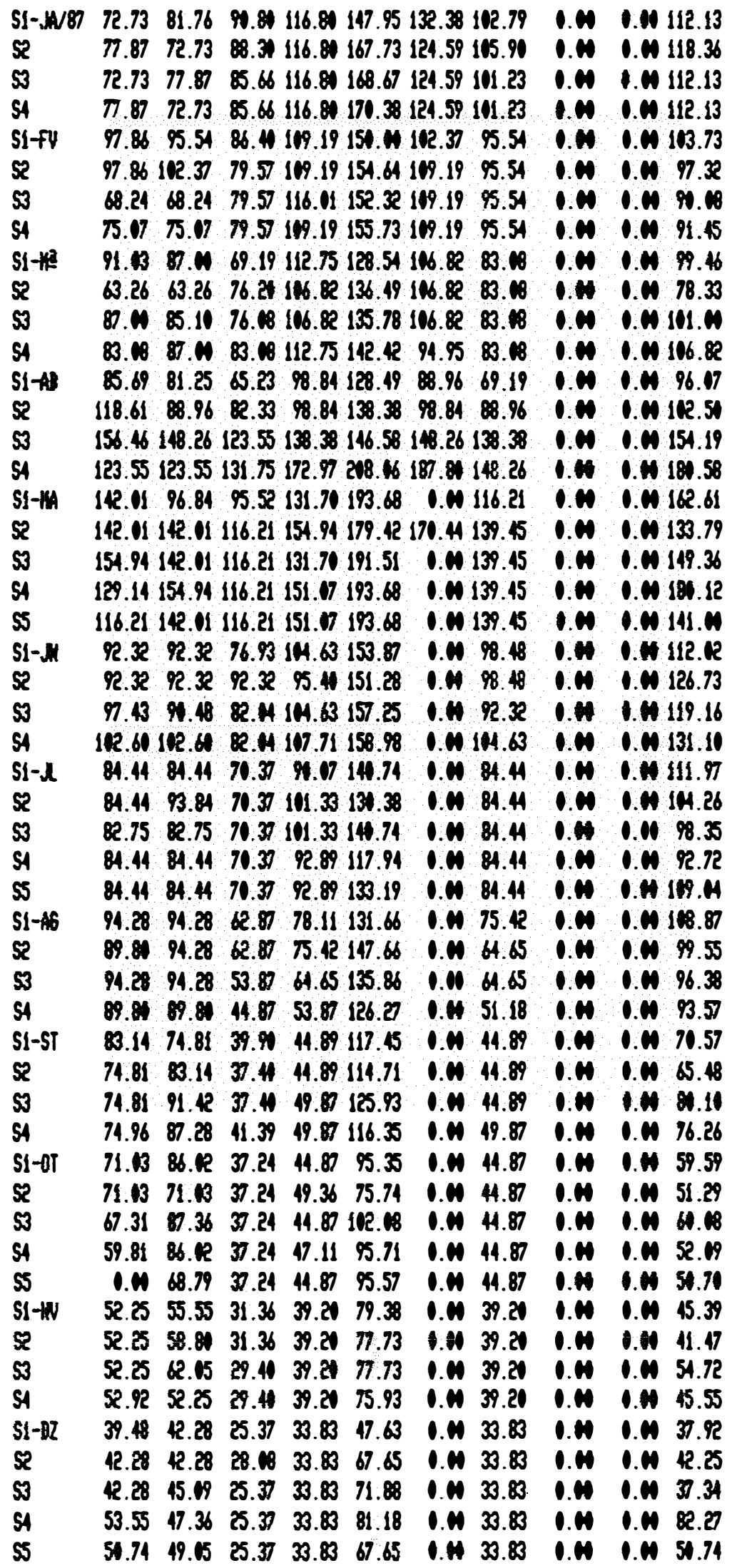




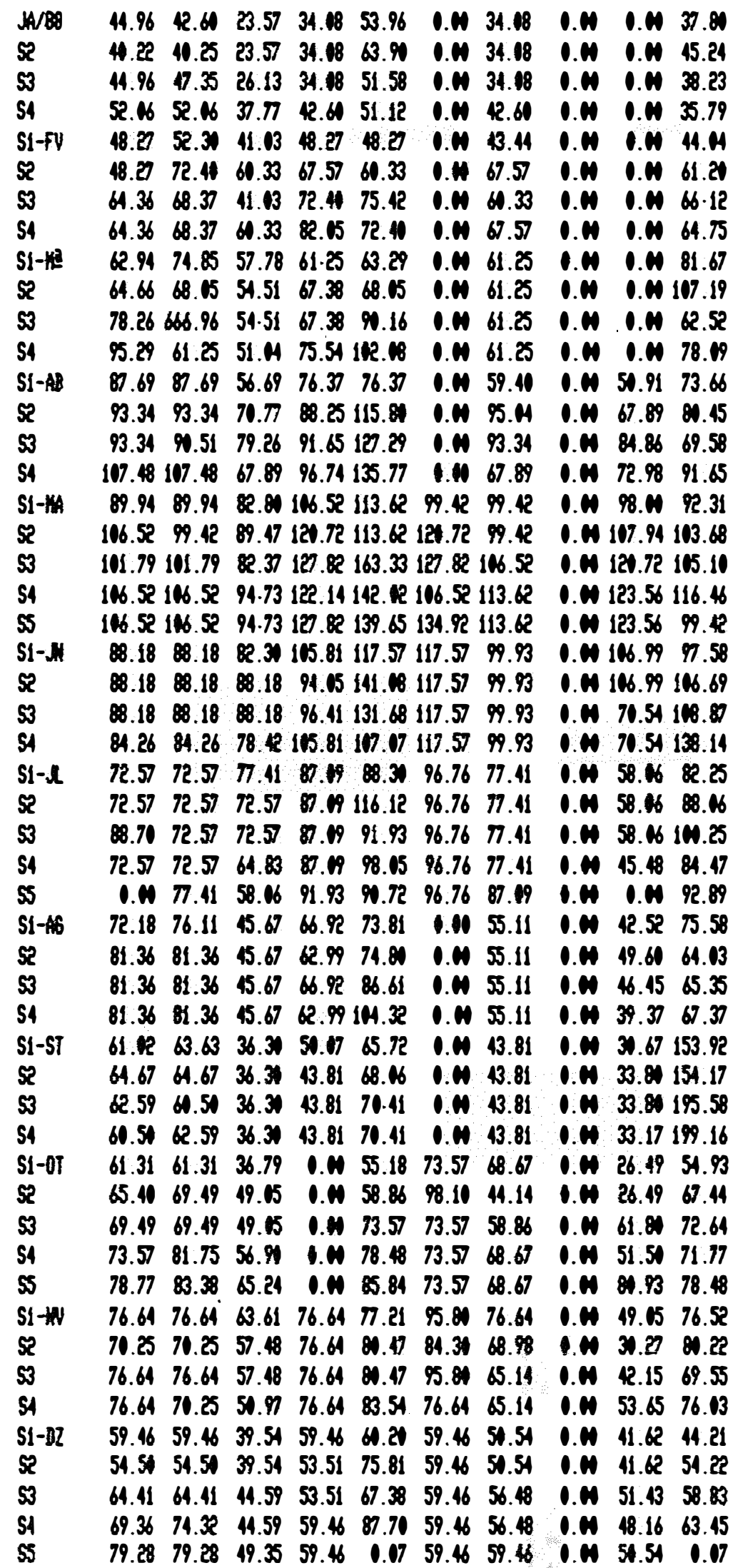




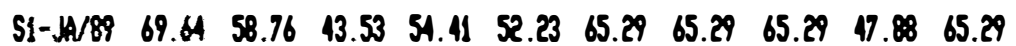
$\begin{array}{lllllllllll}52 & 84.88 & 71.82 & 65.29 & 97.93 & 82.70 & 97.93 & 87.05 & 82.70 & 82.70 & 71.82\end{array}$ $\begin{array}{lllllllllllll}53 & 71.82 & 82.70 & 65.29 & 87.05 & 95.76 & 108.81 & 87.05 & 97.93 & 69.64 & 91.4\end{array}$

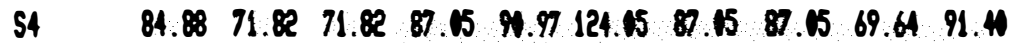
$\begin{array}{llllllllllllll}S 1 \text { fV } & 79.81 & 83.70 & 71.08 & 97.33 & 85.65 & 97.33 & 77.86 & 87.61 & 62.29 & 87.60\end{array}$ $\begin{array}{llllllllllll}52 & 89.54 & 93.44 & 70.18 & 97.33 & 126.53 & 97.33 & 87.61 & 87.61 \quad 62.29 & 66.18\end{array}$ $53 \quad 93.4483 .70 \quad 79.81 \quad 116.81163 .17 \quad 97.33107 .06113 .17103 .17169 .01$ $54 \quad 83.7083 .70 \quad 87.60120 .69116 .81103 .17107 .06101 .22103 .17 \quad 97.33$ 51 the $\quad 87.8089 .6784 .07112 .09127 .03168 .35112 .7599 .01 \quad 16.7599 .01$ $52 \quad 166.48166 .4893 .41158 .79139 .77112 .09112 .0999 .01168 .35110 .22$ $53 \quad 117.69117 .6991 .54121 .43139 .77131 .77112 .09110 .22121 .43113 .96$ $54 \quad 119.56119 .56102 .75140 .11186 .81140 .11121 .43110 .22112 .09127 .03$

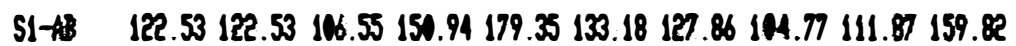

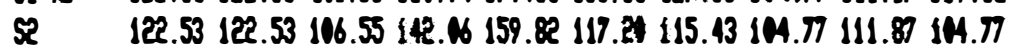
$53 \quad 127.86127 .861166 .55142 .06 \quad 195.34124 .31115 .43$ 144.77 111.87159 .82 S4 $\quad 138.51138 .51124 .31142 .6218 .42177 .58115 .43144 .7799 .67168 .70$

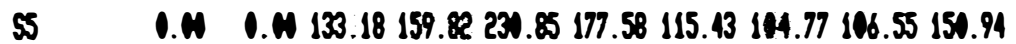
S1-1. $\quad 134.67217 .25149 .56236 .1424 .66173 .17188 .91264 .48112 .33162 .33$ $52 \quad 270.78270 .78288 .09393 .57314 .86393 .57346 .34283 .37399 .11362 .18$ $53 \quad 217.25217 .25182 .62314 .86267 .63314 .86236 .14251 .88299 .11251 .88$

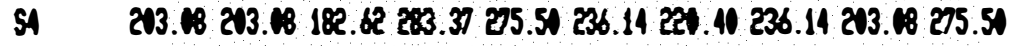

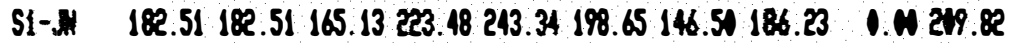
$52 \quad 268.58192 .44186 .23248 .31265 .69186 .23148 .99211 .06 \quad$ I.N 198.65 $53 \quad 171.33171 .33165 .13248 .31245 .83186 .23148 .99211 . \% \quad$ O.N 213.61 $54 \quad 182.51182 .51144 .02235 .89228 .44173 .82184 .02$ 198.65 N.N 225.96

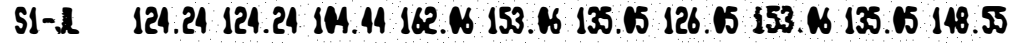
$52 \quad 124.24$ 143.15 144.44 162.N 172.86 135.15 135.05 153.06 135.05 139.55 $53 \quad 116.14116 .14119 .74162 .06153 .06162 .06144 .05144 .05135 .60142 .25$ S4 $\quad 139.55154 .86112 .54162 .06156 .66141 .05135 .05135 .05115 .24142 .97$ $55 \quad 139.53139 .55126 .95162 .0157 .56150 .4144 .05134 .55115 .24144 .05$ S1-A6 IR2.23 $112.23 \quad 76.51 \quad 165.53 \quad 155 . N \quad 131.92 \quad 98.91 \quad 92.31 \quad 85.75110 .81$

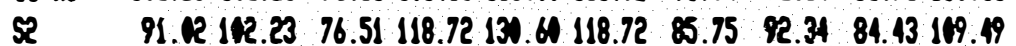
$53 \quad 79.15$ 91.R $76.51 \quad 98.94$ 131.92 $112.13 \quad 85.75 \quad 92.34 \quad 58.70 \quad 97.62$ $\begin{array}{lllllllllllll}54 & 79.81 & 79.81 & 54.74 & 98.94 & 131.92 & 79.15 & 79.15 & 92.34 & 58.70 & 98.94\end{array}$ $\begin{array}{llllllllllllllllll}51-S T & 57.46 & 57.46 & 39.41 & 94.97 & 98.77 & 56.98 & 47.49 & 80.73 & 52.23 & 56.51\end{array}$ $\begin{array}{lllllllllllll}52 & 73.61 & 65.53 & 47.49 & 85.47 & 91.65 & 94.97 & 47.49 & 8 & 0.73 & 37.99 & 64.58\end{array}$ $\begin{array}{lllllllllllllll}53 & 73.61 & 73.61 & 63.16 & 61.73 & 16.37 & 71.23 & 71.23 & 75.98 & 56.98 & 72.18\end{array}$

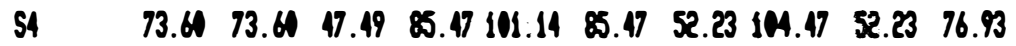
$\begin{array}{lllllllllll}51-07 & 52.69 & 52.69 & 33.99 & 61.18 & 67.98 & 67.98 & 42.49 & 74.78 & 37.39 & 49.63\end{array}$ $\begin{array}{lllllllllll}52 & 52.69 & 52.69 & 33.99 & 61.18 & 66.96 & 122.37 & 40.79 & 61.18 & 37.39 & 49.63\end{array}$ $\begin{array}{lllllllllll}53 & 50.99 & 52.69 & 33.99 & 50.99 & 75.46 & 67.98 & 40.79 & 67.98 & 37.39 & 52.35\end{array}$

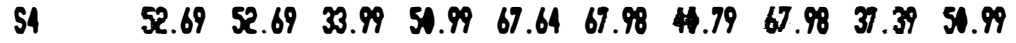
$\begin{array}{lllllllllll}55 & 52.69 & 52.69 & 33.99 & 50.99 & 72.40 & 61.18 & 40.79 & 67.98 & 37.39 & 46.23\end{array}$ $\begin{array}{lllllllllll}S !+W & 48.76 & 48.76 & 29.44 & 42.40 & 70.67 & 47.11 & 35.33 & 54.18 & 0.4 & 46.17\end{array}$ $\begin{array}{lllllllllll}52 & 61.01 & 61.01 & 43.11 & 70.67 & 54.65 & 47.11 & 51.82 & 56.53 & 1.10 & 55.59\end{array}$ $\begin{array}{lllllllllll}53 & 65.01 & 65.01 & 47.11 & 56.53 & 70.67 & 71.67 & 54.18 & 61.25 & 0.46 & 66.43\end{array}$ $\begin{array}{lllllllllll}54 & 65.01 & 61.01 & 49.47 & 58.89 & 94.22 & 82.45 & 56.53 & 73.02 & 0.41 & 61.48\end{array}$ $\begin{array}{lllllllllll}51-32 & 38 . N & 40.84 & 26.84 & 44.15 & 52.03 & 47.31 & 36.26 & 47.31 & 1.4 & 39.26\end{array}$ $\begin{array}{lllllllllll}52 & 46.21 & 46.20 & 26.84 & 39.42 & 63.07 & 47.30 & 33.11 & 47.31 & 31.53 & 46.67\end{array}$ $\begin{array}{llllllllllll}53 & & 59.76 & 54.40 & 28.38 & 39.42 & 59.91 & 47.31 & 34.69 & 55.18 & 0.40 & 45.72\end{array}$ $\begin{array}{lllllllllll}54 & 76.15 & 89.71 & 34.69 & 47.31 & 55.97 & 47.31 & 34.69 & 63.17 & 1.01 & 47.31\end{array}$ $\begin{array}{lllllllllll}55 & 76.15 & 89.71 & 56.76 & 55.18 & 69.37 & 55.18 & 70.95 & 94.60 & \text { O.N } & 54.45\end{array}$ 
PRECO REAL - BATATA (1985 - 90) - VALOR REAL DE DEZ/9O

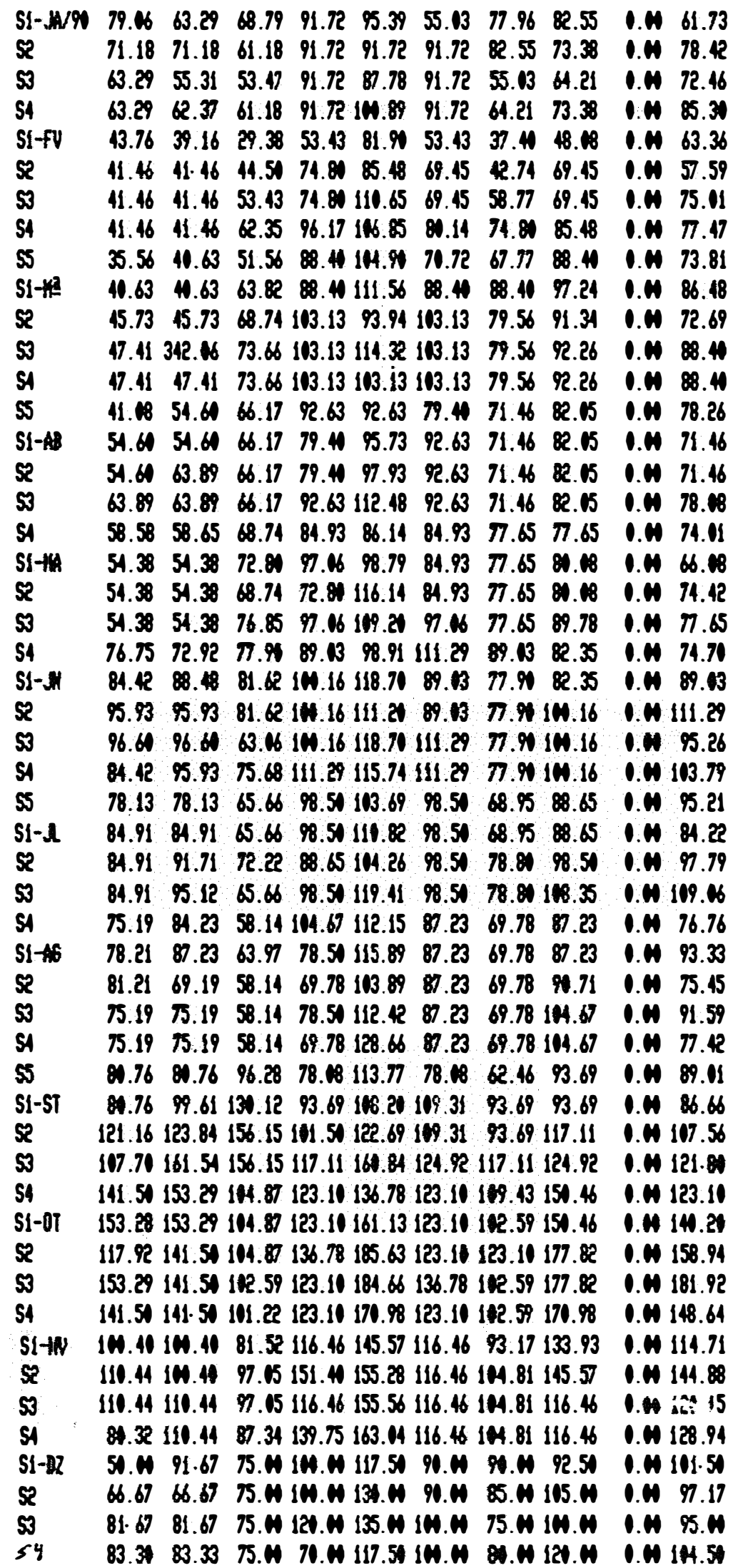


154.

FREGO REAL - BANANA (1985 - 90) - VALOR REAL DE DEZ/90

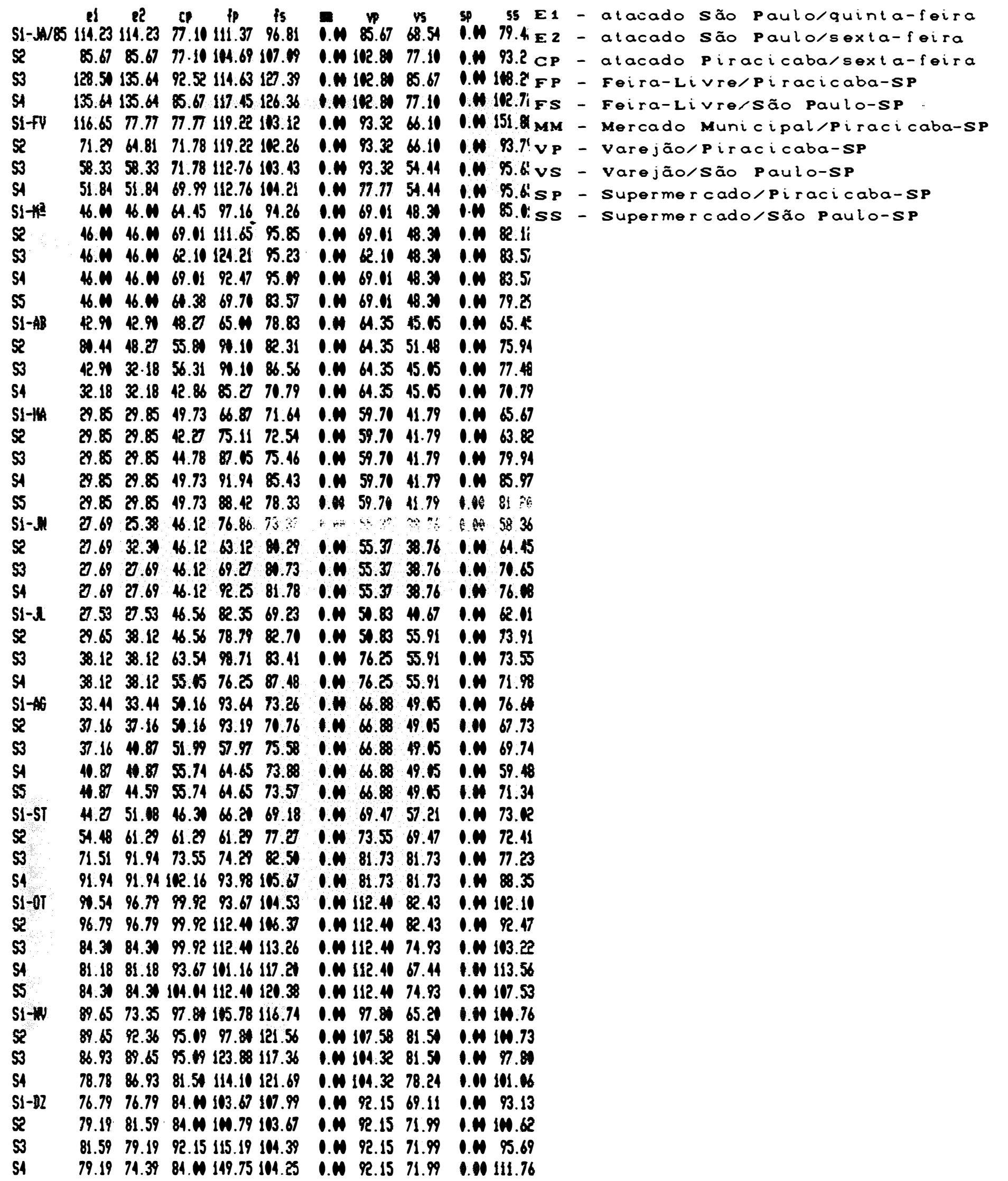




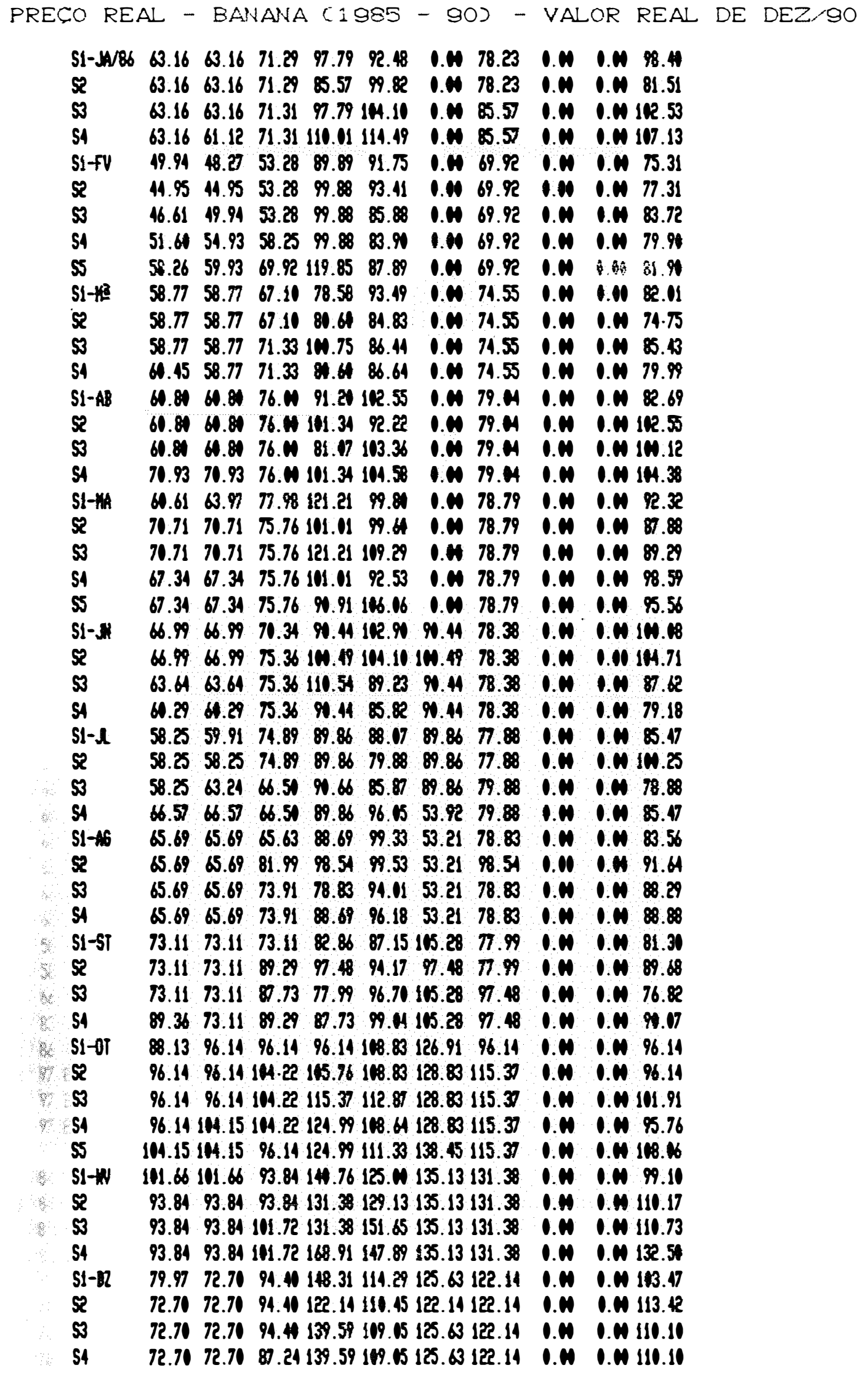


PRECO REAL - BANANA (1985 - 90) - VALOR REAL DE DEZ/9O

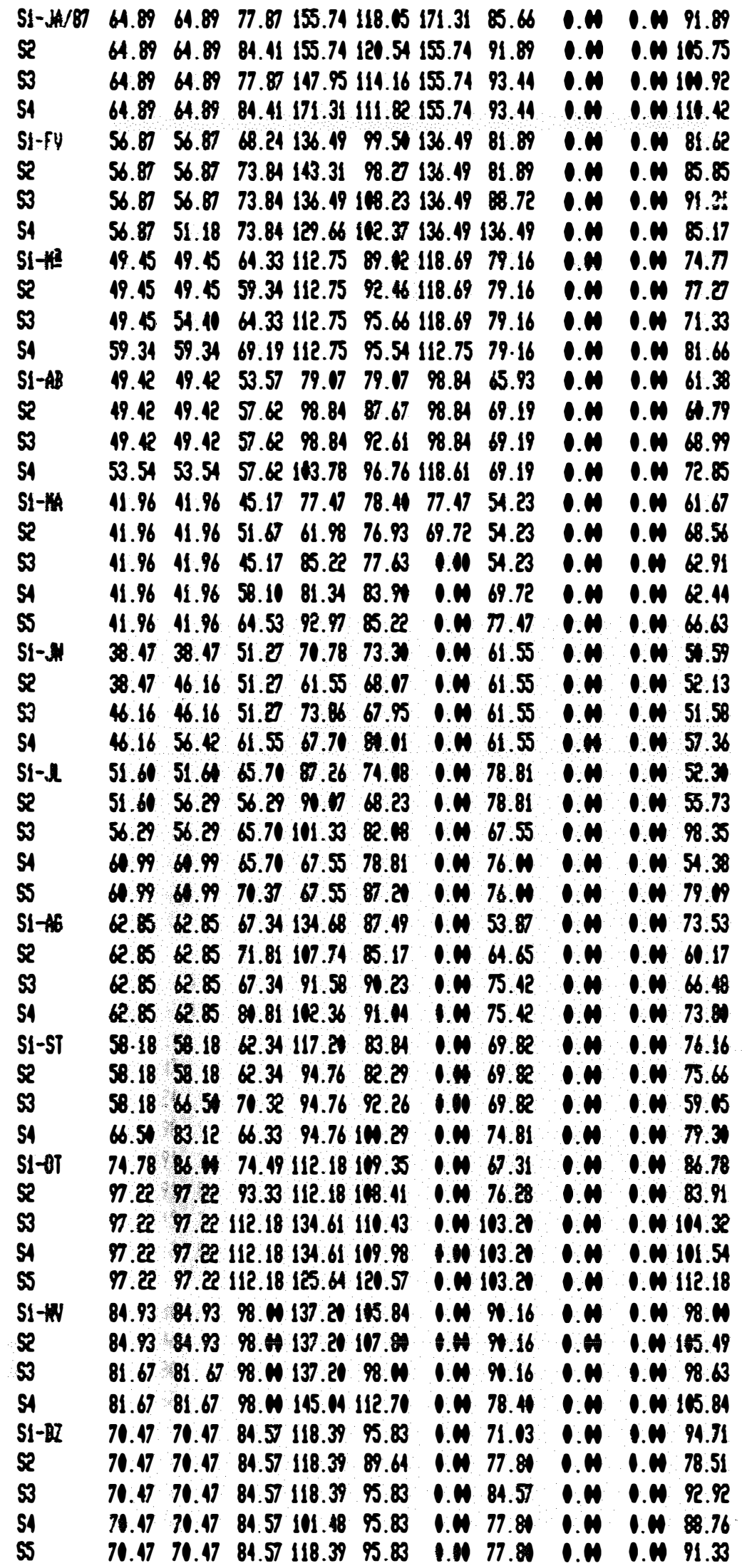




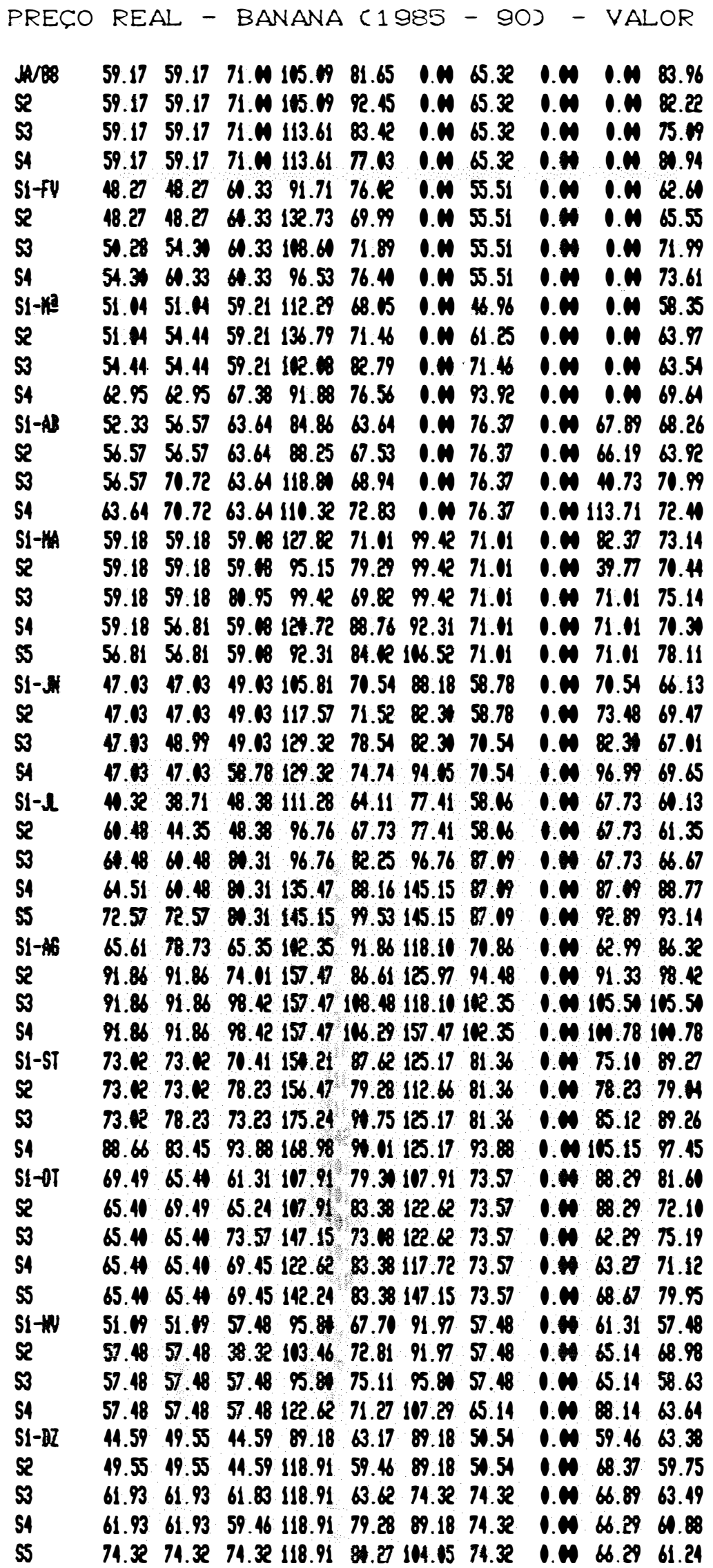


PREGO REAL - BANANA (1985 - 90) - VALOR REAL DE DEZ 90

$\begin{array}{lllllllllll}51-5489 & 54.41 & 50.05 & 51.41 & 108.81 & 56.58 & 87.05 & 65.29 & 56.58 & 65.29 & 58.76\end{array}$

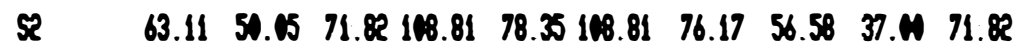

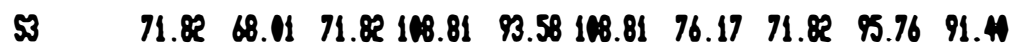

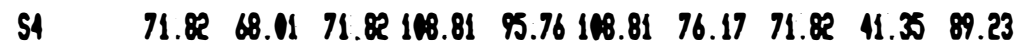

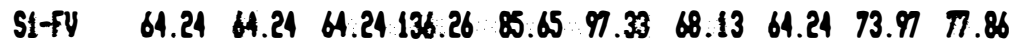

$\begin{array}{lllllllllll}58 & 64.24 & 64.24 & 64.24 & 155.73 & 87.60 & 97.33 & 68.13 & 64.24 & 73.97 & 77.86\end{array}$

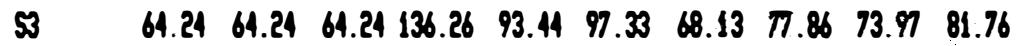

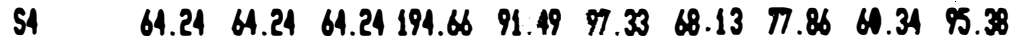

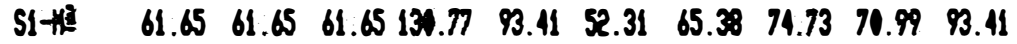

$\begin{array}{lllllllllll}52 & 61.65 & 70.05 & 61.65 & 149.45 & 97.14 & 93.41 & 65.38 & 74.73 & 14.62 & 97.14\end{array}$

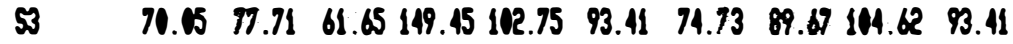

S4 $\quad 93.41 \quad 93.41 \quad 61.65112 .09118 .35 \quad 52.31 \quad 74.73 \quad 89.67 \quad 144.62 \quad 162.75$

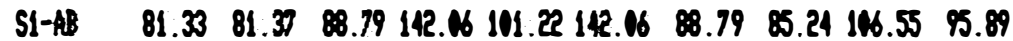

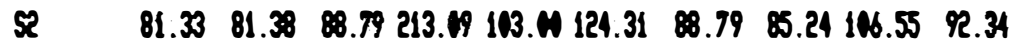

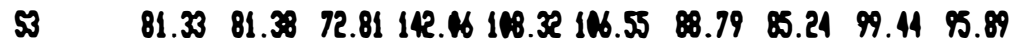

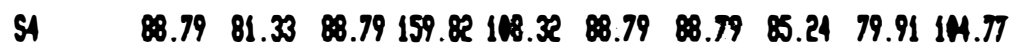

$\begin{array}{lllllllllll}55 & 88.79 & 88.79 & 72.81 & 213.09 & 101.22 & 106.55 & 88.79 & 85.24 & 79.91 & 97.67\end{array}$

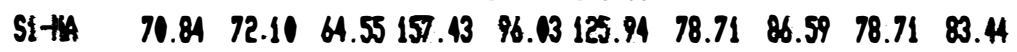

$\begin{array}{llllllllllll}52 & 51.95 & 51.95 & 64.55 & 125.94 & 115.48 & 125.94 & 78.71 & 86.59 & 75.57 & 89.73\end{array}$

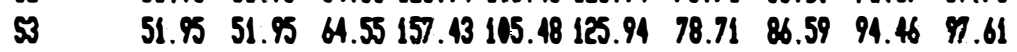

$\begin{array}{lllllllll}51 & 51.95 & 51.95 \quad 4.55 & 157.43 & 119.65125 .94 & 78.71 & 86.59 & 70.84 & 88.16\end{array}$

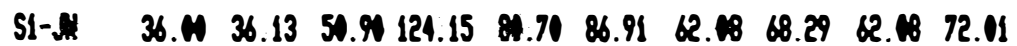

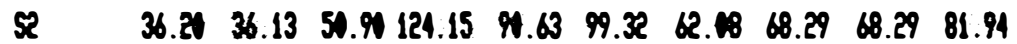

$\begin{array}{lllllllllll}53 & 36.13 & 4.97 & 59.91 & 124.15 & 83.18 & 99.32 & 62.68 & 68.29 & 68.29 & 85.67\end{array}$

$\begin{array}{llllllllllll}54 & 40.97 & 4.97 & 50.91 & 124.15 & 94.36 & 99.32 & 74.49 & 86.91 & 71.49 & 86.91\end{array}$

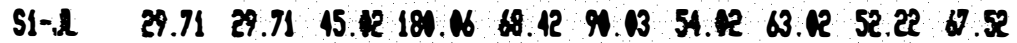

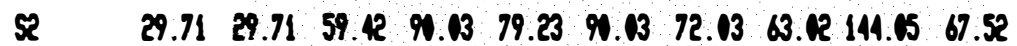

$\begin{array}{lllllllllllllll}53 & 29.71 & 29.71 & 59.42 & 135.15 & \pi & 71.43 & 91.13 & 72.13 & 63.12 & 70.23 & 69.32\end{array}$

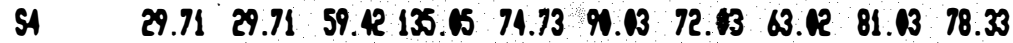

$\begin{array}{lllllllllllllll}55 & 29.71 & 37.51 & 59.42 & 135.05 & 103.54 & 90.03 & 90.03 & 63.02 & 81.03 & 53.12\end{array}$

$\begin{array}{llllllllllll}51-46 & 32.98 & 32.98 & 52.77 & 131.92 & 83.77 & 92.34 & 65.96 & 52.77 & 68.60 & 67.94\end{array}$

$\begin{array}{llllllllllllll}52 & 32.98 & 38.45 & 65.96 & 131.92 & 96.96 & 98.94 & 65.96 & 72.55 & 112.13 & 89 . \mathrm{H}\end{array}$

$53 \quad 65.96 \quad 98.94 \quad 22.45131 .92127 .31131 .92 \quad 98.9498 .94112 .13121 .36$

$54 \quad 98.9498 .94109 .49197 .87133 .89131 .92 \quad 131.92105 .53139 .60119 .38$

SI-57 $\quad 71.23 \quad 71.23 \quad 78.83 \quad 94.97101 .62118 .71 \quad 94.97 \quad 89.73 \quad 94.02 \quad 96.87$

$\begin{array}{lllllllllllll}52 & 71.23 & 71.23 & 78.83 & 118.71 & 113.49 & 118.71 & 94.97 & 80.73 & 75.98 & 92.12\end{array}$

$\begin{array}{lllllllllll}53 & 59.36 & 59.36 & 78.83 & 118.71 & 107.79 & 118.71 & 94.97 & 94.97 & 85.47 & 110.17\end{array}$

$54 \quad 67.24 \quad 67.2494 .97$ 142.46 114.92142 .46118 .7194 .97113 .97112 .07

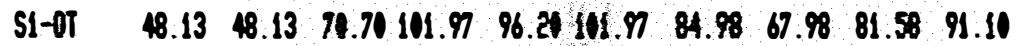

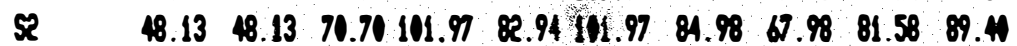

$53 \quad 48.13 \quad 4.13 \quad 62.4101 .97 \quad 95.18 \quad 14.97 \quad 74.78 \quad 74.78 \quad 81.58 \quad 88.72$

$\begin{array}{llllllllllll}S 4 & 48.13 & 48.13 & 64.92 & 101.97 & 87.36 & 101.97 & 81.58 & 67.98 & 81.58 & 91.76\end{array}$

$\begin{array}{lllllllllll}55 & 48.13 & 48.13 & 71.70101 .97 & 72.4 & 118.97 & 84.98 & 67.98 & 84.98 & 89.4\end{array}$

$\begin{array}{llllllllllll}51+H & 33.36 & 33.36 & 4.40 & 70.67 & 44.78 & 70.67 & 58.89 & 51.82 & \text { N.N } & 64.31\end{array}$

$\begin{array}{lllllllllllllll}52 & & 33.36 & 33.36 & 47.11 & 70.67 & 64.78 & 70.67 & 58.89 & 58.89 & \text { O.N } & 71.61\end{array}$

$\begin{array}{llllllllllllll}53 & 35.33 & 47.11 & 58.89 & 82.45 & 76.56 & 94.22 & 70.67 & 65.96 & 1.4 & 76.32\end{array}$

$\begin{array}{llllllllllll}51 & 54.96 & 54.89 & 58.89 & 117.78 & 70.67 & 117.78 & 70.67 & 70.67 & 0.4 & 81.09\end{array}$

$\begin{array}{lllllllllllll}51-82 & 36.78 & 35 . N & 45.72 & 78.83 & 66.22 & 78.83 & 55.18 & 47.34 & 56.76 & 71.42\end{array}$

$\begin{array}{llllllllllll}52 & 36.74 & 32.84 & 31.53 & 78.83 & 65.12 & 78.83 & 55.18 & 47.31 & 69.37 & 70.85\end{array}$

$\begin{array}{lllllllllllllll}53 & & 46.99 & 32.84 & 45.72 & 78.83 & 67.64 & 78.83 & 55.18 & 55.18 & \text { N.N } & 69.69\end{array}$

$\begin{array}{llllllllllll}\text { S1 } & 32.84 & 32.84 & 45.72 & 94.64 & 68.74 & 78.83 & 63.07 & 55.18 & \text { 1.N } & 67.96\end{array}$

55 $\quad 32.84 \quad 32.84 \quad 53.61 \quad 94.60110 .37 \quad 94.64 \quad 63.07 \quad 55.18 \quad$ O.N 86.69 
PRECO REAL - BANANA (1985 - 90) - VALOR REAL DE DEZ/90

S1-.W/9 28.25 28.25 $34.5491 .72 \quad 76.59 \quad 55.03 \quad 41.28 \quad 41.36$ $\begin{array}{lllllllll}52 & 34.40 & 45.86 & 34.40 & 91.72 & 93.56 & 91.72 & 45.86 & 73.38\end{array}$ $53 \quad \quad 45.86 \quad 15.86 \quad 61.18 \quad 110.07 \quad 96.31 \quad 137.58 \quad 73.38 \quad 73.38$ S4 $\quad 45.86 \quad 15.86 \quad 53.47 \quad 319.24 \quad 14.89137 .58 \quad 64.21 \quad 73.38$ $\begin{array}{llllllllll}51+\mathrm{FV} & 26.71 & 26.71 & 31.15 & 80.14 & 71.22 & 84.11 & 30.40 & 2.74\end{array}$ $\begin{array}{lllllllllll}52 & 26.71 & 26.71 & 35.64 & 106.85 & 66.03 & 89.14 & 42.74 & 45.95\end{array}$ $\begin{array}{lllllllll}53 & 26.71 & 26.71 & 35.68 & 89.14 & 72.77 & 89.14 & 42.74 & 48.68\end{array}$ $54 \quad 28.94 \quad 31.16 \quad 35.64 \quad 89.14 \quad 89.06 \quad 89.14 \quad 42.74 \quad 53.43$ $\begin{array}{lllllllll}55 & 24.54 & 19.64 & 24.54 & 54.69 & 48.79 & 58.93 & 29.47 & 35.36\end{array}$ $\begin{array}{lllllllll}51 & 34.54 & 19.64 & 29.47 & 58.93 & 61.61 & 58.93 & 35.36 & 35.36\end{array}$ $\begin{array}{lllllllll}52 & 24.54 & 24.54 & 41.75 & 88.40 & 69.26 & 73.66 & 51.09 & 44.21\end{array}$ $\begin{array}{lllllllll}53 & 24.54 & 24.54 & 41.75 & 73.66 & 74.64 & 88.44 & 54.09 & 44.21\end{array}$ $\begin{array}{llllllllll}54 & 24.54 & 24.54 & 41.75 & 88.41 & 64.18 & 86.4 & 54.09 & 41.21\end{array}$ $\begin{array}{lllllllll}55 & 22.15 & 33.18 & 30.51 & 79.41 & 74.11 & 79.41 & 44.99 & 39.70\end{array}$ $\begin{array}{lllllllll}51-A & 55.14 & 50.13 & 39.70 & 79.41 & 79.4 & 99.40 & 44.99 & 39.70\end{array}$ $\begin{array}{lllllllll}59 & 66.17 & 70.59 & 55.13 & 79.40 & 81.28 & 79.44 & 44.99 & 39.70\end{array}$ $\begin{array}{lllllllll}53 & 70.59 & 70.59 & 66.17 & 165.87 & 82.71 & 79.40 & 44.99 & 39.71\end{array}$

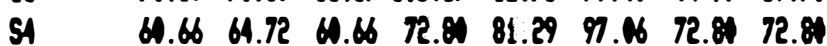
$\begin{array}{lllllllll}51-14 & 60.66 & 60.66 & 70.78 & 97.66 & 86.02 & 97.06 & 72.89 & 97.66\end{array}$ $52 \quad 76.85 \quad 76.8389 .88121 .33 \quad 99.49169 .2184 .93169 .21$ $53 \quad \quad 76.80 \quad 76.83 \quad 90.88149 .21 \quad 92.21121 .33 \quad 84.93169 .21$ $54 \quad 83.47 \quad 64.81 \quad 74.19 \quad 89.03 \quad 91.81$ 111.29 77.9114 .16 S1-N $\quad 64.969 .03 \quad 83.47$ 111.29 IN.16 III.29 89.03 iW.16 $52 \quad 64.9899 .0392 .75$ III.29 IN.21 I33.55 IN.16 IN.16 $53 \quad 89.13112 .01$ 22.75 $111.29 \quad 99.36111 .2914 .16111 .29$ $54 \quad 16.0110 .01$ 22.75 I11.29 102.39 133.55 IN.16 111.29 s5 $\quad 73.88 \quad 78.9182 .99137 .91 \quad 114.26 \quad 118.27 \quad 98.51 \quad 98.51$ S1-d 98.59114 .91 114.91 118.21 113.28 157.61 118.21 I18.35 $52 \quad 114.91114 .91114 .91137 .91166 .38157 .61118 .21$ I18.35 $53 \quad 98.51$ 123.13 123.13 118.21 $147.76 \quad 157.61$ 118.26 118.21 S4 $\quad 109.03109 .03109 .03139 .56114 .39139 .56104 .67 \quad 87.23$ S1-A6 109.03 123.56 169.03 157.01 122: 12 139.56 144.67 144.67 S2 $\quad 116.31 \quad 87.23116 .31$ 174. 15 127.11 157.01 1M4.67 IM4.67 $53 \quad 87.23 \quad 87.23116 .31139 .56121 .37157 .01$ IN.67 IM.67

S1 $\quad 87.23 \quad 94.51116 .31157 .01 \quad 134.33157 .01 \quad 144.67144 .67$

55 $\quad 78.18$ 78.6 IAL.11 $93.69107 .74140 .5493 .69 \quad 93.69$ S1-5T $52.15 \quad 52.1514 .11 \quad 93.69109 .31140 .54 \quad 93.69109 .31$ S2 $\quad 84.59117 .1114 .11117 .11117 .11$ 140.54 117.11101 .50 $53 \quad 91.0117 .11$ 14. 11 124.92 121.81 187.38 124.22 117.11 $54 \quad 79.79162 .59113 .98 \quad 123.10118 .55164 .14169 .43$ lKR.59 SL-0T $\quad 95.75162 .59113 .98136 .78110 .48164 .14109 .43102 .59$ S2 $\quad 79.79$ IR2.59 113.98 136.78114 .9164 .14109 .43112 .59 $53 \quad 79.79162 .59113 .98169 .13127 .21164 .14109 .13162 .59$ S4 IR2.59 IR2.59 $113.98 \quad 136.78 \quad 110.67164 .14 \quad 109.13 \quad 182.59$

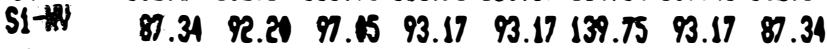

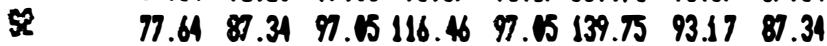
$53: 77.44 \quad 77.64 \quad 87.34116 .46 \quad 101.63116 .46 \quad 81.52 \quad 87.34$ S4 $\quad 77.64 \quad 77.64 \quad 77.64139 .75103 .27139 .75 \quad 81.52 \quad 87.34$

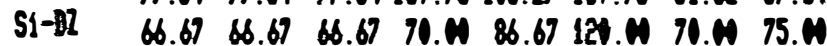
$52 \quad 66.67 \quad 66.67 \quad 66.67 \quad 70 . N \cdot 87.59$ 127.N $70 . N$ T5.N $53 \quad 68.67 \quad 86.67 \quad 66.67 \quad 70 . N$ 84. 10 iN.N $70 . \omega$ T5.N 54 75.N 75.N 83.33 70.N \%.N iN.N 71.N 75.N
I.N 73.65

I.N 71.82

1.N 73.38

I.N. 8.14

1.11 98.68

1.11 58.55

1.N 56.58

1.N 7.46

I.N 4.21

I.N 48.82

I.N 54.72

I.N 54.51

I.N 51.31

I.N 55.58

1.N 6.87

1.N 20.66

1.N 6.98

1.11 58.24

O.N17.4

1.4 79.79

1. 11116.69

I.N 97.69

1.N 9.11

I.N 101.\%

I.N 94.2

O.N I6.84

1.N109.83

I.N 118.78

0. 133.9

I.N 145.79

I.N 123.65

O.M 125.4

O.N 131.13

1.N 128.9

O. 1129.55

1.41 125.44

O.N 125.39

O.N 125.64

O.N 111.65

O.N IA.3

I.N 92.74

O.N 116.69

O.N 121.44

O.N 112.82

1.11 94.33

1.10 93.17

I. $N$ in. 43

1. 1196.24

I.N $86 . N$

1.N 8.11

1.4 76.4

O.N 86.4 